Western Washington University

Western CEDAR

\title{
Constructing the Klamath: Nature, Culture, and the Management of a Western River
}

Zander Albertson

Western Washington University, albertson.zander@gmail.com

Follow this and additional works at: https://cedar.wwu.edu/wwuet

Part of the Environmental Studies Commons

\section{Recommended Citation}

Albertson, Zander, "Constructing the Klamath: Nature, Culture, and the Management of a Western River" (2017). WWU Graduate School Collection. 560.

https://cedar.wwu.edu/wwuet/560

This Masters Thesis is brought to you for free and open access by the WWU Graduate and Undergraduate Scholarship at Western CEDAR. It has been accepted for inclusion in WWU Graduate School Collection by an authorized administrator of Western CEDAR. For more information, please contact westerncedar@wwu.edu. 
Constructing the Klamath:

Nature, Culture, and the Management of a Western River

By

Zander E. Albertson

Accepted in Partial Completion

of the Requirements for the Degree

Master of Arts

Kathleen L. Kitto, Dean of the Graduate School

ADVISORY COMMITTEE

Chair, Dr. Andrew Bach

Dr. Mark Neff

Dr. David Rossiter 


\section{MASTER'S THESIS}

In presenting this thesis in partial fulfillment of the requirements for a master's degree at Western Washington University, I grant to Western Washington University the nonexclusive royalty-free right to archive, reproduce, distribute, and display the thesis in any and all forms, including electronic format, via any digital library mechanisms maintained by WWU.

I represent and warrant this is my original work, and does not infringe or violate any rights of others. I warrant that I have obtained written permissions from the owner of any third party copyrighted material included in these files.

I acknowledge that I retain ownership rights to the copyright of this work, including but not limited to the right to use all or part of this work in future works, such as articles or books.

Library users are granted permission for individual, research and non-commercial reproduction of this work for educational purposes only. Any further digital posting of this document requires specific permission from the author.

Any copying or publication of this thesis for commercial purposes, or for financial gain, is not allowed without my written permission.

Zander E. Albertson

May 10, 2017 
Constructing the Klamath:

Nature, Culture, and the Management of a Western River

\author{
A Thesis \\ Presented to \\ The Faculty of \\ Western Washington University \\ In Partial Fulfillment \\ Of the Requirements for the Degree \\ Master of Arts
}

\author{
by \\ Zander E. Albertson
}

May 2017 


\begin{abstract}
$\underline{\text { Abstract }}$
This thesis addresses the sociocultural dimensions of the ongoing debate over the management of the Klamath River in southern Oregon and northern California. I used a social constructionist approach to qualitatively analyze discourse from 165 comments submitted to the Department of Interior in 2011 regarding the proposed removal of four dams on the Klamath River to develop typologies based on ideas of nature and preferred management outcomes. Analysis was informed by literature spanning environmental history, political ecology, historical geography, anthropology, science and technology studies, and sociology. My analysis indicates that commenters drew on diverse and divergent ideas of nature, used competing problem framings, claimed science supported their preferred management outcome, and drew on larger cultural narratives. These ideas and narratives are both culturally embedded and meaningful. In defining nature and what it is good for, commenters invoked ideas of the democratic individual, virtuous pristine nature, deserving yeoman farmer, precisely managed resources, and sacred family heritage. These narratives help to shape the terrain upon which management actions are perceived, valued, and contested, and make management actions symbolic and meaningful beyond their immediate spatial and temporal context. Ultimately, the conflict in the Klamath Basin can be understood as a contest for social power to enact a particular vision for the landscape. I also argue that an appeal to scientific knowledge alone is inadequate to address complex socioecological controversies where factual and normative claims are entangled and management actions are understood not as true or false, but right or wrong.
\end{abstract}




\section{Acknowledgements}

This thesis reflects the support of many people. Special thanks to Dr. Andy Bach, Dr. Mark Neff, and Dr. Dave Rossiter. Your thoughtful guidance, passion, and care made this research possible. Together you fostered a productive environment for scholarship and growth. Many thanks to the graduate student cohort who made graduate school bearable and even enjoyable! Special thanks to the Burns family, Thomas Christian, and Claire Jennings for opening your homes to me. Katie Rosa, thank you for showing the way. Dave and Diane Knutson and Ed Weber, the world works because of people like you. I owe an intellectual debt to Dr. Max Geier for planting the seed for this research, and Dr. Mark Van Steeter and Dr. Shaun Huston for providing a foundation upon which to build this research. Daniel Struble provided meticulous edits and comments. Financial support was provided by the David Clarke Graduate Fellowship and the Environmental Studies Department discretionary fund. Finally, thanks to my family and friends for your enduring support. 


\section{Table of Contents}

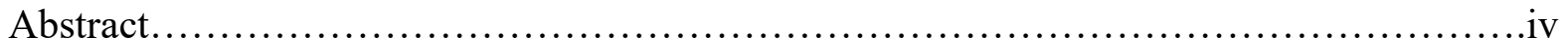

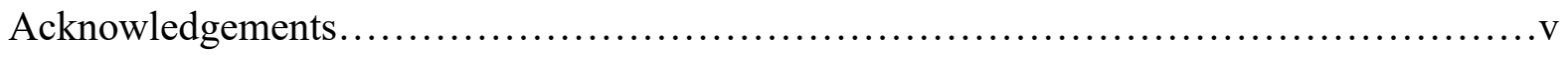

List of Figures and Tables...................................................... viii

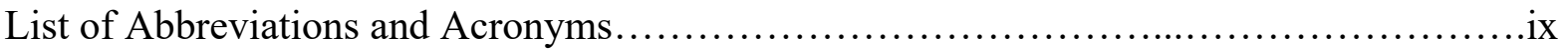

Chapter 1: Introduction.......................................................

Contextualizing the Klamath............................................

Purpose of research........................................................6

Theoretical approach................................................. 8

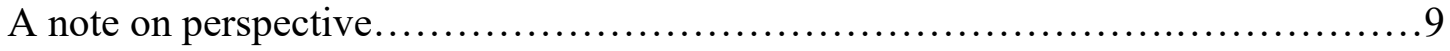

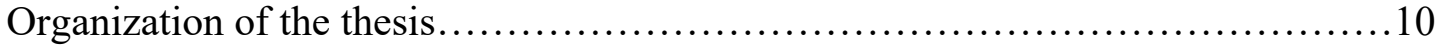

Chapter 2: Background, Literature Review, Theoretical Framework.....................11

The Klamath Basin.................................................... 12

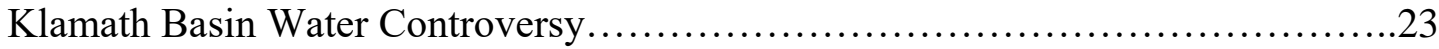

The American West...................................................... 33

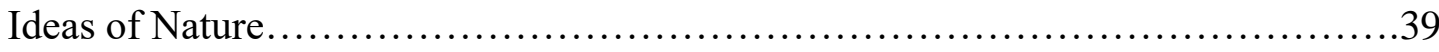

Science, Law, and "Contested Natures" .....................................57

Theoretical Framework..................................................60

Chapter 3: Qualitative Method..............................................69

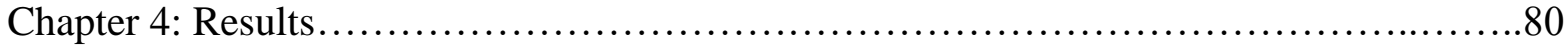

Introduction to Results................................................... 81

Natural Rivers....................................................... 82

Working Rivers...................................................... 88

Future Rivers......................................................... 95

Balanced Rivers......................................................97

Wise Use Movement...............................................99

Summary of Results................................................... 107

Chapter 5: Discussion..................................................... 111

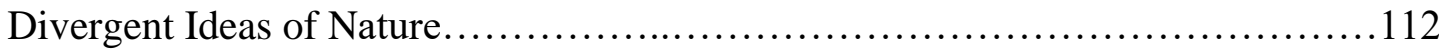

Disputed Problem Framings and Solutions................................ 116

Science.................................................................. 118 


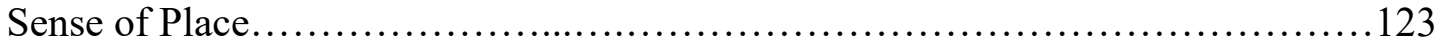

Work and Nature........................................................ 126

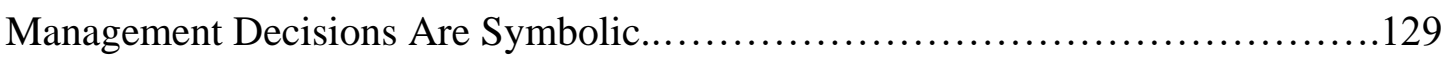

Narratives, History, and Meaning ....................................... 133

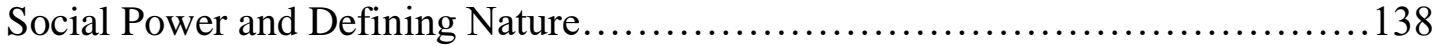

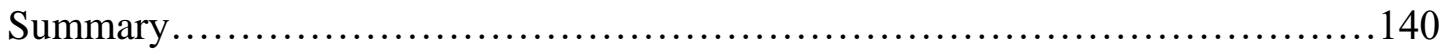

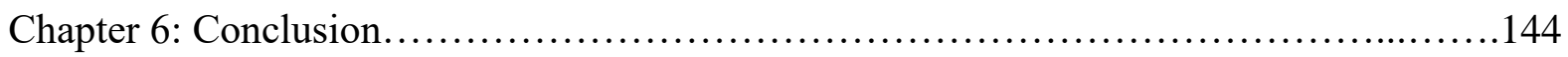

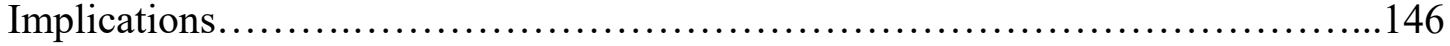

Broadening the Scope.............................................. 147

Limitations and Opportunities for Further Research...........................149

Conclusion............................................................. 150

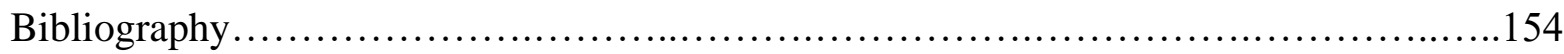

Appendix I: Public Comments................................................ 166 


\section{$\underline{\text { List of Figures and Tables }}$}

Figure 1: Klamath River Basin map.................................................. 13

Figure 2: Average annual precipitation, Western United States, 1981-2010_................15

Figure 3: Selected Klamath Project infrastructure and reservoirs...........................18

Figure 4: Historic range and current status of coho salmon..............................22

Figure 5: Klamath Project water allocation, 1991-2001_................................25

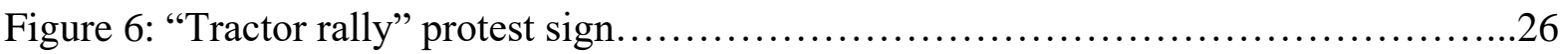

Figure 7: Federal marshals guard the closed headgates of the Klamath Project, 2001 ........28

Figure 8: Fish kill, Klamath River, 2002 .........................................28

Figure 9: Federal land ownership in the American West...................................... 37

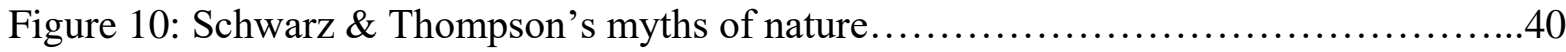

Figure 11: Cultural Theory's four worldviews......................................42

Figure 12: Myths of nature and Cultural Theory .........................................44

Figure 13: "The Story of an Irrigated Farm",............................................ 48

Figure 14: Total United States reservoir storage, 1870-1990_.........................53

Figure 15: Human-nature interactions ............................................62

Table 1: Sample comment excerpts and codes assigned...............................78

Table 2: Typology comment quantities................................................. 107

Table 3: Summary of typologies................................................ 108 


\section{List of Abbreviations and Acronyms}

BoR Bureau of Reclamation

BR Balanced Rivers commenter typology

DEIS Draft Environmental Impact Statement

EIS Environmental Impact Statement

ESA Endangered Species Act

FERC Federal Energy Regulatory Commission

FR Future Rivers commenter typology

FWS U.S. Fish \& Wildlife Service

GYE Greater Yellowstone Ecosystem

KBRA Klamath Basin Restoration Agreement

KHSA Klamath Hydroelectric Settlement Agreement

NEPA National Environmental Policy Act

NMFS National Marine Fisheries Service

NR Natural Rivers commenter typology

NRC National Research Council

Project Bureau of Reclamation irrigation project

The West The American West

WR Working Rivers commenter typology

WUM Wise Use Movement commenter typology 


\section{Chapter 1: Introduction}

"Where different modes of living on Earth collide, differences between forms of knowledge and belief with regard to nature can matter greatly. Such a place is the Klamath."1

On August 21, 2001 a large metal bucket emblazoned with the words "Klamath Bucket Brigade" and crowned with an American flag stood in front of the Klamath county building in Klamath Falls, Oregon. ${ }^{2}$ Nearby, a crowd of several thousand chanted, "Keep the water on! Keep the water on!"3 What had prompted this gathering, atypical for the rural southern Oregon town of 20,000 ?

Water.

As Mark Twain famously wrote, “Whiskey's for drinking, water's for fighting about." ${ }^{4}$ And it was in the spirit of Twain's quote that Klamath Falls, Oregon served as the rally point for farmers protesting the Bureau of Reclamation's decision to restrict irrigation water deliveries amid drought conditions, sending the water downstream to protect fish listed under the Endangered Species Act of $1973 .^{5}$ As the dry summer wore on, disgruntled farmers forced open an irrigation headgate to allow water to flow to their fields, and federal marshals were called in to control the scene. ${ }^{6}$ The event brought national media attention to the rural

\footnotetext{
${ }^{1}$ Stephen Most, River of Renewal: Myth and History in the Klamath Basin (Portland, Oregon: Oregon ${ }^{2}$ Most, River of Renewal: Myth and History in the Klamath Basin.

${ }^{3}$ Ibid.

${ }^{4}$ Sandra K. Davis, "The Politics of Water Scarcity in the Western States," The Social Science Journal 38, no. 4 (2001): 527.

${ }^{5}$ Holly Doremus and A. Dan Tarlock, Water War in the Klamath Basin: Macho Law, Combat Biology, and Dirty Politics (Washington DC: Island Press, 2008).

${ }^{6}$ Ibid.; Matthew McKinney and William Harmon, The Western Confluence: A Guide to Governing Natural Resources (Washington DC: Island Press, 2004).
} 
river basin straddling the Oregon-California border, with headlines portraying the events as "fish versus farmers."

Klamath Basin scholars Holly Doremus and A. Dan Tarlock observed "[t]he principal narrative of the Klamath Basin conflict depicted in the national media pitted farmers against lowly fish and soaring eagles. The Endangered Species Act was portrayed either as the nation's only effective biodiversity conservation law or as a weapon used by urban environmentalists to cleanse the rural landscape of all human imprint." indeed concerned with the material reality of water, fish, and farms, but also carried deeper symbolic meaning. The protesters were concerned about a lack of irrigation water, but also saw an attack on their conception of nature, how nature should be used, and their agrarian way of life. Signs blossomed along roadsides in the basin and at community rallies, reading "No water, no crops, no jobs, no farmers"" and "Feed the Feds to the fish." ${ }^{10}$ Just as the bucket brigade in front of the county building was symbolic of rural support for farmers, the conflict can be understood as a dispute about not only water management but also the symbolic and cultural implications of water management decisions. This thesis will attempt to unravel some of the underlying factors of the ongoing water conflict in the Klamath Basin.

Following the crisis of 2001, stakeholders "chose sides and dug trenches in the battlegrounds of the media and the courtroom," and looked to science and litigation to

\footnotetext{
${ }^{7}$ Michael Milstein, "The Press Portrayed the Story as Fish vs. Farmers. But the Klamath River Story Is a Whole Lot More Complicated than That," Nieman Reports, 2002.

${ }^{8}$ Holly Doremus and A. Dan Tarlock, "Fish, Farms, and the Clash of Cultures in the Klamath Basin," Ecology LQ 30 (2003): 286.

${ }^{9}$ Douglas Jehl, "Cries of 'Save the Suckerfish' Rile Farmers' Political Allies," The New York Times, June 20, 2001, http://www .nytimes.com/2001/06/20/us/cries-of-save-the-suckerfish-rile-farmerspolitical-allies.html.

${ }^{10}$ River of Renewal (Pikiawish Partners, 2009).
} 
arbitrate between competing ideas about the best use of water. ${ }^{11}$ Downstream, Native American tribes and commercial fishermen struggled economically and culturally in the face of declining fish populations; upstream, irrigators desired water for their parched fields. Environmental groups added their voices to the fray. The death of over 30,000 Chinook salmon in 2002 from an outbreak of two parasites further underscored the tenuous situation in the basin, with environmental historian William Robbins characterizing the Klamath Basin to be "by any measure the most troubled waterscape in the Pacific Northwest." 12

As the legal, scientific, and cultural struggles continued following the water crisis of 2001 and fish kill of 2002, local stakeholders convened to cooperatively envision the future of the basin's land and water. Beginning in 2004, a series of encouraging discussions and negotiations culminated in what geographer Brian Chaffin described as "the most comprehensive and inclusive set of resource governance agreements ever envisioned in the western U.S."13 These agreements were intended to take a comprehensive, basin-wide approach and address water security for agriculture, settle disputed water rights claims, and establish funding for fisheries restoration, among other objectives. ${ }^{14}$ Over the next decade, a "complex and formidable" set of agreements was crafted to end the ongoing water war, but Congress failed to approve them in December 2015. ${ }^{15}$ New efforts emerged to draft new agreements, and in April 2016 a subset of stakeholders signed onto the agreements, which

\footnotetext{
${ }^{11}$ Brian C. Chaffin, "Reallocating Resources, Rebuilding Community: The Klamath Basin Agreements and the Emergence of Adaptive Governance" (Ph.D dissertation, Oregon State University, 2014), 2, http://ir.library.oregonstate.edu/xmlui/handle/1957/50604.

${ }^{12}$ William G. Robbins, Landscapes of Conflict: The Oregon Story, 1940-2000 (Seattle: University of Washington Press, 2004), 105; Doremus and Tarlock, "Fish, Farms, and the Clash of Cultures in the Klamath Basin."

${ }^{13}$ Chaffin, "Reallocating Resources, Rebuilding Community," 3.

${ }^{14}$ Chaffin, "Reallocating Resources, Rebuilding Community."

${ }^{15}$ Paige Blankenbuehler, "A New Klamath Water Deal Emerges, but Unease Persists," High Country News, April 8, 2016, https://www.hcn.org/articles/on-the-klamath-leaders-celebrate-dam-removalbut-unease-over-water-deal-persists.
} 
proposed the removal of four dams on the Klamath River. But despite the rhetoric of promise, uncertainty still surrounds the future of water in the basin. Leaders in local counties are rallying support to block dam removal, some local Native American tribes remain skeptical, and irrigators say the new agreement "isn't great... The politics about this are still very nasty." ${ }^{\prime 16}$ Although there is the promise of "peace on the river," a resolution to the conflict appears elusive. ${ }^{17}$

Despite the efforts of competing stakeholders to marshal the "best available science" to support their position, over fifteen years of negotiations, and millions of dollars of restoration money, why aren't things getting better? As William Warren has observed about forest management, why does "a mixture of science and politics and money and litigation and yelling and screaming" continue to characterize environmental management decisions $?^{18}$ Lachapelle et al. offer a starting point, asserting, "natural resource planning is... an intrinsically political process. ${ }^{19}$ Recent academic literature points out that conflict over the management of nature is undergirded by deeper social and cultural factors. ${ }^{20} \mathrm{By}$ understanding environmental conflict as merely a lack of information or a technical problem, managers and policy makers may believe that more information will resolve conflict. In the

\footnotetext{
${ }^{16}$ Ibid.

${ }^{17}$ Hannah Gosnell and Erin Clover Kelly, "Peace on the River? Social-Ecological Restoration and Large Dam Removal in the Klamath Basin, USA," Water Alternatives 3, no. 2 (2010): 362.

${ }^{18}$ William Warren, "What Is a Healthy Forest?: Institutional Logics and the Contest over Natural Resources - Implications for Ecosystem Management and Socio-Ecological Theory" (Ph.D dissertation, Washington State University Department of Natural Resource Sciences, 1998), 1.

${ }^{19}$ Paul R. Lachapelle, Stephen F. McCool, and Michael E. Patterson, "Barriers to Effective Natural Resource Planning in a 'Messy' World," Society \& Natural Resources 16 (2003): 475.

${ }^{20}$ Justin Farrell, The Battle for Yellowstone: Morality and the Sacred Roots of Environmental Conflict (New Jersey: Princeton University Press, 2015); William Warren, "What Is a Healthy Forest?:

Definitions, Rationales, and the Lifeworld," Society \& Natural Resources 20, no. 2 (2007): 99-117, doi:10.1080/08941920600901890; Sara Jo Breslow, "A Complex Tool for a Complex Problem: Political Ecology in the Service of Ecosystem Recovery," Coastal Management 42, no. 4 (July 4, 2014): 308-31, doi:10.1080/08920753.2014.923130.
} 
Klamath Basin, a litany of scientific studies was commissioned, including a report from the prominent National Research Council. ${ }^{21}$ While the scientific basis for management decisions may be well accepted among experts and technocrats, social conflict over management decisions is likely to continue until cultural dimensions of the conflict are addressed. ${ }^{22}$

\section{Contextualizing the Klamath}

Parallels abound between the conflict in the Klamath Basin and other environmental controversies surrounding land and water management in the American West. Spotted owl, salmon, and sage grouse preservation as well as wolf and grizzly bear reintroduction are just some of the conflicts splashed across news headlines..$^{23}$ The conflicts are oftentimes portrayed as "wolves versus ranchers" or "jobs versus the environment," pitting livelihoods and species against one another. While the specifics may vary, similar themes reoccur, creating a "public land noir" of sorts. ${ }^{24}$ Science is called upon to answer normative questions masquerading as technical problems, and warring factions rely upon familiar yet often unexamined cultural narratives as they talk past one another. Even as the technical reports, biological opinions and

\footnotetext{
${ }^{21}$ Doremus and Tarlock, Water War in the Klamath Basin; National Academies Press (U.S.), ed., Endangered and Threatened Fishes in the Klamath River Basin: Causes of Decline and Strategies for Recovery (Washington, D.C: National Academies Press, 2004); Thomas B. Hardy, R. Craig Addley, and Ekaterina Saraeva, "Evaluation of Instream Flow Needs in the Lower Klamath River: Phase II" (Logan, Utah: Institute for Natural Systems Engineering, Utah Water Research Laboratory, Utah State University, July 31, 2006).

${ }^{22}$ Doremus and Tarlock, Water War in the Klamath Basin.

${ }^{23}$ Eric Wagner, "Washington Welcomes Wolves Back - across Deep Political Divides," High Country News, October 26, 2015, http://www .hcn.org/issues/47.18/washington-welcomes-its-wolves-backacross-deep-political-divides; Jodi Peterson, “The Endangered Species Act's Biggest Experiment: Will an Unprecedented Collaborative Effort and Lots of Tax Dollars Be Enough to Finally Save Sage Grouse?," High Country News, August 17, 2015, http://www.hen .org/issues/47.14/biggestexperiment-endangered-species-act-sage-grouse; The Associated Press, "Deschutes Basin Farmers Worry Spotted Frog Lawsuit Could Restrict Irrigation Water," The Oregonian, February 10, 2016, http://www.oregonlive.com/environment/index.ssf/2016/02/deschutes_basin_farmers_worry.html. ${ }^{24}$ Martin Nie, The Governance of Western Public Lands: Mapping Its Present and Future (Lawrence: University Press of Kansas, 2008), 1.
} 
legal opinions are issued, conflict continues. These "wicked" conflicts are not resolvable by scientific, economic, or technical means but are instead rooted in competing conceptions of good and bad, right and wrong, appropriate and inappropriate. ${ }^{25}$ Scientists, lawyers, and historians have written much about the Klamath water conflict, but little research has looked into the cultural dimensions of the dispute.

Doremus and Tarlock note that the "narrative we find most compelling goes directly to the source of the problem - the clash of cultures that must be resolved as the arid West confronts its future. Farmers, fishing communities, environmentalists, and Indians [sic] are all fighting to protect their ideal of the landscape and their relationship to it." ${ }^{26}$ This research seeks to better understand the cultural basis for conflict in the Klamath that goes deeper than technical arguments, biological opinions, and factual claims. As Hull et al. argue, "[s]ociety will be better able to engage in sophisticated discussion about which nature we want and why we want it if we have more explicit examples of the social constructions of nature, environmental quality, and desired future conditions." 27

\section{Purpose of research}

My intention in this thesis is to move beyond the simplifications and blunt dichotomies provided by media accounts and other literature that frame conflict in the Klamath as simply existing between two mutually exclusive and stereotyped groups continually at loggerheads. Using an interpretive approach to deconstruct the discourse used

\footnotetext{
${ }^{25}$ Horst W. J. Rittel and Melvin M. Webber, "Dilemmas in a General Theory of Planning," Policy Sciences 4, no. 2 (1973): 155-169; Martin Nie, "Drivers of Natural Resource-Based Political Conflict," Policy Sciences 36, no. 3/4 (2003): 307-41.

${ }^{26}$ Doremus and Tarlock, "Fish, Farms, and the Clash of Cultures in the Klamath Basin," 287.

${ }^{27}$ R. Bruce Hull, David P. Robertson, and Angelina Kendra, "Public Understandings of Nature: A Case Study of Local Knowledge About 'Natural' Forest Conditions," Society and Natural Resources 14 (2001): 338.
} 
to defend a given position, I hope to obtain a better understanding of the deeper moral and cultural concerns involved. Following the literature surrounding wolf reintroduction, the spotted owl controversy, forest management, and science studies scholars I seek to move beyond the battle for scientific facts and examine the roots of the conflict. This approach serves to contribute to not only the ongoing negotiations over water allocation in the Klamath Basin, but to the growing body of literature taking a cultural and socioecological approach to environmental conflict generally. ${ }^{28}$

Using public comment letters submitted in response to the proposal to remove four dams on the Klamath River, I will examine conceptions of nature in the Klamath Basin and how those are articulated as the "proper" use and management of nature in the Basin. Additionally, I will look for linkages with other cultural factors including the legitimacy of science, government, and private property. This study does not "test" a population for a predetermined set of constructs; instead, it seeks to understand the various conceptions at play about what nature is good for, who should decide, and how it relates to other social and cultural concerns. While topically concerned with dam removal, little of this thesis focuses on the dam removal per se - I focus on the dam removal proposal as a management action that carries symbolic weight, serving to legitimize a particular conception of how nature should be ordered at the expense of other conceptions.

\footnotetext{
${ }^{28}$ Farrell, The Battle for Yellowstone: Morality and the Sacred Roots of Environmental Conflict; Warren, "What Is a Healthy Forest?"; Matthew A. Wilson, "The Wolf in Yellowstone: Science, Symbol, or Politics? Deconstructing the Conflict between Environmentalism and Wise Use," Society \& Natural Resources 10, no. 5 (September 1997): 453-68, doi:10.1080/08941929709381044; William Cronon, ed., Uncommon Ground: Rethinking the Human Place in Nature (New York: W. W. Norton \& Company, 1995).
} 


\section{Theoretical approach}

This research will adopt a social constructivist approach to better understand the conceptual world of informants and their positions. The social constructivist approach, as applied here, recognizes the materiality of nature as it exists "out there" but takes seriously the human context in interacting with and making sense of that materiality. This means we filter material nature through a lens influenced by our values, beliefs, experiences, and cultural affiliations. As William Cronon explains, “[i]deas of nature never exist outside a cultural context, and the meanings we assign to nature cannot help reflecting that context." 29 Similarly, Robbins argues, "because our language, our rhetorical expressions, are culture bound, reflecting the perceptions and values that influence human behavior toward physical nature, it is imperative that we pay close attention to the narratives that represent and give meaning to those realities." ${ }^{30}$ Narratives, defined as "meaningful accounts of human actions arranged into connected events," are more than just statements of historical happenings, but communicate meaning in order to produce an understanding, insight, or explanation about how the world works. ${ }^{31}$ They are inherently moral - prescribing events and actors as good or bad, right or wrong, just or unjust. ${ }^{32}$

In this way, ideas of nature become bound up alongside notions of the legitimacy of government, the virtues of laboring in nature, and the value of private property. How we

\footnotetext{
${ }^{29}$ William Cronon, "Introduction: In Search of Nature," in Uncommon Ground: Toward Reinventing Nature (New York: W. W. Norton \& Company, 1995), 35.

${ }^{30}$ William G. Robbins, Landscapes of Promise: The Oregon Story, 1800-1940 (Seattle: University of Washington Press, 1997), 239.

${ }^{31}$ Farrell, The Battle for Yellowstone: Morality and the Sacred Roots of Environmental Conflict, 15; Christian Smith, Moral, Believing Animals: Human Personhood and Culture (New York: Oxford University Press, 2003).

${ }^{32}$ Farrell, The Battle for Yellowstone: Morality and the Sacred Roots of Environmental Conflict.
} 
understand nature influences both the ways in which material nature is ordered and organized, as well as the ways we talk about and represent nature. Nature is thus discursively produced and carries political implications. The hegemonic discourse shapes the terrain upon which decisions pertaining to nature, such as management decisions, are conducted.

\section{A note on perspective}

As James Proctor observes while writing about the ethics and ideas of nature in the spotted owl controversy, "I am painfully aware of the perils inherent in this journey... one's own perceptual limitations and inadequacies are probably revealed more than in any other kind of work." ${ }^{33}$ Thus it seems worth mentioning my interest in the subject matter at hand. Growing up in a small ski town in central Oregon, I recreated in wilderness mere miles from my doorstep, sympathized with environmentalist perspectives, and saw a beneficent nature that needed protection from the likes of loggers and real estate developers. Yet I also experienced an arbitrary and capricious nature as I stumbled in the clutches of hypothermia across an alpine landscape, and later I confronted the dark histories of using nature to justify Social Darwinism and eugenics. ${ }^{34}$ The singular nature I thought I knew was in fact multifaceted. I have come to see nature as complex, it's meaning malleable, contingent on perspective and different ways of knowing. Might such an understanding be relevant to environmental conflict? I found good company in the academic literature.

While it is impossible to engage with any subject matter in an absolutely detached manner, I have made every effort to consider different perspectives while researching and

\footnotetext{
${ }^{33}$ James D. Proctor, "Whose Nature? The Contested Moral Terrain of Ancient Forests," in Uncommon Ground: Toward Reinventing Nature, ed. William Cronon (New York: W. W. Norton \& Company, 1995), 274.

${ }^{34}$ Jedediah Purdy, After Nature: A Politics for the Anthropocene (Harvard University Press, 2015).
} 
writing this thesis. Reading widely across academic works in environmental history, sociology, science studies, environmental politics, and natural resources, I intend to present a synthetic and interdisciplinary view of the contest for water in the Klamath Basin. It is my hope that a greater understanding of the conceptions of nature and the legitimacy of management decisions will contribute to a more nuanced and multifaceted management approach that acknowledges the divergent and sometimes contradictory cultural understandings of nature.

\section{Organization of the thesis}

Chapter two introduces the Klamath Basin and situates dominant ideas of nature in a cultural and historical context, linking those ideas with the material and social transformation of the American West. The theoretical underpinnings of the research are discussed as well. Chapter three describes the qualitative method used to produce the findings outlined in chapter four. Chapter five places those findings in conversation with the literature about the Klamath Basin as well as general environmental controversy in the West. Chapter six contains concluding thoughts and implications for policy and management. 


\section{Chapter 2: Background, Literature Review, and Theory}

"Ideas of nature, but these are the projected ideas of men." 35

The conflict over water in the Klamath Basin is, superficially, just another in a litany of controversies over resources in the American West (hereafter "the West"). The media characterized the situation in the Klamath Basin as fish versus farmers and jobs versus the environment, as is common in many recent headlines. ${ }^{36}$ What is ignored in these accounts is the complex interplay between a multitude of interests; a fragmented patchwork of intertwined federal, state and local laws; conflicting scientific reports; and deep but frequently unacknowledged cultural differences in thinking about the proper use of nature as well as the legitimacy of the institutions of science and government. As Mark Fiege observes in his history of irrigated agriculture in Idaho, discussion about "the irrigated landscape necessarily must include a history of the human systems that rested on and shaped it." ${ }^{\prime 37}$

To understand the conflict in the Klamath Basin necessarily requires an understanding of ideas about nature, and the laws and institutions in the West that have shaped its use and management. To provide more than a "thumbnail sketch" of these is beyond the scope of this work, and to provide a coherent account of events spanning more than a century I have made some generalizations. A diversity of opinion surely existed during all time periods discussed. What follows are broad statements about the general trajectory of American thought about nature in the West in the $19^{\text {th }}$ and $20^{\text {th }}$ century as informed primarily

\footnotetext{
${ }^{35}$ Raymond Williams, "Ideas of Nature," in Problems in Materialism and Culture (London: Verso, 1980), 82 .

${ }^{36}$ Milstein, "The Press Portrayed the Story as Fish vs. Farmers. But the Klamath River Story Is a Whole Lot More Complicated than That."

${ }^{37}$ Mark Fiege, Irrigated Eden: The Making of an Agricultural Landscape in the American West (Seattle: University of Washington Press, 1999), 8.
} 
by the field of environmental history, as well as sociology and anthropology. Following Raymond Williams, it is my intent to "try to indicate some of the main points, the general outlines... and to see what effects these may have on some of our contemporary arguments and concerns." ${ }^{38}$ As Neil Evernden observes, "[t]he generalist, lacking the security and guidance of disciplinary boundaries, must simply follow where the topic dictates." 39 This interdisciplinary approach was chosen as an avenue to go beyond the superficial accounts of "fish versus farmers" and delve into deeper drivers of conflict over the use of nature in the Klamath.

\section{The Klamath Basin}

The Klamath Basin is unique, having been said to "run backwards" and "upside down. ${ }^{40}$ Typically, river basins have the greatest relief and precipitation near the upper reaches of the river, but in the Klamath Basin its most arid areas lie upstream in the upper basin while the majority of precipitation falls in the lower basin as it nears the Pacific. ${ }^{41}$ While the upper basin composes over half of the total area of the basin, it contributes less than $12 \%$ of the total annual runoff..$^{42}$ Separated from the lower basin by the Iron Gate Dam, the upper basin lies in Oregon and the lower basin in California (figure 1). ${ }^{43}$

\footnotetext{
${ }^{38}$ Williams, "Ideas of Nature," 68.

${ }^{39}$ Neil Evernden, The Social Creation of Nature (Baltimore: The Johns Hopkins University Press, 1992), xii.

${ }^{40}$ Doremus and Tarlock, Water War in the Klamath Basin, 23.

${ }^{41}$ Doremus and Tarlock, Water War in the Klamath Basin.

${ }^{42}$ National Research Council (U.S.) and National Academies Press (U.S.), eds., Hydrology, Ecology, and Fishes of the Klamath River Basin (Washington, DC: National Academies Press, 2008).

${ }^{43}$ Doremus and Tarlock, Water War in the Klamath Basin.
} 


\section{Klamath River Basin}

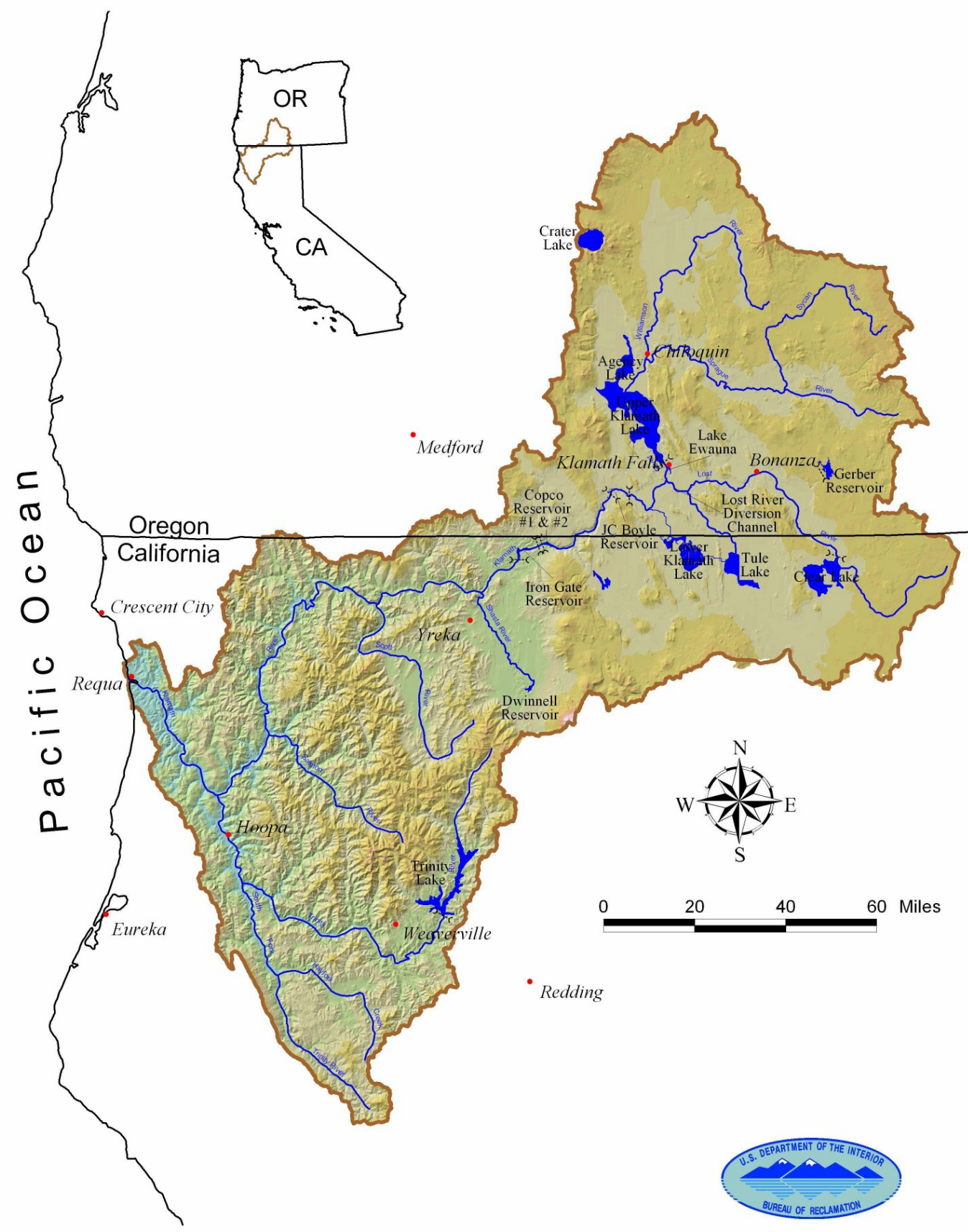

Compiled bv M. Neuman. USBR Klamath Basin Area Office. 9/90

Figure 1: The Klamath Basin of southern Oregon and northern California. ${ }^{44}$

${ }^{44}$ M Neuman, "Klamath River Basin,” Map (USBR Klamath Basin Area Office, September 1999). 
With relatively minimal topographic relief, the upper basin contains shallow, large lakes and slow rivers while the lower basin falls steeply through coastal mountains towards the Pacific Ocean and contains canyons and swift rivers. ${ }^{45}$ The lower basin receives ample precipitation from Pacific storms, up to 100 inches annually. ${ }^{46}$ The primary river in the basin, the Klamath River drains a sparsely populated region in southern Oregon and northern California. Fed by snowmelt from the Oregon Cascades, including the flanks of Crater Lake, the river begins in the broad and shallow Upper Klamath Lake, Oregon's largest lake and the principal reservoir for the Klamath Project. ${ }^{47}$ After crossing the California border, the river is supplemented by several large tributaries, including the Salmon, Scott, Shasta, and Trinity Rivers. Passing through the boundaries of Redwood National Park, the Klamath River enters the Pacific as the fourth largest river in the U.S. West, trailing only the Columbia, Sacramento, and Colorado rivers. ${ }^{48}$

The region experiences the wet winters and dry summers characteristic of Pacific coast states. ${ }^{49}$ Though the lower basin is drenched with rainfall from Pacific storms, the upper basin, and the primary agricultural lands, lie in the rain shadow of the Cascades (figure 2). Klamath Falls, the only sizeable population center in the basin (population approximately 21,000 in 2013), averages 11 to 14 inches annually. ${ }^{50}$ With variable precipitation from year to

\footnotetext{
${ }^{45}$ Most, River of Renewal: Myth and History in the Klamath Basin.

${ }^{46}$ National Research Council (U.S.) and National Academies Press (U.S.), Hydrology, Ecology, and Fishes of the Klamath River Basin.

${ }^{47}$ Doremus and Tarlock, Water War in the Klamath Basin; National Research Council (U.S.) and National Academies Press (U.S.), Hydrology, Ecology, and Fishes of the Klamath River Basin. ${ }^{48}$ Most, River of Renewal: Myth and History in the Klamath Basin; Doremus and Tarlock, Water War in the Klamath Basin.

${ }^{49}$ Edward Aguado and James E. Burt, Understanding Weather and Climate, 5th ed. (Upper Saddle River, New Jersey: Pearson Prentice Hall, 2010); Shaw Historical Library, A River Never The Same: A History of Water in the Klamath Basin, 2nd ed. (Klamath Falls: Oregon Institute of Technology, 1999).

${ }^{50}$ Doremus and Tarlock, Water War in the Klamath Basin.
} 
year, periodic droughts are common, and agricultural demand for water outstrips supply in $70 \%$ of years. ${ }^{51}$ The climate and topography means that the most intense water demands occur in the same portion of the Klamath Basin that is the most arid and susceptible to annual variations in water availability.

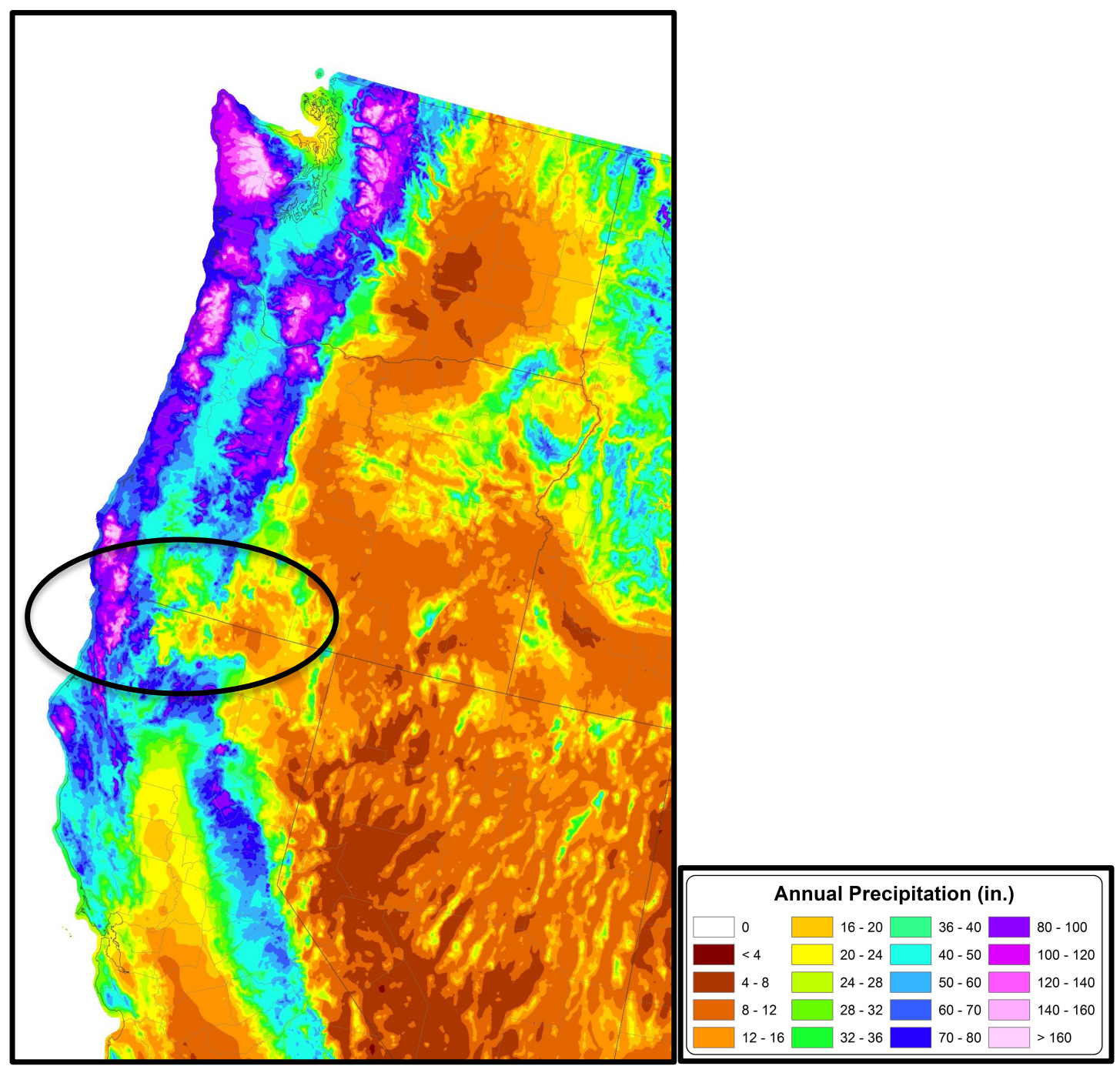

Figure 2: Average annual precipitation, 1981-2010. Note the difference between precipitation in the upper Klamath Basin in south-central Oregon and the lower Klamath Basin in the northwest corner of California (denoted by black circle). ${ }^{52}$

\footnotetext{
${ }^{51}$ Ibid.

${ }^{52}$ PRISM Climate Group, “30-Year Normal Precipitation: Annual, Period: 1981-2010,” accessed February 10, 2017, http://www.prism.oregonstate.edu/normals/.
} 


\section{Irrigated Agriculture: The Klamath Project}

Despite its aridity, the flat plateau of the upper basin has been the site of irrigated agriculture for over a century. To place the aridity in context, directly to the east of the upper basin begins the "forbiddingly" parched Great Basin. ${ }^{53}$ It follows that "[w]ithout question, water is the single most valuable resource of the Klamath Basin." ${ }^{54}$ The Klamath Basin does not have ideal qualities for agriculture. Despite its fertile volcanic soils, the growing season spans just 100-125 days, and frosts can occur during any month.$^{55}$ In spite of these difficulties, the arid landscape was transformed as a result of a federal reclamation project. While the Klamath Project is not the largest project in the West, it is the second oldest. ${ }^{56}$ Authorized in 1905 by the federal Bureau of Reclamation (BoR) and intended as the "cheapest and greatest enterprise by government in the west," the Klamath Project began water deliveries in 1907. The Project receives most of its water from the shallow Upper Klamath Lake. Though large, covering 60,000-90,000 acres, it averages just seven feet deep in the summer. ${ }^{57}$ Because of its lack of storage capacity, a single dry year can spell disaster for Project irrigators.

Though the first privately held irrigation ditch was dug in 1868, irrigated farmland remained minimal until the BoR Project began, integrating several preexisting, privately built canals. ${ }^{58}$ World War I delayed construction, but the scope of the Project expanded

\footnotetext{
${ }^{53}$ Doremus and Tarlock, "Fish, Farms, and the Clash of Cultures in the Klamath Basin," 291.

${ }^{54}$ Martha O. Pagel et al., "Resolving The Klamath" (Oregon Water Resources Department, October 1999), 7.

${ }^{55}$ Doremus and Tarlock, Water War in the Klamath Basin.

${ }^{56}$ Daniel M. Hurley, "Political Ecology of the 2001 Water Crisis in the Upper Klamath Basin: A Case Study in Narrative Policy Analysis" (M.S. thesis, University of Oregon, 2004).

${ }^{57}$ Ibid.

${ }^{58}$ Shaw Historical Library, A River Never The Same: A History of Water in the Klamath Basin.
} 
significantly following the war, with the construction of additional canals and dams. ${ }^{59}$ By the time it was fully completed some fifty years later, the Klamath Project included seven dams, 185 miles of canals, and 516 miles of irrigation ditches (see figure 3 ) ${ }^{60}$ In 2001 , The Project served approximately 2,200 farms producing alfalfa, hay, wheat, and potatoes across 200,000 acres of farmland. ${ }^{61}$ From the 1970s through the 1990s, the Klamath Basin economy grew from approximately 40,000 jobs to 60,000 jobs but farm growth remained flat, meaning that farms' share of income and employment decreased. In the late 1990s, agriculture accounted for $14 \%$ of the region's jobs and $12 \%$ of its income. ${ }^{62}$

\footnotetext{
${ }^{59}$ Ibid.

${ }^{60}$ Hurley, "Political Ecology of the 2001 Water Crisis in the Upper Klamath Basin: A Case Study in Narrative Policy Analysis."

${ }^{61}$ Harry L. Carlson and Rodney Todd, "Effects of the 2001 Water Allocation Decisions on the Agricultural Landscape and Crop Production in the Klamath Reclamation Project," in Water Allocation in the Klamath Reclamation Project, 2001: An Assessment of Natural Resource, Economic, Social, and Institutional Issues with a Focus on the Upper Klamath Basin, Special Report 1037 (Corvallis, Oregon: Oregon State University Extension Service, 2002), 163.

${ }^{62}$ Bruce Weber and Bruce Sorte, "The Upper Klamath Basin Economy and the Role of Agriculture," in Water Allocation in the Klamath Restoration Project, 2001: An Assessment of Natural Resource, Economic, Social, and Institutional Issues with a Focus on the Upper Klamath Basin, 1037 (Oregon State University Extension Service, 2002).
} 


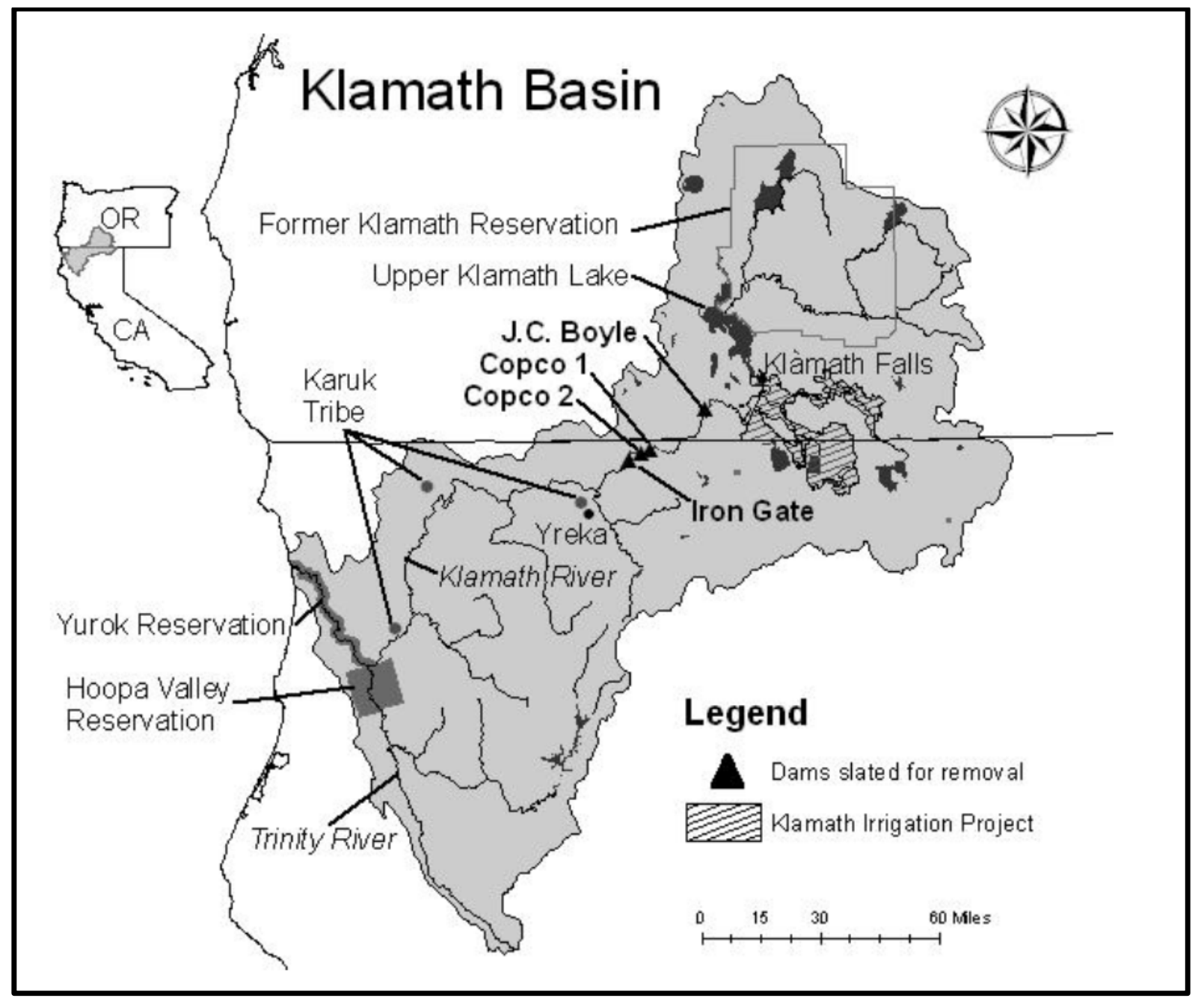

Figure 3: Selected Klamath Project infrastructure and reservoirs. ${ }^{63}$

\section{Native American Tribes}

The Klamath Basin is home to the Klamath, Modoc, Yurok, Karuk and Hoopa tribes.

The tribes of the Klamath Basin have been marginalized in an economic and social sense but, like the farming communities served by the Klamath Project, have a lifestyle and heritage rooted in the region. ${ }^{64}$ The tribes have faced significant challenges to becoming politically empowered actors in shaping the future of the Klamath Basin. As the region was opened to white settlement, tribal rights were ignored in favor of federal reclamation projects and the

\footnotetext{
${ }^{63}$ Gosnell and Kelly, "Peace on the River?"

${ }^{64}$ Doremus and Tarlock, Water War in the Klamath Basin.
} 
development of irrigated agriculture. In the lower basin, the Yurok and Hoopa tribes have retained fishing rights for cultural, subsistence, and commercial purposes and have "withstood white settlement... far better than most other tribes," including the neighboring Klamath tribe in the upper basin. ${ }^{65}$ Despite their fishing rights, serious economic problems persist with a majority of tribal members living in poverty and without electricity. Tribes were granted water rights dated "time immemorial" as part of their 1864 treaty with the federal government, including instream flow sufficient to maintain their fishing rights. ${ }^{66}$ These rights were functionally "largely inchoate" until they were officially recognized by the State of Oregon in 2013 because of a basin-wide water rights adjudication process that spanned nearly four decades. ${ }^{67}$ These water rights have absolute priority over other rights, including senior water rights held by Anglo settlers. Despite their marginalization, tribal senior water rights and legally recognized claims to fish and wildlife remain a "powerful bargaining chip" in changing the balance of political power. ${ }^{68}$

\section{Mountains and water}

The region is relatively isolated from the population centers and consciousness of its home states, Oregon and California. ${ }^{69}$ State capitols Salem and Sacramento are hundreds of

\footnotetext{
${ }^{65}$ Doremus and Tarlock, "Fish, Farms, and the Clash of Cultures in the Klamath Basin," 297. ${ }^{66}$ Michael S. Carolan, "Ontological Politics: Mapping a Complex Environmental Problem," Environmental Values 13, no. 4 (November 2004): 497-522.

${ }^{67}$ Doremus and Tarlock, "Fish, Farms, and the Clash of Cultures in the Klamath Basin," 304; Bettina Boxall, "Winners in Harsh Battle for Klamath River Water Claim Their Rights," Los Angeles Times, June 10, 2013, http://articles.latimes.com/2013/jun/10/local/la-me-klamath-call-20130611; Oregon Water Resources Department, "The Oregon Water Resources Department Completes Klamath River Basin Adjudication (1975 2013)," March 7, 2013, http://www.oregon.gov/owrd/ADJ/docs/2013_03_07_Klamath_River_Basin_Adjudication_Media_R elease_Final.pdf.

${ }^{68}$ Doremus and Tarlock, Water War in the Klamath Basin, 73.

${ }^{69}$ Most, River of Renewal: Myth and History in the Klamath Basin.
} 
miles to the north and south, and the region's inhabitants have grown accustomed to their isolation. Few visitors go out of their way to visit an area "defined by mountains and water rather than by routes, borders, and destinations. ${ }^{, 70}$ Despite its isolation, the region has been connected to larger economic and societal networks for over a century. ${ }^{71}$ Loggers cut thick stands of ponderosa pine and redwood trees for timber markets, agricultural communities produced crops, and the federal government has been a key player in the development of both land and water. ${ }^{72}$ Yet until the listing of several fish species under the Endangered Species Act, the basin remained largely off of the mental map of Oregonians and Californians. ${ }^{73}$ Despite its low profile, the upper basin's aridity, community dependence on agriculture and irrigation, and uncomfortable relationship with the federal government are features that reflect the larger Western geographical context. ${ }^{74}$ While the specifics are unique to the Klamath Basin, conflict over endangered species and the proper use of nature is hardly new in the West.

\section{Fishes of the Klamath Basin}

The Klamath Basin is home to an assortment of fishes, but the species most relevant to the water conflict in the basin are the Lost River sucker (Deltistes luxatus), shortnose sucker (Chasmistes brevirostris), and coho salmon (Oncorhynchus kisutch) ${ }^{75}$ The suckers are endemic to the basin, while the coho salmon belong to the Southern Oregon Northern California Coast "evolutionarily significant unit" and are native to the Klamath Basin and

\footnotetext{
${ }^{70}$ Ibid., $\mathrm{x}$.

${ }^{71}$ Robbins, Landscapes of Promise.

${ }^{72}$ Ibid.

${ }^{73}$ Most, River of Renewal: Myth and History in the Klamath Basin.

${ }^{74}$ McKinney and Harmon, The Western Confluence: A Guide to Governing Natural Resources.

${ }^{75}$ National Academies Press (U.S.), Endangered and Threatened Fishes in the Klamath River Basin.
} 
adjacent river basins ${ }^{76}$ All three were once abundant and now are considered at risk due to myriad factors primarily related to alteration of habitat, water management, poor water quality, and overfishing. ${ }^{77}$ The health of sucker and coho salmon populations follows the general trend of Pacific Coast anadromous fish populations, which have suffered in recent decades. Nehlsen et al. identified 214 stocks of salmon at high risk of extinction in Washington, Oregon, California and Idaho; Frissell observes that coho salmon "experienced an extinction rate of at least $10 \%$ " from 1968 through $1984 .{ }^{78}$ Nearly $25 \%$ of salmon and steelhead experienced a decline over the same period of record (see figure 4). ${ }^{79}$

\footnotetext{
${ }^{76}$ Ibid.

${ }^{77}$ Ibid.

${ }^{78}$ Willa Nehlsen, Jack E. Williams, and James A. Lichatowich, "Pacific Salmon at the Crossroads: Stocks at Risk from California, Oregon, Idaho, and Washington," Fisheries 16, no. 2 (1991): 4-21; Christopher A. Frissell, "Topology of Extinction and Endangerment of Native Fishes in the Pacific Northwest and California (U.S.A.)," Conservation Biology 7, no. 2 (June 1993): 342-54.

${ }^{79}$ Frissell, "Topology of Extinction and Endangerment of Native Fishes in the Pacific Northwest and California (U.S.A.)."
} 


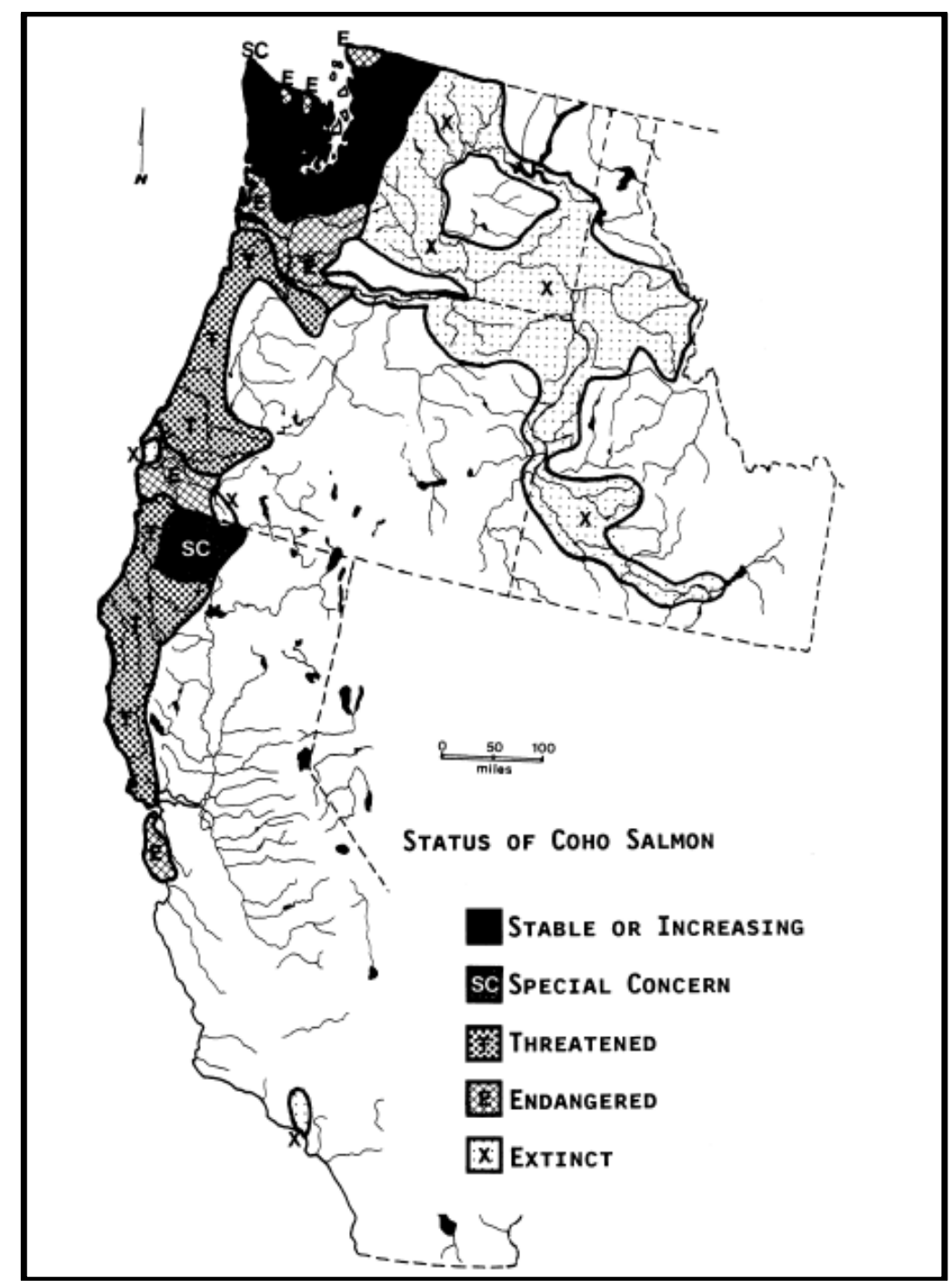

Figure 4: Historic range and current status of coho salmon in Washington, Oregon, California, and Idaho. Note the "special concern" designation for the Klamath Basin. ${ }^{80}$

The Klamath Basin's four species of sucker were likely the most abundant fish in lakes and rivers in the basin prior to their decline.$^{81}$ The Lost River and shortnose suckers were listed under the Endangered Species Act of 1973 (ESA) as endangered by the U.S. Fish and Wildlife Service (FWS) in 1988, following precipitous population declines in the early 1980s. ${ }^{82}$ Between 1984 and 1986, spawning populations of the Lost River sucker reduced by

\footnotetext{
${ }^{80}$ Ibid.

${ }^{81}$ National Academies Press (U.S.), Endangered and Threatened Fishes in the Klamath River Basin.

${ }^{82}$ Doremus and Tarlock, Water War in the Klamath Basin.
} 
one half, and the shortnose sucker "almost disappeared." ${ }^{83}$ Doremus and Tarlock observe "no one seems to have anticipated that the listing might have serious impacts on operation of the Klamath Project." ${ }^{, 84}$

The listing of coho salmon in 1997 as "threatened" generated more interest than the suckers listing, but the response was still muted (174 comments) compared to the flurry of attention to come following the 2001 water curtailment ${ }^{85}$ Like the suckers, coho salmon were once abundant in the basin, though more exact historical populations are unknown because of poor records and misidentification of the fish. ${ }^{86}$ Coho salmon are in decline throughout much of their range, and all California populations have been listed under both state and federal endangered species acts. ${ }^{87}$

\section{Klamath Basin Water Controversy}

2001 water crisis

With the ESA listing of several fish species endemic to the Klamath River in the 1980s and 1990s, the stage was set for future conflict with existing users of river water, notably Klamath Project irrigators. ${ }^{88}$ A serious multi-year drought in the 1990 s resulted in reduced irrigation water deliveries by the BoR in 1992 and 1994, which was necessary for the agency to fulfill downstream flow obligations. A series of fish kills in 1995, 1996, and 1997 resulting from water quality impairment killed more than half of the adult sucker

\footnotetext{
${ }^{83}$ Ibid., 103.

${ }^{84}$ Ibid., 104.

${ }^{85}$ Doremus and Tarlock, Water War in the Klamath Basin.

${ }^{86}$ National Academies Press (U.S.), Endangered and Threatened Fishes in the Klamath River Basin.

${ }^{87}$ Ibid.

${ }^{88}$ Doremus and Tarlock, Water War in the Klamath Basin.
} 
spawning population. ${ }^{89}$ While the dry years in the 1990 s proved challenging for the BoR, the agency was able to fulfill its obligation to make at least partial irrigation water deliveries to water rights holders, while still satisfying the competing uses of water in the basin: the listed fish species, tribes, and the downstream commercial fishing industry..$^{90}$ But the agency's juggling act began to fall apart during the dry winter of 2000-2001. The drought was severe enough to prompt the BoR to forecast record low flows to Upper Klamath Lake, the principle reservoir for the irrigated lands of the Klamath Project. ${ }^{91}$ Upholding their obligations under the ESA, the U.S. FWS as well as the National Marine Fisheries Service (NMFS) issued biological opinions stating that continued operation of the irrigation project would jeopardize the listed fish. In the spring of 2001, the BoR revised its water delivery plan to prioritize water deliveries for fish, and given the water shortage, severe irrigation water curtailments were enacted. An unprecedented event in BoR history, the water curtailment resulted in a $90 \%$ reduction in water deliveries to farmers (figure 5). ${ }^{92}$

\footnotetext{
${ }^{89}$ Hurley, "Political Ecology of the 2001 Water Crisis in the Upper Klamath Basin: A Case Study in Narrative Policy Analysis."

${ }^{90}$ Doremus and Tarlock, "Fish, Farms, and the Clash of Cultures in the Klamath Basin."

${ }^{91}$ Ibid.

${ }^{92}$ Doremus and Tarlock, Water War in the Klamath Basin.
} 


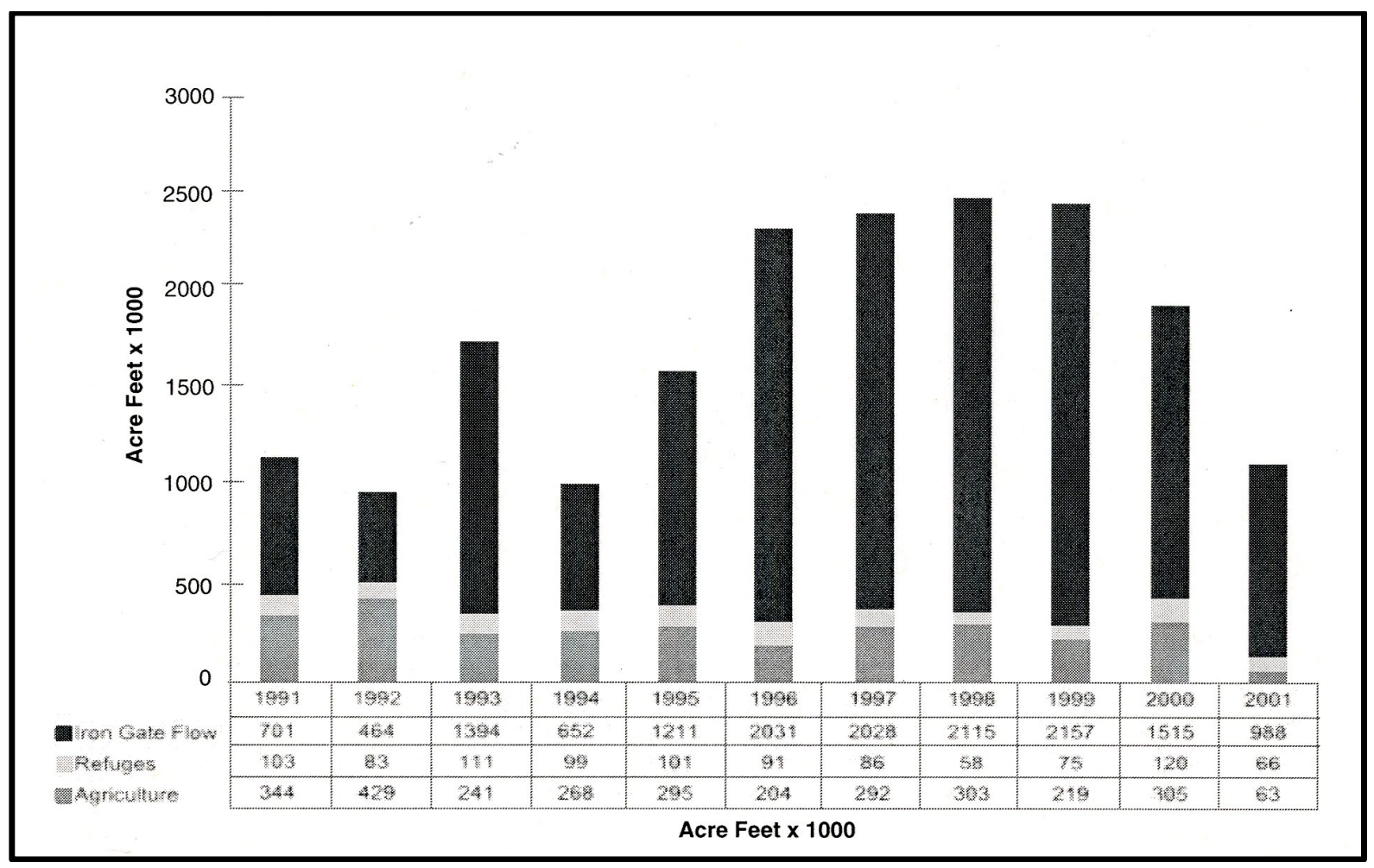

Figure 5: Water allocation for instream flow, wildlife refuges, and agriculture. Compare the irrigation allocation in 2001 with drought years 1992 and $1994 .^{93}$

As they watched what had been irrigation water flow downstream, farmers struggled to maintain crops and livestock, and believed they were entitled to the water needed to maintain their lifestyle. One farmer interviewed at the height of the controversy in the summer of 2001 proclaimed that “they've taken away our water, and they've taken away a way of life." 94 Water shutoffs threatened the very social identity as well as the economic stability of the farmers (figure 6).

\footnotetext{
${ }^{93}$ Kenneth A. Rykbost and Rodney Todd, "An Overview of the Klamath Reclamation Project and Related Upper Klamath Basin Hydrology," in Water Allocation in the Klamath Reclamation Project, 2001: An Assessment of Natural Resource, Economic, Social and Institutional Issues with a Focus on the Upper Klamath Basin (Oregon State University Extension Service, 2002), 45-68.

94 "Fish vs. Farmers," PBS NewsHour, accessed November 7, 2015, http://www.pbs.org/newshour/bb/environment-july-dec01-fish_8-20/.
} 


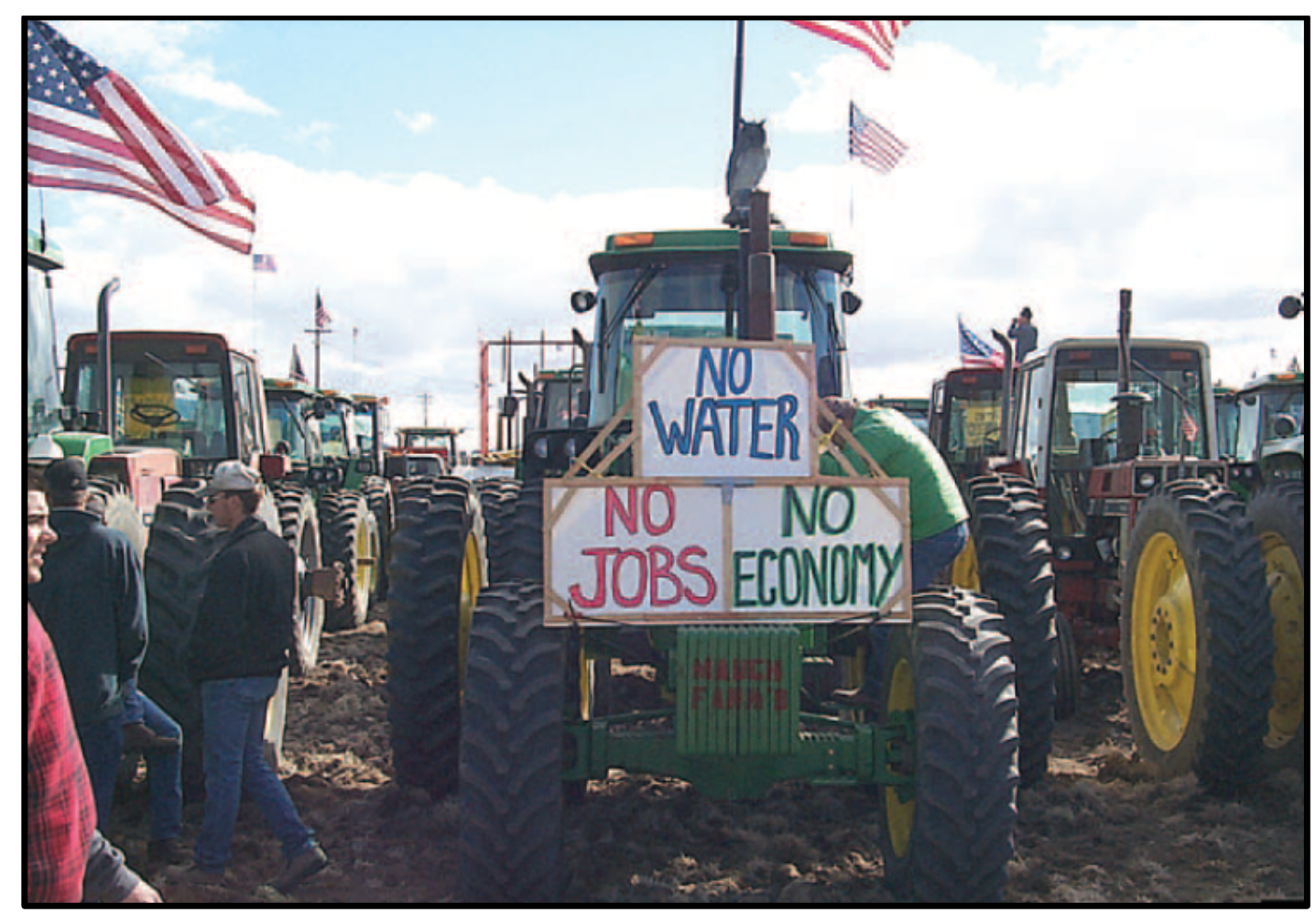

Figure 6: Protest sign at a March 2001 "tractor rally."

Beyond the parched fields, the entire community was impacted by the situation.

Klamath tribal members who supported allowing water to flow downstream for fish were refused restaurant service, and federal employees reportedly feared for their safety amid acts of civil disobedience. ${ }^{96}$ According to newspaper reports, three locals were arrested and charged after driving through a tribal town shouting “[s]ucker lovers, come out and fight!" as well as "blasting signs and buildings with a shotgun, at one point asking a group of children if they were Indians and then shooting over their heads.. ${ }^{97}$ The water crisis made national news headlines as farmers forcibly opened a headgate to release water to irrigation canals, while the local sheriff made no effort to stop the illegal activity. Instead, he pledged his loyalty "to the people of this county and their way of life. The Endangered Species Act is not

\footnotetext{
${ }^{95}$ Sharon Levy, "Turbulence in the Klamath River Basin,” BioScience 53, no. 4 (2003): 315-320.

${ }^{96}$ Robbins, Landscapes of Conflict: The Oregon Story, 1940-2000.

${ }^{97}$ McKinney and Harmon, The Western Confluence: A Guide to Governing Natural Resources, 7.
} 
mine to enforce," underscoring the backlash from the local community. ${ }^{98}$ Federal marshals and National Park Service police were brought in to guard the headgate (figure 7). ${ }^{99}$ U.S. House Representative Greg Walden of Oregon stated the situation in the Klamath Basin was "ground zero in the debate over the Endangered Species Act" and joined politicians from other western states calling for a revision of the ESA. ${ }^{100}$ Senator Gordon Smith of Oregon remarked, "We must never say it's ok to say that sucker fish are more valuable than the farm family," invoking an image of hard-working, virtuous families impacted by draconian environmental law. ${ }^{101}$ While farmers got some relief later in the summer when the BoR released approximately $20 \%$ of their normal irrigation water volume, low streamflow the following year resulted in the largest fish kill of adult salmon ever recorded (figure 8). ${ }^{102}$

\footnotetext{
98 "Fish vs. Farmers."

${ }^{99}$ Robbins, Landscapes of Conflict: The Oregon Story, 1940-2000.

${ }^{100}$ Jehl, "Cries of 'Save the Suckerfish' Rile Farmers' Political Allies"; Michael S. Cooperman and Douglas F. Markle, "The Endangered Species Act and the National Research Council's Interim Judgment in Klamath Basin," Fisheries 28, no. 3 (March 2003): 10-19, doi:10.1577/15488446(2003)28[10:TESAAT]2.0.CO;2.

${ }^{101}$ Ted Williams, "Salmon Stakes," Audubon 105, no. 1 (2003): 42.

${ }^{102}$ Cooperman and Markle, "The Endangered Species Act and the National Research Council's Interim Judgment in Klamath Basin"; Barbara Rose Johnston, "The Political Ecology of Water: An Introduction," Capitalism Nature Socialism 14, no. 3 (September 2003): 73-90, doi:10.1080/10455750308565535.
} 


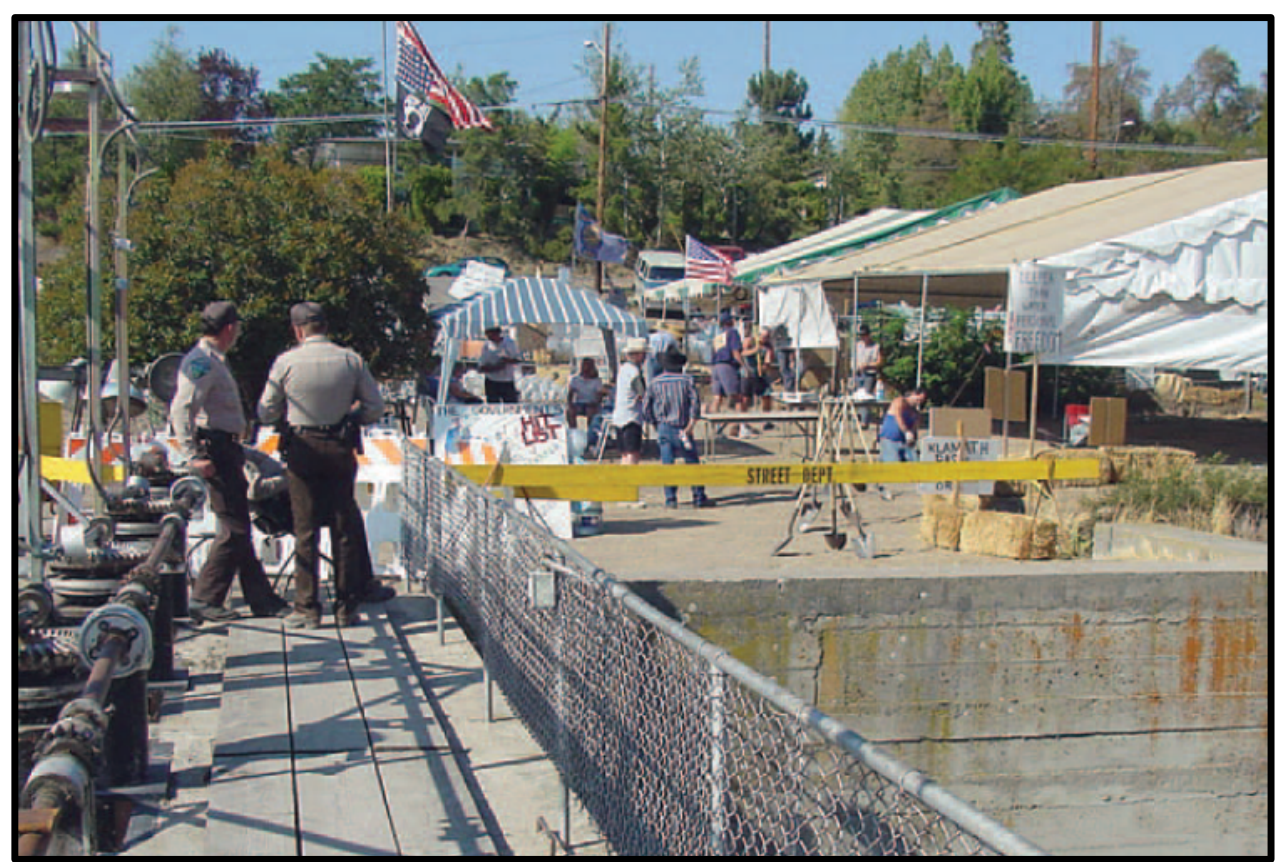

Figure 7: Federal marshals guard the closed headgates to the "A" canal on August 31, 2001 as farmers protest in the background. Note the American flag flown upside down; the sandwich board behind the yellow barricade details the "Government's Hit List."

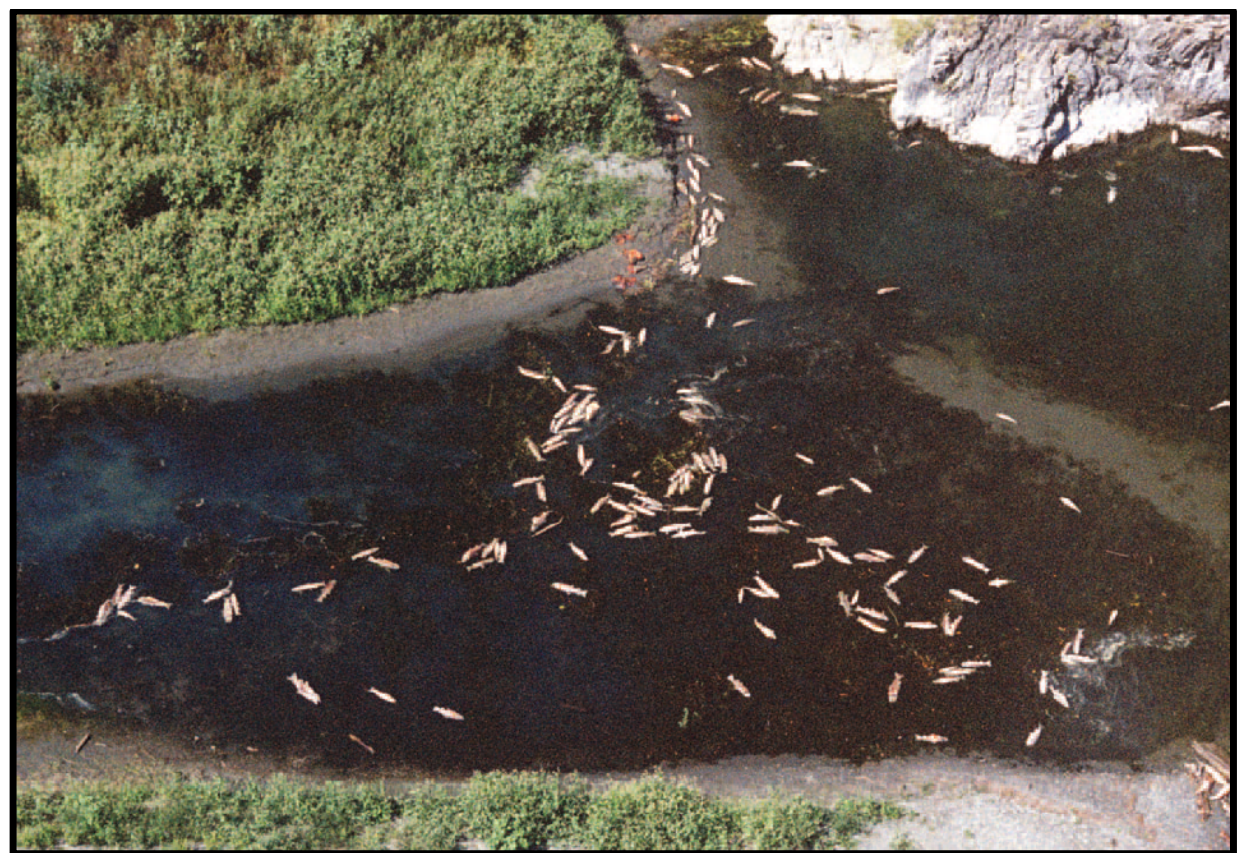

Figure 8: Aerial photo of dead salmon in the Klamath River Basin, September 22, 2002. Over 30,000 salmon died in the largest fish kill of adult salmon on record. ${ }^{104}$

\footnotetext{
${ }^{103}$ Levy, "Turbulence in the Klamath River Basin."

${ }^{104}$ Ibid.
} 
The water crisis served as a symbolic rallying point for those concerned about environmental protection across the West, and populist "wise use" groups from several states joined local farmers calling for a weakening of the ESA. ${ }^{105}$ One result of the flood of support from these outside activists was a symbolic "bucket brigade" that included the installation of a ten foot tall bucket in front of the county building, "a symbol of community support for irrigated agriculture."106 In addition to the symbolic bucket brigade, farmers and their supporters also formed a physical bucket brigade to shuttle water into an irrigation canal as a show of defiance to the water curtailment. ${ }^{107}$ The water crisis "reinvigorated and revived" a familiar debate in the West about environmental management and protection. ${ }^{108}$

The next decade brought an increased focus on the fish and their water needs, but the problems facing the Klamath Basin went beyond endangered species. As Hannah Gosnell and Erin Kelly noted, “The ESA was able to address only one symptom of a larger problem... [the] social and economic issues that were inextricably linked to the ecological problems facing the basin." 109 The Federal Energy Regulatory Commission (FERC) relicensing process for four dams in the basin prompted negotiations with dam owner PacifiCorp to install fish passageways or decommission and remove the dams entirely. PacifiCorp, owned by billionaire Warren Buffet, resisted both options until a legal trial forced PacifiCorp to consider dam removal. ${ }^{110}$ Public comments from the Draft Environmental Impact Statement (DEIS) required for the dam removal proposal form the

\footnotetext{
${ }^{105}$ Doremus and Tarlock, Water War in the Klamath Basin; Rebecca Clarren, "No Refuge in the Klamath Basin," High Country News, August 13, 2001, http://www.hcn.org/issues/208/10647.

${ }^{106}$ Gosnell and Kelly, "Peace on the River?," 370.

${ }^{107}$ McKinney and Harmon, The Western Confluence: A Guide to Governing Natural Resources.

${ }^{108}$ Chaffin, "Reallocating Resources, Rebuilding Community."

${ }^{109}$ Gosnell and Kelly, "Peace on the River?," 370.

${ }^{110}$ Ibid., 374.
} 
data corpus for this research. While the prospect of dam removal prompts hopes for "peace on the river," the science used by federal agencies has been consistently contested by stakeholders in the basin, and the series of conflicting biological opinions, legal decisions, and research reports parallel similar battles over the spotted owl a decade earlier, resembling more "a bar room brawl than a professional, scientific undertaking." 111 In the case of the Klamath water controversy and environmental conflict more broadly, science is expected to arbitrate between competing positions, often with unsatisfactory results. ${ }^{112}$

Science and "wicked problems" in the Klamath Basin

In the Klamath Basin, stakeholders assumed that "good" science would guide water managers' decisions and impartially determine the proper use for the limited water. ${ }^{113}$ This expectation mirrors a broader societal expectation that science can "impartially determine what is in the public's best interest" and is "capable of providing all the information which policy may demand of it." 114 Observing environmental controversies in general, Daniel Sarewitz notes, "for a given value-based position in an environmental controversy, it is often possible to compile a supporting set of scientifically legitimated facts." 115 In the Klamath Basin, the slew of reports, studies, and expert panel conclusions surrounding the needs of the ESA-listed fish produced not certainty, but instead a larger "pool out of which interested

\footnotetext{
${ }^{111}$ Gosnell and Kelly, "Peace on the River?"; Farrell, The Battle for Yellowstone: Morality and the Sacred Roots of Environmental Conflict, 8.

${ }^{112}$ Doremus and Tarlock, Water War in the Klamath Basin.

${ }^{113}$ Ibid.; Cooperman and Markle, "The Endangered Species Act and the National Research Council's Interim Judgment in Klamath Basin."

${ }^{114}$ Warren, "What Is a Healthy Forest?," 112; David Collingridge and Colin Reeve, Science Speaks to Power: The Role of Experts in Policy Making (New York: St. Martin's Press, 1986), 2; Brent Steel et al., "The Role of Scientists in the Environmental Policy Process: A Case Study from the American West," Environmental Science \& Policy 7, no. 1 (February 2004): 1-13.

${ }^{115}$ Daniel Sarewitz, "How Science Makes Environmental Controversies Worse," Environmental Science \& Policy 7, no. 5 (October 2004): 389, doi:10.1016/j.envsci.2004.06.001.
} 
parties can fish differing positions" about the roots of the problem, what should be done, and what the consequences might be. ${ }^{116}$ Existing and emerging contradictory facts led to asking more scientific questions in an attempt to reconcile facts already known.

Science cannot produce absolutely certain findings - there is always a margin of uncertainty. Not all science is disputed, but when the error cost is high or the issues are “culturally disputed, then [experts'] truth-certifying credentials are necessarily put on trial." ${ }^{117}$ Because the stakes were high for the parties - extinction of species, loss of economic livelihood, and change in community identity - those who wished to undermine a particular conclusion pointed to inherent uncertainties as a reason for inaction, calling for more scientific research. Representative Walden characterized the water shutoff as "not scientifically justified," and other politicians characterized the science supporting irrigation water curtailment as "sloppy" and "bad" while calling for "good" science to solve the controversy. ${ }^{118}$ Yet as the amount of scientific information increased, facts became nothing more than ammunition in the battle over water allocation. As Martin Nie observes about the role of science in environmental disputes, "[s]cience, instead of providing finality to these debates, is used strategically by political actors to achieve their goals. Every lawyer, the saying goes, knows what good science is: the science supporting their case."119 Science and politics exist in an uncomfortable relationship when society expects science to answer normative questions with certainty. Thomas Sheridan observes "[m]ost interest groups genuflect at the alter of 'science' during environmental conflicts, selectively employing

\footnotetext{
${ }^{116}$ Ibid.

${ }^{117}$ Dan M. Kahan and Donald Braman, "Cultural Cognition and Public Policy," Yale Law \& Policy Review 24 (2006): 167.

${ }^{118}$ Cooperman and Markle, “The Endangered Species Act and the National Research Council's Interim Judgment in Klamath Basin," 10-11; Jehl, "Cries of 'Save the Suckerfish' Rile Farmers' Political Allies."

${ }^{119}$ Nie, The Governance of Western Public Lands, 191.
} 
scientific data to advance their agendas. At the same time, many non-scientists expect scientists to provide absolute answers to complex questions where scientific evidence is almost always incomplete. ${ }^{\prime 20}$ Seizing on scientific uncertainty, political actors delay unfavorable decisions, and call for more research and "sound science," propagating repeated avoidance of the social and political dimensions of the issue.

The failure of science to "solve" the environmental controversy serves as a reminder of the importance of a more comprehensive approach to problem solving that acknowledges the "messy" nature of environmental conflict. ${ }^{121}$ When the definition of the problem is disputed, solutions and priorities are also disputed. ${ }^{122}$ These "wicked" problems are not easily solved by a technical answer, because instead of answers that are true or false, those with different values and perspectives on the problem view solutions as good or bad, right or wrong. ${ }^{123}$ Each solution has implications, but they are different implications to different people. The conflict in the Klamath Basin is representative of other natural resource management conflicts in the West, as news headlines depict Western landscapes as the battleground between wolves and ranchers, owls and loggers, and more broadly, humanity versus nature. ${ }^{124}$ While environmental controversies are hardly unique to the West, a particular combination of regional factors makes resolving these conflicts challenging.

\footnotetext{
${ }^{120}$ Thomas E. Sheridan, "Embattled Ranchers, Endangered Species, and Urban Sprawl: The Political Ecology of the New American West," Annual Review of Anthropology 36, no. 1 (September 2007): 132, doi:10.1146/annurev.anthro.36.081406.094413.

${ }^{121}$ Lachapelle, McCool, and Patterson, "Barriers to Effective Natural Resource Planning in a 'Messy' World."

${ }^{122}$ Deborah A. Stone, "Causal Stories and the Formation of Policy Agendas," Political Science Quarterly 104, no. 2 (Summer 1989): 281-300.

${ }^{123}$ Rittel and Webber, "Dilemmas in a General Theory of Planning."

${ }^{124}$ Doremus and Tarlock, Water War in the Klamath Basin.
} 


\section{The American West}

Scholars of the American West have failed to agree upon a single definition of the region known as "The West." It has been variously categorized as "all or part of the 18 states lying west of the $100^{\text {th }}$ meridian," ${ }^{125}$ the land west of the Mississippi River, or the 11 western states. ${ }^{126}$ Historian Patricia Limerick defines the West "with flexible borders at the Pacific and at the hundredth meridian, where rainfall drops below the twenty inches a year needed to sustain irrigated agriculture." ${ }^{127}$ Indeed, most scholars agree that the defining characteristic of the region is its aridity.

Marc Reisner asserts that aridity is the "central fact of existence" in the West, and a "whole culture and set of values" has accompanied it. ${ }^{128}$ Matthew McKinney and John Thorson argue that "...one of the features that most defines the American West is water - or more accurately, the lack thereof... Water has always been a vital, scarce, and variable resource in the West. It is a source of both conflict and community, and the region has developed a robust menu of ideas, institutions, and practices over 150 years to manage water and resolve water conflicts." ${ }^{129}$ John Wesley Powell incorporated the challenge of aridity in his vision for the West, one that would prove remarkably prescient with time.

Powell anticipated the need for careful planning if an irrigated West was to succeed. Powell's Arid Lands report was released in 1878, and called for federal government support

\footnotetext{
${ }^{125}$ Matthew McKinney and John E. Thorson, "Resolving Water Conflicts in the American West," Water Policy 17, no. 4 (August 2015): 679, doi:10.2166/wp.2015.146.

${ }^{126}$ Shaun Huston, "Defining the West" (Lecture, Western Oregon University, January 6, 2014).

${ }^{127}$ Patricia Limerick, Something in the Soil: Legacies and Reckonings in the New West (New York: W. W. Norton \& Company, 2001), 23.

${ }^{128}$ Marc Reisner, Cadillac Desert: The American West and Its Disappearing Water, Revised edition (New York, N.Y., U.S.A: Penguin Books, 1993), 12.

${ }^{129}$ McKinney and Thorson, "Resolving Water Conflicts in the American West," 680.
} 
to construct reservoirs to irrigate lands with the best soils and climates. ${ }^{130}$ Though he agreed that irrigation would benefit the West, Powell advocated a reorganization of boundaries to reflect watersheds rather than the geometric survey system that partitioned land into arbitrary grid-shaped spaces. Through Powell's system, water conflict might have been minimized. Additionally, Powell considered it essential that land be designated for different uses based on elevation, climate, soils, and water availability. Powell believed these land parcels should be sized according to their use, with irrigated parcels smaller than the 160 -acre Homestead Act allocation and un-irrigated parcels necessarily larger due to the absence of a water supply. ${ }^{131}$ Such considerations were part of Powell's larger view that the West was not a blank canvas upon which to build a civilization, but rather a landscape both characterized and limited by its aridity. ${ }^{132}$ Ignoring these limits would result in the degradation of both the landscape and the democratic civilization it was to support.

Though Powell has largely been portrayed as a heroic visionary, it is worth noting that Powell was instrumental in making the West legible through governmental science, surveys, and cartography. ${ }^{133}$ Operating under, and thus contributing to, the construct of the West as an empty space on the map that needed to be mapped and surveyed, Powell was in the position to facilitate what James C. Scott has called "projects of legibility and simplification," wherein nature was constructed as an object to be carefully measured,

\footnotetext{
${ }^{130}$ J. W. Powell, "Report on the Lands of the Arid Region of the United States, with a More Detailed Account of the Lands of Utah" (Washington DC: Government Printing Office, 1879).

${ }^{131}$ Reisner, Cadillac Desert.

${ }^{132}$ William deBuys, Seeing Things Whole: The Essential John Wesley Powell (Washington DC: Island Press, 2001).

${ }^{133}$ Wallace Stegner, Beyond the Hundredth Meridian: John Wesley Powell and the Second Opening of the West, 1992nd ed. (Hammondsworth: Penguin Books, 1954); Scott Kirsch, "John Wesley Powell and the Mapping of the Colorado Plateau, 1869-1879: Survey Science, Geographical Solutions, and the Economy of Environmental Values," Annals of the Association of American Geographers 92, no. 3 (2002): 548-72.
} 
surveyed, and known through science. ${ }^{134}$ Powell's collection and mapping of geographic and ethnographic data contributed to a "rational basis for social and environmental control," and Powell defined appropriate land use through the lens of efficiency and use value. ${ }^{135}$ Powell translated nature into natural resources to be used for what Scott Kirsch has called "the governmental values of efficiency, order, and productivity," and his partial vision for valuing the landscape meant that indigenous uses of nature were considered illegitimate sources of environmental degradation. ${ }^{136}$ In his timber surveys, Powell noted evidence of deforestation from forest fires set by native peoples; these fires were counterproductive for the optimization and efficient use of nature in the West, and Powell was complicit in legitimating native people as subjects in need of wise management. ${ }^{137}$ It was from this vision for the productive use of nature that Powell derived his watershed-based system he is lauded for today. In this way, while Powell's vision for the West can indeed be viewed as an innovative yet foolishly overlooked possibility, his vision both reflected and foreshadowed the dominant way of knowing nature in the West: through science, rational management, and valuation of nature as a resource to be tapped.

Though Powell's vision for the irrigated West was largely realized with the Reclamation Act of 1902 and its attendant federal financial support for water development, his word of caution about the perils of overzealously developing the West went largely

\footnotetext{
${ }^{134}$ James C. Scott, Seeing Like a State: How Certain Schemes to Improve the Human Condition Have Failed (New Haven: Yale University Press, 1999), 9.

${ }^{135}$ Kirsch, "John Wesley Powell and the Mapping of the Colorado Plateau, 1869-1879: Survey Science, Geographical Solutions, and the Economy of Environmental Values," 553.

${ }^{136}$ Ibid., 562.

${ }^{137}$ Powell, "Report on the Lands of the Arid Region of the United States, with a More Detailed Account of the Lands of Utah"; Kirsch, "John Wesley Powell and the Mapping of the Colorado Plateau, 1869-1879: Survey Science, Geographical Solutions, and the Economy of Environmental Values."
} 
unheeded. ${ }^{138}$ The boundless enthusiasm and optimism that characterized the settlement of the idealized “mythic West” overshadowed Powell's advice. ${ }^{139}$ A watershed-based system was never instituted, meaning that water conflict often occurs as a result of water flowing through a patchwork of different land management systems and owners.

Like aridity, another defining characteristic of the West is the fragmented system of public and private jurisdictions responsible for managing land and water. The federal government is responsible for managing nearly half of the land in the West, but this is frequently complicated by private landholdings interspersed within federal lands, as well as differing and sometimes contradictory state and local government laws, regulations and zoning (figure 9). ${ }^{140}$ An additional factor is the sovereign authority held by Native American tribes, who often hold a cultural and economic interest in management decisions, especially as they pertain to water for fish populations. ${ }^{141}$

\footnotetext{
${ }^{138}$ Charles F. Wilkinson, Crossing the Next Meridian: Land, Water, and the Future of the West (Washington, D.C.: Island Press, 1992).

${ }^{139}$ Reisner, Cadillac Desert.

${ }^{140} \mathrm{Nie}$, The Governance of Western Public Lands.

${ }^{141}$ McKinney and Thorson, "Resolving Water Conflicts in the American West."
} 


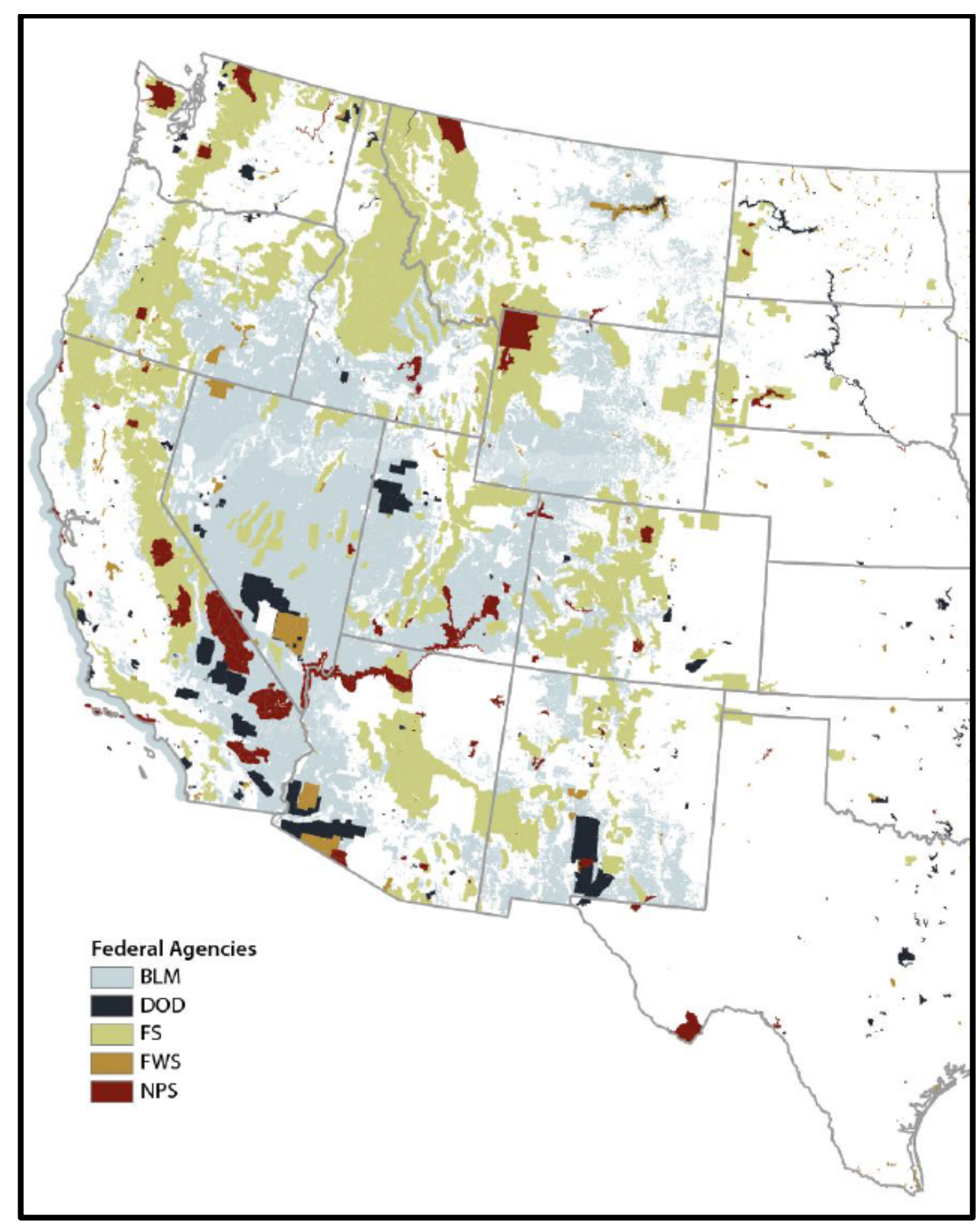

Figure 9: Federal land ownership in the American West. ${ }^{142}$

The West is as much a physical space defined by aridity and land management as it is a product of myth, imagination, and ideas. Just as aridity unifies the physical conception of the West, myth and cultural narrative unifies the imagination of the West. Char Miller notes that the West is a place "more culturally derived than cartographically determined," and acknowledgement of this culturally constructed West is just as important as the physical

\footnotetext{
${ }^{142}$ Carol Hardy Vincent, Laura A. Hanson, and Carla N. Argueta, "Federal Land Ownership: Overview and Data" (Congressional Research Service, March 3, 2017), https://fas.org/sgp/crs/misc/R42346.pdf.
} 
West. ${ }^{143}$ As Fiege has remarked, "[e]very American landscape embodies a myth; to discover the physical place is to discover the great story that its inhabitants told about it."144

These stories, or narratives, comprise "ways of seeing, encountering, and valuing the world... and ways of acting, personally, politically, and legally, that have shaped the world in concrete ways." 145 What the West is, whom it is for, and how it should be best used depends on which narrative is empowered and enacted. According to Jedediah Purdy, "Nearly every American landscape is, in part, a meditation on what people have valued in nature and what they have scorned or ignored." ${ }^{146}$ These narratives also convey an understanding of what is good, moral, and virtuous, as well as a conception of "the good life" and the human place in it. ${ }^{147}$ Narratives guide "a way of seeing, a pattern of supposing how things must be." ${ }^{148}$ The factors of aridity, federal ownership, and cultural investment in what the West should be have coalesced to create a region with a particular relationship with nature. Historian William Cronon has observed that some of the "deepest struggles" in the history of the American West have been among those who have defined "the good life... in conflicting ways." Underlying these ideas, old and new, are relationships between humans and nature.

\footnotetext{
${ }^{143}$ Char Miller, ed., Cities and Nature in the American West, The Urban West Series (Reno, Nevada: University of Nevada Press, 2010), 1.

${ }^{144}$ Fiege, Irrigated Eden: The Making of an Agricultural Landscape in the American West, 8.

${ }^{145}$ Purdy, After Nature, 7.

${ }^{146}$ Ibid., 8.

${ }^{147}$ Farrell, The Battle for Yellowstone: Morality and the Sacred Roots of Environmental Conflict; Purdy, After Nature.

${ }^{148}$ Purdy, After Nature, 22.

${ }^{149}$ William Cronon, "Revisiting the Vanishing Frontier: The Legacy of Frederick Jackson Turner," The Western Historical Quarterly 18, no. 2 (April 1987): 175, doi:10.2307/969581.
} 


\section{Ideas of Nature}

Nature is a fugitive term, eluding easy definition. As Raymond Williams has famously remarked, "nature is perhaps the most complex word in the English language."150 Hull et al. observe "[n]aturalness is a powerful yet contested construct in contemporary society." ${ }^{151}$ Langdon Winner writes of three ideas of nature: nature as a stock of economic goods, nature as an endangered ecosystem, and nature as a source of intrinsic good. ${ }^{152}$ Several scholars have developed visuals to depict ways in which nature is understood. ${ }^{153}$ Michiel Schwarz and Michael Thompson depict four myths of nature (see figure 10, below) with their ball and cup diagrams: nature capricious (random, unpredictable), nature benign (resilient to anthropogenic harm), nature perverse/tolerant (resilient within limits), and nature ephemeral (delicate, fragile). These schemas depict the varied ways in which humans relate to nature, and the ways in which we have constructed nature.

Schwarz and Thompson's nature benign depicts a nature that is resilient and robust, meaning management can adopt a laissez faire approach: "no matter what knocks we deliver the ball will always return to the bottom of the basin." ${ }^{154}$ Nature ephemeral is the opposite of nature benign: the ball is delicately balanced, meaning management must adopt a careful and delicate approach to prevent tipping the ball off balance. ${ }^{155}$ Nature perverse/tolerant portrays

\footnotetext{
${ }^{150}$ Raymond Williams, Keywords: A Vocabulary of Culture and Society (New York: Oxford University Press, 1976), 184.

${ }^{151}$ Hull, Robertson, and Kendra, "Public Understandings of Nature: A Case Study of Local Knowledge About 'Natural' Forest Conditions," 338.

${ }^{152}$ Langdon Winner, The Whale and the Reactor: A Search for Limits in an Age of High Technology (Chicago: University Of Chicago Press, 1989).

${ }^{153}$ Lance H. Gunderson and C. S. Holling, eds., Panarchy: Understanding Transformations in Human and Natural Systems (Washington, DC: Island Press, 2002); Michiel Schwarz and Michael Thompson, Divided We Stand: Re-Defining Politics, Technology, and Social Choice (Philadelphia: University of Pennsylvania Press, 1990).

${ }^{154}$ Schwarz and Thompson, Divided We Stand, 5.

${ }^{155}$ Ibid.
} 
a nature that is forgiving (or tolerant) of many events but management must prevent exceeding the limits of nature, for these will roll the ball over the edge of the basin. ${ }^{156}$ Lastly, nature capricious represents a random world wherein management does not manage, learn, or adapt, but instead "just cope" with events as they occur. ${ }^{157}$

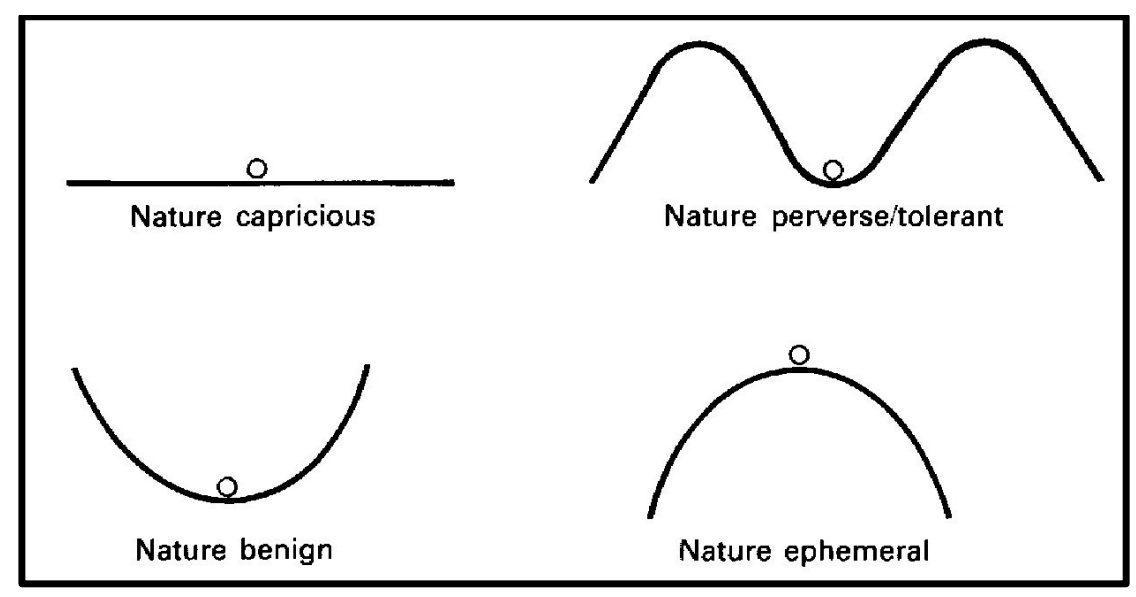

Figure 10: Schwarz \& Thompson's orientations toward, or myths of, nature. ${ }^{158}$

Each of these ideas of nature describes a certain relationship to nature, varied and contradictory though they may be. Working from this premise that nature has many facets, Winner observes, "because they offer the promise of universal truth, conceptions of nature have an astonishing power to persuade." ${ }^{159}$ R. Bruce Hull cautions against "advocating or accepting a single or fixed interpretation [of nature]. We have a tendency to find in nature the lessons we go looking for." ${ }^{160}$ Similarly, an examination of the history of ideas of nature shows "nature will justify anything."161 Similarly, Donald Worster notes that the history of ideas of nature reveals few truths about nature itself but instead reflects the ideas of society, and Winner agrees that nature tells us "a great deal more about the condition of society than

\footnotetext{
${ }^{156}$ Ibid.

${ }^{157}$ Ibid.

${ }^{158}$ Schwarz and Thompson, Divided We Stand.

${ }^{159}$ Winner, The Whale and the Reactor, 123.

${ }^{160}$ R. Bruce Hull, Infinite Nature (Chicago, IL: University of Chicago Press, 2006), 206.

${ }^{161}$ Winner, The Whale and the Reactor, 137.
} 
anything in nature as such." ${ }^{162}$ Together, these scholars point out that there is nothing "natural" about nature - it is malleable and contested, reflecting the visions and ideas of humans as much as speaking an ultimate truth about the world.

The myths of nature introduced above help to conceptualize the different understandings of nature, and reflect particular conceptions of how the world is. These ideas of nature can be understood as in conversation with, and related to, larger cultural worldviews. Schwarz and Thompson integrated the ideas of nature introduced above (figure 10) with cultural theory's four worldviews. Developed by anthropologist Mary Douglas, cultural theory describes four distinct cultural worldviews: egalitarianism, hierarchism, individualism, and fatalism. ${ }^{163}$ These "serve as the primary combinations of values that guide how individuals formulate both broad social orientations and derive more specific policy perspectives." ${ }^{\prime 164}$ These four worldviews are derived from the relationship between two continuums: group and grid.

The group continuum describes the degree to which individuals see themselves as a part of social units. ${ }^{165}$ The "low-group" end represents the view that individuals are autonomous actors, reliant completely upon themselves for survival. Conversely, the "highgroup" end represents those who perceive themselves, and their choices, to be highly defined by group affiliation. The grid continuum represents the degree to which social prescriptions restrict life. Taken together, the group and grid continuums form four typologies (figure 11).

\footnotetext{
${ }^{162}$ Donald Worster, Nature's Economy: A History of Ecological Ideas, 2nd ed. (Cambridge; New York, NY, USA: Cambridge University Press, 1994); Winner, The Whale and the Reactor, 135.

${ }^{163}$ Mary Douglas, Natural Symbols: Explorations in Cosmology (Routledge, 1970).

${ }^{164}$ Hank Jenkins-Smith et al., "Belief System Continuity and Change in Policy Advocacy Coalitions: Using Cultural Theory to Specify Belief Systems, Coalitions, and Sources of Change," Policy Studies Journal 42, no. 4 (2014): 489.

${ }^{165}$ Jenkins-Smith et al., "Belief System Continuity and Change in Policy Advocacy Coalitions."
} 


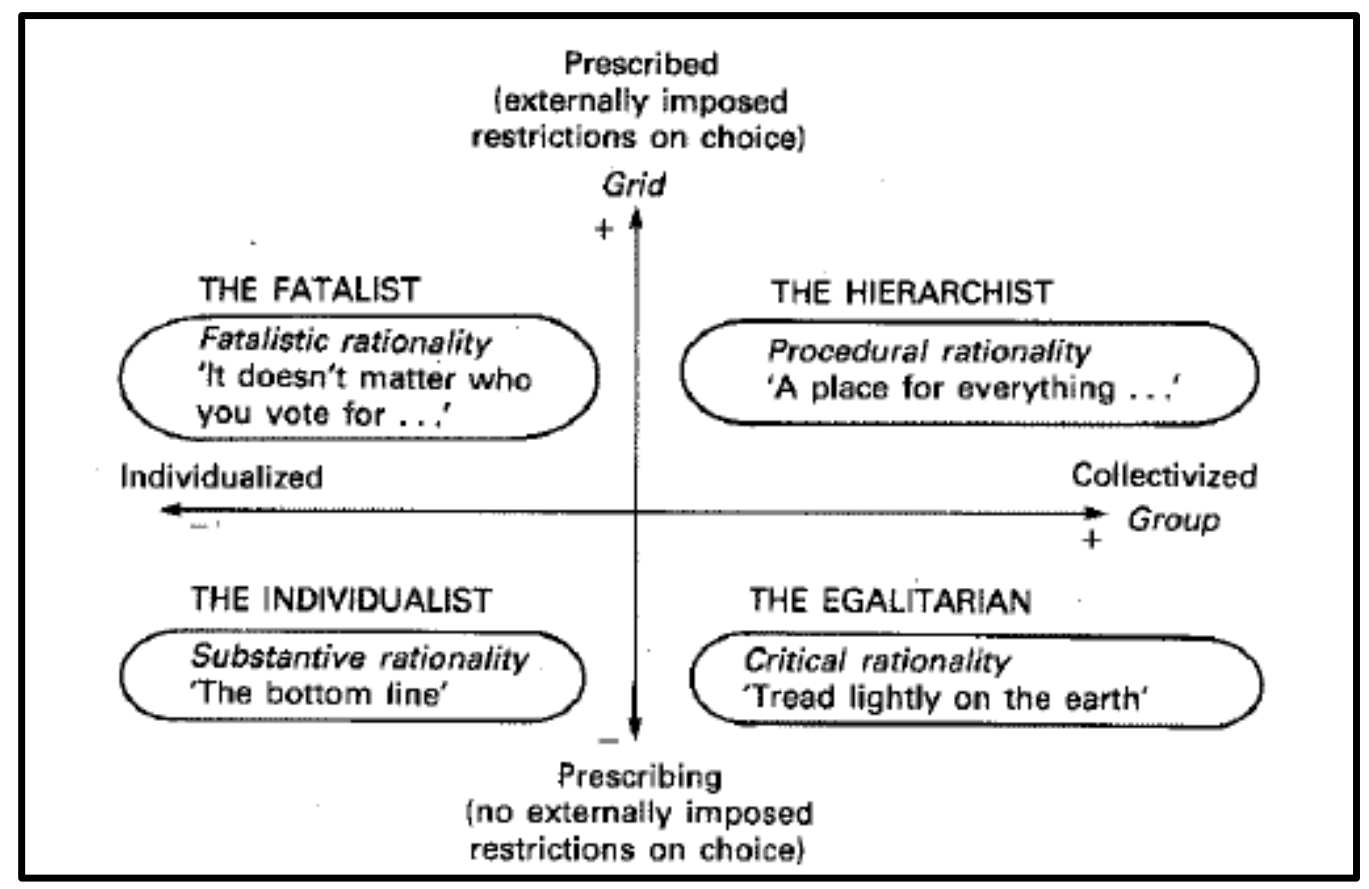

Figure 11: The four worldviews formed by cultural theory's group and grid continuums. ${ }^{166}$

Hierarchists prioritize the welfare of the group over their own, and place "great value on procedures, lines of authority, social stability, and maintenance of institutions." 167

Conversely, individualists feels little group identity, dislikes external constraints, and expects people to "fend for themselves." "168 Thus the procedures preferred by hierarchists are a source of consternation for individualists. Egalitarians strongly relate to groups, but prefer minimal external constraints. This worldview prefers authority to come from within their group and they desire equality within the group. ${ }^{169}$ Fatalists consider themselves bound to external constraints while simultaneously feeling excluded from social groups that influence life. Thus fatalists feel they lack agency and their future is a matter of chance rather than choice. ${ }^{170}$ While these four worldviews are not the central focus of this thesis, they are useful

\footnotetext{
${ }^{166}$ Schwarz and Thompson, Divided We Stand, 7.

${ }^{167}$ Jenkins-Smith et al., "Belief System Continuity and Change in Policy Advocacy Coalitions," 490.

${ }^{168}$ Ibid.

${ }^{169}$ Ibid.

${ }^{170}$ Ibid.
} 
when understood in conjunction with the ideas of nature discussed above (figure 10).

Schwarz and Thompson have synthesized the ball and cup diagrams of nature with cultural theory's four typologies to connect the ways in which nature is viewed with larger cultural worldviews (figure 12). Taken together, this helps to link the way in which nature is viewed with the larger cultural basis for the acceptability of a given management decision. For example, the nature benign myth of nature compliments an individualist worldview: this person sees nature as robust and resilient, and dislikes external constraints on their actions. This means governmental regulation of activities for the purpose of obeying environmental law offends both the individualist worldview, as well as their myth of nature as something that does not warrant protection. 


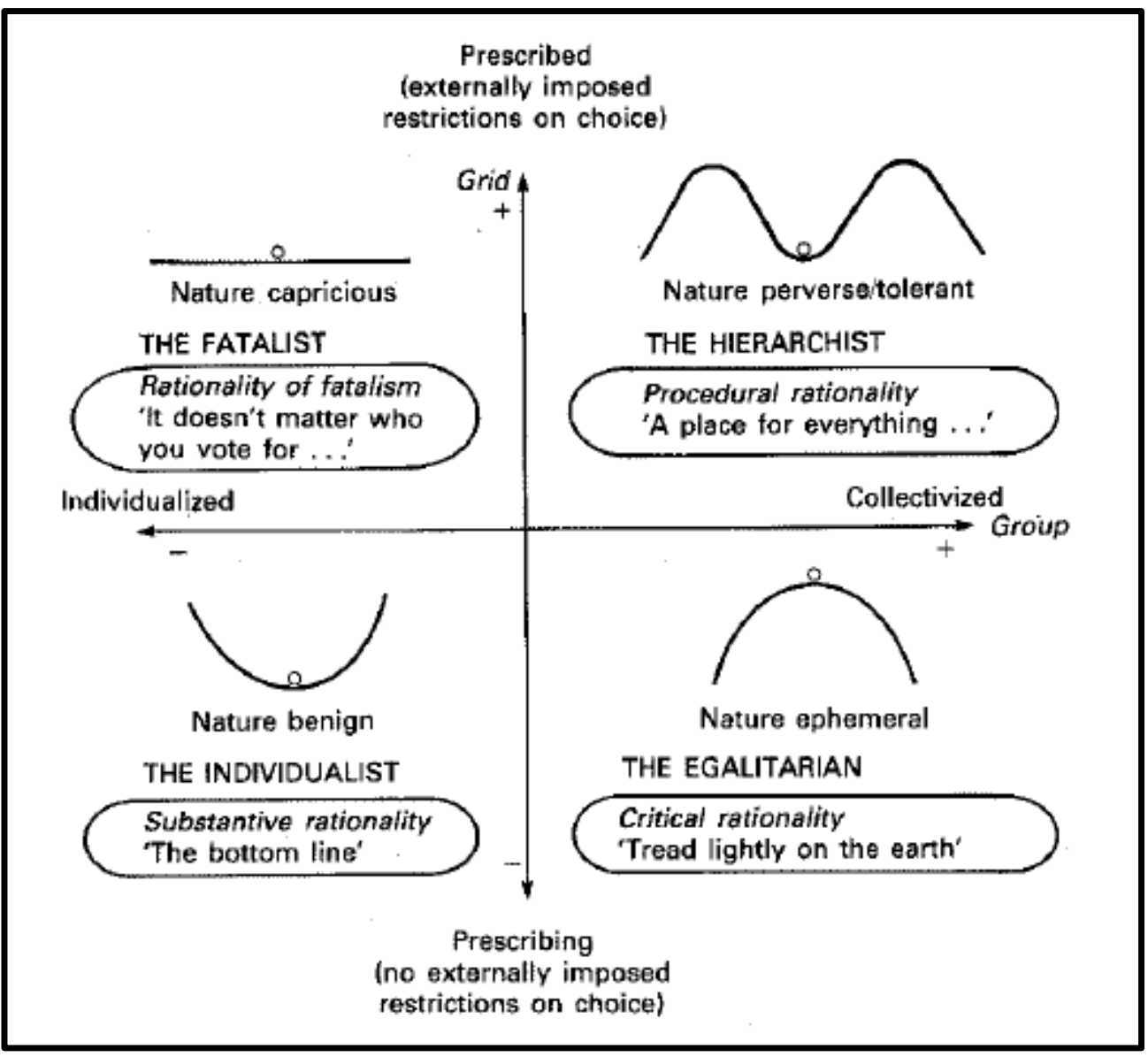

Figure 12: Schwarz and Thompson's myths of nature imposed upon cultural theory's four typologies. ${ }^{171}$

For now, I will focus on the myths or ideas of nature presented in figure 10 . These ideas of nature are important pieces in understanding environmental conflict because they influence cultural thought and attitude, national environmental law, and underlie conceptions about the proper use of nature. A number of studies have shown that people's ideas of nature are related to their preferred management of nature and views on what constitutes "healthy" nature. ${ }^{172}$ Hull et al. related ideas of nature with management preferences, finding "differing

\footnotetext{
${ }^{171}$ Schwarz and Thompson, Divided We Stand, 9.

${ }^{172}$ R. Bruce Hull et al., "Understandings of Environmental Quality: Ambiguities and Values Held by Environmental Professionals," Environmental Management 31, no. 1 (January 1, 2003): 1-13, doi:10.1007/s00267-002-2812-6; Hull, Robertson, and Kendra, "Public Understandings of Nature: A Case Study of Local Knowledge About 'Natural' Forest Conditions"; Warren, "What Is a Healthy
} 
assumptions about nature constrain people's vision of what environmental conditions can and should exist, thereby constraining the future that can be negotiated." ${ }^{173}$ Particular ideas of nature each had a time of national prominence, during which that idea became enshrined in a particular set of laws, cultures, and politics. In the mid $19^{\text {th }}$ and early $20^{\text {th }}$ centuries, nature was seen as boundless and inexhaustible; the philosophy of conservation and managed nature shifted to become a national imperative in the early $20^{\text {th }}$ century, and by the 1960 s nature was seen as endangered at the hand of humanity. ${ }^{174}$ Each shift in thinking did not erase all traces of the others, and as Worster explains, "the present corpus of ecological thought is a conglomeration of all its pasts." By the late 1970s, all of these ideas of nature coexisted uneasily as the topic of the environment, once a point of unity, became as contentious as any other topic in American politics. ${ }^{175}$

"Nature benign" and "landscapes of promise" in the American West

From its beginning, the West inspired westward migration of colonists and homesteaders. The popular discourse surrounding the West centered on the individual as well as freedom and the promise of democracy. The common man (almost certainly a white male), seeking a peaceful and productive life away from the oppressive cities of the East looked toward "landscapes of promise" where, as yeoman farmers, they might live virtuous lives full of opportunity and far from contaminating influence. ${ }^{176}$ By the 1850 s miners were already

Forest?”; Willett M. Kempton, James S. Boster, and Jennifer A. Hartley, Environmental Values in American Culture (Cambridge, Mass.: The MIT Press, 1996).

${ }^{173}$ R. Bruce Hull et al., "Assumptions about Ecological Scale and Nature Knowing Best Hiding in Environmental Decisions," Conservation Ecology 6, no. 2 (2002): 1.

${ }^{174}$ Worster, Nature's Economy.

${ }^{175}$ Ibid., xiii; Paul Sabin, The Bet: Paul Ehrlich, Julian Simon, and Our Gamble over Earth's Future (New Haven: Yale University Press, 2013).

${ }^{176}$ Robbins, Landscapes of Promise. 
developing the lands of the West in search of gold, developing an economy to support mining efforts. ${ }^{177}$ The second "gush of humanity" began in the 1860s in the wake of the Homestead Act of 1862, which allotted land to citizens to encourage westward expansion and settlement. ${ }^{178}$ By granting ownership in exchange for the labor of clearing and planting the land, the act drew on the Lockean idea that a person could turn nature into property by “mix[ing] his labor with it." ${ }^{179}$ It was on this property that citizens would build character and develop resources: Thomas Jefferson in particular prescribed a pastoral lifestyle, which he believed would build an "independent and self-reliant character" and a democratic state. ${ }^{180}$ While not an entirely novel concept, ordering nature by way of property changed not only the physical landscape of the West but also the social one, for, as Williams has remarked, "[o]nce we begin to speak of people mixing their labour with the earth, we are in a whole new world of new relations between people and nature and to separate natural history from social history becomes extremely problematic." 181

The creation of the prior appropriation system of water law was a key evolution in the agrarian control of nature in the West. Prior appropriation began in California but was adopted across all Western states, and follows the doctrine of "first in time, first in right" when claiming rights to a portion of the streamflow of a creek or river. ${ }^{182}$ Under this system, an irrigator who established an earlier use date than another held a more a more senior water right. In periods of water scarcity, water would be prioritized for the senior water rights

\footnotetext{
${ }^{177}$ Wilkinson, Crossing the Next Meridian.

${ }^{178}$ Reisner, Cadillac Desert, 35; Wilkinson, Crossing the Next Meridian.

${ }^{179}$ Purdy, After Nature, 73.

${ }^{180}$ Hull, Infinite Nature, 193; Deborah P. Dixon and Holly M. Hapke, "Cultivating Discourse: The Social Construction of Agricultural Legislation," Annals of the Association of American Geographers 93, no. 1 (March 2003): 142-64, doi:10.1111/1467-8306.93110.

${ }^{181}$ Williams, "Ideas of Nature," 76.

${ }^{182}$ Wilkinson, Crossing the Next Meridian.
} 
holders while denied to junior rights holders. To retain water rights, an irrigator needed to put the water to "beneficial use" such as agriculture. ${ }^{183}$ This deceptively simple system meant that nature became a natural resource, "raw materials that people could manipulate, possess, and transform into wealth." ${ }^{184}$ In this way, irrigators understood the flowing water of a river as both a physical entity and part of an abstract legal entity as well. ${ }^{185}$ Once conceptualized as a resource, nature could be ordered to that end, and the products of labor on the land were commodities to be sold in the marketplace (figure 13).

${ }^{183}$ Ibid.

${ }^{184}$ Fiege, Irrigated Eden: The Making of an Agricultural Landscape in the American West, 87. ${ }^{185}$ Ibid., 88 . 


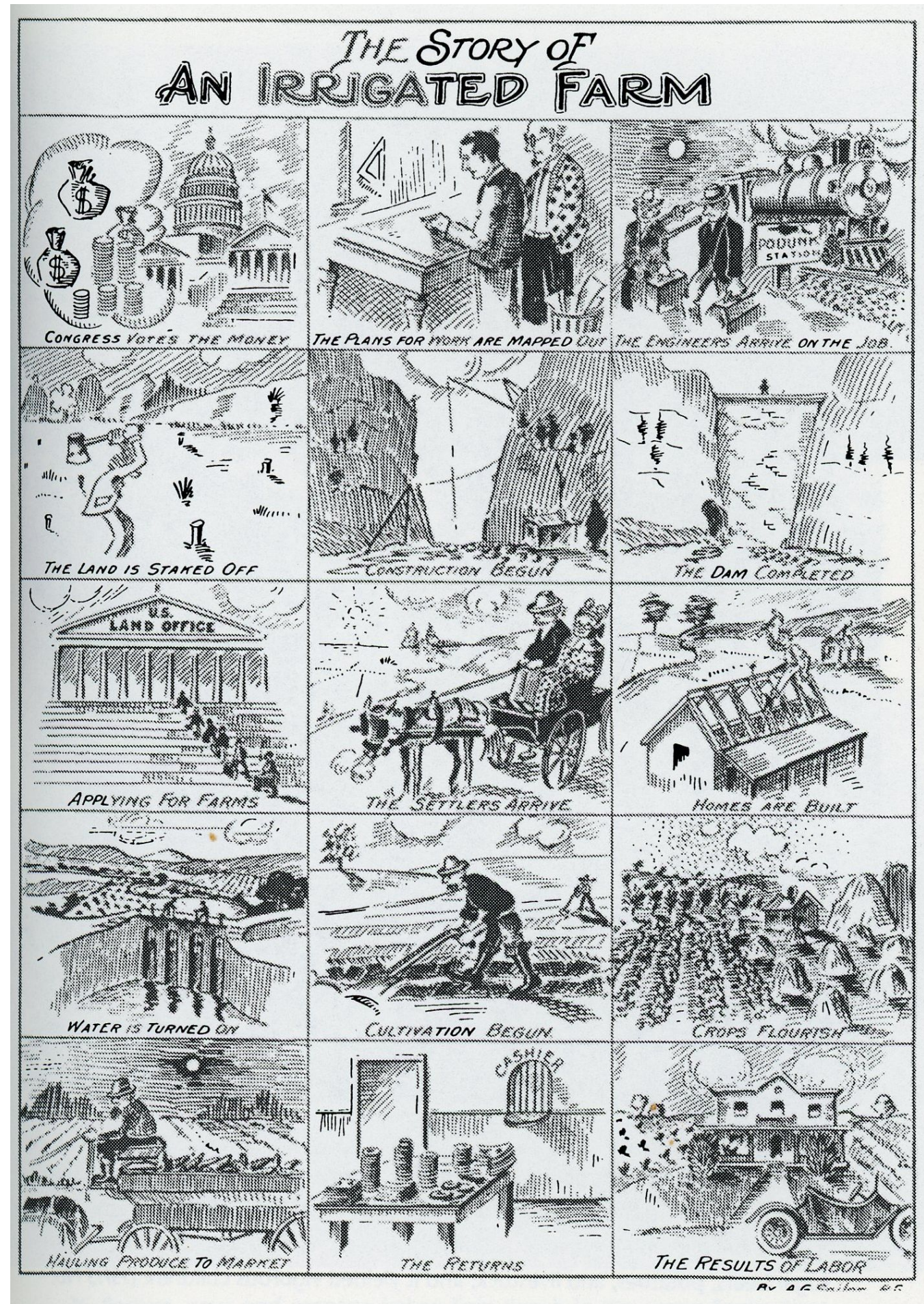

Figure 13: A. G. Seiler's “The Story of an Irrigated Farm” (1915) reflects the ordering of nature to produce crops for the capitalist marketplace. ${ }^{186}$

${ }^{186}$ Fiege, Irrigated Eden: The Making of an Agricultural Landscape in the American West. 
A certain conception of nature helped to shape the ways in which settlers approached the landscape as they attempted to realize their agrarian dreams in the West. Nature was seen as something to be conquered and overcome: human control was to "make the crooked straight and the rough forces plain; force the desert to blossom like a rose." ${ }^{187}$ Wild places were "a moral and physical wasteland fit only for conquest and transformation in the name of progress, civilization, and Christianity." 188 Settlers conquered the hellish wilderness, worked valiantly to re-create a lost Eden, redeemed themselves and the land, and "realized God's plan for the earth." 189 The Creator's grand plan was for man to reclaim the "desert waste" and live in an Eden-like garden. ${ }^{190}$ In this providential view, man dominated the wild and it emerged conquered, tamed, and ready to suit the destiny of man. That humanity belonged in the West, should thrive there, and seek total dominion, was to be at the core of Western ideology for the next century. ${ }^{191}$ Nature in the agrarian West was seen as an inexhaustible storehouse for the sustenance of the virtuous farmer and the growth of a democratic nation.

Although the popular rhetoric of the time espoused the notion that "rain follows the plow," the limited success of civilian irrigation projects coupled with frigid winters and drought in the late 1880 s and early 1890 s spelled disaster for farmers on the western plains. ${ }^{192}$ As part of the effort to rescue struggling farmers, the federal government passed the Reclamation Act of $1902 .{ }^{193}$ Though intended to support small farmers, the passage of the Reclamation Act marked a shift away from a Jeffersonian society composed of democratic

\footnotetext{
${ }^{187}$ Roderick Frazier Nash, Wilderness and the American Mind, 4th ed. (New Haven: Yale University Press, 2001), xii.

${ }^{188}$ Ibid., xiii.

${ }^{189}$ Fiege, Irrigated Eden: The Making of an Agricultural Landscape in the American West, 171.

${ }^{190}$ Ibid., 42.

${ }^{191}$ Reisner, Cadillac Desert.

${ }^{192}$ Ibid.

${ }^{193}$ Ibid.
} 
and virtuous farmers. ${ }^{194}$ In its place was a vision of growth, progress, and the technical mastery of nature. ${ }^{195}$ This "doctrine of progress" that would ultimately remake the West into a "hydraulic society" was dependent on technology and engineering for its survival. ${ }^{196}$ The rise of progressivism would provide both a justification and a mechanism for the large-scale development of water in the West. Efficient use of nature became a national imperative.

Nature perverse/tolerant - optimizing nature through management and conservation

While the moral work for the pioneer was domesticating wild nature and bringing morality to a howling evil wilderness, that work in the progressive period in the first decades of the $20^{\text {th }}$ century focused on tackling larger collective problems and national challenges, all in the name of the national interest. ${ }^{197}$ As in earlier decades, nature was servant to human needs, but now it was believed that nature was too complex for unmanaged use. Nature, in this view, required careful expert management. Progressives saw the lassiez-faire model of individual citizens developing private property as they wished as "a period of destruction" characterized by "ruinous exploitation" in the face of a complex nature; clearing of the land and farming lead to the rapid depletion of resources, and inefficient use of resources led to waste. ${ }^{198}$ To prevent misuse, nature required "intelligent, extensive, and powerful government" to steward resources. ${ }^{199}$ Gifford Pinchot, a key champion of progressive ideals, saw "the world as badly in need of managing, and he was convinced that science could teach

\footnotetext{
${ }^{194}$ Purdy, After Nature.

${ }^{195}$ Ed Marston, "Reclaiming the Spirit of Reclamation," Nat. Resources J. 44 (2004): 681.

${ }^{196}$ Donald Worster, Under Western Skies: Nature and History in the American West (New York: Oxford University Press, 1992), 6; Donald Worster, Rivers of Empire: Water, Aridity, and the Growth of the American West (Cambridge: Oxford University Press, 1985), 7.

${ }^{197}$ Samuel P. Hays, Conservation and the Gospel of Efficiency: The Progressive Conservation Movement, 1890-1920 (Cambridge: Harvard University Press, 1959).

${ }^{198}$ Purdy, After Nature, 157.

${ }^{199}$ Ibid., 156.
} 
man to improve on nature, to make its processes more efficient and its crops more abundant."200

Progressives saw an imperative to protect nature from and for the self-interested citizen and their corporations. For a complex nature in need of educated management, conservation was the answer. Conservation focused on eliminating waste, and this in turn required "knowledge to understand the problem, the cultural maturity for self-restraint, and government to enforce limits on exploitation."201 It was believed that the "stream now dry, [would be] running bank full for the welfare of the people" under progressive administration. ${ }^{202}$ Conservation was cast as patriotic, something that furthered the common good, and a philosophy to which citizens should be devoted. That common good was an economic one: prosperity from the extraction of natural resources could be sustained for the long term if managed properly.

Although the rhetoric implied it, additional management for the greater good of the public did not translate into a vigorous democracy. While purportedly in the "public interest", the assumptions and values that conservation embodied "came from a limited group of people, with a particular set of goals, who played a special role in society."203 The progressive framework relied exclusively on the expert, leaving the average citizen to support conservation only in the abstract. To this end, conservation necessarily employed large institutions and technical managers to bring about the efficient use of resources. In the process, political questions were framed as scientific ones, answerable only by experts confident in their skills and skeptical of a general public increasingly viewed as incompetent

\footnotetext{
${ }^{200}$ Worster, Nature's Economy, 267.

${ }^{201}$ Purdy, After Nature, 169.

${ }^{202}$ Ibid., 158.

${ }^{203}$ Hays, Conservation and the Gospel of Efficiency: The Progressive Conservation Movement, 18901920, 4.
} 
and self-interested. Samuel P. Hays observes "[s]ince resource matters were basically technical in nature, conservationists argued, technicians, rather than legislators, should deal with them... Conflicts between competing resource users, especially, should not be dealt with through the normal processes of politics." 204 Scott characterizes "high modernism" as a strong faith in scientific and technical progress, expansion of production, "the growing satisfaction of human needs, and, not least, an increasing control over nature (including human nature) commensurate with scientific understanding of natural laws." ${ }^{205}$ High modernism looks to improve the human condition using exclusively authoritative scientific knowledge, excluding other "competing sources of judgment."206 The control and development of water in the West via the impoundment of rivers can be seen as a form of high modernism, with implications for both the landscape and society. The promotion of experts and the demotion of the citizen would linger into the 21 st century and have implications for the way in which environmental problems were framed and adjudicated.

In the West, the growth of reclamation was fueled by the logic of conservation in the 1920s, and in the 1930s river development furthered the New Deal's mission of economic and environmental development. ${ }^{207}$ To the progressives, seeing water flow downstream unused meant the water was wasted; if rivers could be captured and controlled, their waters would further the common good. President Roosevelt in a 1901 speech asserted that " $[\mathrm{t}] \mathrm{he}$ western half of the United States would sustain a population greater than that of our whole country today if the waters that now run to waste were saved and used for irrigation."208 To

\footnotetext{
${ }^{204}$ Ibid., 3.

${ }^{205}$ Scott, Seeing like a State, 89.

${ }^{206}$ Ibid., 93.

${ }^{207}$ Neil M. Maher, Nature's New Deal: The Civilian Conservation Corps and the Roots of the American Environmental Movement (Oxford University Press, 2008).

${ }^{208}$ Reisner, Cadillac Desert, 112.
} 
that end, federal agencies such as the BoR and the Army Corps of Engineers carried out the grand technical plans needed to deliver water to agricultural areas, control floods, and ultimately, subjugate a wild nature to benefit the common good. Dam construction was a fitting project for the times: the scale and scope necessitated expertise and a faith in technology. By the 1930s, dam building was in high gear, with dozens of projects across the country. ${ }^{209}$ The rate of dam construction in the United States peaked between 1935 and 1965, with a full quarter of all dams constructed in the 1960s alone (figure 14). ${ }^{210}$ Nearly every major river system in the country was dammed, straightened, diverted, or otherwise improved, and less than $1 \%$ of rivers in the United States now exist undammed and freeflowing. ${ }^{211}$

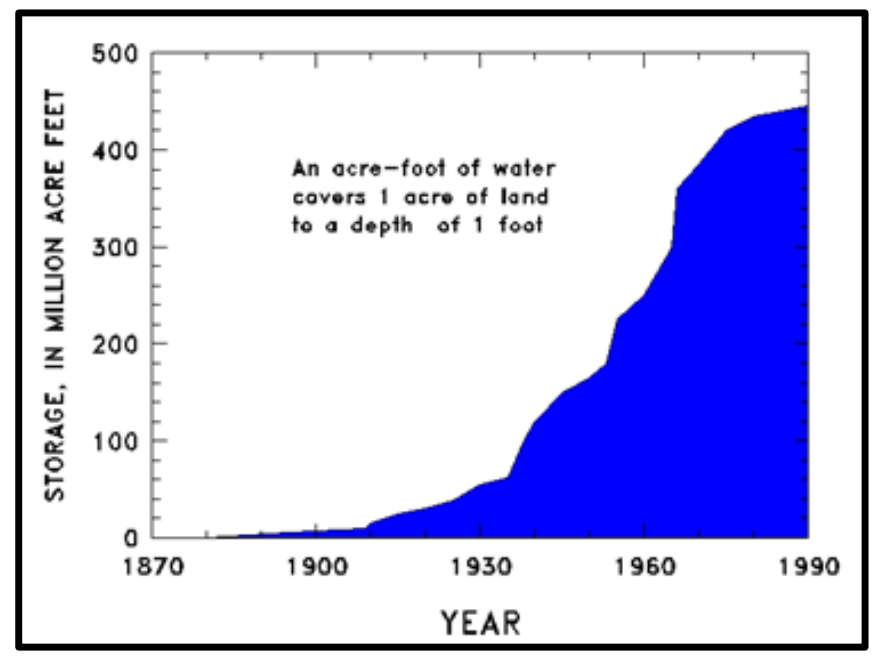

Figure 14: Total United States reservoir storage (acre-feet). Note the sharp increase in water impoundment during the 1930s-1960s. ${ }^{212}$

\footnotetext{
${ }^{209}$ Reisner, Cadillac Desert.

${ }^{210}$ William L. Graf, "Geomorphology and American Dams: The Scientific, Social, and Economic Context," Geomorphology 71 (2005): 3-26.

${ }^{211}$ Bradley T. Clark, "River Restoration in the American West: Assessing Variation in the Outcomes of Policy Change," Society \& Natural Resources 22, no. 5 (2009): 401-16.

${ }^{212}$ William L. Graf, "Dam Nation: A Geographic Census of American Dams and Their Large-Scale Hydrologic Impacts," Water Resources Research 35, no. 4 (April 1999): 1305-11.
} 
Dams were ideal projects for the New Deal, and they served to symbolize that “America could still do remarkable things." ${ }^{213}$ Major dam building projects on the Columbia River provided Great Depression-era employment and the hydropower they produced proved invaluable during the peak of World War II. ${ }^{214}$ As on the Columbia, dams on the Colorado River were constructed during the peak years of dam construction, and served to control water for multiple uses, including irrigating the arid lands of the West. ${ }^{215}$ As with the larger reclamation projects, the Klamath Project was part of the general goal to reclaim the West through the technical management and development of nature.

Nature ephemeral - spiritual nature and the emergence of ecology

While the lands and waters of the West were being settled, conquered, and then managed, others were wondering if nature was more than a storehouse of economic resources: "Is the divine in nature, or standing far above a dead and disenchanted nature?"216 Admiring nature rather than exploiting it ran counter to the dominant paradigm of the time, and this divergent philosophy would simmer below the surface until the rise of ecology. This divergence emerged amid the loss of the frontier and the recognition that the West might not be inexhaustible after all. Already, the ills of the urban East that pioneers sought to escape were appearing on the Western horizon. ${ }^{217}$ Instead of wilderness areas as places of despair and evil, untamed nature was seen a place for the physical self to merge with the sublime

\footnotetext{
${ }^{213}$ Reisner, Cadillac Desert, 159.

${ }^{214}$ Reisner, Cadillac Desert.

${ }^{215}$ Michael Collier, Robert H. Webb, and John C. Schmidt, Dams and Rivers: A Primer on the Downstream Effects of Dams., 2nd ed., U.S. Geological Survey Circular 1126. (Denver, CO: U.S. Geological Survey, 2000).

${ }^{216}$ Farrell, The Battle for Yellowstone: Morality and the Sacred Roots of Environmental Conflict, 39.

${ }^{217}$ Reisner, Cadillac Desert.
} 
natural world. ${ }^{218}$ The ability to withdraw from human-dominated nature meshed with a view of unsettled nature as virtuous and even spiritual. For John Muir and his followers, nature could offer "positive moral instruction" as well as "peace" and "good tidings." 219 This philosophy regarded wild nature as the place where "spiritual truths were least blunted... in the woods we return to reason and faith." ${ }^{220}$ Contrary to the perspective of both the settler and the conservationist, nature had intrinsic value. While the settler saw his development of nature as providential and the conservationist saw anthropogenic benefits from the careful management of nature, the spiritual view of nature saw nature as sacred and good in-and-of itself.

In the mid $20^{\text {th }}$ century, this spiritual approach fused with ecology, which offered the authority of the flourishing discipline that portrayed itself as a hard science. ${ }^{221}$ The writings of Charles Darwin a century earlier had laid the foundation for "demoting humanity, promoting nature" and influential ecologists such as Frederic Clements and Aldo Leopold contributed to a view of nature as an endangered ecosystem. ${ }^{222}$ Clements' ecological theory, which contended that succession ultimately reached a climax state of equilibrium, served to legitimize the "nature-knows-best" understanding of nature. It was humans and their activities that threatened this balance; a "leave nature alone" approach was required in light

\footnotetext{
${ }^{218}$ Nash, Wilderness and the American Mind.

${ }^{219}$ Winner, The Whale and the Reactor; John Muir, "The Yellowstone National Park," The Atlantic, April 1898, http://www.theatlantic.com/magazine/archive/1898/04/the-yellowstone-nationalpark $/ 376185 /$.

${ }^{220}$ Nash, Wilderness and the American Mind, 86.

${ }^{221}$ Worster, Nature's Economy.

${ }^{222}$ Farrell, The Battle for Yellowstone: Morality and the Sacred Roots of Environmental Conflict, 57; Worster, Nature's Economy; Fred P. Bosselman and A. Dan Tarlock, "The Influence of Ecological Science on American Law: An Introduction," Chi.-Kent L. Rev. 69 (1993): 847; Winner, The Whale and the Reactor.
} 
of a fragile nature. ${ }^{223}$ Leopold argued for an "ethical extension" wherein rights should be extended to all members of the biological community. ${ }^{224}$ While the emerging science of ecology sought to model the environment after economics and energy flows, its emphasis on quantification legitimized the moral views that Leopold, Muir, and others espoused. In this new ethical-ecological order humans could no longer operate unchecked on the landscape, and nature was not just an object of economic extraction. Humans were another species among many, rather than the chosen ones, and it was aesthetically, morally, and ethically wrong to exploit the natural world. In this view, reclamation and the larger human control over nature represented a disruption of the balance of nature and an arrogant display of anthropocentrism.

Paul Ehrlich's Population Bomb and Garrett Hardin's Tragedy of the Commons fed a sense of "apocalyptic urgency" which fueled the growth of scientific studies, activist groups, and environmental laws. ${ }^{225}$ While having other political implications, the National Environmental Policy Act (NEPA) institutionalized technical decision making, meaning that management and policy decisions became "highly bureaucratic," technical, and scientific. ${ }^{226}$ This reliance on technical experts meant that questions about how endangered a species was became a question answerable by legal experts and scientists. Science became the legitimate way to know nature, with its findings carrying both cultural and legal authority.

\footnotetext{
${ }^{223}$ Worster, Nature's Economy; Bosselman and Tarlock, "Influence of Ecological Science on American Law."

${ }^{224}$ Worster, Nature's Economy; Aldo Leopold, A Sand County Almanac (New York: Oxford University Press, 1987).

${ }^{225}$ Paul R. Ehrlich, The Population Bomb (New York: Ballantine Books, 1968); Garrett Hardin, "The Tragedy of the Commons," Science 162 (1968): 1243-48; Farrell, The Battle for Yellowstone: Morality and the Sacred Roots of Environmental Conflict, 61.

${ }^{226}$ Farrell, The Battle for Yellowstone: Morality and the Sacred Roots of Environmental Conflict, 62.
} 
$\underline{\text { Science, Law, and "Contested Natures" }}$

Redefining nature as fragile gained additional authority as these ideas were written into law in the form of the Endangered Species Act (ESA) of 1973 and the National Environmental Policy Act of 1969 (NEPA), among others. These laws elevated the protection of nature to an equal position among other more traditional interests, moved "ecological rationality" onto a level plain with economic rationality, and "thus fatally wounded the western idea that man had a duty to master nature. ${ }^{227}$ Ecology was critical to the making of environmental laws because it provided the basic foundation and legitimization for the philosophy of "leave nature alone." Though ecology evolved to accept new understandings of nature that suggested anything but a stable, climax condition, the idea of a fragile nature easily disturbed by man remains enshrined in environmental law. ${ }^{228}$

The ESA gave "the legal equivalent of a nuclear arsenal" to the FWS and NMFS to compel federal agencies to consider more than the immediate economic ramifications of a decision. ${ }^{229}$ Despite its power, the political costs of ESA enforcement can be high, particularly when threatening politically powerful or entrenched interests. ${ }^{230}$ Though the BoR revised its mission statement in 1992 to consider environmental concerns, it also remains dedicated to delivering water to the beneficiaries of its projects. ${ }^{231}$ Applying the ESA to water resources in the West is particularly contentious, as it threatens established entitlements such as water rights. Indeed, the dry summer of 2001 in the Klamath Basin was a contentious one

\footnotetext{
${ }^{227}$ Bosselman and Tarlock, "Influence of Ecological Science on American Law," 868.

${ }^{228}$ Daniel Botkin, Discordant Harmonies: A New Ecology for the Twenty-First Century (New York: Oxford University Press, 1990); Bosselman and Tarlock, "Influence of Ecological Science on American Law."

${ }^{229}$ Doremus and Tarlock, "Fish, Farms, and the Clash of Cultures in the Klamath Basin," 282.

${ }^{230}$ Johnston, "The Political Ecology of Water"; Doremus and Tarlock, Water War in the Klamath Basin .

${ }^{231}$ Congress of the United States, Water Use Conflicts in the West: Implications of Reforming the Bureau of Reclamation's Water Supply Policies (Congressional Budget Office, 1997).
} 
as the science used by the FWS and NMFS was called into question. ${ }^{232}$ The major parties in the Klamath conflict and subsequent litigation shared the view that science would "solve" the conflict, so long as the facts could be known and the science was not contaminated by politics. Though the parties desired the support of science, they held competing ideas of the desired outcome and divergent visions for the future.

\section{Environmental Backlash and the "Wise Use" Movement}

Though concern over a fragile nature muddied by humans promised national unity in the 1960s and early 1970s, by the mid-1970s the "supporters of environmentalism were destined to have to share the political stage with its opponents." ${ }^{\text {"233 }}$ Nationally, industry resisted increasing regulations, while in the West a coalition of organizations opposed to national forest logging regulations and wilderness designations staged protests including the Sagebrush Rebellion. ${ }^{234}$ Anti-environmental concerns over regulation were appeased in the 1980s with the Reagan administration's appointment of Anne Gorsuch to the Environmental Protection Agency and James Watt to the Department of the Interior, with Watt expressing his disdain for “a small group of extremists who don't concern themselves with a balanced perspective or a concern about improving the quality of life for mankind - they are called environmentalists." ${ }^{235}$ Although this period catalyzed the environmental movement (the Sierra Club's membership grew 30 percent annually in the early 1980s), groups skeptical of

\footnotetext{
${ }^{232}$ Doremus and Tarlock, Water War in the Klamath Basin.

${ }^{233}$ Harvey M. Jacobs, "The Anti-Environmental 'Wise Use' Movement in America," Land Use Law 47, no. 2 (February 1995): 3.

${ }^{234}$ Judith Layzer, The Environmental Case: Translating Values into Policy (Washington, D.C.: CQ Press, 2012).

${ }^{235}$ Sabin, The Bet: Paul Ehrlich, Julian Simon, and Our Gamble over Earth's Future, 147.
} 
claims about an imperiled nature and concerned about property rights and economic development responded vigorously as well. ${ }^{236}$

By the late 1980s and 1990s, the "wise use" and property rights movements gained widespread recognition for their calls for local authority to veto federal environmental regulation, the opening of all public land to development, and compensation for property devalued by regulation. To the wise use community, outsiders and environmentalists were waging "war on the West" in a cultural and economic sense. ${ }^{237}$ While challenging environmental regulation, the wise use movement simultaneously tapped into populist rhetoric and property rights concerns. Activist and wise use movement founder Ron Arnold asserted, "[w]e are sick to death of environmentalism and so we will destroy it. We will not allow our own right to own property and use nature's resources for the benefit of mankind to be stripped from us by a bunch of eco-fascists." 238 Given the prevalence of federal landholdings in the West and a citizen base increasingly suspicious of regulation, the environment served as a focal point for ideological conflict. To the wise use community, private property is "inextricably linked to the existence of a modern democratic state, and actions which increase the power of the state over the individual decrease the institution of democracy. ${ }^{239}$ In this way, conflict over the environment via regulation meant that ideas about nature became increasingly inextricable from the conflict over property rights, individualism, and the legitimacy of government.

Conflict over environmental management and regulation in the West has become increasingly visible in recent decades with the increasing frequency and fervor of debates

\footnotetext{
${ }^{236}$ Layzer, The Environmental Case: Translating Values into Policy; Sabin, The Bet: Paul Ehrlich, Julian Simon, and Our Gamble over Earth's Future.

${ }^{237}$ Layzer, The Environmental Case: Translating Values into Policy, 388.

${ }^{238}$ Ibid., 391.

${ }^{239}$ Jacobs, "The Anti-Environmental 'Wise Use' Movement in America," 3.
} 
over the management and use of nature. The debates over the spotted owl in Pacific Northwest forests, wolf reintroduction in the Greater Yellowstone Ecosystem, and endangered fish in rivers of the West serve as some visible examples. ${ }^{240}$ The conflict over water in the Klamath Basin can thus be seen as a confluence of competing visions for the appropriate use of nature, with each vision legitimized by laws and ingrained in culture. While these "contested natures" are indeed real in the sense that they exist, and have material implications, they are also socially constructed. ${ }^{241}$ The following section expands on the larger theoretical underpinnings of the present case study.

\section{Theoretical Framework}

From Space to Place

The "contested natures" discussed above are not ideas or philosophies alone - they occur in material, physical space. The space that is composed of soils, mountains, trees, and the like exists separately from the humans that inhabit and define them, and these physical entities possess no a priori meaning. As definition and meaning is applied, space is transformed into place. ${ }^{242}$ Multiple symbolic meanings can be assigned to the same place, and these divergent meanings can transform these places into "contested natures." ${ }^{243}$ Every

\footnotetext{
${ }^{240}$ Wilkinson, Crossing the Next Meridian; Farrell, The Battle for Yellowstone: Morality and the Sacred Roots of Environmental Conflict; Warren, "What Is a Healthy Forest?"; Terre Satterfield, Anatomy of a Conflict: Identity, Knowledge, and Emotion in Old-Growth Forests (Vancouver: East Lansing: Michigan State University Press, 2003); R. McGreggor Cawley, Federal Land, Western Anger: The Sagebrush Rebellion \& Environmental Politics (Lawrence: University Press of Kansas, 1993).

${ }^{241}$ Phil Macnaughten and John Urry, Contested Natures, Theory, Culture \& Society (Thousand Oaks, Calif: SAGE Publications Ltd, 1998).

${ }^{242}$ Yi-Fu Tuan, Space and Place: The Perspective of Experience (Minneapolis: University of Minnesota Press, 1977).

${ }^{243}$ Mark C. J. Stoddart, Making Meaning out of Mountains: The Political Ecology of Skiing (Vancouver: UBC Press, 2012); Macnaughten and Urry, Contested Natures.
} 
physical place has the potential for multiple meanings, each representing the cultural definitions of those assigning the meaning. Because social actors assign it, meaning is "flexible in the hands of different people or cultures, malleable over time, and inevitably contested."244 Thomas Greider and Lorraine Garkovich use the example of an open field to illustrate the multiple symbolic meanings invested in the same physical thing: a developer sees a housing development, a farmer sees rows of wheat, a hunter sees an animal grazing, and an ecologist sees species interacting in a network. ${ }^{245}$ In this way, the same physical field reflects the various sociocultural visions for it, which "transforms the open field into a symbolic landscape. ${ }^{246}$ As R. McGreggor Cawley and John Freemuth point out, the same parcel of physical land can be construed as a "tree farm" for natural resource production, or an embodiment of "mother earth," depending on the assigned meaning. ${ }^{247}$

\section{Social Constructions and Nature}

These meanings can be viewed as social constructions, which "generate webs of cultural meaning" superimposed on physical space. ${ }^{248}$ Greider and Garkovich use the term "landscape" to encompass both the physical place and the assigned meaning, noting that landscape reflects what people "define to be proper and improper relationships among themselves and between themselves and the physical environment." ${ }^{249}$ Likewise, Gretel Ehrlich describes the "-scape" in landscape as "a projection of human consciousness... and

\footnotetext{
${ }^{244}$ Thomas F. Gieryn, “A Space for Place in Sociology,” Annual Review of Sociology, 2000, 465.

${ }^{245}$ Thomas Greider and Lorraine Garkovich, "Landscapes: The Social Construction of Nature and the Environment," Rural Sociology 59, no. 4 (1994): 1-24.

${ }^{246}$ Ibid., 1.

${ }^{247}$ R. McGreggor Cawley and John Freemuth, "Tree Farms, Mother Earth, and Other Dilemmas: The Politics of Ecosystem Management in Greater Yellowstone," Society \& Natural Resources 6, no. 1 (1993): 41-53.

${ }^{248}$ Stoddart, Making Meaning out of Mountains: The Political Ecology of Skiing, 26.

${ }^{249}$ Greider and Garkovich, "Landscapes: The Social Construction of Nature and the Environment," 2.
} 
the ways in which we see and describe this spectacle represent our 'frame of mind,' what we know and what we seek to know." ${ }^{250}$ The ideas of nature introduced above help to define the proper and improper relationship between humans and nature and thus influence both the ways in which people order the landscape and the vision they hold for it. These social constructions have implications beyond the use of physical space, however. They also matter because they "define who may legitimately inhabit and use these places," as well as who is included and excluded from decisions about those places. ${ }^{251}$ Figure 15 illustrates the reflexive relationship between people and nature. As Phil Macnaughton and John Urry explain, "there is no single 'nature,' only natures. And these natures are not inherent in the physical world but discursively constructed through economic, political and cultural" acts. ${ }^{252}$

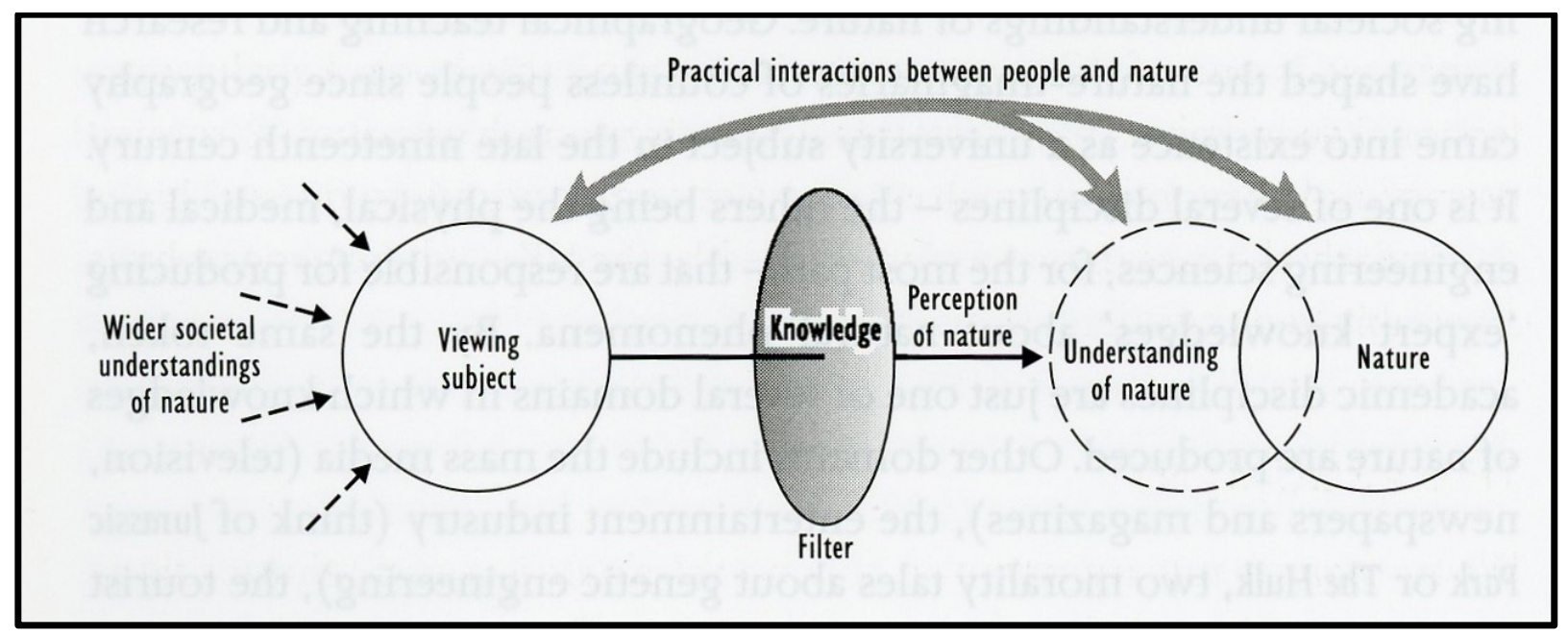

Figure 15: Interaction between humans and nature, with understanding mediated by knowledge. Note the reflexive relationship. ${ }^{253}$

Put in the context of the Klamath Basin, a certain cultural construction of nature has influenced its material ordering. The trenching of irrigation canals, impoundment of flowing

\footnotetext{
${ }^{250}$ Gretel Ehrlich, "Surrender to the Landscape,” Harpers, September 1987, 24.

${ }^{251}$ Stoddart, Making Meaning out of Mountains: The Political Ecology of Skiing, 26.

${ }^{252}$ Macnaughten and Urry, Contested Natures, 95.

${ }^{253}$ Noel Castree, Nature, Key Ideas in Geography (New York: Routledge, 2005).
} 
rivers, and allocation of farmland reflects ideas about how nature works, its best use, and who can legitimately act in the landscape. A competing construction of nature, one in which nature is fragile and disturbed by human control, collides with earlier constructions of nature. In this way, the struggle over fish or the agrarian lifestyle are not inherently good or bad but represent the contest between cultural groups to define and order the landscape according to their constructions of it. The Klamath Basin is thus a stage upon which groups vie to define the landscape.

While not the central theoretical focus of this thesis, French philosopher Henri Lefebvre's theory of space offers one way to conceptualize the relationship between space and socially assigned meanings. ${ }^{254}$ Though Lefebvre's writings concern the capitalist city, his theory contributes to understanding the contest to define space in the Klamath Basin. Lefebvre's spatial triad is composed of representations of space, spatial practices, and spaces of representation. According to Lefebvre, space is "produced" by way of social practices. Representations of space describe the dominant or hegemonic spaces in society produced by the dominant social group. This conceptual space is composed of representations and symbols, which serve to naturalize and normalize certain definitions of that space. Discourses thus help to define space in a particular way, at the expense of other definitions. Spatial practices consist of "production and reproduction" to maintain the normative experience of everyday life. ${ }^{255}$ Spaces of representation comprise space "as directly lived through it's associated images and symbols."256

\footnotetext{
${ }^{254}$ Henri Lefebvre, The Production of Space, trans. Donald Nicholson-Smith (Malden, Mass: Blackwell Pub, 2000).

${ }^{255}$ Ibid., 33.

${ }^{256}$ Ceri Watkins, "Representations of Space, Spatial Practices and Spaces of Representation: An Application of Lefebvre's Spatial Triad," Culture and Organization 11, no. 3 (2005): 33.
} 
A Lefebvrian understanding of space is useful when used in the context of the Klamath Basin. The hegemonic social definition of space in the Klamath Basin prescribes the use of land and water for agrarian purposes, and the spatial practices reproduce that space according to the abstract and symbolic definition assigned to it. By conceptualizing space as one for agriculture, the agrarian social group carries out the (re)production of space in that image with their daily practices, while the institutions of the state both reinforce and make possible those practices. In the same way, the hegemonic production of space can be challenged by alternative discourses. Space can thus be conceived of as social, produced, and "constantly in a state of flux." ${ }^{257}$ It is the possibility of resistance to the hegemonic production of space through alternative discourses that makes Lefebvre's trialectic useful for our purposes - the contest to redefine the use of space challenges the hegemonic representation of it. Acknowledging that a purely Lefebvrian approach would understand space as a whole to be produced, I intend to focus primarily on the discursive constructions of an a priori space that is transformed into place as meaning is invested.

\section{Environmental Discourse and Social Power}

An analysis of the discourse surrounding the Klamath conflict is a useful method to understand which ideas of nature are taken for granted, which are accepted as truth, and which are used to justify action. Trevor Barnes and James Duncan define discourses as "frameworks that embrace particular combinations of narratives, concepts, ideologies, and signifying practices, each relevant to a particular realm of social action." ${ }^{258}$ The combination

\footnotetext{
${ }^{257}$ Puneet Dhaliwal, "Public Squares and Resistance: The Politics of Space in the Indignados Movement," Interface 4, no. 1 (May 2012): 258.

${ }^{258}$ Trevor J. Barnes and James S. Duncan, Writing Worlds: Discourse, Texts, and Metaphors in the Representation of Landscape (New York: Routledge, 1992), 8.
} 
of those elements makes discourses "powerful, coherent, mutually supporting frameworks, which are persuasive and stand the test of time. ${ }^{, 259}$ Discourses help to naturalize particular views of the world, and though they appear totalizing from the perspective of an individual, discourses "always provide partial, situated knowledges" and as such can be understood as reflecting a particular point of view. ${ }^{260}$ As Mark Stoddart explains, "Through engagement with pro-environmental discourse... we might take on the label 'environmentalist' as an identity. ${ }^{261}$ Because discourse is represented through written and spoken language, discourse analysis allows for an examination of the narratives that are at work, including constructions of nature.

Because social constructions influence the legitimacy of actors and actions in a landscape, it is useful to consider the relationship between power and knowledge. Noel Castree asserts: "[t]here is no way to understand nature except through the particular filters and templates that are bequeathed to us by all the knowledge-producing organisations of modern societies. Our experience of nature is rarely direct. Rather, it is thoroughly mediated for us... By telling us that nature is this rather than that they govern our understanding of the natural world and how we behave towards it." ${ }^{262}$ Different discursive framings mean that different social practices are "enabled or inhibited," and the dominant discourse holds power to shape these practices. ${ }^{263}$ To this end, French Philosopher Michel Foucault asserts that discourses are "embedded in relations of power" and that "[p]ower and knowledge directly

\footnotetext{
${ }^{259}$ Paul Robbins, John Hintz, and Sarah A. Moore, Environment and Society: A Critical Introduction, 1st ed. (Malden, Mass: Wiley-Blackwell, 2010), 123.

${ }^{260}$ R. J. Johnston, Derek Gregory, and David M. Smith, eds., “Discourse,” The Dictionary of Human Geography (Cambridge: Blackwell Pub, 1994).

${ }^{261}$ Stoddart, Making Meaning out of Mountains: The Political Ecology of Skiing, 30.

${ }^{262}$ Castree, Nature, xxii.

${ }^{263}$ Tim Kurz et al., "The Ways That People Talk about Natural Resources: Discursive Strategies as Barriers to Environmentally Sustainable Practices," British Journal of Social Psychology 44, no. 4 (December 2005): 606, doi:10.1348/014466604X18064.
} 
imply one another" ${ }^{264}$ Dominant discourses are powerful because they serve to naturalize a given understanding of nature (and, more broadly, the world). As Maureen Hickey and Vicky Lawson observe, "dominant discourses are all the more powerful because they are understood not as historical constructions but instead as obvious knowledge about the 'natural' state of the world."265 In this way, the dominant discourse empowers certain ideas of legitimate actions in the landscape, and also serves to marginalize or silence other discourses. Foucault posits that the flow of power is not absolute; instead it is constantly shifting in an uneven distribution. ${ }^{266}$ In contesting the hegemonic discourse and constructions of nature, it is possible to shift understandings of nature and the appropriate use of it.

In the realm of environmental conflict, scientific and technical discourse holds particular power. As Hull et al. observe, "People are empowered or disadvantaged depending on whether they have a scientific language with which to express their agendas." ${ }^{267}$ According to Frank Fischer, "access to technical knowledge and skill has allowed those with the power to legitimate their political decisions in these areas." ${ }^{268}$ Society writ large has granted an especially generous amount of power to science and rationality as ways of understanding the world and the way to live within it, and thus it is no surprise that competing social groups seek to marshal science to legitimize their vision for the landscape. The debate over the ordering of the landscape can be understood as various groups using competing discourses to obtain additional power to define the landscape.

\footnotetext{
${ }^{264}$ Stoddart, Making Meaning out of Mountains: The Political Ecology of Skiing, 30.

${ }^{265}$ Maureen Hickey and Vicky Lawson, "Beyond Science?: Human Geography, Interpretation and Critique," in Questioning Geography: Fundamental Debates, ed. Noel Castree, Alisdair Rogers, and Douglas Sherman (Malden, Mass: Blackwell, 2005), 104.

${ }^{266}$ Cole Harris, "Power, Modernity, and Historical Geography," Annals of the Association of American Geographers 81, no. 4 (December 1991): 671-83.

${ }^{267}$ Hull et al., "Understandings of Environmental Quality," 1.

${ }^{268}$ Frank Fischer, Citzens, Experts, and the Environment, 2nd ed. (Durham: Duke University Press, 2002), 23.
} 


\section{Constructionism and Relativism}

It is worth noting that an acceptance of the social constructivist perspective does not necessarily mean all knowledge is relative only to its social context. I seek to avoid the longrunning debate between realists and constructionists by accepting that humans and nonhumans are in constant interaction, influencing one another in an iterative process. Even though ideas about nature and discourses are social and influence human thinking, they have material consequences for the non-human world. Simultaneously, the non-human world influences the social world and shifts discourses and understandings of the world. ${ }^{269}$ Social constructionism can further important understandings about the world, including how intimately intertwined nature and culture are. At the same time, a material reality exists apart from our understanding of it, one that is not invented or constructed. ${ }^{270}$ Accepting this dialectic, this research is situated within a constructionist perspective to better understand the conceptual worlds involved.

In light of the view that nature is not something that can be known in an absolute sense, but is instead understood through a lens tinted with culture, the purpose of this research is to understand competing discourses in the Klamath Basin water conflict and the ideas of nature they rely on. A social constructionist approach facilitates this by situating "competing knowledges about the world," and exposing the "material and discursive effects of different environmental narratives." ${ }^{271}$ The qualitative inductive method and specific steps

\footnotetext{
${ }^{269}$ Robbins, Hintz, and Moore, Environment and Society: A Critical Introduction; Stoddart, Making Meaning out of Mountains: The Political Ecology of Skiing.

${ }^{270}$ William Cronon, "Comment: Cutting Loose or Running Aground?," Journal of Historical Geography 20, no. 1 (1994): 38-43.

${ }^{271}$ David Demeritt, "Ecology, Objectivity and Critique in Writings on Nature and Human Societies," Journal of Historical Geography 20, no. 1 (1994): 33.
} 
used to discern and make sense of the deeper logics and larger conceptual worlds involved in the conflict are detailed in the next chapter. 


\section{Chapter 3: Qualitative Method}

"Discursive practices inherently determine the 'social construction' of any environmental conflict. What humans say about the issues - even how the issues are defined - will determine interpretation, treatment, and outcome of the public debate."272

As stated in the introduction chapter, this thesis uses public comment letters in response to a Klamath River dam removal proposal as the data source to examine conceptions of nature in the Klamath Basin and how they are related to ideas about the "proper" management of the river. In this chapter, I describe the data corpus in more detail, and explain the method used to analyze the comments that form the basis for the discussion that follows.

\section{Research Questions}

This study investigated the following research questions:

- How do commenters construct the "proper" management and use of water in the Klamath Basin?

- What rationales, discourses, and narratives do commenters draw on to justify their positions?

- What do these rationales reveal about commenters' underlying and differing assumptions about nature and the place of humans in it?

\footnotetext{
${ }^{272}$ Jonathan L. Lange, "The Logic of Competing Information Campaigns: Conflict over Old Growth and the Spotted Owl," in A Wolf in the Garden: The Land Rights Movement and the New Environmental Debate (Lanham, Maryland: Rowman \& Littlefield Publishers, 1996), 135.
} 
- Do these assumptions relate to broader narratives about the legitimacy of private property, government, and science?

The goal was to understand and describe what positions and justifications commenters present and how they relate to larger arguments about human-environmental relations and how the landscape should be ordered. I follow the work of Warren in that this research did not seek to test a hypothesis or produce statistically valid results. ${ }^{273}$

\section{The Data}

As required by the National Environmental Policy Act of 1969, comments were solicited by the U.S. Department of the Interior concerning the Draft Environmental Impact Statement (DEIS) which evaluated dam removal impacts on the Klamath River as well as the related Klamath Hydroelectric Settlement Agreement (KHSA) and Klamath Basin Restoration Agreement (KBRA). The 100-day comment period spanned September 22, 2011 - December $30,2011 .{ }^{274}$ Community members were notified of the process via advertisements published in ten local and regional newspapers, and postcards were sent to over 5,000 "individuals and entities. ${ }^{275}$ Written comments were accepted via mail and email, as well as at community hearings. A total of six community hearings were held to allow for oral statements. ${ }^{276}$ Public hearing attendance numbers were not available. The hearings were held at the following locations:

- Klamath Falls, Oregon, October 18, 2011

\footnotetext{
${ }^{273}$ Warren, "What Is a Healthy Forest?"

${ }^{274}$ U.S. Department of the Interior and California Department of Fish \& Game, "Klamath Facilities Removal Final EIS/EIR: Volume III Comments and Responses," December 2012.

${ }^{275}$ Ibid., 10-14.

${ }^{276}$ U.S. Department of the Interior and California Department of Fish \& Game, "Klamath Facilities Removal Final EIS/EIR: Volume III Comments and Responses."
} 
- Chiloquin, Oregon, October 19, 2011

- Yreka, California, October 20, 2011

- Orleans, California, October 25, 2011

- Arcata, California, October 26, 2011

- Klamath, California, October 27, 2011

I retrieved both the written comments sent by mail and email and transcriptions of the oral comments from the public hearings from a single digital file at the U.S. Department of the Interior website. ${ }^{277}$ Some comments contained personally identifying information including addresses, phone numbers, and email addresses. For the purposes of this analysis and subsequent discussion, I have omitted all personal information.

\section{Comment Selection and Data Management}

The entire data set of over 800 comments totaled nearly 3,000 pages, so I selected every fifth comment for analysis, regardless of its length or content. This was intended to reduce the volume of material to a manageable amount, one that would facilitate a more indepth reading and analysis than if all comments were analyzed. I selected comments in the order they came in the original document to avoid introducing selection bias. Since the overarching objective of this research is to understand the variety of perspectives present, this sampling technique helped prevent a conscious or unconscious selection bias that might have occurred if comments were chosen in another manner. Ultimately, 165 comments were

\footnotetext{
${ }^{277}$ U.S. Department of the Interior, "Individual Comments," Draft EIS/EIR, March 28, 2017, https://klamathrestoration.gov/sites/klamathrestoration.gov/files/Additonal\%20Files\%20/1/4/Volume \%20III_Individual.pdf.
} 
selected for analysis. There were a few comments that were scrawled so illegibly that I replaced them with another comment blindly selected from the pool of remaining comments.

I parsed comments from the original digital comment document into their own uniquely numbered documents, and imported them into the software used for analysis. The software used for coding and analysis was Dedoose, a web application that supports both quantitative and qualitative data analysis. ${ }^{278}$ The online version of the software was used. While the Dedoose text recognition tool was fairly accurate, some comments needed to be transcribed and manually entered into the software. These comments were reviewed for accuracy after transcription. Comment length ranged from a few sentences to many pages.

\section{Qualitative Research Methodology}

In keeping with the aims of the study, I decided to employ a qualitative approach to analyze the data set. ${ }^{279}$ In contrast to quantitative studies wherein a specific hypothesis is tested according to a predetermined protocol, and typically statistically analyzed, the objective of qualitative research is to gain a deeper, richer, and more textured view of the subject matter. ${ }^{280}$ While some previous studies of environmental attitudes and values have used surveys or questionnaires to efficiently assess popular understanding, these methods "represent a blunt instrument for exploring the complexities of how people understand nature." ${ }^{281}$ Some studies of environmental values have used both qualitative and quantitative

\footnotetext{
${ }^{278}$ SocioCultural Research Consultants, LLC, "Dedoose,” 2017, dedoose.com.

${ }^{279}$ Warren, "What Is a Healthy Forest?"

${ }^{280}$ John W. Creswell, Research Design: Qualitative \& Quantitative Approaches (Thousand Oaks, California: Sage Publications, Inc, 1994).

${ }^{281}$ Stephen R. Kellert, The Value of Life: Biological Diversity And Human Society (Washington, D.C.: Island Press, 1997), 38.
} 
methods to have the benefits of both. ${ }^{282}$ A qualitative approach allows for a more "sensitive" approach to concepts, themes, and patterns in the data, whereas surveys and questionnaires impose certain predetermined categories on the respondents. ${ }^{283}$ Further, while survey questions may effectively probe a wide range of ideas, they do not permit the depth or nuance that a qualitative approach can. ${ }^{284}$

As John Creswell explains, “[q]ualitative research is exploratory. The researcher seeks to listen to informants and to build a picture based on their ideas. The logic of qualitative research suggests an emerging design... wherein the categories develop during the study, rather than are predetermined before the study begins." ${ }^{285}$ The interpretive nature of qualitative research allows the researcher to search for meaning and nuance, rather than universal truths and laws sought after by quantitative research. By moving away from "operationalization and deduction" and toward "thick description" the research can better access, in the words of Clifford Geertz, "the conceptual world in which our subjects live so that we can, in some extended sense of the term, converse with them." 286 Indeed, one of the primary objectives of this research is to better understand the perspectives of commenters in a more detailed and nuanced manner than possible with quantitative research.

\section{Limitations}

A limitation to the qualitative approach includes an inability to directly compare different groups of comments to test hypotheses or generate statistical conclusions.

\footnotetext{
${ }^{282}$ Kempton, Boster, and Hartley, Environmental Values in American Culture.

${ }^{283}$ Warren, "What Is a Healthy Forest?: Institutional Logics and the Contest over Natural Resources Implications for Ecosystem Management and Socio-Ecological Theory."

${ }^{284}$ Ibid.

${ }^{285}$ Creswell, Research Design: Qualitative \& Quantitative Approaches, 144.

${ }^{286}$ Clifford Geertz, The Interpretation of Cultures (New York: Basic Books, 1973), 24.
} 
Additionally, the findings cannot be compared in a quantitative sense with other literatures or studies. Research bias in the interpretation of comments is a limitation, as is the incomplete information available about the commenter. I countered the issue of bias by using a coding system to systematically approach each comment. Because comments included varied amounts of personal information about the commenter, full profiles of the commenters' demographics or views on other topics were not always possible. I was limited to the information that the commenter volunteered, as opposed to personal interviews where a statement or topic might be queried further. In this sense, the data are static or "dead," limiting any follow-up inquiry. ${ }^{287}$ This is perhaps the primary limitation of using the public comments without a secondary source of data, such as personal interviews. ${ }^{288}$

\section{Abductive Approach to Discourse Analysis}

There is no singular correct qualitative research method, and methods texts consulted for this research advocated varied procedures and processes. ${ }^{289}$ While I have taken a largely inductive approach, this research is best described as abductive as the literature and research questions broadly guided the research, providing signposts and a general direction for inquiry. ${ }^{290}$ Induction is a familiar form of inquiry where the researcher attempts to approach a

\footnotetext{
${ }^{287}$ Alan R. H. Baker, “'The Dead Don't Answer Questionnaires': Researching and Writing Historical Geography," Journal of Geography in Higher Education 21, no. 2 (July 1997): 231-43, doi:10.1080/03098269708725427.

${ }^{288}$ Warren, "What Is a Healthy Forest?: Institutional Logics and the Contest over Natural Resources Implications for Ecosystem Management and Socio-Ecological Theory."

${ }^{289}$ Graham R. Gibbs, Qualitative Data Analysis: Explorations with NVivo (Philadelphia: Open University Press, 2002); H. Russell Bernard, Research Methods in Anthropology: Qualitative and Quantitative Approaches, 4th ed. (Lanham, MD: AltaMira Press, 2006); Matthew B. Miles and A. Michael Huberman, Qualitative Data Analysis: An Expanded Sourcebook, 2nd ed. (Thousand Oaks, Calif: Sage Publications, Inc, 1994).

${ }^{290}$ Klaus Krippendorff, Content Analysis: An Introduction to Its Methodology, 2nd edition (Thousand Oaks, Calif: Sage Publications, Inc, 2003).
} 
phenomenon or object of inquiry "on its own terms." ${ }^{291}$ Abduction is similar to induction in that it does not begin with a hypothesis to be tested (as in deduction), but differs in that it relies on both observation and description of the phenomenon as well as preexisting information, such as the academic literature on a given subject. As Simon Watts and Paul Stenner observe, "abductive reasoning never treats 'observations for themselves, but [always] as a sign of other things. ${ }^{, 292}$ In this way, specific themes were developed that were based upon the comments but in conversation with "signs" found in the literature. By this I mean that a truly inductive approach would be guided solely by the data - instead, I began the analysis process by relating developing themes to the literature to help guide the development of my inquiry. As an example, I was open to statements about nature in the comments, but also was guided by Schwarz and Thompson's four myths of nature (figure 10). ${ }^{293}$ In this way, the process was not purely inductive but instead was abductive.

As discussed in the previous chapter, the way people talk about nature and management offers a window into their conceptual world. One way to make sense of this talk is through discourse analysis. By analyzing what comments talk about, what they refer to as justification for their arguments, and what other themes they draw on, it is possible to paint a picture of the "combinations of narratives, concepts, ideologies, and signifying practices" found in the comments. ${ }^{294}$ In this way, these comments are not merely random statements but reflect individuals' ways of understanding the situation at hand. It is through the analysis

\footnotetext{
${ }^{291}$ Simon Watts and Paul Stenner, Doing Q Methodological Research: Theory, Method and Interpretation (Thousand Oaks, California: Sage Publications, Inc, 2012).

${ }^{292}$ Ibid., 39.

${ }^{293}$ Schwarz and Thompson, Divided We Stand.

${ }^{294}$ Barnes and Duncan, Writing Worlds: Discourse, Texts, and Metaphors in the Representation of Landscape, 8 .
} 
process that I attempt to distill and organize the common discursive themes, and thus common ways of understanding, that are present in the comments.

I used a coding process to analyze the comments to create - rather than discover - the findings. While this is generally similar to "grounded theory," I did not employ a fully inductive method or generate new theory as is done in grounded theory. ${ }^{295}$ The specifics of coding are discussed below.

\section{Codes, Themes, and Categories}

Once I had the comments imported to the Dedoose software, I began the coding process. To help organize demographic data, I assigned "descriptors" based on available information. If the commenter volunteered their occupation, length of residence in the area, city/state/zip code, or any other relevant information, those "descriptors" were attached to the given comment. While this information was not available for each and every comment, I noted it where available.

I developed the coding tree as coding progressed. Some loose codes were imagined beforehand as a result of common themes found in the literature, but actual codes were developed as they were assigned to text. As Johnny Saldaña explains, a code is “.... a word or phrase that symbolically assigns a summative, salient, essence-capturing, and/or evocative attribute for a portion of language-based or visual data... Just as a title represents and captures a book or film or poem's primary content and essence, so does a code represent and capture a datum's primary content and essence."296

\footnotetext{
${ }^{295}$ Anselm L. Strauss and Juliet Corbin, Basics of Qualitative Research: Grounded Theory Procedures and Techniques (Newbury Park: Sage Publications, Inc, 1990).

${ }^{296}$ Johnny Saldaña, The Coding Manual for Qualitative Researchers, 1st ed. (Thousand Oaks, Calif: Sage Publications, Inc, 2009), 3.
} 
I used Saldaña's Descriptive, In Vivo, and Initial coding methods. Descriptive coding "summarizes in a word or short phrase - most often as a noun - the basic topic of a passage of qualitative data." ${ }^{297}$ In Vivo coding refers to a word or phrase derived from the language in the data, and is useful for "studies that prioritize and honor the participant's voice." 298 "We The People" is an example of an In Vivo code used because it captured the essence of the commenters' sentiment particularly well (Table 1). Initial coding is less of a formulaic coding method but rather an open-ended approach to coding that generates codes for future comparison of possible meaning. ${ }^{299}$ These codes can be (and were in this research) revised as the analysis evolved. While these coding methods were not the only methods that could have been used, they allowed for the development of themes specific to the comments while still allowing some conversation with the literature.

\footnotetext{
${ }^{297}$ Ibid., 70.

${ }^{298}$ Ibid., 74.

${ }^{299}$ Ibid., 81.
} 


\begin{tabular}{|l|l|}
\hline \multicolumn{1}{|c|}{ Comment excerpt } & Code assigned \\
\hline $\begin{array}{l}\text { Our years of "development" have unknowingly brought immeasurable } \\
\text { damage to our environment. }\end{array}$ & nature fragile \\
\hline $\begin{array}{l}\text { Dams also strangle the ecological integrity out of the rivers and the } \\
\text { surrounding vegetation... }\end{array}$ & nature fragile \\
\hline $\begin{array}{l}\text { Is Southern California in line to acquire our water? Is the Department of } \\
\text { Interior in cahoots with those who will benefit the most at the cost of } \\
\text { Siskiyou County and Its [sic] residents? }\end{array}$ & conspiracy \\
\hline $\begin{array}{l}\text { This... makes it clear that the top level officials within the Department of } \\
\text { Interior conspired to orchestrate the removal of dams from the beginning } \\
\text { and that the rest of his discussion was simply window dressing and not a } \\
\text { sincere attempt to settle the issues with all options available... }\end{array}$ & conspiracy \\
\hline $\begin{array}{l}\text { Siskiyou County has voted to save the dams. Why is there still a movement } \\
\text { to remove the dams? We are the People, and we have voted to retain the } \\
\text { dams }\end{array}$ & We The People \\
\hline $\begin{array}{l}\text { Why are the votes of the people not worth anything? The people have } \\
\text { voted to not remove the dams but I guess it doesn't matter what the } \\
\text { residents of Siskiyou County feel. }\end{array}$ & We The People \\
\hline
\end{tabular}

\section{Table 1: Sample comment excerpts and codes assigned.}

I assigned codes to text ranging from a single sentence to a paragraph. I coded some segments of text with multiple codes if multiple ideas were expressed simultaneously or in relation to one another.

At the end of the first coding cycle, I examined codes for overlap and similarity, and merged codes together where appropriate. This process was repeated to develop higher order "parent" codes from the lower order codes, thus moving the analysis from being directly grounded in the comments to representing the larger patterns expressed in the comments. The coding process was iterative as I considered multiple meanings and compared developing themes. For example, early in the coding process I had created the codes "local vote," "populism," and "We The People." The first two codes were merged or "re-parented" with "We The People" because of their similar meanings. I chose to retain "We The People" as 
the parent code because it expressed the desire for local voices to be heard and also captured the accompanying patriotic sentiment in those passages of text.

I assigned each comment to a group, or typology. These typologies can be understood as a container of sorts for comments that I deemed to be similar to one another based on their expressed management preference, their ideas of nature, and views on secondary issues such as private property and the appropriate role of government. These criteria for grouping were informed by the literature, but ultimately used because of the strong patterns about these topics noted in the comments. To help represent viewpoints, I did not objectively count the times a particular word or phrase was used, but instead paid attention to the priority that commenters gave to their different statements. For example, while a commenter might briefly mention the negative economic consequences of dam removal as well as social impacts to their community, if they spent the majority of their comment vehemently critiquing the impact of government regulation on private property, that was taken as the primary statement of the commenter. The resulting typologies and their similarities, differences, and relationships are presented and summarized in the following chapter. 


\section{Chapter 4: Results}

We have just one world, but we live in different ones. ${ }^{300}$

This chapter will present the categories in which I placed the comments, based on the opinions expressed about the appropriate management of water and use of nature, including how or what the water should be used for, and who should decide. Comments were primarily classified by this metric, but I was also sensitive to the arguments made to support the preferred management decision. The rationales used to justify management decisions exposed opinions and views on other secondary issues, including the legitimacy of government, science, environmental regulation, and private property. As mentioned in chapter three, commenters were asked to write or speak about their opinion on the proposal to remove four dams on the Klamath River.

Comments were classified primarily on their conceptions of the management of nature and their views on the secondary issues, rather than the social groups that the commenter may have identified with (such as "rancher"). By grouping comments together in etic typologies, I hope to paint a more nuanced or comprehensive picture of the comments. It should be noted that while comments were assigned to a typology, the views of commenters might be best represented on a continuum - but this system would result in as many typologies as there were comments. Thus, while I have made the attempt to represent the range of views and values, any categorization results in some simplification. This thesis does not intend to directly represent each commenter's reality but rather develop typologies that might be used heuristically for the purposes of discussion.

\footnotetext{
${ }^{300}$ Mark Knopfler, Brothers In Arms, vol. Brothers In Arms (Warner, 1985).
} 
$\underline{\text { Introduction to Results }}$

I developed five typologies, Natural Rivers (NR), Working Rivers (WR), Future Rivers (FR), Balanced Rivers (BR) and Wise Use Movement (WUM). These typologies are summarized briefly here, and developed in more detail later in this chapter. NRs support the removal of dams on the Klamath River, and construct nature as a fragile system thrown out of balance by the destructive actions humans, including farming, ranching, and dam building. NRs believe dam removal will restore harmony to the river.

WRs construct nature as a robust storehouse of materials for economic production, link their livelihoods of working on the land with their identities, and express a sense of place that has developed alongside laboring in nature. WRs oppose dam removal.

Like NRs, FRs support dam removal because they believe it will end the enduring conflict in the basin and allow them to continue their farming and ranching lifestyle.

BRs argue that better river management is preferable to outright dam removal. This typology reflects Pinchot's conservation philosophy, calling for better and more rigorous scientific management of the river to meet the needs of multiple uses.

WUMs construct dam removal as a symbolic on property rights and economic freedoms, asserting that the dam removal proposal is a conspiracy of government officials and environmentalists. This typology expresses the least concern with the local outcome of dam removal.

What follows are descriptions of the themes of each typology, supported by quotes drawn from comments in that typology. In Chapter Five I will place the results presented in this chapter in the context of, and in conversation with, the broader literature discussing the 
Klamath Basin and environmental controversy more generally. The number following each quote below indicates which comment the quote was sourced from. For the full text of comments, see Appendix I. At the end of each typology's description I have developed a summary narrative, which is intended to synthesize the perspective of that typology and summarize the main themes.

\section{Natural Rivers}

Commenters in the Natural Rivers (NR) typology support the full removal of all four dams on the Klamath River. In this view, dams upset the natural balance of the river, and are the dominant contributor to the environmental, social and economic troubles in the basin. These commenters see dam removal as an essential step in "saving the Klamath," and they emphasize the interconnectedness of the river system with the health of human and nonhuman species, as well as the economy, and future generations. For NRs, dam removal is about much more than merely removing dams - it will restore "harmony" to the river and benefit fisheries, biodiversity, water quality, and improve fish habitat. NRs believe dam removal will result not only in a healthy river but also in healthy communities and a healthy local economy. NRs see the economy as broader than irrigated agriculture and farming, seeing greater value in a restoration economy including tourism and fishing. NRs also note the ecological, cultural, and symbolic importance of salmon to the Pacific Northwest's regional identity, while largely ignoring the ecological and cultural significance of the suckers.

Without salmon we would be sadly diminished here on the California North Coast. (22) 
The area is in crucial need of restoration to bring back wild populations of salmon, so important to so many of us who live in the Pacific Northwest. (67)

Commenters in the NR typology speak with a sense of urgency about dam removal, asserting that time is running out to save the fish before extinction occurs. This sense of urgency was pervasive throughout NR comments, and parallels the NRs view of nature as a fragile system on the brink of collapse at the hand of humankind.

The fish don't have time. It's already going to be 2020 by the time the dams come out, which, hopefully, they will. We can't wait any longer. (17)

If you don't act soon and take down all the dams, there won't be any salmon left to worry about. It's called extinction. (29)

Dam removal is an immediate necessity to protect the remaining runs of steelhead and salmon. (11)

The dams on the Klamath need to be removed as soon as possible. If they are not, the salmon may not last long enough for the river to be un-dammed. I urge this organization to call for an earlier year of dam removal than 2020. As it is, the salmon may not last that long. (37)

NRs characterize dams as the root cause of problems in the Klamath Basin, with all other issues stemming from the existence of the dams. It follows that removing the dams will be a panacea for the full spectrum of river basin woes including ecological, social and economic problems. This parallels the NR sentiment that the fish are central to the health of both the river and the basin - and that dams and fish are simply incompatible. Following dam removal, fish will return along with a healthy river, social equity, and a thriving economy.

To save our salmon and clean water, we must remove the Klamath dams. (75) 
The fisheries will continue to decline so long as the dams exist. Let's get it [dam removal] done, as soon as possible. (71)

Dams have choked off a major source of food, cultural subsistence, and economic benefits. Dams, in this area more than most, perpetuate the legacy of abuse against indigenous tribes. Dams also strangle the ecological integrity out of the rivers and the surrounding vegetation. (60)

Historically, this free-running river supported numerous Native tribes, many, many, sport fishermen, and several distinct ecosystems. All of these individuals, groups, and living systems suffer irreparably from each moment those dams exist. (48)

These dams are decimating what used to be the west coast's third most productive steelhead and salmon fisheries, and strangling the area's economy. (36)

Dam removal will reduce the toxic bluegreen algae that now threaten human health in the warm reservoirs behind the lower dams. It will reopen salmon access to some former spawning streams. If, as a result, the salmon increase in number, commercial ocean fishermen, sports fishermen, and Indian tribes will benefit. (22)

NRs are believers in the value of a restoration economy rather than one premised on agrarian economic uses of the land and water, such as ranching and farming. This restoration economy is predicted to benefit many sectors of the basin and, like dam removal, is discussed as a sweeping and obvious solution with a value that is tangible but difficult to quantify.

Life for fish. Jobs for man. Slam dunk. (45)

The restoration economy is an economy that promotes more health, economic health, more ecological health, and overall has very many widespread impacts that may be difficult to estimate but, I think, are currently being underestimated... I think we underestimate the benefits of a healthy fishery (26)

And you talk about livelihoods and stuff like that, we are all lost without fish, without - we no longer have guides on the lower Klamath for fish[ing]... We have lost those incomes, but fish will bring it back. (4)

I would like to ask that you call consider the value of a restoration economy in this Basin versus an economy that extracts resources, uses them up, spits them out on the other side and we have to restore them and figure out how to find the money to do that. It's very costly, and I would argue that the value is significantly less. (73) 
This typology generally views dams as outdated and believes that society has moved on. Dams that remain are characterized as more trouble than they are worth, and dam removal is perceived as an eventuality.

This is an era of dams coming out. (73)

The age of dams has passed. (75)

The time has come to remove all four dams on the Klamath. They have outlived their intended usefulness and have become not only a liability to the region but remain a MAJOR hindrance to the steelhead and salmon runs that once were so abundant on the Klamath River. (79)

The NR typology accepts the science underlying the listings of the fish species and water management decisions. NRs believe the river can be understood legitimately through science and ecology. NRs see the ESA as a legitimate tool to correct a fragile nature thrown out of balance by humans. This typology of commenters points to precedent to support their preference for dam removal, observing positive changes that have come about following dam removals in other locations. As with their characterization that dams alone are the single problem facing the Klamath Basin, NRs also generalize that dam removals on the Klamath River will have the same results they have on other rivers in other locations. NRs also have difficulty understanding how people opposed to dam removal cannot "understand the scientific facts" supporting dam removal.

The success of other dam removals, i.e. Savage Rapids, Elwha, and Condit demonstratively predict likewise success with the Klamath River Dams. (6) 
I lived in Maine when the Edwards Dam was removed from the Kennenec River. It was estimated that though the river had been dammed for 160 years, the Atlantic Salmon would return after 5 to 10 years. THE ATLANTIC SALMON RETURNED IN THE FIRST YEAR! I saw it with my own eyes... I have heard it said that there is no scientific evidence that the salmon will return to the upper reaches of the Klamath after dam removal. Yet every time I offer proof, no one in the "do not remove the dams group" returns my calls or answers my emails. (15)

NRs closely match the description of Schwarz and Thompson's "nature ephemeral” wherein nature is inherently balanced, but human disturbance and disruption tips the system out of balance. NRs consider it amoral to dam the river, asserting that it will be emancipated after dam removal. When describing the river conditions that will occur following dam removal, they reference a pristine, beneficent, and harmonious nature.

It will bring harmony to our basin and restore the natural balance that is critical to the Klamath River. (74)

I am in favor of removing the dams and letting the Klamath River go back to its ancestral river status (15)

Take the dam down! Free the river. (70)

Not only is it morally right, it is one more step towards restoring the natural balance to an area long abused by ranchers, and farmers. (63)

Dam removal... will be good for the Klamath Basin and its communities. Restoring the river to some point closer to its natural baselines will promote harmony in the socio-ecological system. (30)

NRs see all species as possessing rights that should not be compromised, especially for anthropocentric reasons. Damming of the river is indicative of a culture and society NRs see as illegitimate, damaging, and shortsighted. This view reflects their distrust of those who labor in nature and control nature to benefit productive uses. NRs venerate pre-European practices which are seen to be "in harmony" with nature. 
Are potatoes really more important than preventing the extinction of salmon species that play a major ecological role? I don't think so. (22)

There are things that no amount of mitigation can bring back once they're gone and the state or county surely doesn't have the money to fix the environment once we have demolished the ecosystem with poor decisions. The dam has never made sense and no dam ever will. (7)

Our years of "development" have unknowingly brought immeasurable damage to our environment. (41)

Uglification and abuse of Earth for profit - do what we need another way. (31)

For too many years "resource extraction" has been the mantra of those who are so myopic that they won't look beyond their own pocket books and political power. (63)

In the 150 years since the arrival of the Caucasians, various shortsighted practices have transformed the landscape from one of great plenty to one of unsustainability... these extractive practices were put into place without a clear understanding of the devastating results. Today, however, we are starting to comprehend the damage we have caused. (55)

Accordingly, institutions and societal structures (i.e. the ESA and regulation generally) that promote maintaining or restoring the "natural balance" are legitimate, which reflects NRs view of nature as intrinsically valuable and irreplaceable. This view links with the sense of urgency over dam removal. Humans are implicated in the consequences of disturbing the natural balance, with commenters asserting that not just fish, but also humans, are at risk of extinction.

We must change the way we think or go extinct. (7)

I am a great believer in, and supporter of, the Endangered Species Act. As time has passed, I have become ever more convinced that man drives species into extinction at his own grave risk. I really believe that there is [a] potential tipping point in the destruction of the natural world, which, when passed, will result in man's following into extinction all of the species he has previously driven there. (54) 
The narrative the Natural Rivers typology tells might go something like this: Before the arrival of destructive white settlers, beautiful rivers were full of fish and salmon made their great journey from river to sea and back again. Indigenous peoples and their culture thrived alongside a healthy river where people existed in harmony with nature. But 150 years ago everything changed. Greedy settlers arrived, bringing with them little respect for the delicate balance of nature as they mined the hills, dammed the rivers and plowed the soils in the myopic pursuit of monetary gain. As a result of their abusive actions and desire to control a beneficent nature, fish struggle to live, much less thrive, and our tribal neighbors suffer a similar fate. Dams in particular strangle the life out of rivers and the human communities surrounding them. Society is at risk when it prioritizes its own welfare over the welfare of all living creatures, which have intrinsic rights to exist. Fortunately, with the help of the Endangered Species Act, we may be able to bring balance back to the Klamath Basin, save the fish, and free the river before it is too late.

\section{Working Rivers}

Commenters in the Working Rivers (WR) typology see the Klamath River as a resource to be tapped for productive uses. They conceive of water as a resource to irrigate land, support ranching, and produce hydroelectricity. WRs see government regulation as illegitimate if it interferes with the productive use of resources, and many commenters draw on previous instances of government regulation to support their contention that life is better with fewer restrictions. In this view, nature is bountiful and should be used to its maximum potential to meet anthropocentric needs; nature is a generator of wealth and economic 
growth, and humans have higher rights than other species to utilize nature. WRs are skeptical that fish are endangered and question the science used to support the claims of NRs and dam removal. WRs speak more directly of economic and social harm resulting from regulations in their communities.

We had timber here until 1995. We had 22 operating mills. We had 6,000 living wage jobs. We have two mills left in this county, and I think there is something like 300 employees. So I don't know if you can overcome that type of a loss. We lost dredge mining because of North Coast Regional Water Quality Control Board's actions and decisions about dredge mining. So all we have left is agriculture. It's a marginal place to run agriculture, it always has been... What we do need to be concerned about is sustainable economy, not a sustainable environment. (105)

Government action that does not support productive uses is considered illegitimate, and many WRs draw on their previous experience with the spotted owl controversy of the 1990s to justify their suspicion of environmental regulation and government generally.

... as my father used to say, beware when a man comes to the door and says "Hi, I'm here from the government, and I am here to help." (87)

It appears that our government has two sets of standards, two sets of regulations. One of them for our private citizens wherein they hold the private citizen to a standard that severely restricts and virtually bars their activities in or near rivers... The other standard essentially allows the government to do whatever they wish so long as that purpose is politically correct and adheres to the desires of the environmentalist's agenda. (98)

The govt plays one group against another. The govt encourages one group with subsidies to harvest even more fish, yet attempts to attack innocent water users up stream if they so much as harm one fingerling. The government's behavior on this issue is bipolar - manic depressive. (113)

The legacy of the spotted owl controversy, wherein timber harvests on federal lands in Washington and Oregon were greatly reduced to maintain habitat for the endangered 
spotted owl, is particularly evident among WRs. The subject is discussed like an old injury that still aches, especially when aggravated by the prospect of additional burdensome environmental protection. Government's legitimacy is particularly tainted because of impacts of the ESA on economic activity. Some WRs support efforts to weaken the ESA or invalidate it altogether.

We can't even mine recreationally in the River according to California Fish \& Game. Our economy has spiraled down and the only real value we have is the real estate. In the name of endangered species, the "spotted owl" issue closed 47 sawmills and created NO NEW JOBS, thus heavy unemployment. (108)

We, in this community, have watched as [the] ESA in protection of the spotted owl decimated the timber industry. I'm not willing to stand by and let the same thing happen to agriculture... Save our dams, amend the ESA... (82)

In the last serious recession... I witnessed the audacity of the "Spotted Owl Worship" that truly shut down for the last 40 years the majority of the lumber industry in the entire Pacific Northwest. Your actions in tearing down dams and controlling these and any other resources have a verifiable history of terrible consequences to the area's industries and entire economies of regions of a state. (103)

While they are most concerned with the material implications of environmental regulation on the economy, WRs also express concern with the moral dimensions of regulation, asserting that environmental regulations are misanthropic and mistakenly place nonhuman species on the same plane as humans. Environmental regulation is seen as more than a set of rules or laws but a plan to intentionally exclude people and human uses.

Fish are not more important than Humans. (95)

We share the environment, we live here. I should have as many rights as the fish, or, you know, a deer that runs in my yard, he has rights. I have rights. (93) 
Today you can't fish in the Shasta River or Scott River. Today if you go to the Shasta River or the Scott River, you have fences on both sides of the river, not only to keep the cattle out but to keep the people out as well. (105)

This typology's view of nature follows Schwarz \& Thompson's “nature benign” and they see local, regional, and national greatness stemming from the full and unhindered utilization of nature. The dam removal proposal is seen as an attack on a virtuous way of life, as well as the foundations of what has allowed the local community, and the nation, to prosper. WRs venerate the decisions of previous generations, arguing that there is wisdom in the decisions past generations, whose hard work allowed them to triumph over nature and develop the region and nation.

To me, taking out dams is counterproductive to what we should be doing. Cheap electricity is what built industry and farming in the Klamath Basin and the Pacific Northwest. Without cheap electricity, the Klamath Project could never have been as productive as it is. (82)

It is hard to imagine that in America removing our infrastructure would even be entertained. The ones joining in to kill America by any means are so happy to watch America slip to third world status by decisions like removing dams. Remember with the power generation problems of America, the food problems and flood control we need to be building dams, not removing [them]. (92)

Why did our forefathers ever build those dams in the first place? Would Klamath Falls, with everything we have in this community, even exist without those dams prior to now? (88)

What I do know is that these dams and all of the structures put into the rivers and streams of this county were put there to enhance the environment, the economic environment of this county. (105)

While NRs tout the benefits of removing dams, WRs consistently speak of the benefits of the hydroelectricity produced by retaining the dams. Harnessing the rivers of the Pacific Northwest is seen by WRs to have been essential to the development of the region, 
especially for the purposes of irrigation and production of inexpensive electricity. WRs supplement their arguments with statements about how the "green energy" is "clean" and they express concern with both the economic and environmental consequences of removing that source of energy. Hydroelectricity from dams is characterized as "progress" while removing dams and associated energy production is "going backwards." Such a view reflects the notion that progress is characterized by increased control of natural systems for anthropocentric benefit.

It is insanity to remove the Greenest power available. (95)

How will the green, affordable energy currently provided by the four hydroelectric dams be replaced? (104)

If the dams need upgrades or replacement with better systems, that is one thing. Going backwards by total removal, that is insanity. Where is the replacement energy production to the grid? A coal plant in Utah? (113)

WRs cite potential consequences of dam removal, primarily the release of sediment downstream. Sediment mobilization is seen as the greatest environmental threat, and discussion of the consequences of sediment release was frequently accompanied by a mention of the benefits of hydroelectricity. Thus concern over sediment combined with loss of hydroelectricity benefits serve to deal a one-two punch against dam removal.

While they question the legitimacy of the science supporting dam removal and the ESA-listings of fish, WRs capitalize on the scientific uncertainty of what will happen downstream after dam removal. This is in contrast to NRs who use the same examples to support their position on dam removal. While NRs see science as fundamentally legitimate, WRs see science as warped by politics and thus failing to represent truth or justify dam removal. 
All studies, including yours, confirm major damage to the stream conditions for years to come... This is evidenced on a small scale by the problems... caused by the removal of the small Dams (Savage Rapids and Gold Ray) on the Rogue River. (90)

Dams must be saved to save the salmon and all the fish... Real science now proves original statements were fraudulent - It has been admitted this is an "experiment" we can't afford this kind of experiment! (86)

I do not believe the propaganda about the salmon being endangered. (96)

WRs appropriate the discourse of NRs to argue that dam removal will actually harm the environment rather than help it - in order to "save the Klamath" dams need to be retained rather than removed. WRs see NRs as confused about what dam removal will really accomplish, stating that dam removal will release enormous amounts of sediment downstream and ruin, rather than restore, the ecosystem downstream for fish. While WRs generally emphasize the scientific uncertainty surrounding the dam removals, they speak with certainty that large quantities of sediment will be released downstream and have a negative effect on the riverine ecosystem.

Dams must be saved to... Save the salmon and all the fish... An estimated 22 million cubic yards of toxic sediment will sludge its way down the Klamath River destroying salmon runs, mucking up the environment affecting water clarity and purity! This amount of sediment will sterilize the river for 100 years. (86)

That amount of sediment is equal to two million ten-yard dump trucks of river sediment, silt and organic material. Two million dump trucks, regular ten wheelers, lined up from head to heel, will stretch about 12,500 miles. Halfway around the planet. If you look at it in a different way, if you were to dump one truck load every five minutes, every day, every week of every month of every year it would take nearly 20 years to dump all that sediment into the river. (98)

Removing Dams will flush millions of tons of sediment downriver choking fish and covering spawning beds killing billions of eggs and salmon fry. (106) 
WRs are the foil to NRs in regards to the symbolic meaning of dam removal. While NRs see dams as the root cause of problems in the Klamath, WRs see the dam removal proposal as the problem.

[Dam removal] is the poster child of what is destroying our nation's economy. All the ingredients responsible for sinking this great nation have been included. (111)

Like NRs, WRs speak fondly of days past when everything was right in the world. Yet the two categories have divergent ideas of what made the past great, and similar to their views on whether dam removal is the problem or solution, WRs and NRs have different visions of why the past was better. WRs venerate days of unrestricted resource development and access to nature for economic uses.

Up until the mid 1980s Klamath Lake was full of suckers, the ocean and rivers were full of salmon, the farmers and refuges received unlimited water and family wage jobs were abundant. The only constants contributing to those successful times were full utilization of our public lands (including logging), an extensive hatchery program and unlimited water for agriculture and refuges. (111)

Both NRs and WRs see economic issues in the basin that need to be solved, but have divergent ideas of both the cause and solution. While NRs see a new economy based around the restoration of the river, WRs have a more traditional view of what the economy is and should be. WRs see their economic contributions as central to the economy of the basin economy as a whole, and predict that dam removal will lead to community economic hardship or even outright collapse. In this way, WRs conflate the agrarian economy with the entire economy of the basin, with removal leading to a disastrous outcome. 
The Working Rivers narrative could be summarized thusly: When our forefathers arrived in the Klamath Basin, they found an abundant nature waiting to be put to work. In order to survive in the arid basin, they diverted a little water to make a living. It was a hard life but they scraped by. Those ancestors built a life from nothing here in the rugged basin. Through their hard work and labor on the land they created a community of good people who produced food to feed a growing nation, while timber mills provided lumber and wood products as well as good jobs in our community. Dams provided a steady supply of water and affordable electricity. Life was good until the environmentalists decided owls were more important than human lives, and government regulations took away our logging jobs, our communities, and our identities. Times were hard, but we still had agriculture. Then, in 2001, they took away our water, our rights, and our economic foundation. Now environmentalists want to remove dams to "save" a fish that isn't even endangered, washing sediment downstream and destroying the ecosystem they purport to want to save. Nature is robust and resilient, and a little bit of farming can't change that. Our economy and virtuous agrarian lifestyle is threatened once again by government regulation and environmentalists.

\section{Future Rivers}

Those in the Future Rivers (FR) typology support dam removal primarily to ensure a sustainable future for their current livelihoods as well as future generations. While NRs primarily focus on the environmental benefits of dam removal, and cite social benefits as an important but secondary benefit, FRs support the same management action for more anthropocentric reasons. FRs cite family history or heritage when they describe their ties to the basin, and the desire to continue the family tradition of farming or ranching forms the 
basis for their support of dam removal. This typology sees dam removal as the best option to maintain their lifestyle for future generations to enjoy. Dam removal is considered to lead to an end to the water wars that result in an unpredictable supply of water and compromise the future viability of the ranches and farms. It should be noted that the FR typology is composed of just two commenters, but their statements are distinctive because of their rationale as well potential for accommodating competing interests.

We believe settlement, not litigation and the status quo, will create another hundred years. I want my children to have the opportunity to ranch in this basin in the future. Ranching is what we love to do. "No solution" means crisis. (151)

I am a third-generation rancher, I have my farm inside the Klamath Reclamation Project, and when I say, "third generation", I'm trying to be third generation. 2001 was almost "it" for us, and I would like to see my ranch go through my life as well. And with this settlement, I believe that it gives me more of a consistent supply of water. And for future generations I think that's a benefit to us all. (135)

The narrative for Future Rivers goes something like this: Our families have been ranching in the Klamath Basin since the early days of settlement. Past generations have invested in this place, and our ranching lifestyle has become our identity. It is what we love to do. Recently there have been disagreements about how we should be using water here in the basin. For over a decade we haven't been sure what our water supply will be and when it might be shut off. Recently, many of our neighbors have been upset at the idea that the dams that have given us water might be removed, while others can't wait to see the dams taken out. We support removing the dams, but not for the same reasons as the environmentalists. We support the removal plan because we are tired of enduring conflict and uncertainty. It will be a solution to the crisis that has plagued us and will allow our families to get back to 
ranching. We feel dam removal will help ensure our ranches are around for our children and grandchildren .

\section{Balanced Rivers}

Those in the Balanced Rivers (BR) typology vary in their conceptions of what the river should be used for, but advocate tweaking at the margins rather than the extremes advocated by the NRs and WRs. These commenters express a desire for water managers to account for multiple interests, making adjustments to water releases and instream flows and constructing functional fish ladders instead of implementing full dam removal. BRs see holistic benefits from maintaining and aggressively managing the dams to promote management balanced between interests.

I believe there can be better ways of moving fish up the river, fish ladders - I'm not talking about wimpy fish ladders, I'm talking good fish ladders that could support the tribes and support the farmers. (115)

These commenters have a multifaceted view as to the source of the problems on the Klamath River, noting that multiple factors have combined to take their toll on fish populations. This group also expresses personal knowledge and experience with the rivers, with commenters reporting nearly 40 years of fishing experience to three generations of ranching in the basin.

I feel the dams on the Trinity and Klamath were the first blow [to fish populations] but overfishing by both sport fisherman [sic] and Native American gillnets, logging, farming (pollution and water flow effect), etc. all have taken a toll. (122) 
Dams are seen neither as the source of all problems (NRs) nor essential infrastructure that must be maintained (WRs). Instead, the dams are merely tools in the management toolbox instead of fundamentally flawed or critically important. BRs see management as fundamentally legitimate, even essential, but that management requires adjustment if it is to adequately serve the needs of the river and its many uses, including commercial and tribal fishermen, irrigators, fish, and hydroelectricity generation. These commenters express a desire to maintain healthy fish populations, but not at the expense of all other river uses as the NRs do.

The river is being mismanaged in a way that causes more disease, and has nothing to do with the dams. The flow is kept too high in the summer... maintaining significant flow by releases from Upper Klamath Lake should not be as important as controlling disease. (120)

[Dam removal] is an unnecessary and expensive endeavor that can be accomplished in a much better way... Maintain clean Hydro-Electric Power for 70,000 homes. Maintain flood protection for downriver cities, roads, bridges, and private property. (119)

Keep the dams - They are green. Put in sophisticated ladders. Manage the water accordingly. (118)

The BR typology sees management as legitimate but hamstrung: nature needs to be managed to serve human needs, but its management should be changed to be as fully legitimate. This view is concerned with the wellbeing of fish but does not prioritize environmental concerns over the multiple, functional uses of the river.

The Balanced River narrative is as follows: In recent decades we have seen declining fish populations in the Klamath River, and the changes have been sobering. Many factors have contributed to the fish problems, including fishermen, gillnetting, extractive uses of the 
landscape, and irrigation water misuse. Recently there has been increasing attention paid to the causes of fish declines and the best way to return fish populations to a healthy level. Some groups want to remove dams on the Klamath River while others think the river should be used exclusively for irrigation and farming. We think those perspectives are too extreme, and are not appropriate solutions to the problem. Society should be supporting fish, but not at the expense of all of the other uses of the river. Instead of spending exorbitant sums of money removing dams, we need to take a more reasonable approach and make small adjustments to how we manage the river while serving multiple uses. To support fish passage, we should install high quality, functional fish ladders and maintain the dams, which provide affordable and green hydroelectricity. Additionally, water managers need to rethink their management strategy and manage for local conditions the way they really occur. We need management on the river, but that management needs to change if it is to be effective.

\section{Wise Use Movement}

Those in the Wise Use Movement (WUM) typology exhibit similar characteristics to those in the WR typology. Both categories oppose the dam removal proposal, and characterize environmental regulation as harmful and illegitimate. WUMs and WRs differ in the specifics of their discourse, as well as their ultimate concerns. While WRs draw on their personal experience in describing the implications of environmental regulation (primarily the ESA and the spotted owl), WUMs speak broadly with little reference to local conditions or local experience. WUMs characterize environmental regulation as advancing Agenda 21 (a United Nations Sustainable Development initiative) and a conspiracy of government officials and environmentalists. This, in turn, is part of a larger premeditated plan by government to 
compromise the rights of citizens, compromise their economic freedoms, and drive them from their private property. My typology name of "Wise Use Movement" reflects the parallels between this group of commenters and the broader "wise use" movement documented in the literature (see Chapter Two for an overview). It should be noted that the name for the movement was appropriated from Gifford Pinchot's term, and is intended to position the movement's "agenda as one of restoring a historic balance [of land use] thrown awry in the direction of preservationism in recent years. ${ }^{301}$ The WUM typology does not truly represent Pinchot's intended idea of wise use but instead promotes unrestricted access to nature as a natural resource for economic development. This typology could also have been named "America's Freedom Fighters" or "Conspiracy Theorists" but the strong parallels with the academic literature on the broader wise use movement justifies this typology's name. As James McCarthy observes, the wise use movement "defined itself mainly in opposition to the environmental movement, environmental regulations, and federal agencies governing land uses, all of which it portrayed as arrogant, ignorant outsiders intruding on local communities and denying them their livelihoods and right to selfdetermination." ${ }^{302}$ This observation largely mirrors the comments that comprise my WUM typology.

To WUMs, dam removal is seen as a symbolic attack on patriotic citizens who are victims of an aggressive government. While they share some rhetoric with WRs, WUMs have a larger ultimate concern: a government that is corrupt and in collusion with environmentalists to remove virtuous citizens from their private property and deprive them of

\footnotetext{
${ }^{301}$ James McCarthy, "Environmentalism, Wise Use, and the Nature of Accumulation in the Rural West," in Remaking Reality: Nature at the Millennium (New York: Routledge, 1998), 136. 302 James McCarthy, "First World Political Ecology: Lessons from the Wise Use Movement," Environment and Planning A 34, no. 7 (July 2002): 1283, doi:10.1068/a3526.
} 
their constitutional, inalienable rights - by any means necessary. WUMs nearly universally use the terms "citizens" and "destroy." Citizens are those who have voted against dam removal or those who are victims of their government, and while NRs characterize the proposed management action as dam removal, WUMs speak of dams getting destroyed, which is reflective of their concern that destruction of the nation will follow destruction of dams. The use of these terms lends a distinctly patriotic and apocalyptic tone to the comments of WUMs.

The typology name lacks "rivers" in it because of the lack of concern expressed for the Klamath Basin or its local condition (contrasted with WRs). Instead, the ultimate concern for this typology is not local, but much broader in its physical and conceptual scope. WUMs allude to a conspiracy of environmentalists and government agencies that are colluding to cleanse the rural landscape of honest, hardworking citizens. These citizens cast themselves as victims of a ruthless government carrying out the wishes of environmentalists.

...dam removals... are a disguised attempt by several small/special interest groups, aligned with agendas ranging from personal enrichment, to driving citizens off their private property, to sending Oregon water to overpopulated Southern California.

This entire movement is a patronization of the environmentalists' desire to decivilize our human race from adherence to electricity generation by dams, to patronize the politically powerful Indian caucus both in Sacramento and Washington DC, to unconditionally destroy the water rights used for food cultivation and recreational purposes, and to ultimately destroy the entire ecosystem of the Klamath River downstream... (141)

...transition the land and supply of water to an "idealist's" idea to make it like it may have been 150 years ago before man developed the land. (150)

The stupid and crazy nonsense that the EPA and the other enviro-whackos are perpetrating on the good people of this country will not be tolerated any more. You uneducated, Fabian Socialist progressives are destroying this country and her 
freedoms. We will fight you every step of the way. We will not allow you to be tyrants over us. (159)

We've been assessing how the radical environmentalists have wormed there [sic] way into almost every water district in the U.S. They start with the water manager and offer him future positions and under the table deals. After the manager is in cahoots with radical enviros, they get the manager to bring their deal to the table with the board members that manager works for. The board members that fall into the manager's recommendation on agreements with radical environmental groups have at this point started representing the manager's interest and not the people who elected them to the board. This has happened in every water take over re; [sic] Central Valley Project Improvement Act, San Joaquin river settlement, and again in the Klamath river restoration that is so mixed up the farmers are kept out of secret meetings. (162)

While WRs cite the ESA and what they have seen in their communities, WUMs are concerned with a more abstract agenda designed by environmentalists and implemented by government. Instead of describing more specific and local instances of the downsides of the ESA, WUMs speak in sweeping terms about environmental regulation using the term “Agenda 21.” Agenda 21 is considered illegitimate, illegal, morally flawed, and fundamentally un-American. The presence of regulation is seen as incompatible with the respect of foundational rights. The individual is seen as threatened by the collectivist implications of Agenda 21.

Do not open the doors for the future for "The U.N.'s Agenda 21, taking away property rights for our people by the year 2030. (153)

It seems that the true goal is to destroy the economy, the people, take over the land and destroy the environments which removing dams would do. I guess this furthers Agenda 21, doesn't it? (155)

It is sad that you don't respect our American history and [are] against individual and wanting in the end result by destroying the dams in N. California and Oregon etc. so you can hasten us into this horrendous Agenda 21. If you go along with this, we know where your heart is and that you want no more private ownership of lands everywhere. (150) 
I believe the reasons for the dam removals comes from the implementation of Agenda 21 (sustainable development). I also believe it was responsible for the recent closure of dredge mining, another employment "confiscation" ... Sustainable development has no respect or concern for the human population, but uses the environment as the "guise" to take away our unalienable rights, by implementing regulations that force the citizens of this great nation, out of jobs and property. Case in point: the spotted owl (endangered species act) destroyed the timber industry in the Pacific Northwest... We do not need... nor do we want implemented strategies that require surrendering our God given unalienable rights which are firmly planted in the U.S. Constitution! (144)

But the agenda is not to comply democratically with people it is to rule people. This to me is obviously... Agenda 21 as stated very clearly [on the] UN Agenda 21 web site. In the United States, we are not governed by man or nature, we are governed by laws. You have broken our laws and ignored the residents. (129)

Turning back to the days of complete wilderness is ridiculous and damaging to communities everywhere. Please DO NOT proceed with these plans that have to do with the Agenda 21, and the United Nations take over over [sic] all our sovereignty. (130)

Like WRs, WUMs see the science supporting the dam removals as flawed and tainted by politics. But while WRs see science as flawed in a basic (perhaps innocent) way, WUMs sees the science as one of the tools used by the vast conspiracy. To WUMs, scientific findings were predetermined and manipulated as part of a premeditated plan, and the request for public comments is believed to be little more than a charade to create the illusion of public input and the presence of a democratic system.

It's based on purchased science with predetermined conclusions, political science. What it amounts to is a pretty big biological experiment... So it is basically a biological experiment. I'm more concerned about the social experiment... The social engineering of this direction that uses smoking mirrors [sic] of consensus and designated quorums has been deliberate while deceptive. This is what's frightening. Deception, coercion, threats to our liberty and civil rights. (127)

I hope you realize that you work is already being discredited. In the future, graduate students will be re-analyzing your biased research and will soundly discredit your 
reputations for your lack of sound scientific practices expected from all professional scientists. (133)

...you come to us 18 months later saying that all this time you were doing unbiased research, that you want to listen to our opinion before you make a final decision on dam removal. We all know the decision has been made. (133)

...the Secretary of the Interior has been rightfully criticized on misrepresenting scientific facts and manipulation of scientific information to achieve the Administration's desired results. (148)

Years of seeing vast amounts of current science and documented history submitted by "public comment" have failed to show a single change in the predetermined direction of this unaccountable special interest experiment... meetings which occurred in secret demanded unsupported preconditioned agreements to dams' removals. (132)

WUMs characterize the dam removal proposal as moving ahead against the will of "the people." While I was coding these comments, this sentiment was so dominant that an In Vivo code "We The People" was created to represent the feeling of solidarity among victims of an aggressive government. This typology prizes the principles of democracy, the individual, and America, thus dam removal is illegitimate simply because citizens have spoken against it. The "local vote" (another In Vivo code) is considered the ultimate test of legitimacy, and WUMs cannot fathom why there is even a discussion of dam removal still occurring.

Siskiyou County has voted to save the dams. Why is there still a movement to remove the dams? We are the People, and we have voted to retain the dams. (160)

Your inability to listen to the citizens of California is why many citizens are coming to the realization that our government is more committed to serving environmental activists than local and state citizens. An average of $80 \%$ of citizens VOTED NO on Dam Removal in Siskiyou County, California, and Klamath County, Oregon. (137, bold in original)

The dams are important to the ranchers, farmers and all the people of Siskiyou County. Their rights are more important than a fish that is not even native to the area. 
What kind of government do we have to throw out the rights of its citizen without any representation? (154)

Have you not heard the voices that have been shouting from the rooftops? KEEP OUR DAMS IN-TACT! (134, capitalization in original)

Why are voted of the people not worth anything? The people have voted to not remove the dams but I guess it doesn't matter what the residents of Siskiyou County feel. Just another case of Bureaucratic misspending, mismanagement and corruption. (157)

Like WRs, WUMs consider the effects of regulation to be misanthropic, and this typology objects to placing nonhuman rights on the same level as those of humans. But as mentioned above, WUMs are in conversation with the broader theme of environmentalistgovernment conspiracies to manipulate "citizens" and withhold their rights.

Use common sense, do not ever put lower animals ahead of humans. You have been lied to by environmentalists who seek power and control over you and me. (139)

Why are fish more important than people/farmers/citizens? (125)

Your inhumane decisions will not improve the lives of the citizens of California, but make it much harder for the people to pursue happiness (prosper). Based on the actions of the Federal Government I must assume fish and wildlife are more important than your fellow citizens. (137)

WUMs do not speak as directly to their conception of nature as do NRs and WRs, yet they exhibit a Lockean perspective on nature and property, and see unrestricted access to nature as not just a cornerstone of economic success but as fundamentally related to the survival of democracy and freedom. ${ }^{303}$ In this way, WUMs see environmental regulation as a front for the takeover of land by outsiders (socialists, the United Nations, environmentalists)

\footnotetext{
${ }^{303}$ Jacobs, "The Anti-Environmental 'Wise Use' Movement in America."
} 
at the expense of the individual and their rights. Nature, and development of it via property, is cast as the foundation for the existence of the individual, America, and democracy.

Environmental regulation is cast as deeply un-American and un-democratic, and thus represents a fundamental threat to the very foundation of not just the Klamath Basin but also the entire nation and all it stands for. Using apocalyptic language, WUMs doubt that the nation as a whole will survive implementation of the misguided plan to remove dams. In this way, dam removal is strongly symbolic for this group of commenters.

It's time we protected our working citizens and stop any more destruction of our rural communities... The American way of life is under attack. (142)

The DEIR and DEIS are nothing more than political, their recommendations are detrimental to the surrounding communities. Putting the life of a SALMON above human sustainability is beyond ridiculous and you can't possibly expect the citizens to not realize this as yet another step to government takeover of private property... Our country is at stake. (146)

The Wise Use Movement narrative goes something like this: Once upon a time, an individual could mix labor with nature and create something that was his: property. From this he could create wealth and prosperity. Ownership of the land provided the foundation for the moral order that makes America great: freedom from oppression, freedom to pursue economic wealth and a voice in the Great Democracy. Unfortunately, things have been changing as the government grows larger and more out of touch with the citizens it is supposed to be serving. Today the government is power hungry and seeks to control The People. To make matters worse, environmental whackos have infiltrated government agencies, and together they conspire to drive hardworking rural citizens from their lands and place the lives of fish above those of humans! This is America! Removing citizens from their 
private property is just the first step in depriving us of our freedoms. Ultimately, the government and environmentalists plan to drive us into a collectivist state, ignoring the will of citizens who rightfully oppose it. Using predetermined science and false "facts" the government intends to hurt hard working people by removing the dams that have helped make America prosper. We must stop this scheme before it erodes this great nation's values any further!

$\underline{\text { Summary of Results }}$

Table 2 shows the number of comments in each typology. Quantities are mentioned not to weight particular typologies, but rather to show the distribution of comments in this sample. It is possible that the distribution would be different with another sample of comments, and what matters for the purposes of this thesis is the presence of different voices, not their absolute quantity.

\begin{tabular}{|l|l|l|}
\hline Comment Typology & Dam Removal Support & Comment Quantity \\
\hline Natural Rivers (NR) & Yes & 80 \\
\hline Working Rivers (WR) & No & 34 \\
\hline Future Rivers (FR) & Yes & 2 \\
\hline Balanced Rivers (BR) & No & 8 \\
\hline Wise Use Movement (WUM) & No & 41 \\
\hline Total & & 165 \\
\hline
\end{tabular}

Table 2: Quantity of comments assigned to each typology. 


\begin{tabular}{|c|c|c|c|c|c|}
\hline & $\begin{array}{l}\text { Natural Rivers } \\
\text { (NR) }\end{array}$ & $\begin{array}{l}\text { Working Rivers } \\
\text { (WR) }\end{array}$ & $\begin{array}{l}\text { Future Rivers } \\
\text { (FR) }\end{array}$ & $\begin{array}{l}\text { Balanced } \\
\text { Rivers (BR) }\end{array}$ & $\begin{array}{l}\text { Wise Use Movement } \\
\text { (WUM) }\end{array}$ \\
\hline Nature is... & Fragile & Benign & Perverse/tolerant & Perverse/tolerant & Benign \\
\hline The river is... & $\begin{array}{l}\text { Home of deserving } \\
\text { species, lifeblood } \\
\text { of region }\end{array}$ & $\begin{array}{l}\text { For commodity } \\
\text { production and } \\
\text { economic gain }\end{array}$ & $\begin{array}{l}\text { Essential to } \\
\text { culture and } \\
\text { livelihood }\end{array}$ & $\begin{array}{l}\text { For multiple } \\
\text { uses and users }\end{array}$ & $\begin{array}{l}\text { Nature is property, } \\
\text { foundation of freedom }\end{array}$ \\
\hline Human rights are... & $\begin{array}{l}\text { Equal to other } \\
\text { species }\end{array}$ & $\begin{array}{l}\text { Higher than other } \\
\text { species }\end{array}$ & [Not described] & $\begin{array}{l}\text { Higher, but } \\
\text { should consider } \\
\text { other species }\end{array}$ & Singularly important \\
\hline $\begin{array}{l}\text { Ecocentric/ } \\
\text { Anthropocentric }\end{array}$ & Ecocentric & Anthropocentric & Anthropocentric & Mix & Anthropocentric \\
\hline $\begin{array}{l}\text { Dam removal } \\
\text { science is... }\end{array}$ & Legitimate & Illegitimate & [Not described] & Mix & Illegitimate \\
\hline $\begin{array}{l}\text { Government } \\
\text { regulation is... }\end{array}$ & Legitimate & $\begin{array}{l}\text { Illegitimate if not } \\
\text { serving productive } \\
\text { purposes }\end{array}$ & Legitimate & $\begin{array}{l}\text { Legitimate but } \\
\text { hamstrung }\end{array}$ & Illegitimate \\
\hline Manage river for... & $\begin{array}{l}\text { Fish, biodiversity, } \\
\text { ecosystem }\end{array}$ & $\begin{array}{l}\text { Humans, productive } \\
\text { purposes }\end{array}$ & $\begin{array}{l}\text { Future } \\
\text { generations }\end{array}$ & $\begin{array}{l}\text { Multiple uses, } \\
\text { humans first but } \\
\text { consider others }\end{array}$ & Don't manage! \\
\hline
\end{tabular}

Table 3: Summary of the five typologies described above. 
Table 3 summarizes the five typologies described in this chapter. This table is not intended to adequately represent the nuances in each typology, but to rather serve as a guide for comparison and reference.

One interesting finding was the dearth of comments from tribal individuals. This may have resulted from a lack of access to the commenting process, other forums or avenues for interacting with federal agencies, or simply a lack of tribal voices in my specific sample of comments. While it is unclear exactly why these voices are absent, it should be noted that the perspectives represented in the aforementioned five typologies do not represent indigenous voices. Thus these results can be interpreted as divergent perspectives within the "settler" population rather than a more comprehensive portrait of all stakeholders in the basin.

NRs advocate for dam removal, and characterize dams as the primary or even single cause of the problems in the Klamath Basin. Their ultimate concern is with restoring the river back to a condition that includes no dams, minimal human disturbance, and thriving fish populations: "leave nature alone." Government action and regulation, especially the Endangered Species Act, is considered legitimate and appropriate if they support restoration and preservation. NRs see productive uses of the river as amoral, greedy, and shortsighted because they throw the river out of its delicate balance.

WRs focus on the river as part of a societal system of production for economic ends. This typology sees dam removal as a management action that will compromise both their social livelihoods and economic well-being. They are weary of environmental regulation and cite personal experience with the spotted owl to justify their opposition to the ESA. WRs would like to see the river managed for irrigation and for the benefit of humans, not other species that are less deserving. 
BRs and FRs are more moderate in their views, with BRs advocating for management of the river to benefit multiple user groups while FRs see dam removal as the best option to continue their preferred lifestyle. BRs and FRs share a lack of alarmist rhetoric.

WUMs see dam removal as a symbolic attack on property rights and economic freedoms. WUMs are less concerned with the material outcome in the Klamath Basin and more concerned with what they see as a conspiracy between environmentalists and government agencies to drive working people from their lands.

These typologies reflect the notion that the differing conceptions of the "proper" use and management of the river are rooted in diverse and divergent conceptions of nature and the appropriate relationship between society and nature. They also point to the normative appeal that science holds in justifying value-based positions in environmental controversy, as well as the ways in which commenters draw on larger cultural narratives in understanding the issue and justifying their position. In the next chapter, these categories of comments are put into conversation with the existing literature described in Chapter Two. Themes are discussed and compared with both the categories described here and the broader literature, and considered in light of environmental controversy in the West. 


\section{Chapter 5: Discussion}

"In the beginning was the story. Or rather: many stories, of many places, in many voices, pointing toward many ends." 304

In this chapter, I will place the results detailed in the previous chapter in conversation with the literature on the Klamath Basin as well as with environmental controversies more broadly. I will suggest that the different conceptions of the proper use of water in the Klamath Basin have a deeper cultural basis than meets the eye. This follows other scholars who have written about environmental controversies more generally, including wolf reintroduction and forest management. ${ }^{305}$ The conflict that stems from the competition to define and order nature according to those conceptions has real political, economic, and material consequences and thus deserves attention and consideration by those tasked with the development of management plans and policy. Recognizing, understanding, and incorporating these differences may be necessary to conceptualize the social and cultural factors at play and move past seemingly intractable debates over natural resource management policy. Seen another way, this research highlights that assumptions about nature - and the human relationship to it - are deeply rooted and may be even more difficult to move beyond than managers and policymakers realize.

As described in the results chapter, comments were categorized into five typologies based on conceptions of proper river management and associated ideas of nature (NR, WR, BR, FR, and WUM; Table 2). These typologies framed the problem in divergent ways,

\footnotetext{
${ }^{304}$ William Cronon, “A Place for Stories: Nature, History, and Narrative," The Journal of American History 78, no. 4 (March 1992): 1347, doi:10.2307/2079346.

${ }^{305}$ Wilson, "The Wolf in Yellowstone"; Warren, "What Is a Healthy Forest?"; Farrell, The Battle for Yellowstone: Morality and the Sacred Roots of Environmental Conflict.
} 
exhibited varying conceptions of sense of place, and disagreed about the science supporting dam removal. Commenter discourse also reflected larger social differences related to private property and the legitimacy of government regulation. Commenters drew on larger narratives about the individual, pristine nature, the virtuous farmer, and scientific management to construe dam removal as an action with important consequences for the Klamath Basin but also one that carries moral and symbolic weight. Because this research was principally focused on the relationship of ideas of nature with conceptions of the appropriateness of management, I will first discuss the role of ideas of nature, and then expand on other themes including problem framing, the role of science, sense of place, work and nature, the symbolic nature of management decisions, and the role of narratives.

\section{Divergent Ideas of Nature}

The nature of nature is contested between comment typologies. This study found four typologies (NR, WR, BR, FR) expressed a linkage between a construction or idea of nature and their preferred management outcome. One typology, the WUM, appears to be driven more by broader social concerns than by an embedded conception of nature.

\section{Natural Rivers (NR) - "Nature Ephemeral”}

NRs draw on the discourse of ecology to describe both what they see as the problem and what they see as the solution in the Klamath, characterizing both in terms of a system that spans the length of the river, is connected, and relates to other biotic and abiotic components. NRs recognize a clear connection between human action and the natural environment, drawing attention to changes in the land and water over time as a result of 
human use. NRs believe these changes have damaged the natural system, throwing it out of its inherently delicate but harmonious balance. This construction of nature reflects the preferred management option of NRs, which is to remove the dams, as quickly as possible, and leave nature alone. It is suggested that because nature knows best, the river will heal itself following dam removal and return to a balanced or harmonious state. NRs also rely on moral assertions, stating that human rights should be prioritized over the inherent rights of other species or the river itself.

These findings in regard to the NR assumptions of nature are echoed by Kempton et al., who found that people who think "nature knows best" believe nature has the following properties: nature has a self-healing capacity and is resilient, nature is fragile and may cease to function if disturbed too greatly by humans, and nature is too complex for humans to understand and manipulate. ${ }^{306}$ In their research using interviews to identify discursive themes among people influential in forest ecosystem management, Hull et al. also found similar themes. ${ }^{307}$ These themes are reproduced by those in the NR typology, particularly in their assertion that dam removal will be the ultimate panacea for the myriad problems facing the river basin: if society will just remove the dams and "get out of the way," nature will restore itself to a healthy condition. These "maturing and self-regulating" qualities can be traced to a Clementsian understanding of ecology (see Chapter Two, as well as Worster). ${ }^{308}$

Furthermore, the NR sense of urgency reflects their concern that human disturbance will result in a permanently damaged river ecosystem, with the specter of fish extinction looming as the most concerning outcome.

\footnotetext{
${ }^{306}$ Kempton, Boster, and Hartley, Environmental Values in American Culture.

${ }^{307}$ Hull et al., "Assumptions about Ecological Scale and Nature Knowing Best Hiding in Environmental Decisions."

${ }^{308}$ Ibid., 10; Worster, Nature's Economy.
} 


\section{Working Rivers (WR) - "Nature Benign"}

Those in the WR typology also draw on a particular conception of how nature operates when justifying their preferred management plan for the river. While NRs use an ecological filter to characterize productive uses of the landscape as disrupting a fragile, organismic nature, WRs draw on an idea of nature as robust and resilient, capable of returning to a stable state following human use. ${ }^{309}$ This conception of nature supports the WR contention that management of the river should maximize productive uses valued by humans. In the view of WRs, maximal productive use of nature fosters a healthy human community and economy, and commenters in this typology characterize nature as a storehouse of goods to be entered into the marketplace. WRs directly link economic use of nature with human well being, and diverge sharply from NRs in their conception of the priority of inherent rights. WRs are unable to fathom how NRs would be willing to place fish on an equal or higher plane than humans, and water flowing downstream unused by humans is "wasted."

\section{Balanced Rivers (BR) - "Nature Perverse/Tolerant"}

Those in the BR typology are best characterized as falling between the NR and WR view, for they see nature as resilient within certain limits. ${ }^{310}$ This typology expresses a preference for river management that does not favor one interest over another; instead, human uses can and should coexist alongside the needs of fish, tribes and fishermen. NRs advocate for river management that fully favors the needs of fish and the related ecosystem, while WRs favor fully anthropocentric management. In line with their view of nature as resilient to a point, BRs call for management that recognizes the needs of fish while also

\footnotetext{
${ }^{309}$ Schwarz and Thompson, Divided We Stand.

${ }^{310}$ Ibid.
} 
serving the needs of irrigators and downstream users: in this view, nature will allow for water withdrawals for human uses, but these withdrawals have some limit. This position echoes Progressive-era multiple use management, but perhaps integrates greater consideration for ecosystem needs and recognition of ecosystem services. ${ }^{311}$ Likewise, this group argues that fish needs should be recognized through the installation of fish ladders and managed instream flows. While BRs do not call for dam removal, they advocate for fish ladders that are truly functional. In this way, BRs call for changes at the margins, reflecting their more balanced construction of nature and their faith in technology to engineer nature.

\section{Future Rivers (FR) - "Nature Perverse/Tolerant"}

FRs follow BRs in characterizing nature as resilient within limits, recognizing that continued human-centric uses of the river will compromise their long-term viability working on the land. It is unclear whether this position is influenced more by an embedded conception of nature as malleable within limits or instead by the enduring political conflict that has resulted in water delivery disruption. What is clear is that this group is willing to accept limits to anthropocentric uses of the river in order to ensure long-term sustainability of their livelihood.

\section{Wise Use Movement (WUM) - "Nature Benign"}

Like WRs, WUMs see nature as robust and resilient to human disturbance, and this typology calls for the unrestricted use of nature. WUMs appear to be least influenced by a particular conception of nature, and are instead influenced more by an understanding of

\footnotetext{
${ }^{311}$ Hays, Conservation and the Gospel of Efficiency: The Progressive Conservation Movement, 18901920.
} 
nature as property that furthers sacred ideas including capitalism, liberty, freedom, and the individual. In contrast to the other categories where ideas of nature influence the proper management and use of nature, WUMs' larger social commitments appear to influence their conception of nature.

Commenters draw on embedded ideas of nature when describing the appropriateness of river management plans, and use these assumptions about nature to justify why a course of action is or is not justified. As Winner argues, "nature will justify anything," and the discursive constructions of nature by these commenters reflect the notion that different viewers can construe nature in different ways. ${ }^{312}$ Just as the observers of Greider and Garkovich's field constructed the field differently, so too did commenters talking about the river. ${ }^{313}$ In a similar way, the ways in which commenters frame the problem draws on particular conceptions of nature. Problem framing both shapes and reflects what is seen to be wrong, and in turn influences what the solutions may be.

\section{Disputed Problem Framings and Solutions}

Another theme revealed in the comment analysis is that commenters disagreed on what the problems were in the Klamath Basin, who to blame, and the solutions to those problems. Problem definition, according to Deborah Stone, "is a process of image making, where the images have to do fundamentally with attributing cause, blame, and responsibility. ${ }^{, 314}$ Commenters in the NR typology frame the problem ecologically, stating that declining fish populations and habitat loss were nearly exclusively a result of the presence of dams on the river. WRs and BRs characterized the source of the fish declines

\footnotetext{
${ }^{312}$ Winner, The Whale and the Reactor, 137.

${ }^{313}$ Greider and Garkovich, "Landscapes: The Social Construction of Nature and the Environment."

${ }^{314}$ Stone, "Causal Stories and the Formation of Policy Agendas," 282.
} 
more broadly, pointing to downstream commercial and tribal fishermen, as well as factors beyond the basin such as ocean conditions and "natural" (outside the control or influence of people in the basin) cycles of population growth and decline. Both WRs and BRs cited these factors, but BRs also included water withdrawals for irrigation and lack of fish passage at dams as problems, while WRs did not frame the problem to include these factors. The ultimate problem, according to BRs, is a lack of "good" management to account for the many users of the river, while WRs pointed to other users of the river as the source of fish declines. WRs in particular characterized tribal fishermen as "greedy" and framed the problem of fish declines as resulting from tribal overfishing. FRs spoke most broadly, with the commenters in this typology speaking to the general conflict that has gripped the basin for decades. For these commenters, simple resolution to the conflict is a sufficient solution.

Though WRs acknowledged fish declines as a problem, their ultimate concern was not about fish, but about the availability of irrigation water, implicating the ESA in irrigation water shortages. WUMs did not see fish declines as a problem, but instead framed the problem as the restriction of hard-working people and their freedoms by government. Notably, the solution espoused by NRs is a contributor to the very problem that WRs and WUMs seek to avoid. In these ways, commenters framed the problem, its causes, and proper solutions in varied - and incompatible - ways.

NRs and WRs expressed concern that the "others" did not "understand" the true causes of the problems in the basin. Some commenters attributed this lapse in judgment to ignorance, while other commenters saw deliberate attempts to discount and discredit the obvious truth. Though they framed the problem in different ways, some commenters in both the NR and WR categories called for those in the other group to become more educated about 
their perspective and "the facts." This dispute over what constitutes the problem and its solution is reflective of the ways in which commenters understand nature, but perhaps just as importantly, it points to the contest over science, "truth," and what comprises legitimate knowledge. Claiming knowledge of the true cause of the problem reflects not just an empirical disagreement, but also a struggle to assign blame and define solutions. ${ }^{315}$ One notable observation is that commenters in four of the five categories (NRs, WRs, BRs, WUMs) asserted a claim to true understanding of the problems and solutions - and all four claimed that "real" science supported their positions. Despite the different causal stories, all four marshaled science to support their preferred solution. The science that is "true" for each of typology reflects their problem framing as well as their ideas of nature.

\section{Science}

Stakeholders in the Klamath water conflict have turned to science to arbitrate the dispute for decades. Individual stakeholders, outside conservation groups, and federal agencies have believed that the "best available science" will provide clear guidance on how to allocate water, and to whom. ${ }^{316}$ As the enduring nature of the conflict has demonstrated, science alone is not the panacea - instead, as more and more scientific findings were produced, conflict intensified as parties involved in the conflict had a larger pool of facts to use as ammunition. This phenomenon is evident the discourse of these commenters, as well as the broader science studies literature. ${ }^{317}$ As Sarewitz observes, "for a given value-based

\footnotetext{
${ }^{315}$ Stone, "Causal Stories and the Formation of Policy Agendas"; Lange, "The Logic of Competing Information Campaigns: Conflict over Old Growth and the Spotted Owl."

${ }^{316}$ Doremus and Tarlock, Water War in the Klamath Basin; Doremus and Tarlock, "Fish, Farms, and the Clash of Cultures in the Klamath Basin."

${ }^{317}$ Sarewitz, "How Science Makes Environmental Controversies Worse"; Collingridge and Reeve, Science Speaks to Power: The Role of Experts in Policy Making.
} 
position in an environmental controversy, it is often possible to compile a supporting set of scientifically legitimated facts." ${ }^{318}$ Though parties may disagree on the problem or desired outcome, science is seen as an essential tool in the contest for legitimacy, which contributes to the production of "contesting fact-value positions" or "contradictory certainties." 319 Four of the five typologies (NR, WR, FR, and BR) expressed their opinions by marshaling science, but the legitimacy of the available science was disputed. Supporters of dam removal characterized the science supporting it as valid, whereas those who disagreed with dam removal characterized the science supporting removal as flawed. Those opposed to dam removal also offered up other scientific findings that countered dam removal as a sound management action.

NRs speak broadly about science, usually noting briefly that science supports dam removal, and they simply state this in a settled, matter-of-fact way - these commenters fail to acknowledge the many years of disputed science in the basin. Some NRs used precedent to support their statements that science supports dam removal, characterizing the events following dam removal on other rivers as positive and uniformly beneficial. BRs also use science to support their position, with one commenter stating that the river has been mismanaged and that science supports their suggested changes in water release timing and flow. WRs and WUMs contest the science used to support dam removal, arguing that "real science" proves dam removal will damage the river. WRs and WUMs consider the science supporting dam removal to be manipulated, fraudulent, or "predetermined." These commenters focus on the uncertainty surrounding removal, particularly with regards to the potential for damaging sediment release.

\footnotetext{
${ }^{318}$ Sarewitz, "How Science Makes Environmental Controversies Worse," 389.

${ }^{319}$ Ibid., 390; Schwarz and Thompson, Divided We Stand, 3.
} 
Commenters who contest science do not seem centrally concerned with science itself. Instead, the debate over science serves as a surrogate for defending larger value commitments as to whether dam removal is right or wrong. According to Kahan and Braman's cultural cognition model, "culture is prior to fact" meaning that people view the implications of policies and management decisions through the lens of their cultural worldview. ${ }^{320}$ This means parties in the conflict do not accept all facts as truth, but rather filter them according to a given view of the world. Kahan and Braman assert that citizens are not acting "duplicitously" when filtering facts, but rather taking the word of trusted people and institutions regarding the types of claims and data that are credible. ${ }^{321}$ The people and institutions that are trusted are naturally the ones who already share the values and worldview of the citizen. "As a result, even citizens who earnestly consider empirical policy issues in an open-minded and wholly instrumental way will align themselves into warring cultural factions. $" 322$

I observed similar sets of phrases and "truth claims" made in comments of a particular persuasion, which suggests that advocacy groups may have circulated fact sheets or sent out emails encouraging people to make public comments. While it is not possible to verify that this has occurred here, the possibility would make sense in light of Kahan and Braman's model: citizens who may not be able to digest the full volume of information on the dam removal proposal would rely on a trusted source of information, one that shares their cultural worldview, such as an environmental organization or irrigation board, to guide their opinion.

\footnotetext{
${ }^{320}$ Kahan and Braman, "Cultural Cognition and Public Policy," 150.

${ }^{321}$ Ibid., 151.

${ }^{322}$ Ibid.
} 
Kahan and Braman assert that factual claims are not evaluated on their individual merits, but are evaluated through "a powerful heuristic for identifying which positions to espouse or denounce" especially in the case of complex, technically oriented matters where citizens are bounded in their knowledge. ${ }^{323}$ The Klamath conflict, with decades of litigation, scientific reports, and a lengthy Draft Environmental Impact Statement (DEIS), fits this description. Many commenters made statements regarding the impossible length and technical density of the DEIS, and the short time span they were given to review it. My findings indicate that parties in the conflict turn to science to legitimize their positions, and by filtering those scientific findings through cultural lenses compile sets of "contradictory certainties." ${ }^{\prime 324}$ The result is fact flinging as parties dance around the inherently political questions at the root of the conflict.

The claims to the "accepted" science by NRs - and the discounting of that science by WRs and WUMs - is indicative of a larger struggle over what constitutes acceptable and legitimate knowledge. Science is the culturally dominant way of knowing nature, and it carries weight both in legitimizing decisions in the material world as well as legitimizing discursive constructions. ${ }^{325}$ It is perhaps not surprising that science is contested, but what is notable is that parties with divergent notions of what constitutes "good" and "true" science still reify science in the abstract sense and seek its legitimizing support.

Though commenters frequently invoked science and a claim to truth to support their positions, these technical or scientific statements were accompanied by, and intertwined with, value or moral-based assertions. This finding parallels Justin Farrell's observation that commenters writing about wolf reintroduction in the Greater Yellowstone Ecosystem "rarely

\footnotetext{
${ }^{323}$ Ibid., 163.

${ }^{324}$ Sarewitz, "How Science Makes Environmental Controversies Worse," 390.

${ }^{325}$ Fischer, Citzens, Experts, and the Environment; Scott, Seeing like a State.
} 
make Ecology arguments in isolation, but rather pair them with deeper meaning-making" statements. ${ }^{326}$ Taken in the context of the scientific and technically-based framing and understanding of environmental problems in the Klamath, these findings serve as both a reminder of the importance of questioning the framing and possible solutions for environmental controversies. In the Klamath, the focus on quantities of water needed to maintain fish, the timing of the flows, or whether or not water levels or dams themselves were implicated in fish declines only addresses part of the situation. Indeed, science and the type of knowledge it produces is valuable, but especially when in conversation with an approach that acknowledges sociocultural dimensions.

By framing the problem as simply one amenable to technical management, an opportunity is missed to incorporate different understandings of what constitutes problems and solutions, as well as to recognize the social position of science itself. In reframing the problems in the Klamath, new paths forward might become possible. As Matthew McKinney and William Harmon argue, while alternative problem framing may not address the underlying cultural and value differences, "it can help disputants focus on a common problem, which in turn fosters better working relationships and greater trust." ${ }^{327}$ However the problem is recast, the co-concurrence of scientific and value statements serves as a reminder of the importance of recognizing social factors at play, but also of paying attention to factors that make every environmental controversy unique. As Leah Wilds suggests in her description of water resource conflict resolution in Nevada, a "'one-size-fits-all' approach does not work. We need to tailor the approach to any given water conflict to the specific

\footnotetext{
${ }^{326}$ Farrell, The Battle for Yellowstone: Morality and the Sacred Roots of Environmental Conflict, 213.

${ }^{327}$ McKinney and Harmon, The Western Confluence: A Guide to Governing Natural Resources, 27.
} 
nature of that conflict. ${ }^{, 328}$ It seems that tailoring the restoration goals to the local context and recognizing that scientific knowledge claims are normative may further the social acceptability of restoration work in the Klamath. ${ }^{329}$

Writing about disputes over salmon restoration in the Skagit Valley of western Washington, Sara Jo Breslow attributes the contest over science not to science itself, fish declines, or loss of farms. "Rather, these are tangible proxies for defending more fundamental stakes: the places, identities, communities, and meanings that salmon and farmland make possible. ${ }^{{ }^{330}}$ Similarly, while science in the Klamath was disputed, it did not serve as the true locus for conflict. Just as ideas of nature help to shape the ways in which management actions are construed and the ways in which problems are framed, divergent senses of place also contribute to the ways in which commenters discursively construct the nature of nature in the Klamath Basin.

\section{Sense of Place}

Commenters expressed different senses of place and relations to the Klamath Basin. NRs spoke about the river as a generic or abstract ecological unit, with few commenters describing personal experiences in the river basin. NRs did not express concern about maintaining the existing local community, or describe specific ties or family history in the basin. While WRs characterize the downsides of dam removal in local and specific terms, NRs speak romantically and in sweeping terms about the benefits of dam removal to the river

\footnotetext{
${ }^{328}$ Leah Wilds, Water Politics in Northern Nevada: A Century of Struggle, 2nd ed., Wilbur S. Shepperson Series in Nevada History (Reno: University of Nevada Press, 2014), 113.

${ }^{329}$ R. Bruce Hull and David P. Robertson, "The Language of Nature Matters: We Need a More Public Ecology," in Restoring Nature: Perspectives from the Social Sciences and Humanities, ed. Paul H. Gobster and R. Bruce Hull (Washington DC: Island Press, 2000), 97-118.

${ }^{330}$ Breslow, "A Complex Tool for a Complex Problem," 317.
} 
and the natural community more broadly. Unlike NRs, WRs describe specific personal experiences in the basin and relate the river to their economic livelihood and identity. NRs speak of the river as an ecological unit, spanning the length of the river, while WRs speak of the relationship between a specific farm or ranch and the river. Thinking spatially, NRs and WRs conceive of the river-land relationship in different ways: NRs talk about the river as an entire connected unit, whereas WRs see the river as centrally related to a specific place or parcel of land.

FRs and WRs exhibit the strongest place attachment, talking about family or community ties to the river or a specific farm or ranch, and in this way the local community is constructed as a place based community, dependent on a particular relationship with the river. While both WRs and FRs described specific ways in which they had personally invested themselves in, or interacted with, the Klamath Basin, WRs discourse was strongly flavored by an economic perspective. FRs spoke about sustaining family heritage, as opposed to sustaining an economic relationship with the land.

While sharing other similarities with WRs, WUMs show the weakest sense of place, speaking broadly with little reference to any experience with the Klamath Basin. WUMs expand the threat from the local to the regional and national scale, linking local regulatory actions with a threatened western way of life and decline of national greatness. ${ }^{331}$ I see the lack of sense of place as a key factor differentiating the WR and WUM categories. "Rivers" is missing from the name because of the few substantive references to the river or the Klamath Basin, and while not a single commenter in the group referred to themselves as part

\footnotetext{
${ }^{331}$ Paystrup, “The Wolf at Yellowstone's Door: Extending and Applying the Cultural Approach to Risk Communication to an Endangered Species Recovery Plan Controversy" (Ph.D dissertation, Purdue University, 1993).
} 
of the wise use movement, the WUM typology adopts wise use movement discourse documented in the literature. ${ }^{332}$

I believe sense of place offers the most promise for reframing the dispute in the Klamath Basin in terms amenable to multiple parties. It is worth noting that both FRs and WRs demonstrated close ties to place, with their identity, community, and sense of place rooted in local particulars. Importantly, these two groups have differing opinions on dam removal. Recasting management options in terms of the potential benefits it can offer those who have personal investment in the river basin and its surrounding lands may be beneficial. This reflects other findings in the literature that demonstrate that the vehement responses to management plans stem from the threat of a shifting or disappearing place-based identity or way of life. ${ }^{333}$ Andrea Brandenburg and Matthew Carroll found that a place-based typology of stakeholders in a management planning process grouped together "individuals who said they identified with divergent primary groups, such as loggers and environmentalists. Thus, it was the experience of place instead of common group values that appeared to shape their environmental values and landscape meanings regarding the river drainage." ${ }^{334}$ Similarly, Breslow observed that stakeholders in the Skagit River controversy might be united through place and common ground rather than interests or perceived differences. ${ }^{335} \mathrm{~A}$ "politics of place" might be a useful starting point in reframing the dispute in the Klamath, and I believe

\footnotetext{
${ }^{332}$ Jacobs, "The Anti-Environmental 'Wise Use' Movement in America"; Wilson, "The Wolf in Yellowstone"; Paystrup, "The Wolf at Yellowstone's Door: Extending and Applying the Cultural Approach to Risk Communication to an Endangered Species Recovery Plan Controversy."

${ }^{333}$ Satterfield, Anatomy of a Conflict; Farrell, The Battle for Yellowstone: Morality and the Sacred Roots of Environmental Conflict; Andrea M. Brandenburg and Matthew S. Carroll, "Your Place or Mine?: The Effect of Place Creation on Environmental Values and Landscape Meanings," Society and Natural Resources 8, no. 5 (1995): 381-98.

${ }^{334}$ Brandenburg and Carroll, "Your Place or Mine?: The Effect of Place Creation on Environmental Values and Landscape Meanings," 391.

${ }^{335}$ Sara Jo Breslow, "Salmon Habitat Restoration, Farmland Preservation and Environmental Drama in the Skagit River Valley" (Ph.D dissertation, University of Washington, 2011).
} 
that this could offer a way to acknowledge that local concerns (particular the WR's) stem from not just cold economic calculations but a perceived loss of place and identity. ${ }^{336}$

I see an important distinction in the senses of place, one centered about the appropriateness of working in nature. NRs construct laboring in nature (farming, ranching) as amoral and destructive to the balance of nature. In contrast, FRs and WRs see nature as a space where labor is appropriate and meaningful. It appears that work in nature is related to the formation of place attachment, and perceptions of the moral appropriateness of working in nature appear to be related to constructions of nature.

\section{Work and Nature}

Work and nature are entangled in both the constructions of nature and the symbolic dimensions of the conflict. The contested relationship between work and nature is a theme that underpins the conflict in the Klamath, and while related to ideas of nature, the topic deserves a more explicit discussion. As Richard White argues, work and nature constitute "perhaps the most critical elements" in the debate over the environment ${ }^{337}$ In keeping with their view that nature is easily disturbed by human use, NRs suggest that people need to leave nature alone. Conversely, WRs and WUMs see human labor in nature as not only necessary because of a particular idea of nature, but because of the virtue and value that labor in nature produces. Even BRs and FRs express an understanding for the necessity of working in nature (but are more reserved about the virtues of doing so). Working in nature was an

\footnotetext{
${ }^{336}$ Antony S. Cheng, Linda E. Kruger, and Steven E. Daniels, “'Place' as an Integrating Concept in Natural Resource Politics: Propositions for a Social Science Research Agenda," Society and Natural Resources 16 (2003): 88.

${ }^{337}$ Richard White, ““Are You an Environmentalist or Do You Work for a Living?': Work and Nature," in Uncommon Ground: Toward Reinventing Nature, ed. William Cronon (New York: W. W. Norton \& Company, 1995), 172.
} 
emergent theme in the comments, and I see the question of what work is appropriate in the Klamath Basin as a silent contributor to the conflict.

As White observes in his essay "Are You an Environmentalist or Do You Work For a Living?", modern environmentalists tend to "disdain and distrust those who most obviously work in nature. ${ }^{338}$ This includes physical bodily labor that is found on the farm, in the forests, or at the manufacturing plant. This labor in nature is imagined to leave nature "poorer for it. Nature seems safest when shielded from human labor., ${ }^{339}$ In a similar way, the NR vision for the landscape is influenced, but perhaps more importantly, constrained by, their assumptions about the appropriateness of work in nature. This suspicion about work reproduces the dichotomy that environmental conflict is a choice between humans and nature, or jobs and the environment. If work in nature is the enemy of the environment, so too are farmers, loggers, and ranchers.

Yet work, as White points out, is hardly so mono-dimensional. Work in nature contributes to a way of knowing nature and understanding place that is unique, but is also accessible through leisure in nature, such as skiing, backpacking, and climbing. In those activities of play the actor becomes aware of their body in relation to nature, is conscious of the weather, and is alert to the topography and terrain. A similar phenomenon occurs as the laborer works in their fields or fells trees ${ }^{340}$ This interaction is more than an ephemeral experience in nature, but creates both a bodily and social knowledge. ${ }^{341}$ This knowledge, or "habitus," to use Pierre Bourdieu's term, "mediates between social structures and practical

\footnotetext{
${ }^{338}$ White, “'Are You an Environmentalist or Do You Work for a Living?': Work and Nature.”

${ }^{339}$ Ibid., 172.

${ }^{340}$ Ibid., 174.

${ }^{341}$ R. J. Johnston, Derek Gregory, and David M. Smith, eds., "Habitus," The Dictionary of Human Geography (Cambridge: Blackwell Pub, 1994).
} 
activity" and is negotiated through social practices including farming. ${ }^{342}$ In this way, work is not merely an economic activity, but contributes to identity, sense of place, and community. Indeed, WRs identify this importance of work in nature from both an economic and social identity standpoint, and reference the spotted owl regulations as displaying little respect for their local economy as well as their way of knowing nature through logging, ranching, and farming.

WUMs who assert that NRs wish to turn the river and surrounding lands into a wilderness also tap into the work in nature problematic. By constructing farmers and ranchers as amoral, NRs reproduce a tension between humans and nature, which Cronon notes in his “Trouble With Wilderness.” ${ }^{343}$ By characterizing wilderness as separate from human society, the wilderness (and larger environmental) movement ignores the inherent and necessary relationship between society and nature. Indeed, as Cronon observes, wilderness itself is a construct that can only exist in opposition to society. Isolating wilderness (and nature writ large) from society ignores the issues of work and livelihood that take place in nature.

There are several parallels between wilderness and the way NRs construct the river following dam removal. As with the construct of wilderness, human uses are secondary to the needs of nature, and there exists a blindness to the historical presence and use of nature by indigenous peoples. ${ }^{344}$ Though NRs acknowledge that Native American tribes have a claim to fish and water resources, they discursively construct the tribes as "dependents," to borrow Ingram et al.'s term, who are deserving of societal privileges and rights but lack the agency

\footnotetext{
${ }^{342}$ Ibid.

${ }^{343}$ William Cronon, "The Trouble with Wilderness: Or, Getting Back to the Wrong Nature," Environmental History 1, no. 1 (1996): 7-28, doi:10.2307/3985059.

${ }^{344}$ Mark David Spence, Dispossessing the Wilderness: Indian Removal and the Making of the National Parks (New York: Oxford University Press, 1999).
} 
and political power to obtain them. ${ }^{345}$ The narrative of a fallen pristine nature fails to account for the agency of tribal members both historically and today, and the NR desire for a river with no human influence is difficult to reconcile with both work in the landscape and the questions of social justice that face the tribes. Acknowledging that work and nature are not antithetical seems essential if environmental concerns expressed by those including the NR typology are to be compatible with agrarian ways of knowing nature.

The presence of the farmer in the West has indeed contributed to certain ways of knowing nature but, perhaps just as importantly, the farmer has also carried important symbolic weight. Just as the farmer represents Jeffersonian virtues and American individualism, fish migrating upstream represent the beauty and power of nature. The symbolic dimension of dam removal in the Klamath Basin is another important theme in understanding the conflict.

\section{Management Decisions Are Symbolic}

Much of this thesis has focused on nature as a construct, based in the realm of thoughts and ideas. While I wish to make the argument that the way we think and talk about nature matters, the discursive terrain itself influences the material ordering of nature, which has tangible implications. The preferred management outcomes professed by commenters will have material consequences in the Klamath Basin: no matter the course of action taken, fish may continue to encounter very physical barriers to migration, dam structures may be altered to better accommodate a spectrum of uses, or dams themselves may be removed, resulting in a cascade of effects both at the dam sites as well as downstream. Human users of

\footnotetext{
${ }^{345}$ Helen Ingram, Anne Schneider, and Peter Deleon, "Social Construction and Policy Design," in Theories of the Policy Process, ed. Paul A. Sabatier, 2nd ed. (Westview Press, 2007), 93-126.
} 
the river will also experience material impacts as a result of management changes. That being said, comments across all typologies demonstrate that management decisions are symbolic as well as material, and it is the symbolic nature of these decisions that engenders much of the debate over "the right thing to do." Dams simultaneously serve as sites of symbolic meaning and sites of conflict. Commenters discursively construct dam removal as much more than dam removal: removal represents a return to ecological wholeness (NRs); removal is a surrogate for the destruction of a way of life (WRs); dam removal is symbolic of loss of freedom, property rights, and American nationalism (WUMs). In this way, dams are more than dams - they are infused with material and symbolic meaning.

\section{Natural Rivers (NR)}

For NRs, dam removal represents the freeing of a river previously suppressed and the return of a complete, fully-functioning river. Dam removal also means the potential return of fish, another potent symbol. Seeing the return of fish to rivers is invested with similar symbolic meaning that is documented in the literature surrounding wolf reintroduction: like wolves, returning fish to the entire reach of the river is "a symbol of ecological reconciliation" for a river that has been abused. ${ }^{346}$ Dam removal is also symbolic of the descent of man and the promotion of nature: NRs are suspicious of productive uses of the landscape, holding the values of fish, biodiversity, and recreation higher than productive and agricultural uses. Just as NRs see the river through an ecological lens where all parts are connected, they also predict that dam removal will have a ripple effect on the ecosystem as well as the human community, automatically bringing positive change to both realms.

\footnotetext{
${ }^{346}$ Wilson, "The Wolf in Yellowstone," 463.
} 
Working Rivers (WR)

Just as NRs advocate for a free, unrestricted river, WRs advocate the same approach in regards to their ability to utilize nature for productive purposes. Management should not impinge on the "natural" capitalist market that those working on the land depend on. Dam removal symbolizes a threat to the virtuous agrarian lifestyle advocated by Jefferson and previously supported by the federal government. Dam removal is thus symbolic of both abandonment by government that had historically promised its support, as well as the destruction of a way of life and the community built around that way of life. Dams also serve as a sign of modernity, progress, and mastery over nature. ${ }^{347}$ Thus dam removal is symbolically construed by WRs as "going backwards." WRs draw on their experience with the spotted owl to point to a government that has failed their communities and their livelihoods, and for this group, dam removal represents the revival of spotted owl-like regulatory imposition by outsiders. In contrast to NRs who construe the ESA to be the best hope for the survival of fish and the river, WRs construe the ESA as a symbol of all that is wrong with government regulation and environmentalists. Concerns about the viability of rural communities both economically and culturally are bound up in dam removal, making the proposal represent an attack on a symbolic level.

\section{Wise Use Movement (WUM)}

While both WRs and WUMs construct dam removal as a threat to a virtuous way of life, WUMs construct the prospect of dam removal as a symbol of the decline of America

\footnotetext{
${ }^{347}$ Maria Kaika, "Dams as Symbols of Modernization: The Urbanization of Nature Between Geographical Imagination and Materiality," Annals of the Association of American Geographers 96, no. 2 (2006): 276-301.
} 
and an attack on all it stands for. Infringing on the economic freedoms of landholders via environmental regulation is untenable and represents an attack not only on the individual rights of citizens but an attack on the core of American values. Control of property rights by “outsiders" presents as a strong theme in WUM comments, and property rights are conceived of as a last stand against a capricious government perceived to be in cahoots with environmental groups. ${ }^{348}$ In the face of changing attitudes about the appropriate use of nature and the ability of environmentally minded groups to leverage legal and regulatory action, WUMs simultaneously ennoble those working on the land as virtuous, hard-working citizens struggling to survive, and vilify government as an oppressive communitarian regime seeking to "destroy" what has built America. Dam removal is seen as merely a surrogate for a wholesale takeover of property, leading to the loss of livelihoods, the individual, capitalism, and the decline of America. Government and environmentalists are seen by WUMs to challenge embedded and sacred ideals of private property and individual freedom.

These findings echo the literature about the symbolic nature of environmental conflict. Warren found that "larger sociocultural institutions" such as capitalism, the market economy, environmentalism, and the intrinsic value of nature infuse the debate over forest management. ${ }^{349}$ Similarly, Matthew Wilson found that in the battle over wolf reintroduction in the Greater Yellowstone Ecosystem (GYE), "wolves are merely symbols delineating the battle lines of a much larger conflict." ${ }^{350}$ Also examining wolves and the GYE, Patricia Paystrup observed that those who protest wolf reintroduction discursively construct wolves as more than a "flesh-and-fur risk," symbolically conflating hungry and dangerous wolves

\footnotetext{
${ }^{348}$ Wilson, "The Wolf in Yellowstone," 462.

${ }^{349}$ Warren, "What Is a Healthy Forest?: Institutional Logics and the Contest over Natural Resources Implications for Ecosystem Management and Socio-Ecological Theory," 178.

${ }^{350}$ Wilson, "The Wolf in Yellowstone," 453.
} 
with a predatory government prowling for a meal of property rights and constitutional liberties. ${ }^{351}$

Understanding dam removal as a proposal that carries symbolic weight is critical to understanding the vociferous opposition as well as the stalwart support for it. As demonstrated above, dam removal is about much more than just deconstructing cement structures, underscoring the importance of acknowledging the cultural dimensions present in the controversy. This symbolism, while powerful in its own right, becomes more meaningful in the context of, and in conversation with, the broader context of how humans make sense of the world and understand events that take place in it.

\section{Narratives, History, and Meaning}

One final theme worth noting is how commenters draw on larger ideas of the way the world works, told in narratives, to make sense of events in the Klamath. These narratives transcend the Klamath Basin spatially and temporally; the divergent perspectives are not isolated phenomena but rather speak to, and are in conversation with, larger cultural stories and histories. Narratives, defined as "meaningful accounts of human actions arranged into connected events," are more than just statements of historical happenings but are a way to communicate meaning, so as to produce an understanding, insight or explanation about how the world works. ${ }^{352}$ They are inherently moral, prescribing events and actors as good or bad, right or wrong, just or unjust. ${ }^{353}$

\footnotetext{
${ }^{351}$ Paystrup, "The Wolf at Yellowstone's Door: Extending and Applying the Cultural Approach to Risk Communication to an Endangered Species Recovery Plan Controversy."

${ }^{352}$ Farrell, The Battle for Yellowstone: Morality and the Sacred Roots of Environmental Conflict, 15; Smith, Moral, Believing Animals: Human Personhood and Culture.

${ }^{353}$ Farrell, The Battle for Yellowstone: Morality and the Sacred Roots of Environmental Conflict.
} 
Cronon suggests that narratives succeed because they mask "the discontinuities, ellipses, and contradictory experiences that would undermine the intended meaning of its story." ${ }^{354}$ When placed in the context of narrative, people make sense of dam removal by placing it into a storyline with actors, a beginning, and an end. Such a practice helps people to understand their place in the world, and what events mean. In the case of commenters discussing dam removal in the Klamath Basin, my findings point to the power of history in shaping the understanding of dam removal in the context of larger narratives.

Natural Rivers (NR)

The NR typology draws on larger narratives of a nature that was once a harmonious garden, but was then trampled by modern civilization. This viewpoint draws on a pristine nature sullied by humans, particularly white settlers, though indigenous uses and modification of nature is considered appropriate. A return to a "world of barely perceptible human disturbance" draws on the pristine myth and the notion of wilderness as an unpeopled nature. ${ }^{355}$ While WRs characterize the development of rivers and control of nature as progress, implying an upward trajectory, NRs see "progress" and the economic valuation of nature as a downward path toward a future where both nature and society is weakened because of greedy and foolish actions in relation to nature.

\footnotetext{
${ }^{354}$ Cronon, “A Place for Stories,” 1350.

${ }^{355}$ William M Denevan, "The Pristine Myth: The Landscape of the Americas in 1492," Annals of the Association of American Geographers 82, no. 3 (September 1992): 369; Cronon, "The Trouble with Wilderness: Or, Getting Back to the Wrong Nature."
} 


\section{Working Rivers (WR)}

WRs rely on a narrative that has been well documented by scholars of the West, wherein generations of hard-working settlers forged a living out of a harsh and unforgiving nature, overcoming all odds to live a virtuous, democratic life in the image of the yeoman farmer. ${ }^{356}$ The Jeffersonian narrative runs deep for this typology. To WRs, in the beginning was a landscape that deserved to be conquered and transformed, which became "a stage for human freedom" - terrain upon which the seeds of democracy might be planted ${ }^{357}$ With perseverance, the individual could scratch out a living against a hostile nature, but all of this changed as environmentalists and regulations devalued the rural lifestyle and economy. For WRs, the trajectory of the narrative is one of ascent, driven forward by progress - but now a hostile government instead of a hostile nature threatens the future. ${ }^{358}$ The WR narrative makes it possible to simultaneously construct government as unsympathetic while ignoring the contradictions in the history of reclamation in the West, where federal funding for, and construction of, reservoirs and dams made much of the West irrigable and inhabitable by Anglo settlers, homesteaders, and farmers. ${ }^{359}$

\section{Balanced Rivers (BR)}

BRs draw on the narrative popularized by Gifford Pinchot, who advocated for scientific management to "conserve" resources for multiple uses and for multiple generations. A belief in this narrative wherein management of nature can be optimized to

\footnotetext{
${ }^{356}$ Robert G. Athearn, The Mythic West in Twentieth-Century America (Lawrence, Kansas: University Press of Kansas, 1986); Fiege, Irrigated Eden: The Making of an Agricultural Landscape in the American West; Farrell, The Battle for Yellowstone: Morality and the Sacred Roots of Environmental Conflict.

${ }^{357}$ Cronon, “A Place for Stories,” 1362.

${ }^{358}$ Cronon, "A Place for Stories."

${ }^{359}$ Worster, Rivers of Empire: Water, Aridity, and the Growth of the American West.
} 
meet the needs of users pervades the BR view, and they simply advocate for more and better information to support management decisions. While NRs advocate for outside influence on management by way of dam removal and the ESA, BRs see continued bureaucratic, technical, and professional expertise as essential to managing nature, even while maintaining the dams on the river. This narrative draws on the failure of early yeoman farmers to succeed with civilian irrigation projects: while WRs see early farmers as virtuous pioneers of democracy, BRs draw on a historical narrative of civilians incapable of controlling nature without the help of government, science, and technology. The trajectory of this narrative is one of sustained upward progress from the inception of management, were technical expertise will account for any future problems that arise.

\section{Wise Use Movement (WUM)}

WUMs invoke "the people" to draw on narratives of democracy and Jeffersonian ideals, and their fundamental understanding of the way the world works revolves about the individual. By constructing environmentalists as outsiders in cahoots with government to take away fundamental rights, commenters in the WUM typology tap into deeply held narratives about the individual, the regional identity of the West, and America as a whole. For WUMs, private property is the foundation of American society. This belief ties into the belief asserted by both WRs and WUMs that the farmer must be present in the landscape, at nearly any cost, because of the virtues of the lifestyle and its relationship to democracy and the prosperity of the nation. ${ }^{360}$ Both WRs and WUMs draw on Jeffersonian agrarianism in

\footnotetext{
${ }^{360}$ Dixon and Hapke, "Cultivating Discourse."
} 
understanding work in nature to be both morally and economically superior. Jefferson believed that independent, landholding farmers were essential for democracy to flourish. ${ }^{361}$

A central focus of the WUM narrative is property. Property can be understood as both social and symbolic, and WUMs draw on Lockean and Jeffersonian narratives in espousing the virtues of holding property and laboring on it. Yet WUMs also draw on a nationalistic narrative that has a distinctive moral order to it. Nicholas Blomley observes, "when we talk about land and property, we are... engaging some deeply moral questions about social order... Does the state have a legitimate interest in regulating activities to advance environmental goals? Is private property defensible?" ${ }^{362}$ Indeed, the WUM narrative centers on the rise of the individual in a past wherein an individual was free to act as they wished in the bounded space known as property, freely engaging with the capitalist marketplace and enjoying the full freedoms and liberties that constitute America. WUM discourse weaves together strains of Turnerian frontier logic with Lockean ideas of the individual and property, drawing on the larger American project of appropriating and developing nature. ${ }^{363}$

In this way, the WUM narrative is one of ascents of the individual, freedoms, and America itself is rooted in private property. Like the NR narrative, this narrative tells a story of what was once great becoming contaminated - but instead of a pristine nature tainted by humans, for WUMs the ideal of the democratic individual, and the character of the nation itself, is threatened by government encroachment on all that is held dear. The trajectory of this storyline implies that not only will the individual citizen suffer, but America's place in the world will fall along with democracy, freedom, and capitalism.

\footnotetext{
${ }^{361}$ Ibid.

${ }^{362}$ Nicholas Blomley, "Law, Property, and the Geography of Violence: The Frontier, the Survey, and the Grid," Annals of the Association of American Geographers 93, no. 1 (2003): 122.

${ }^{363}$ McCarthy, "Environmentalism, Wise Use, and the Nature of Accumulation in the Rural West."
} 
One key conclusion to be drawn from these narratives is that the difference from the beginning of the story to the end allows the chance to "learn a lesson." Much as a parable ends with a lesson to take away for another day, narratives situate changes and events to characterize them as right or wrong, good or bad. Consider the NR and WR narratives: in the beginning was a nature pristine (NR) or wild and dark wilderness (WR) which, through “domestication," ends as a nature destroyed and damaged (NR) or reflective of the virtues of hard work (WR). As Cronon observes, "if the tale is of progress, then the closing landscape is a garden; if the tale is of crisis and decline, the closing landscape... is a wasteland."364 These narratives are important because they help people understand the meaning of the actions and frame events in moral terms. Indeed, the power of narratives lies in their ability to include certain people and events while excluding others. In this way, narratives contribute to the vision for the landscape - who belongs, and who does not. By discursively constructing a storyline that includes and excludes, the storyteller exercises power. These stories are told between people, and are produced and reproduced in the social world through our daily practices and institutions.

\section{$\underline{\text { Social Power and Defining Nature }}$}

If science is the hegemonic way in which knowledge about nature is produced, it follows that to claim this knowledge is also to claim the power that accompanies it. ${ }^{365}$ I see the contest over science, as well as the contest over the legitimacy of the ESA and government regulation, as a struggle for social power to define the landscape as a particular group sees fit. Historically, this balance of power favored those that constitute the WR and

\footnotetext{
${ }^{364}$ Cronon, “A Place for Stories,” 1370.

${ }^{365}$ David Demeritt, "Science, Social Constructivism and Nature," in Remaking Reality: Nature at the Millennium (New York: Routledge, 1998), 173-93.
} 
WUM typologies - typologies that discursively describe the dominant way of understanding, appropriating and relating to nature (and space, in a more abstract sense). Capitalism and the marketplace, the liberal individual, water rights, and private property as a way of ordering space via the Cartesian grid are all part of the hegemonic power structure, from which WRs and WUMs have historically benefitted.

While WUMs and WRs represent perhaps the "purest" form of this hegemony because they rely on the systems of property and rational science, NRs, FRs, and BRs also try to marshal dominant ways of knowing to support their vision for the landscape. FRs draw on the long-standing American tradition of keeping the agrarian in the landscape ${ }^{366}$ NRs and BRs both lay claim to science to support their ends, with BRs drawing on technical scientific management as the way to understand the world. In this way, BRs represent the hegemonic construction of nature as something to be known through science and manipulated as a mechanistic system. NRs perhaps embody the resistance to the long-standing "lords of yesterday" - laws, institutions, and ideas that promote an extractive use of nature in the West - but NRs also enjoy the support of national environmental legislation, changing attitudes about nature and dams, and recent victories in the courtroom. ${ }^{367}$ In this milieu I see shifting power flows between individuals and their social groups as well as more vertical power shifts as laws such as the ESA and disciplines such as ecology are granted additional cultural power. Older ideas, the laws and institutions that embody them, and the social groups that enact them, now must compete for power to define and order nature and the landscape to fit their vision for it.

\footnotetext{
${ }^{366}$ Dixon and Hapke, "Cultivating Discourse."

${ }^{367}$ Wilkinson, Crossing the Next Meridian.
} 
Summary

The conflict in the Klamath can be understood as divergent constructions of nature that have been embedded in discourse, institutionalized in federal policies, acts, and laws, and lived through social practices. Two particularly important and conflicting federal visions for nature are manifested in the legislation intended to further the development of nature and settlement of the American West and the environmental laws of the 1970s that forced consideration of the value of nature outside of anthropocentric and economic understandings. Federal agencies themselves represent this tension, as the Bureau of Reclamation's historical mandate to deliver irrigation water comes up against the National Marine Fisheries Service and Fish and Wildlife Service mandates to consider the implications of federal actions under the ESA. Changing access to legal, cultural, and social power by tribes and environmental groups challenges the nearly monolithic control that agrarian interests have had in shaping the discourse and producing space in the Klamath Basin. In defining nature and what it is good for, commenters draw on cultural narratives that transcend the Klamath Basin, invoking ideas of the democratic individual, virtuous pristine nature, deserving yeoman farmer, precisely managed resources, and sacred family heritage. These narratives help to shape the terrain upon which management actions are perceived, valued, and contested.

My aim in examining the sociocultural dimensions of environmental conflict in the Klamath Basin has not been to discount the real ecological and material effects that take place on the river and landscape as a result of farming or dams, but to illustrate how farming, dams, fish, and environmental changes are viewed through a normative lens which draws on conceptions of how nature is used to shape visions of how it should be. The social constructionist approach is not intended to imply that problems are unreal or that scientific 
knowledge is false - instead, it is my hope that this approach has shown how thoroughly bound facts and values are in the ways in which we perceive and frame true and false and right and wrong in the context of environmental decisions and management. ${ }^{368}$ Science and expertise is still valuable, especially as it compliments and contextualizes local knowledge. My point here is that science alone cannot answer the many important questions in the Klamath Basin alone - and an overreliance on science becomes problematic when it is a surrogate for fundamentally political choices. ${ }^{369}$ Additionally, the imposition of technical management from state and federal agencies can exacerbate conflict and ignore local complexity. ${ }^{370}$ Nancy Langston, writing about the Malheur Lake Basin of Oregon (east of the Klamath Basin), observes locals pushing back on the imposition of outside expertise, saying: "I live here, I know this land, I love this land. Who are you to tell me what I can and can't do on my land? You experts think you know more about my land than I do? You couldn't possibly!" ${ }^{371}$ Like Langston, I see a need for a more balanced approach between local knowledge and scientific expertise - neither one should be venerated at the expense of the other. For while locals can contribute context specific knowledge, science can provide other valuable knowledge about particular elements that locals may not be aware of, or perceive differently. Placing faith in one form of knowledge alone (whether that is technocratic management or traditional knowledge) ignores other ways of framing and understanding problems that might exist. ${ }^{372}$

\footnotetext{
${ }^{368}$ Demeritt, "Science, Social Constructivism and Nature."

${ }^{369} \mathrm{Nie}$, The Governance of Western Public Lands.

${ }^{370}$ Ibid.; Breslow, "Salmon Habitat Restoration, Farmland Preservation and Environmental Drama in the Skagit River Valley"; Scott, Seeing like a State.

${ }^{371}$ Nancy Langston, Where Land and Water Meet: A Western Landscape Transformed (Seattle: University of Washington Press, 2006), 160.

${ }^{372}$ Langston, Where Land and Water Meet.
} 
Breslow notes the power of acknowledging multiple ways of seeing problems: "In their choice of language and framings, managers are in a position to shift the terms of ecosystem recovery to address its full socioecological complexity." 373 This can offer the benefit of reframing the problems and contribute to understanding not just the problems as framed by each set of stakeholders, but also the areas of shared concern. By focusing on common threats to (all) the members of the community, areas of shared concern might be identified and provisions made to address those areas of concern. This will require parties to consider alternatives ways of understanding and framing the problem, and it will likely entail environmental groups that exist outside of the basin to take the time and energy to understand the perspectives of those who work and live within the basin - tribal members, conservationists, and agrarians alike.

Science also has an important role to play by helping to identify boundaries for what is "ecologically probable for a given place during a given time." 374 Acknowledging and incorporating the postmodern view of science as normative and limited need not diminish its utility in environmental problem solving. Instead of wholly abandoning science, the "challenge to all stakeholders is to help construct an environmental knowledge that is meaningful within ecological science and effective within environmental policy." 375 Conflicts between citizens, and citizens and experts, over whose knowledge is "best" misses the point that engaging in debates over management of nature is to engage in not just technical discussions but also the social lifeworld. I have attempted to demonstrate that the Klamath Basin conflict is a tournament of competing visions for the landscape, where ideas about

\footnotetext{
${ }^{373}$ Breslow, "A Complex Tool for a Complex Problem," 326.

${ }^{374}$ R. Bruce Hull and David P. Robertson, "Which Nature?," in Restoring Nature: Perspectives from the Social Sciences and Humanities, ed. Paul H. Gobster and R. Bruce Hull (Washington DC: Island Press, 2000), 302.

${ }^{375}$ Hull and Robertson, “The Language of Nature Matters: We Need a More Public Ecology,” 98.
} 
nature and the human place in it are championed through the expression of the "proper" management of that nature.

As I have demonstrated, ideas of nature, cultural narratives, and senses of place are both culturally embedded and meaningful, making management actions symbolic and meaningful beyond their immediate spatial and temporal context. Problem framing contributes to which groups are vilified and ennobled, and constrains the possible outcomes. While a social constructionist approach reveals the historical and cultural origins of conflict, it can also point to ways of re-envisioning nature such that both ecological and social concerns are addressed. Further, I have demonstrated that environmental controversies are rooted in much more fundamental differences than science alone is capable of recognizing, much less resolving. Environmental conflict in the Klamath Basin thus involves questions of not just true and false, fact and fiction, but of right and wrong, good and bad - tied up with history and law, culture and meaning, knowledge and power. Acknowledging the entanglements of these various factors seems essential to evolving approaches to deal with environmental conflict that address its complex political, social, and ecological dimensions. 


\section{Chapter 6: Conclusion}

"Nature is both a symbol and mirror, pointing the way and reflecting the past. When we look to nature for a moral compass, we may instead find a reflection of our own values. Rather than an impartial guide, we find something closer to a blank slate onto which we write our own meanings. Rather than a crystal ball, we find muddied reflections of our own assumptions and worldviews. Perhaps no other reason for valuing nature is more eagerly sought or hotly debated. ${ }^{376}$

It is July, 2013 and Jim and Caren Goold are worrying about their cows, their income, and the future of their Klamath Basin ranch. ${ }^{377}$ What is the source of their concern?

Water.

In June, state officials ordered irrigation water curtailments for the Goold ranch amid a drought emergency in the upper basin and a "historic assertion" of water rights by the Klamath Tribes. ${ }^{378}$ "It's beyond frustrating... We have all this wonderful water going by and we can't touch any of it," says Caren. ${ }^{379}$ In March 2013, the Klamath Tribes were granted "time immemorial" senior water rights, and old tensions simmer, as echoes of the events of 2001 remain fresh in the memories of locals. ${ }^{380}$ Some look forward to the

\footnotetext{
${ }^{376}$ Hull, Infinite Nature, 207.

${ }^{377}$ Scott Learn, "Water Squeeze in Oregon's Klamath Basin Pits Ranchers against Tribes, Both with Strong Ties to the Land," The Oregonian, July 6, 2013, http://www.oregonlive.com/environment/index.ssf/2013/07/water_squeeze_in_oregons_klama.html. ${ }^{378}$ Boxall, "Winners in Harsh Battle for Klamath River Water Claim Their Rights."

${ }^{379}$ Learn, "Water Squeeze in Oregon's Klamath Basin Pits Ranchers against Tribes, Both with Strong Ties to the Land."

${ }^{380}$ Tony Barboza, "Water War between Klamath River Farmers, Tribes Poised to Erupt," Los Angeles Times, May 7, 2013, http://articles.latimes.com/2013/may/07/local/la-me-klamath-20130507/2.
} 
removal of four dams, slated for 2020 , while others still vociferously oppose the plan. ${ }^{381}$ PacifiCorp spokesman Bob Gravely, speaking in the upper basin, observes “[u]p here, it's like dam removal is the end of civilization... Down river, the dams are the root of all evil. You can't convince people either way."382 As stakeholders look to the future, it appears that the cultural contest to define what water and the river should be used for is far from over. Assuming that dam removal does indeed occur in 2020 , negotiations over water allocation remain to be settled. If history is any indicator, those too will be fraught with conflict. As Stephen Most asserts, “it is clear that the notion that 'the West was won' is a myth." ${ }^{383}$ Nor is the Klamath Basin "one" as conflict continues. ${ }^{384}$ In light of the continuing disagreement about how water should be used, and who should decide, I see a growing need for approaches to the conflict that address conceptions of what nature is good for, and why. This research has been a start in that direction.

In this thesis I have offered a sociocultural perspective on the dam removal debate in the Klamath River Basin. This research has shown that commenter values are articulated discursively and are embedded in their conception of the proper course of management for the river. Through analysis of public commenter discourse, I discovered that commenters drew on culturally embedded ideas of nature to discursively construct dam removal as right or wrong. I also discovered that commenters framed problems in competing ways and drew on cultural narratives about how the world works to construe dam removal as both a material and symbolic management action. The conflict is about much more than "fish vs. farmers" or

\footnotetext{
${ }^{381}$ Will Houston, "Klamath River Dam Removal Plan on Track as Administration Shifts," February 28, 2017, http://www .times-standard .com/article/NJ/20170228/NEWS/170229795.

382 Jeremy P. Jacobs, "Republicans in Hot Seat over Landmark Deal for Dam Removal," E\&E News, March 13, 2017, http://www.eenews.net/stories/1060051348.

${ }^{383}$ Most, River of Renewal: Myth and History in the Klamath Basin, 258.

${ }^{384}$ Peter A. Walker, "How the West Was One: American Environmentalists, Farmers and Ranchers Learn to Say 'Howdy, Partner,'” Outlook on Agriculture 35, no. 2 (2006): 129-135.
} 
the scientific uncertainties of dam removal - it is about the various cultural lenses that commenters use to construe the meaning and implications of dam removal. My findings also point toward the importance of science as constituting access to social power to define what nature is and how it should be ordered. Despite their divergent views on appropriate river management, different typologies of commenters claimed that "true" scientific knowledge supported their position. This research complements the works of Warren, Wilson, and Farrell and adds to the discussion about the role of the social and cultural in environmental controversies. It addresses what Klamath Basin scholars Doremus and Tarlock have called the "source of the problem - the clash of cultures that must be resolved as the arid West confronts its future." 385

\section{Implications}

My findings point to the need for policymakers and resource managers to recognize that "wicked" environmental conflicts will not resolve themselves with more and better science. These conflicts draw on deeply embedded, socially constructed ideas about nature, the role of humans, and what constitutes "the good life." Those tasked with resolving environmental conflict should recognize that disputes such as the one in the Klamath are as cultural as they are technical. It seems unlikely that these morally-rooted conflicts will be "solved," but instead might be reframed to further respect or empathize with divergent ways of knowing. Constructions of nature are deeply rooted and as such, it may be difficult to achieve true social consensus on problems and solutions. ${ }^{386}$

\footnotetext{
${ }^{385}$ Doremus and Tarlock, "Fish, Farms, and the Clash of Cultures in the Klamath Basin," 287.

${ }^{386}$ Peter A. Walker, "How the West Was One: American Environmentalists, Farmers and Ranchers Learn to Say 'Howdy, Partner," Outlook on Agriculture 35, no. 2 (2006): 129-35.
} 
My findings indicate that disputes over the proper management on the Klamath River are less about scientific facts and more about underlying values and beliefs about what is and what should be. I believe that both stakeholders and managers would do well to recognize that science, however it is used, does not prove the necessity or virtue of a given management action. Commenters across categories intermingled statements about what is (using science) with what should be (values) - this co-occurrence suggests that facts and values cannot be cleanly disentangled and that the two influence one another in understanding the implications of management decisions. I agree with Warren that a key takeaway is the need for managers to "recognize that the 'ends' of management policy are socially, not scientifically, determined." ${ }^{387}$ Management plans and planning processes that recognize the interplay between cultural ideas and nature will be better complemented by the existing mechanisms for generating scientific information.

\section{Broadening the Scope}

These findings have some generalizable implications. A look at history serves as a reminder that the events in the Klamath Basin, both in recent years as well as in centuries past, are both locally unique and simultaneously reflective of a changing regional and national trajectory of thought. Ideas of nature have mattered a great deal in shaping the Klamath, as well as the American West. Cultural constructions of nature have remade nature in the image of the dominant discourse used to describe it, and these ideas remain layered atop one another, rearing their heads in the struggle to define and order nature. The landscape is never scraped clean of the human visions for it; rather the old and the new coalesce, much

\footnotetext{
${ }^{387}$ Warren, "What Is a Healthy Forest?: Institutional Logics and the Contest over Natural Resources Implications for Ecosystem Management and Socio-Ecological Theory," 188.
} 
as ideas of a robust nature and democratic farmer today mingle with conceptions of a fragile nature, in need of protection or careful management. The narratives we tell ourselves and each other are enduring and powerful.

Across the American West, local residents, policymakers, and resource managers grapple with reconciling conflicting mandates embodied in water rights entitlements, endangered species obligations, and economic development goals. Changing regional and national perspectives on what is important in the landscape and who is involved in the decision making process have historical roots and are institutionalized in laws, agency mandates, and cultural views. The region itself is changing too, leading scholars to speculate on what the "New West" might mean for the region. ${ }^{388}$ While the Klamath Basin may not attract as many of the amenity-seeking transplants as other charismatic locations in the West, the region remains linked to a changing national trajectory of reevaluating and contesting what nature is good for, why, and who gets to decide.

By talking to one another and, more importantly, listening to one another, I believe that it is possible to uncover the ways we construct nature, what constitutes the "good life," and why. In doing so, I agree with Hull et al. that through this process society "will be better able to engage in sophisticated discussion about which nature we want and why we want it if we have more explicit examples of the social constructions of nature, environmental quality, and desired future conditions." ${ }^{389}$ Martin Nie suggests, "instead of debating the meaning of nature and our place in it until we are blue in the face, let us just walk the ground and tell

\footnotetext{
${ }^{388}$ Richelle Winkler et al., "Social Landscapes of the Inter-Mountain West: A Comparison of 'Old West' and 'New West' Communities," Rural Sociology 72, no. 3 (2007): 478-501; William R. Travis, New Geographies of the American West: Land Use and the Changing Patterns of Place (Washington, DC: Island Press, 2007).

${ }^{389}$ Hull, Robertson, and Kendra, "Public Understandings of Nature: A Case Study of Local Knowledge About 'Natural' Forest Conditions," 338.
} 
each other what we like and don't like and then see what happens." ${ }^{390}$ While I appreciate Nie's practicality, this research suggests a relationship between the way we discursively construct nature, and the way we order it materially. As Purdy suggests, "It should be clear that, far from being frivolous make-believe, imagination is intensely practical. What we become conscious of, how we see it, and what we believe it means - and everything we leave out - are keys to navigating the world..."391 The way we understand nature and our role in it necessarily demands explicit discussion of these embedded ideas of nature.

\section{Limitations and Opportunities for Further Research}

It is worth mentioning some important limitations to my research design. This analysis is based on a selection of comments submitted over a short timespan, and on a single topic. As such, it serves as more of a snapshot rather than a comprehensive approach to commenter views. Additionally, the very format of the data presents some important limitations. Because the data were presented in the form of comments, I was limited to the information volunteered about both the subject matter and commenter demographics. This research could be both extended and enriched by ethnographic interviews with stakeholders wherein a more complete picture of their social and cultural "lifeworld" might be obtained. A more interactive approach would allow findings to be more generalized if the researcher had access to more of the demographic characteristics about the research informants.

This research also raises some important questions. What is the relationship between science and values? In a more practical sense, does raising awareness about the role of culture in the Klamath controversy actually contribute to moving forward to find mutually

\footnotetext{
${ }^{390}$ Nie, The Governance of Western Public Lands, 43.

${ }^{391}$ Purdy, After Nature, 7.
} 
agreeable solutions? How might policymakers better understand and apply these values and understandings? How might more opportunities be created to foster the expression and discussion of these values? Satterfield found stakeholders to be "delightfully articulate" about such topics when stakeholders had the appropriate context to express non-utilitarian views and describe "morally meaningful" viewpoints. ${ }^{392}$ One answer to the above question would be the development of a public opinion solicitation model that allows such expression.

\section{Conclusion}

I suggest that a better understanding of the cultural factors at work will allow those tasked with managing and designing policy for the Klamath River to focus in on some of the underlying drivers of conflict, rather than solely commissioning more scientific studies of fish disease transmission or river water levels. While these are valuable, they alone cannot move the conflict towards resolution. I agree with Doremus and Tarlock who assert, "there is no single 'right' or 'optimum' vision [for the Klamath]. The final political choice must, like the ecosystem itself, work and integrate with other systems at a variety of scales. It must recognize that the Klamath is both a unique and valuable natural system and a working landscape. ${ }^{, 393}$ Indeed, privileging a single vision for the landscape over others, as has historically occurred in the Klamath Basin and elsewhere, fuels conflict.

And that conflict may not be such a bad thing, especially as it sheds light on historically muted and marginalized communities, particularly the Native American tribes in the basin. Water governance makes clear that there will not always be win-win solutions, but I believe focusing on winners or losers misses the larger social and historical opportunities

\footnotetext{
${ }^{392}$ Satterfield, Anatomy of a Conflict, 171.

${ }^{393}$ Doremus and Tarlock, Water War in the Klamath Basin, 192.
} 
that conflicts such as this one offers. Though my analysis does not specifically link commenters with social groups, it is clear that tensions between users of the river have run high in the past and continue to simmer below the surface. Local landowners have felt marginalized by outside technical experts, and tribes are only beginning to have a powerful voice in the decision making process. If nothing else, all parties need to find ways to better understand the social and cultural spheres surrounding the Klamath conflict, which is at least a start toward respect and compromise, and a more just use of nature. Wherever water is concerned, no one user is truly isolated from the other. It is perhaps the fish themselves that have been the most powerful agents of change, upsetting the institutional and legal hegemony that irrigation and agriculture has had on the river. In doing so, the fish have divided people further, but also provided new opportunities for collaboration and cooperation, as well as a more equitable sharing of finite water. As Breslow observes, if fish "are the proverbial canary in the coal mine of the Pacific Northwest, then the lesson they are teaching us is clear: it is not only the fish that depend on a new integration of people and ideas, but so too do the increasingly complex interrelated ecological and social processes that we all depend on."${ }^{3994}$ Understanding and talking to one another, recognizing the role that embedded ideas of nature play, and questioning hegemonic systems of knowing and governing seem pregnant with possibility.

Purdy suggests, "because environmental lawmaking dedicates acreage and resources to visions of nature's value and our place in it, it unavoidably engages questions about what is valuable and how to live. ${ }^{395}$ Indeed, environmental management and governance translates ideas into reality, and the possibility of removing four dams serves as a reminder of

\footnotetext{
${ }^{394}$ Breslow, "Salmon Habitat Restoration, Farmland Preservation and Environmental Drama in the Skagit River Valley," 352.

${ }^{395}$ Purdy, After Nature, 285.
} 
the material implications of the way we think and talk about nature. Just as our ideas about nature have material implications for the landscape, so too do they implicate larger social questions about the "good life" and social power to decide. Environmental management decisions are thus interwoven with other political, social, and economic aspects - giving society all the more reason to have an explicit discussion about ideas of nature and the implications of those ideas.

How should this be done? Indeed, I have offered few tangible solutions. Much as a primary care doctor refers the patient to a specialist after the initial diagnosis, I will leave the development of specific policy guidelines to planners and managers who are far more qualified than I. However, it is my hope that this research offers a convincing argument that unpacking and deconstructing the discourse and cultural assumptions surrounding environmental controversy is worthwhile and productive amid the polarizing rhetoric that characterizes the events in the Klamath Basin as "fish versus farmers." To ignore the sociocultural dimensions of the dispute is to ignore the ways in which our ideas of nature both define and constrain visions for the appropriate use of nature.

In a complex, polarized, wicked conflict such as the one presented in the Klamath, the conflict between deeply held constructions of nature and values placed in salmon, science, capitalism, and agrarianism may not be resolved. Yet by articulating more expressly the varied ways in which we understand nature, and our relation to it, stakeholders, managers, and policymakers will be better equipped to negotiate a future to accommodate those understandings. Arguments about what is "natural" or what science "proves" provide cover for the values of people, not the values of the river. Constructions of nature constrain the possible future that can be negotiated: narrowly framing disputes as economics or 
environment misses the other natures and cultural values that may exist, and the possibilities they engender. 


\section{Bibliography}

Aguado, Edward, and James E. Burt. Understanding Weather and Climate. 5th ed. Upper Saddle River, New Jersey: Pearson Prentice Hall, 2010.

Athearn, Robert G. The Mythic West in Twentieth-Century America. Lawrence, Kansas: University Press of Kansas, 1986.

Baker, Alan R. H. “'The Dead Don't Answer Questionnaires': Researching and Writing Historical Geography." Journal of Geography in Higher Education 21, no. 2 (July 1997): 231-43. doi:10.1080/03098269708725427.

Barboza, Tony. "Water War between Klamath River Farmers, Tribes Poised to Erupt." Los Angeles Times, May 7, 2013. http://articles.latimes.com/2013/may/07/local/la-meklamath-20130507/2.

Barnes, Trevor J., and James S. Duncan. Writing Worlds: Discourse, Texts, and Metaphors in the Representation of Landscape. New York: Routledge, 1992.

Bernard, H. Russell. Research Methods in Anthropology: Qualitative and Quantitative Approaches. 4th ed. Lanham, MD: AltaMira Press, 2006.

Blankenbuehler, Paige. "A New Klamath Water Deal Emerges, but Unease Persists." High Country News, April 8, 2016. https://www.hon.org/articles/on-the-klamath-leaderscelebrate-dam-removal-but-unease-over-water-deal-persists.

Blomley, Nicholas. "Law, Property, and the Geography of Violence: The Frontier, the Survey, and the Grid." Annals of the Association of American Geographers 93, no. 1 (2003): 121-41.

Borden, Richard J. “Part I: A Social Scientist's Perspective." In Humans as Components of Ecosystems, edited by Mark J. McDonnell and Steward T. A. Pickett, 299-309. New York: Springer, 1993. doi:10.1007/978-1-4612-0905-8_23.

Bosselman, Fred P., and A. Dan Tarlock. "The Influence of Ecological Science on American Law: An Introduction." Chi.-Kent L. Rev. 69 (1993): 847.

Botkin, Daniel. Discordant Harmonies: A New Ecology for the Twenty-First Century. New York: Oxford University Press, 1990.

Boxall, Bettina. "Winners in Harsh Battle for Klamath River Water Claim Their Rights." Los Angeles Times, June 10, 2013. http://articles.latimes.com/2013/jun/10/local/la-meklamath-call-20130611.

Brandenburg, Andrea M., and Matthew S. Carroll. "Your Place or Mine?: The Effect of Place Creation on Environmental Values and Landscape Meanings." Society and Natural Resources 8, no. 5 (1995): 381-98.

Breslow, Sara Jo. "A Complex Tool for a Complex Problem: Political Ecology in the Service of Ecosystem Recovery." Coastal Management 42, no. 4 (July 4, 2014): 308-31. doi:10.1080/08920753.2014.923130. . "Salmon Habitat Restoration, Farmland Preservation and Environmental Drama in the Skagit River Valley." Ph.D dissertation, University of Washington, 2011. 
Campbell, Marcia C. "Intractability in Environmental Disputes: Exploring a Complex Construct." Journal of Planning Literature 17, no. 3 (February 1, 2003): 360-71. doi:10.1177/0885412202239138.

Carlson, Harry L., and Rodney Todd. "Effects of the 2001 Water Allocation Decisions on the Agricultural Landscape and Crop Production in the Klamath Reclamation Project." In Water Allocation in the Klamath Reclamation Project, 2001: An Assessment of Natural Resource, Economic, Social, and Institutional Issues with a Focus on the Upper Klamath Basin, 163-76. Special Report 1037. Corvallis, Oregon: Oregon State University Extension Service, 2002.

Carolan, Michael S. “Ontological Politics: Mapping a Complex Environmental Problem." Environmental Values 13, no. 4 (November 2004): 497-522.

Castree, Noel. Nature. Key Ideas in Geography. New York: Routledge, 2005.

Cawley, R. McGreggor. Federal Land, Western Anger: The Sagebrush Rebellion \& Environmental Politics. Lawrence: University Press of Kansas, 1993.

Cawley, R. McGreggor, and John Freemuth. "Tree Farms, Mother Earth, and Other Dilemmas: The Politics of Ecosystem Management in Greater Yellowstone." Society \& Natural Resources 6, no. 1 (1993): 41-53.

Chaffin, Brian C. "Reallocating Resources, Rebuilding Community: The Klamath Basin Agreements and the Emergence of Adaptive Governance." Ph.D dissertation, Oregon State University, 2014. http://ir.library.oregonstate.edu/xmlui/handle/1957/50604.

Cheng, Antony S., Linda E. Kruger, and Steven E. Daniels. "'Place' as an Integrating Concept in Natural Resource Politics: Propositions for a Social Science Research Agenda." Society and Natural Resources 16 (2003): 87-104.

Clark, Bradley T. "River Restoration in the American West: Assessing Variation in the Outcomes of Policy Change." Society \& Natural Resources 22, no. 5 (2009): 401-16.

Clarren, Rebecca. "No Refuge in the Klamath Basin." High Country News, August 13, 2001. http://www.hcn.org/issues/208/10647.

Collier, Michael, Robert H. Webb, and John C. Schmidt. Dams and Rivers: A Primer on the Downstream Effects of Dams. 2nd ed. U.S. Geological Survey Circular 1126. Denver, CO: U.S. Geological Survey, 2000.

Collingridge, David, and Colin Reeve. Science Speaks to Power: The Role of Experts in Policy Making. New York: St. Martin’s Press, 1986.

Congress of the United States. Water Use Conflicts in the West: Implications of Reforming the Bureau of Reclamation's Water Supply Policies. Congressional Budget Office, 1997.

Cooperman, Michael S., and Douglas F. Markle. "The Endangered Species Act and the National Research Council's Interim Judgment in Klamath Basin." Fisheries 28, no. 3 (March 2003): 10-19. doi:10.1577/1548-8446(2003)28[10:TESAAT]2.0.CO;2.

Creswell, John W. Research Design: Qualitative \& Quantitative Approaches. Thousand Oaks, California: Sage Publications, Inc, 1994. 
Cronon, William. “A Place for Stories: Nature, History, and Narrative.” The Journal of American History 78, no. 4 (March 1992): 1347-76. doi:10.2307/2079346.

- "Comment: Cutting Loose or Running Aground?" Journal of Historical Geography 20, no. 1 (1994): 38-43.

- "Introduction: In Search of Nature." In Uncommon Ground: Toward Reinventing Nature, 23-56. New York: W. W. Norton \& Company, 1995.

—. "Revisiting the Vanishing Frontier: The Legacy of Frederick Jackson Turner." The Western Historical Quarterly 18, no. 2 (April 1987): 157. doi:10.2307/969581.

—. "The Trouble with Wilderness: Or, Getting Back to the Wrong Nature." Environmental History 1, no. 1 (1996): 7-28. doi:10.2307/3985059.

- ed. Uncommon Ground: Rethinking the Human Place in Nature. New York: W. W. Norton \& Company, 1995.

Davis, Sandra K. "The Politics of Water Scarcity in the Western States." The Social Science Journal 38, no. 4 (2001): 527-542.

deBuys, William. Seeing Things Whole: The Essential John Wesley Powell. Washington DC: Island Press, 2001.

Demeritt, David. "Ecology, Objectivity and Critique in Writings on Nature and Human Societies." Journal of Historical Geography 20, no. 1 (1994): 22-37.

—. "Science, Social Constructivism and Nature." In Remaking Reality: Nature at the Millennium, 173-93. New York: Routledge, 1998.

Denevan, William M. “The Pristine Myth: The Landscape of the Americas in 1492." Annals of the Association of American Geographers 82, no. 3 (September 1992): 369-85.

Dhaliwal, Puneet. "Public Squares and Resistance: The Politics of Space in the Indignados Movement." Interface 4, no. 1 (May 2012): 251-73.

Dixon, Deborah P., and Holly M. Hapke. "Cultivating Discourse: The Social Construction of Agricultural Legislation." Annals of the Association of American Geographers 93, no. 1 (March 2003): 142-64. doi:10.1111/1467-8306.93110.

Doremus, Holly, and A. Dan Tarlock. "Fish, Farms, and the Clash of Cultures in the Klamath Basin.” Ecology LQ 30 (2003): 279.

- Water War in the Klamath Basin: Macho Law, Combat Biology, and Dirty Politics. Washington DC: Island Press, 2008.

Douglas, Mary. Natural Symbols: Explorations in Cosmology. Routledge, 1970.

Ehrlich, Gretel. "Surrender to the Landscape.” Harpers, September 1987.

Ehrlich, Paul R. The Population Bomb. New York: Ballantine Books, 1968.

Evernden, Neil. The Social Creation of Nature. Baltimore: The Johns Hopkins University Press, 1992.

Farrell, Justin. The Battle for Yellowstone: Morality and the Sacred Roots of Environmental Conflict. New Jersey: Princeton University Press, 2015. 
Fiege, Mark. Irrigated Eden: The Making of an Agricultural Landscape in the American West. Seattle: University of Washington Press, 1999.

Fischer, Frank. Citzens, Experts, and the Environment. 2nd ed. Durham: Duke University Press, 2002.

"Fish vs. Farmers." PBS NewsHour. Accessed November 7, 2015. http://www.pbs.org/newshour/bb/environment-july-dec01-fish_8-20/.

Frissell, Christopher A. "Topology of Extinction and Endangerment of Native Fishes in the Pacific Northwest and California (U.S.A.)." Conservation Biology 7, no. 2 (June 1993): 342-54.

Geertz, Clifford. The Interpretation of Cultures. New York: Basic Books, 1973.

Gibbs, Graham R. Qualitative Data Analysis: Explorations with NVivo. Philadelphia: Open University Press, 2002.

Gieryn, Thomas F. "A Space for Place in Sociology." Annual Review of Sociology, 2000, 463-496.

Gosnell, Hannah, and Erin Clover Kelly. "Peace on the River? Social-Ecological Restoration and Large Dam Removal in the Klamath Basin, USA." Water Alternatives 3, no. 2 (2010): 362 .

Graf, William L. "Dam Nation: A Geographic Census of American Dams and Their LargeScale Hydrologic Impacts.” Water Resources Research 35, no. 4 (April 1999): 130511 .

_. "Geomorphology and American Dams: The Scientific, Social, and Economic Context." Geomorphology 71 (2005): 3-26.

Greider, Thomas, and Lorraine Garkovich. "Landscapes: The Social Construction of Nature and the Environment." Rural Sociology 59, no. 4 (1994): 1-24.

Gunderson, Lance H., and C. S. Holling, eds. Panarchy: Understanding Transformations in Human and Natural Systems. Washington, DC: Island Press, 2002.

Hardin, Garrett. "The Tragedy of the Commons." Science 162 (1968): 1243-48.

Hardy, Thomas B., R. Craig Addley, and Ekaterina Saraeva. "Evaluation of Instream Flow Needs in the Lower Klamath River: Phase II." Logan, Utah: Institute for Natural Systems Engineering, Utah Water Research Laboratory, Utah State University, July 31, 2006.

Harris, Cole. "Power, Modernity, and Historical Geography." Annals of the Association of American Geographers 81, no. 4 (December 1991): 671-83.

Hays, Samuel P. Conservation and the Gospel of Efficiency: The Progressive Conservation Movement, 1890-1920. Cambridge: Harvard University Press, 1959.

Hickey, Maureen, and Vicky Lawson. "Beyond Science?: Human Geography, Interpretation and Critique." In Questioning Geography: Fundamental Debates, edited by Noel Castree, Alisdair Rogers, and Douglas Sherman, 314. Malden, Mass: Blackwell, 2005. 
Holton, Judith A., and Isabelle Walsh. Classic Grounded Theory: Applications With Qualitative \& Quantitative Data. Thousand Oaks, California: Sage Publications, Inc, 2017.

Houston, Will. "Klamath River Dam Removal Plan on Track as Administration Shifts," February 28, 2017. http://www.timesstandard.com/article/NJ/20170228/NEWS/170229795.

Hull, R. Bruce. Infinite Nature. Chicago, IL: University of Chicago Press, 2006.

Hull, R. Bruce, David Richert, Erin Seekamp, David Robertson, and Gregory J. Buhyoff. "Understandings of Environmental Quality: Ambiguities and Values Held by Environmental Professionals." Environmental Management 31, no. 1 (January 1, 2003): 1-13. doi:10.1007/s00267-002-2812-6.

Hull, R. Bruce, and David P. Robertson. "The Language of Nature Matters: We Need a More Public Ecology." In Restoring Nature: Perspectives from the Social Sciences and Humanities, edited by Paul H. Gobster and R. Bruce Hull, 97-118. Washington DC: Island Press, 2000.

. "Which Nature?" In Restoring Nature: Perspectives from the Social Sciences and Humanities, edited by Paul H. Gobster and R. Bruce Hull, 299-307. Washington DC: Island Press, 2000.

Hull, R. Bruce, David P. Robertson, and Angelina Kendra. "Public Understandings of Nature: A Case Study of Local Knowledge About 'Natural' Forest Conditions." Society and Natural Resources 14 (2001): 325-40.

Hull, R. Bruce, David P. Robertson, David Richert, Erin Seekamp, Gregory J. Buhyoff, and others. "Assumptions about Ecological Scale and Nature Knowing Best Hiding in Environmental Decisions." Conservation Ecology 6, no. 2 (2002): 12.

Hurley, Daniel M. "Political Ecology of the 2001 Water Crisis in the Upper Klamath Basin: A Case Study in Narrative Policy Analysis." M.S. thesis, University of Oregon, 2004.

Huston, Shaun. "Defining the West." Lecture, Western Oregon University, January 6, 2014.

Ingram, Helen, Anne Schneider, and Peter Deleon. "Social Construction and Policy Design." In Theories of the Policy Process, edited by Paul A. Sabatier, 2nd ed., 93-126. Westview Press, 2007.

Jacobs, Harvey M. "The Anti-Environmental 'Wise Use' Movement in America." Land Use Law 47, no. 2 (February 1995): 3-8.

Jacobs, Jeremy P. "Republicans in Hot Seat over Landmark Deal for Dam Removal." $E \& E$ News, March 13, 2017. http://www.eenews.net/stories/1060051348.

Jehl, Douglas. "Cries of 'Save the Suckerfish' Rile Farmers' Political Allies." The New York Times, June 20, 2001. http://www.nytimes.com/2001/06/20/us/cries-of-save-thesuckerfish-rile-farmers-political-allies.html.

Jenkins-Smith, Hank, Carol L. Silva, Kuhika Gupta, and Joseph T. Ripberger. "Belief System Continuity and Change in Policy Advocacy Coalitions: Using Cultural 
Theory to Specify Belief Systems, Coalitions, and Sources of Change." Policy Studies Journal 42, no. 4 (2014): 484-508.

Johnston, Barbara Rose. "The Political Ecology of Water: An Introduction." Capitalism Nature Socialism 14, no. 3 (September 2003): 73-90. doi:10.1080/10455750308565535.

Johnston, R. J., Derek Gregory, and David M. Smith, eds. "Discourse.” The Dictionary of Human Geography. Cambridge: Blackwell Pub, 1994.

, eds. "Habitus." The Dictionary of Human Geography. Cambridge: Blackwell Pub, 1994.

Kahan, Dan M., and Donald Braman. "Cultural Cognition and Public Policy." Yale Law \& Policy Review 24 (2006): 147.

Kaika, Maria. "Dams as Symbols of Modernization: The Urbanization of Nature Between Geographical Imagination and Materiality." Annals of the Association of American Geographers 96, no. 2 (2006): 276-301.

Kellert, Stephen R. The Value of Life: Biological Diversity And Human Society. Washington, D.C.: Island Press, 1997.

Kempton, Willett M., James S. Boster, and Jennifer A. Hartley. Environmental Values in American Culture. Cambridge, Mass.: The MIT Press, 1996.

Kirsch, Scott. "John Wesley Powell and the Mapping of the Colorado Plateau, 1869-1879: Survey Science, Geographical Solutions, and the Economy of Environmental Values." Annals of the Association of American Geographers 92, no. 3 (2002): 54872.

Knopfler, Mark. Brothers In Arms. Vol. Brothers In Arms. Warner, 1985.

Krippendorff, Klaus. Content Analysis: An Introduction to Its Methodology. 2nd edition. Thousand Oaks, Calif: Sage Publications, Inc, 2003.

Kurz, Tim, Ngaire Donaghue, Mark Rapley, and Iain Walker. "The Ways That People Talk about Natural Resources: Discursive Strategies as Barriers to Environmentally Sustainable Practices." British Journal of Social Psychology 44, no. 4 (December 2005): 603-20. doi:10.1348/014466604X18064.

Lachapelle, Paul R., Stephen F. McCool, and Michael E. Patterson. "Barriers to Effective Natural Resource Planning in a 'Messy' World." Society \& Natural Resources 16 (2003): 473-90.

Lange, Jonathan L. "The Logic of Competing Information Campaigns: Conflict over Old Growth and the Spotted Owl." In A Wolf in the Garden: The Land Rights Movement and the New Environmental Debate, 135-50. Lanham, Maryland: Rowman \& Littlefield Publishers, 1996.

Langston, Nancy. Where Land and Water Meet: A Western Landscape Transformed. Seattle: University of Washington Press, 2006.

Layzer, Judith. The Environmental Case: Translating Values into Policy. Washington, D.C.: CQ Press, 2012. 
Learn, Scott. "Water Squeeze in Oregon's Klamath Basin Pits Ranchers against Tribes, Both with Strong Ties to the Land." The Oregonian, July 6, 2013.

http://www.oregonlive.com/environment/index.ssf/2013/07/water_squeeze_in_orego ns_klama.html.

Lefebvre, Henri. The Production of Space. Translated by Donald Nicholson-Smith. Malden, Mass: Blackwell Pub, 2000.

Leopold, Aldo. A Sand County Almanac. New York: Oxford University Press, 1987.

Levy, Sharon. "Turbulence in the Klamath River Basin.” BioScience 53, no. 4 (2003): 315320.

Limerick, Patricia. Something in the Soil: Legacies and Reckonings in the New West. New York: W. W. Norton \& Company, 2001.

Macnaughten, Phil, and John Urry. Contested Natures. Theory, Culture \& Society. Thousand Oaks, Calif: SAGE Publications Ltd, 1998.

Maher, Neil M. Nature's New Deal: The Civilian Conservation Corps and the Roots of the American Environmental Movement. Oxford University Press, 2008.

Marston, Ed. "Reclaiming the Spirit of Reclamation." Nat. Resources J. 44 (2004): 681.

McCarthy, James. "Environmentalism, Wise Use, and the Nature of Accumulation in the Rural West." In Remaking Reality: Nature at the Millennium, 126-49. New York: Routledge, 1998.

_. "First World Political Ecology: Lessons from the Wise Use Movement." Environment and Planning A 34, no. 7 (July 2002): 1281-1302. doi:10.1068/a3526.

McKinney, Matthew, and William Harmon. The Western Confluence: A Guide to Governing Natural Resources. Washington DC: Island Press, 2004.

McKinney, Matthew, and John E. Thorson. "Resolving Water Conflicts in the American West." Water Policy 17, no. 4 (August 2015): 679-706. doi:10.2166/wp.2015.146.

McMahan, Ethan A., Jaime M. Cloud, Patrick Josh, and Michaell Scott. "Nature With a Human Touch: Human-Induced Alteration Negatively Impacts Perceived Naturalness and Preferences for Natural Environments." Ecopsychology 8, no. 1 (March 2016): 54-63. doi:10.1089/eco.2015.0068.

Miles, Matthew B., and A. Michael Huberman. Qualitative Data Analysis: An Expanded Sourcebook. 2nd ed. Thousand Oaks, Calif: Sage Publications, Inc, 1994.

Miller, Char, ed. Cities and Nature in the American West. The Urban West Series. Reno, Nevada: University of Nevada Press, 2010.

Milstein, Michael. "The Press Portrayed the Story as Fish vs. Farmers. But the Klamath River Story Is a Whole Lot More Complicated than That.” Nieman Reports, 2002.

Most, Stephen. River of Renewal: Myth and History in the Klamath Basin. Portland, Oregon: Oregon Historical Society Press, 2006. 
Muir, John. "The Yellowstone National Park.” The Atlantic, April 1898.

http://www.theatlantic.com/magazine/archive/1898/04/the-yellowstone-nationalpark $/ 376185 /$.

Nash, Roderick Frazier. Wilderness and the American Mind. 4th ed. New Haven: Yale University Press, 2001.

National Academies Press (U.S.), ed. Endangered and Threatened Fishes in the Klamath River Basin: Causes of Decline and Strategies for Recovery. Washington, D.C: National Academies Press, 2004.

National Research Council (U.S.), and National Academies Press (U.S.), eds. Hydrology, Ecology, and Fishes of the Klamath River Basin. Washington, DC: National Academies Press, 2008.

Nehlsen, Willa, Jack E. Williams, and James A. Lichatowich. "Pacific Salmon at the Crossroads: Stocks at Risk from California, Oregon, Idaho, and Washington." Fisheries 16, no. 2 (1991): 4-21.

Neuman, M. “Klamath River Basin.” Map. USBR Klamath Basin Area Office, September 1999.

Nie, Martin. "Drivers of Natural Resource-Based Political Conflict." Policy Sciences 36, no. 3/4 (2003): 307-41.

- The Governance of Western Public Lands: Mapping Its Present and Future. Lawrence: University Press of Kansas, 2008.

Oregon Water Resources Department. "The Oregon Water Resources Department Completes Klamath River Basin Adjudication (1975 2013),” March 7, 2013. http://www.oregon.gov/owrd/ADJ/docs/2013_03_07_Klamath_River_Basin_Adjudic ation_Media_Release_Final.pdf.

Pagel, Martha O., Dick Bailey, Weston J. Becker, and Scott Perry. "Resolving The Klamath." Oregon Water Resources Department, October 1999.

Paystrup. "The Wolf at Yellowstone's Door: Extending and Applying the Cultural Approach to Risk Communication to an Endangered Species Recovery Plan Controversy." Ph.D dissertation, Purdue University, 1993.

Peterson, Jodi. "The Endangered Species Act's Biggest Experiment: Will an Unprecedented Collaborative Effort and Lots of Tax Dollars Be Enough to Finally Save Sage Grouse?" High Country News, August 17, 2015.

http://www.hcn.org/issues/47.14/biggest-experiment-endangered-species-act-sagegrouse.

Peterson, Tarla Rai, and Cristi Choat Horton. "Rooted in the Soil: How Understanding the Perspectives of Landowners Can Enhance the Management of Environmental Disputes." Quarterly Journal of Speech 81, no. 2 (May 1995): 139-66.

Powell, J. W. "Report on the Lands of the Arid Region of the United States, with a More Detailed Account of the Lands of Utah." Washington DC: Government Printing Office, 1879. 
PRISM Climate Group. “30-Year Normal Precipitation: Annual, Period: 1981-2010.” Accessed February 10, 2017. http://www.prism.oregonstate.edu/normals/.

Proctor, James D. "The Social Construction of Nature: Relativist Accusations, Pragmatist and Critical Realist Responses." Annals of the Association of American Geographers 88, no. 3 (September 1998): 352-76. doi:10.1111/0004-5608.00105.

—. "Whose Nature? The Contested Moral Terrain of Ancient Forests." In Uncommon Ground: Toward Reinventing Nature, edited by William Cronon, 269-97. New York: W. W. Norton \& Company, 1995.

Purdy, Jedediah. After Nature: A Politics for the Anthropocene. Harvard University Press, 2015.

Reisner, Marc. Cadillac Desert: The American West and Its Disappearing Water. Revised edition. New York, N.Y., U.S.A: Penguin Books, 1993.

Rittel, Horst W. J., and Melvin M. Webber. "Dilemmas in a General Theory of Planning." Policy Sciences 4, no. 2 (1973): 155-169.

River of Renewal. Pikiawish Partners, 2009.

Robbins, Paul, John Hintz, and Sarah A. Moore. Environment and Society: A Critical Introduction. 1st ed. Malden, Mass: Wiley-Blackwell, 2010.

Robbins, William G. Landscapes of Conflict: The Oregon Story, 1940-2000. Seattle: University of Washington Press, 2004.

- Landscapes of Promise: The Oregon Story, 1800-1940. Seattle: University of Washington Press, 1997.

Rykbost, Kenneth A., and Rodney Todd. "An Overview of the Klamath Reclamation Project and Related Upper Klamath Basin Hydrology." In Water Allocation in the Klamath Reclamation Project, 2001: An Assessment of Natural Resource, Economic, Social and Institutional Issues with a Focus on the Upper Klamath Basin, 45-68. Oregon State University Extension Service, 2002.

Sabin, Paul. The Bet: Paul Ehrlich, Julian Simon, and Our Gamble over Earth's Future. New Haven: Yale University Press, 2013.

Saldaña, Johnny. The Coding Manual for Qualitative Researchers. 1st ed. Thousand Oaks, Calif: Sage Publications, Inc, 2009.

Sarewitz, Daniel. "How Science Makes Environmental Controversies Worse." Environmental Science \& Policy 7, no. 5 (October 2004): 385-403. doi:10.1016/j.envsci.2004.06.001.

Satterfield, Terre. Anatomy of a Conflict: Identity, Knowledge, and Emotion in Old-Growth Forests. Vancouver: East Lansing: Michigan State University Press, 2003.

Schwarz, Michiel, and Michael Thompson. Divided We Stand: Re-Defining Politics, Technology, and Social Choice. Philadelphia: University of Pennsylvania Press, 1990.

Scott, James C. Seeing Like a State: How Certain Schemes to Improve the Human Condition Have Failed. New Haven: Yale University Press, 1999. 
Shaw Historical Library. A River Never The Same: A History of Water in the Klamath Basin. 2nd ed. Klamath Falls: Oregon Institute of Technology, 1999.

Sheridan, Thomas E. "Embattled Ranchers, Endangered Species, and Urban Sprawl: The Political Ecology of the New American West." Annual Review of Anthropology 36, no. 1 (September 2007): 121-38. doi:10.1146/annurev.anthro.36.081406.094413.

Smith, Christian. Moral, Believing Animals: Human Personhood and Culture. New York: Oxford University Press, 2003.

Smith, Michael D., and Richard S. Krannich. “'Culture Clash' Revisited: Newcomer and Longer-Term Residents' Attitudes Toward Land Use, Development, and Environmental Issues in Rural Communities in the Rocky Mountain West." Rural Sociology 63, no. 3 (2000): 396-421.

SocioCultural Research Consultants, LLC. "Dedoose,” 2017. dedoose.com.

Spence, Mark David. Dispossessing the Wilderness: Indian Removal and the Making of the National Parks. New York: Oxford University Press, 1999.

Steel, Brent, Peter List, Denise Lach, and Bruce Shindler. "The Role of Scientists in the Environmental Policy Process: A Case Study from the American West."

Environmental Science \& Policy 7, no. 1 (February 2004): 1-13.

Stegner, Wallace. Beyond the Hundredth Meridian: John Wesley Powell and the Second Opening of the West. 1992nd ed. Hammondsworth: Penguin Books, 1954.

Steinberg, Ted. Down to Earth: Nature's Role in American History. New York: Oxford University Press, 2002.

Stoddart, Mark C. J. Making Meaning out of Mountains: The Political Ecology of Skiing. Vancouver: UBC Press, 2012.

Stone, Deborah A. "Causal Stories and the Formation of Policy Agendas." Political Science Quarterly 104, no. 2 (Summer 1989): 281-300.

Strauss, Anselm L., and Juliet Corbin. Basics of Qualitative Research: Grounded Theory Procedures and Techniques. Newbury Park: Sage Publications, Inc, 1990.

The Associated Press. "Deschutes Basin Farmers Worry Spotted Frog Lawsuit Could Restrict Irrigation Water." The Oregonian, February 10, 2016. http://www.oregonlive.com/environment/index.ssf/2016/02/deschutes_basin_farmers _worry.html.

Travis, William R. New Geographies of the American West: Land Use and the Changing Patterns of Place. Washington, DC: Island Press, 2007.

Tuan, Yi-Fu. Space and Place: The Perspective of Experience. Minneapolis: University of Minnesota Press, 1977.

U.S. Department of the Interior. "Individual Comments." Draft EIS/EIR, March 28, 2017. https://klamathrestoration.gov/sites/klamathrestoration.gov/files/Additonal\%20Files\% 20/1/4/Volume\%20III_Individual.pdf. 
U.S. Department of the Interior, and California Department of Fish \& Game. "Klamath Facilities Removal Final EIS/EIR: Volume III Comments and Responses," December 2012.

Van Koppen, C. S. A. "Resource, Arcadia, Lifeworld. Nature Concepts in Environmental Sociology." Sociologia Ruralis 40, no. 3 (2000): 300-318.

Vandergeest, Peter, and E. Melanie DuPuis. "Introduction." In Creating the Countryside: The Politics of Rural and Environmental Discourse, edited by E. Melanie DuPuis and Peter Vandergeest, 1-25. Conflicts in Urban and Regional Development. Philadelphia: Temple University Press, 1996.

Vincent, Carol Hardy, Laura A. Hanson, and Carla N. Argueta. "Federal Land Ownership: Overview and Data." Congressional Research Service, March 3, 2017. https://fas.org/sgp/crs/misc/R42346.pdf.

Wagner, Eric. "Washington Welcomes Wolves Back - across Deep Political Divides." High Country News, October 26, 2015. http://www.hcn.org/issues/47.18/washingtonwelcomes-its-wolves-back-across-deep-political-divides.

Walker, Peter A. "How the West Was One: American Environmentalists, Farmers and Ranchers Learn to Say 'Howdy, Partner." Outlook on Agriculture 35, no. 2 (2006): 129-135.

Walker, Peter, and Louise Fortmann. "Whose Landscape? A Political Ecology of the 'Exurban' Sierra." Cultural Geographies 10, no. 4 (2003): 469-91.

Warren, William. "What Is a Healthy Forest?: Definitions, Rationales, and the Lifeworld." Society \& Natural Resources 20, no. 2 (2007): 99-117. doi:10.1080/08941920600901890. . "What Is a Healthy Forest?: Institutional Logics and the Contest over Natural Resources - Implications for Ecosystem Management and Socio-Ecological Theory." Ph.D dissertation, Washington State University Department of Natural Resource Sciences, 1998.

Watkins, Ceri. "Representations of Space, Spatial Practices and Spaces of Representation: An Application of Lefebvre's Spatial Triad." Culture and Organization 11, no. 3 (2005): 209-20.

Watts, Simon, and Paul Stenner. Doing Q Methodological Research: Theory, Method and Interpretation. Thousand Oaks, California: Sage Publications, Inc, 2012.

Weber, Bruce, and Bruce Sorte. "The Upper Klamath Basin Economy and the Role of Agriculture." In Water Allocation in the Klamath Restoration Project, 2001: An Assessment of Natural Resource, Economic, Social, and Institutional Issues with a Focus on the Upper Klamath Basin. 1037. Oregon State University Extension Service, 2002.

White, Richard. “'Are You an Environmentalist or Do You Work for a Living?': Work and Nature." In Uncommon Ground: Toward Reinventing Nature, edited by William Cronon, 171-85. New York: W. W. Norton \& Company, 1995. 
Wilds, Leah. Water Politics in Northern Nevada: A Century of Struggle. 2nd ed. Wilbur S. Shepperson Series in Nevada History. Reno: University of Nevada Press, 2014.

Wilkinson, Charles F. Crossing the Next Meridian: Land, Water, and the Future of the West. Washington, D.C.: Island Press, 1992.

Williams, Raymond. “Ideas of Nature.” In Problems in Materialism and Culture, 67-85. London: Verso, 1980.

- Keywords: A Vocabulary of Culture and Society. New York: Oxford University Press, 1976.

Williams, Ted. "Salmon Stakes.” Audubon 105, no. 1 (2003): 42.

Wilson, Matthew A. "The Wolf in Yellowstone: Science, Symbol, or Politics? Deconstructing the Conflict between Environmentalism and Wise Use." Society \& Natural Resources 10, no. 5 (September 1997): 453-68. doi:10.1080/08941929709381044.

Winkler, Richelle, Donald R. Field, A. E. Luloff, Richard S. Krannich, and Tracy Williams. "Social Landscapes of the Inter-Mountain West: A Comparison of 'Old West' and 'New West' Communities.” Rural Sociology 72, no. 3 (2007): 478-501.

Winner, Langdon. The Whale and the Reactor: A Search for Limits in an Age of High Technology. Chicago: University Of Chicago Press, 1989.

Worster, Donald. Nature's Economy: A History of Ecological Ideas. 2nd ed. Cambridge; New York, NY, USA: Cambridge University Press, 1994.

- Rivers of Empire: Water, Aridity, and the Growth of the American West. Cambridge: Oxford University Press, 1985.

—. Under Western Skies: Nature and History in the American West. New York: Oxford University Press, 1992. 


\section{Appendix I: Public Comments}

This appendix contains selected public comments and oral testimony used as the data set for this thesis research. It is included here for the interested reader and as a resource for additional research projects. Refer to Chapter Four for details about the comment collection process. The number preceding each comment corresponds with the numbering system used in Chapter Four.

(82) I started what was One-Stop Auto Wreckers 35 years ago after completing four years of study at OIT, so I have been in the community a while. I've also been a Klamath Falls city council member for 17 of the last 25 years. But I'm not here to represent the city or my constituents. I've been opposed to the KBRA since the idea's inception because I believe in hydropower. To me, taking out dams is counterproductive to what we should be doing. Cheap electricity is what built industry and farming in the Klamath Basin and the Pacific Northwest. Without cheap electricity, the Klamath Project could never have been as productive as it is. And guess what? Hydropower is renewable. This billion-dollar boondoggle known as the KBRA is unfair to the farmers, electric ratepayers, and the American taxpayer. Without a change to the ESA, the farmers are not helped by the KBRA. We, in this community, have watched as ESA in its protection of the spotted owl decimated the timber industry. I'm not willing to stand by and let the same thing happen to agriculture. I believe that the information being used to push the KBRA is slanted and being handled in the same manner as was done in the San Joaquin Valley. A federal judge recently issued a scathing judgment of what took place in San Joaquin with the ESA and the delta smelt. In response to this judgment, U.S. Representative Devin Nunnes sent a letter to Secretary Ken Salazar, chastising him and his department for their abuse of the process, and the Obama administration for pushing the green agenda at any cost. Save our dams, amend the ESA, stop rural cleansing.

(83) I am an outsider from Montana but don't think it is a good idea to remove the dams. There must have been a reason to build them in the first place.

(23) This note is in support of maintaining the natural ecosystem and health of Upper Klamath Lake and the entire Klamath Basin. Not only is this ecosystem important to millions of migratory birds as well as year-round animals, it is a unique source of wild edible microalgae. This algae supports the health of tens of thousands of consumers; as a harvestor and manufacturer, Simplexity Health supports the financial health of several thousand people, world-wide. Please protect the lake and all it stands for.

(21) I support the proposal to remove four dams on the Klamath River in OR and CA and restore over 420 miles of salmon habitat. As I understand it, this could become the largest dam removal project in the world, and while not perfect - it is the best solution currently available to save the Klamath -and the salmon that need a healthier river system. As someone 
that held an international family reunion in the Klamath watershed a few years ago and enjoys visiting the region, I look forward to this project proceeding.

(20) Please adopt option 2, removal of all 4 dams on the Klamath River. It is past time for a sensible and sustainable approach to the river. Go for option 2 for our future and our children.

(84) I don't have much to say, but I have been upset mostly about this KBRA and all its facilities. I think it is ridiculous to tear out dams that are creating electric power for us to use, that we need herein the basin. At the same time, President Obama is talking about creating new power that will cost us millions of dollars to create, and I think it's just plain ridiculous to remove dams that are creating power for us. Now, I read in the paper today that there is a new power plant being constructed up on Shore Road. I don't know anything about it, but I just think we should keep our present dams, enjoy the power we get from them, and God bless the fish.

(65) I support alternative 2 within the draft dam removal EIS/EIR - full removal of four Klamath River dams. The draft EIS/EIR correctly shows that alternative 2 is the best option for fisheries restoration, job creation, and the reduction of toxic pollution. Option 2 is supported by a growing body of scientific research and best serves the public interest.

(18) Breach the 4 Klamath River Dams!!! It only serves as a cause of Deterioration of the Water Quality!!

(17) I am 32 years old. I have spent most of my life in this area. I was born on the South Fork of the Salmon River and grew up up there and in Scott Valley, and I've spent the last few years outside of Orleans. I support Option 2, which is complete dam removal. And for one thing, the Klamath River, most of the summer, isn't fit to even swim in, and that's - I think that's one main indicator that there is a problem with the river. The salmon runs are incredibly diminished, and, personally, I don't -- I catch trout in the lakes, but I don't even try and fish in the river, just because there aren't enough. And I know that the Karuk Tribe can't even catch enough fish to feed their people, and that I see as a major problem. I know some folks have an issue with the KBRA. But whatever those issues are, I don't think they're big enough to put a stop to this process. The fish don't have time. It's already going to be 2020 by the time the dams come out, which, hopefully, they will. We can't wait any longer. And so, I think we need to move forward with Option 2. Thank you.

(85) We want to strongly urge that the dams on the Klamath River NOT be torn down because to do so would be to destroy a great source of green energy and would be very 
harmful to both wildlife and the agricultural endeavors that depend on a predictable source of water...to say nothing of the damage that silt and flood waters would cause downstream.

(19) I support alternative 2 within the draft dam removal EIS/EIR - full removal of four Klamath River dams. The draft EIS/EIR correctly shows that alternative 2 is the best option for fisheries restoration, job creation, and the reduction of toxic pollution. Option 2 is supported by a growing body of scientific research and best serves the public interest.

(15) I am in favor of removing the dams and letting the Klamath River go back to its ancestral river status. Thank you for allowing me to write to you regarding the potential Copco Lake dam removal on the Klamath River. I have two comments: ONE) I have heard it said that there is no scientific evidence that the salmon will return to the upper reaches of the Klamath after dam removal. Yet every time I offer proof, no one in the "do not remove the dams group" returns my calls or answers my emails. I lived in Maine in 1999 when the Edwards Dam was removed from the Kennebec River. It was estimated that though the river had been dammed for 160 years, the Atlantic Salmon would return after 5 to 10 years. THE ATLANTIC SALMON RETURNED IN THE FIRST YEAR! I saw it with my own eyes. Anyone needing sci ly fly to Maine, go to the Kennebec River and LOOK DOWN. TWO) I have researched what happened to the local Maine economy after dam removal and local tourism, fishing, boating, etc. It has almost all been positive following dam removal. Reading some of the listed Websites will even give first hand accounts of riverfront (formerly lakefront) homeowners and their impressions of dam removal. You will read from many riverfront homeowners who had been against dam removal and who are now very pleased with the post-dam results. Please do the following Google search for many Websites with the above scientific proof. Google the following: Edwards Dam removal on the Kennebec River Thank you for allowing me to make comment on this issue.

(86) To Whom It May Concern: REASONS FOR THE KLAMATH RIVER DAMS [4] MUST BE SAVED! DO NOT DESTROY THEM, NOW OR EVER! Dams must be saved to: - Save the salmon and all the fish - Save ESA listed eagles and their habitat in the Tulelake Refuge, which will be devoid of water. Other reasons: - An estimated 22 million cubic yards of toxic sediment will sludge its way down the Klamath River destroying salmon runs, mucking up the environment affecting water clarity and purity! This amount of sediment will sterilize the river for 100 years. - Real science now proves original statements are fraudulent - It has been admitted this is an "experiment" - we can't afford this kind of experiment! - The four hydro-electric dams have been producing enough for 70,000 homes and businesses AND has potential to produce enough to power 150,000 - How will it be replaced? This is a true green electricity. There are alternatives to aid returning salmon past the dams BUT the federal agencies and CA DFG will not consider them. The settlement agreement does not appear to provide any assurances that the irrigation water inside or outside the Klamath Project will be delivered. Additional in-stream flows for the Klamath River will put 30,000 acre feet of irrigation water 
diverted to the Rogue Valley in Oregon AT RISK! - Feds will be paying out millions of TAX PAYER money, besides cost of dam removal there will be millions spent in grants for fake and fraudulent RESTORATION. - Several federal and state agencies will spend \$63 million on restoration projects on the Sprague, Williamson and Wood rivers; $\$ 67$ million for the fringe wetlands around Upper Klamath Lake and fish diversions for the Keno Dam; \$92 million for water conservation and ground water management; $\$ 47$ million is budgeted for acquisition of lease of water rights, water conservation and land management programs; and $\$ 7$ million for modification of dikes on the Wood River. A total of \$385 million would support implementation of the water deal - things like paying for farmers to idle land and not farm, provide lower power rates to pump water, $\$ 65$ million for tribal economic development and environmental management; each tribe will also get $\$ 14$ million for fisheries management. The Salmon River Restoration Council will get $\$ 10$ million for their projects. -The Klamath tribe would like fishing rights on the Klamath River from Iron Gate to Interstate 5. This tells me that they don't expect the fish to get to Klamath Falls where their territory is, and they also get $\$ 21$ million to purchase the Mazama Forest. The wildlife refuges get more water. There is $\$ 100$ million budgeted to acquire water on a year-to-year basis for environmental needs.

(128) I urge you to reconsider your plan to destroy Klamath river dams. It is the wrong thing to do. Would you feel differently if this was in your own backyard?

(14) I recommend option 2, full removal of the dams on the Klamath River. This will be the best option for fish, and it will result in restoration of a healthy river free of toxic algae and warm water. It will also provide good jobs.

(129) I am writing you regarding the Draft Environmental Impact Report (DEIR) and the Draft Environmental Impact Statement (DEIS). I support the farmers and ranchers of Southern Oregon and Northern California. I do not understand why our government would go to the measures it has planned to hurt good people barely making a living off their land. What is proposed by the Department of the Interior will be the final blow to an already decimated area economically. The Federal Government is planning to destroy four dams on the Upper Klamath River. One in southern Oregon; the other three in northern California. Allegedly, it is to save the Coho salmon. According to people in the area, dam removal will wipe out clean, affordable, electrical power to 70,000 homes, release tons of sediment from behind the dams and make the river less reliable for irrigation; the river will be a mere stream in the summer, a flood threat in the spring, and toxic. Already government policies have removed miners and loggers from the area; now the target is ranchers and farmers. One reason California is in such bad shape economically is because of government policies in our rural areas. It's time to stop any more destruction of our rural communities and their economies. The Coho salmon are not native to the Klamath and were planted in the river in the late 1800's. Coho are not natural to the Klamath and yet millions of fish produced at the Iron Gate fish hatchery are not included in the river population because they are not considered natural. Coho typically spawn within 30 miles of the ocean; first dam on the 
Klamath is 187 miles upstream. I believe it was intended by the federal government to excluded 40,000 Siskiyou County residents and their local, elected representatives in the Klamath River Dam removal meetings. Also, four tribes exist in the Klamath Basin - the Shasta, Karuk, Yurok, and Hupa; the Shasta have been left out of all agreements and their sacred burial grounds will be destroyed when the dams are breached. If they had a voice in this matter it would not have gone this far.

But the agenda is not to comply democratically with people it is to rule people. This to me is obviously a California ABAG agenda, better known at Agenda 21 as stated on the very clearly UN Agenda 21 web site. In the United States, we are not governed by man nor by nature, we are governed by laws. You have broken our laws and ignored the residents. Where will these people go? How will they get electricity? Do you simply want to move them to relocation camps? Then what? What is your plan? DO NOT REMOVE THE 4 DAMS AT UPPER KLAMATH RIVER.

(130) I can not express enough how important it is that the destruction of this dam or others throughout California is creating havoc, loss of jobs, loss of propery and stable economic enviroment. Turning back to the days of complete wilderness is ridiculous and damaging to communities everywhere. Please DO NOT proceed with these plans that have to do with the Agenda 21, and the United Nations take over over all our sovereignty

(108) Thank you for your letter of May 5, 2011 on behalf of Secretary of Interior, Ken Salazar. It is unfortunate that our CZAR's in Washington are TOO busy to look at our problems here on the Klamath River in California and Oregon. I don't blame any one group over another, whether it be County, State, Federal, timber, gold, agriculture, Indian. Chinese, Irish, Italian, or English. THIS IS AN AMERICAN PROBLEM. We are all now Americans. The problem and opportunities we face today in this beautiful area, was created by GOD; climate and nature for many centuries. The Indian Tribes got to the area second after the cave man, then came the white man, each in their own way, mistreating the Klamath River, the life blood and economic heart of the area The economics of the area since the 1850 's to the current time, has gone from gold to timber \& now cattle \& hay. Having said that. it is true that "He who has the Gold makes the rules", so the gold mines played out @\$37 an ounce and is now $\$ 1600$. We can't even recreationally mine in the River according to California Fish \& Game. Our economy has spir aled down and the only real value we have is the real estate. In the name of endangered species, the "spotted owl" issue closed 47 saw mills and created NO NEW JOBS, thus heavy unemployment. To this day. over $20 \%$ are on unemployment or on permanent disability. I understand that southern Oregon has most of the same problems. Siskiyou County is the 5th largest geographic county in California and arguably the most scenic in the state. We have the same population, as of 1964 census, of about 44,000 . Our economy is so bad that when our children grow up. if they have any get up $\&$ go, they leave to make a living. They don't want to go, but they have no choice. This applies to the Indian as well as Caucasians. We have no jobs!! It only takes a few cowboy's (or girls) to run the cattle ranches. So we produce nothing that our local Walmart or grocery stores can buy and when we spend a dollar in the county it is sent out within 24 hours. Yes, even the Walmart payroll goes out the day after payday. Siskiyou county, I understand, is the 
biggest employer next to the US Forest Service. They produce nothing for the future economy; we export our dollar \& our childen. I use this preamble to go beck a., reference to my letter (File MP 1-40, ADM 1-10) of 4-22-2011 and your letter ofMay 5, 2011. I came to Siskiyou County starting in the late 70's. Fishing which WAS \& IS great. I only bought my property in 2001. It was my desire to build a tourist recreation vacation spot I bad been made aware of the above facts and thought I could make a difference by sharing the recreation aspects of the River and Iron Gate Lake. The RV Park gets many visitors from all over \& tell us. and others about the beauty of the area, clean air and green. trees. The stars at night $\&$ the sun rises arc beautiful coming over the eastern mountain. Take a hike up to the area where a lodge has been planned and see seven bends in the Klamath River, Mt. Shasta \& Pilot Rock. It is no wonder the Department of Interior wants to make a Monumeot down river. Y oubave alteady closed the forest roads \& if you close the Monument. as you have Soda Mouotain, we will only be able to view it from the AIR or as pedestrians. Yes, my dream for the future is going down in a spiral because of the Dam removal My business plan calls for 40 plus employees and in my Golden years, leaving something for future generations. Your letter of May 5, 2011, said that ${ }^{\circ}$ the sub-teams have reviewed the January, 2011, Federal Emergency Management Age:DCJ Flood Zone Map A which shows your property within a flood mne however. it is poSSI\}lc the sub-team are unaware of ALL of the available information that exists about your propeytf". Ms. Rhea Graham, Progmm Manager, is to contact me, but as of this writing, I have not heard from her, so I am attaching the FEMA report of September 29, 2004, stming • with the Iron Gate Dam in place, there was a 1 $\%$ chance of flooding in any given year. Certainly with the Dam out. we would go back to pre 1962 flooding and low flow in September \& October (salmon run). I am sending this infonnation along to you at this time because it appears that the sub committee referred to above, arc trying very hard to prove the scooping that was done with the stakeholders Was and IS fact (whether true or not) and would require dam removal. It seems to have become HOW not WHEN the dams are removed. I refer you to the Klamath Basin Coordinating Council annual report (copy attached) of May 3, 2011. Please review them carefully. Who will make up for the next 50 years on the Council that will represent the Property Owners and rate payers????? (Only one (1) for the county?) This all starts with the endangered Sucker Fish (2004) to Cobo Salmon (2010). FEMA started the scoping process for relicensing Iron Gate Dam. Now they can't or won't supply determination letter on my property (see attachment). May 16, 2011 Department of Interior has turned the scoping over to USGA (because they are the scientific division of government.) At the Klamath Falls Fisheries Meeting, the leader says and explains that they will tum all material to Independent Experts to validate whether to recommend lo Secretary Ken Salazar. keeping or closing the dams. We, the public \& property owners, won't have any input or ex pens to help verify findings and only 30 days to even contemplate what is going to happen. In my opinion, the Independent experts are going to follow the gold \& formulate the goal of the Department's wishes which only represents the STAKE HOLDERS. No County coordination at the table. Our County held and informational election \& $80 \%$ voted to keep the dams. My property has become very de-valued and un-saleable with just the publicity of possible dam Removal. With no comparable sales, we are all under water. Even if it takes 10 years for dam removal it will continue to go down in value. Most of us bought for long-term, but many are being foreclosed on because they can't sell. The economy is down now, but won't recover soon with the dam removal being studied. PLEASE, coordinate with our local officials and get some 
local input. We need the real estate being developed for recreational \& upper end retirement level income. The County won't economically be capable of surviving. If the Dams come down we will, in effect, by the actions of the Department of the Interior, will have our property taken by condemnation. The Tribes get more dollars from BIA, Dept. of Agriculture, California Indian Gaming, etc. than our County tax income will have to run the County. I thank you, and request a face to face meeting with the sub-committee to exchange FACTUAL information as it relates to economic \& real estate devaluation.

(87) I'll read this because I don't want to be misquoted at any point. My wife and I have the Klamath Ranch Resort, one-half mile below Iron Gate Dam. I want to congratulate you, Mr. Lynch, the US California Fish and Game and the Klamath Restoration Group who seem to be totally dedicated to this project as individuals and government bodies they represent. However, as my father used to say, beware when a man comes to the door and says hi, I'm here from the government, and I am here to help. It looks as if you have strayed a long way from your objective, your official Klamath Hydroelectric Settlement site, and I will read it so you can compare the thoughts that have come up tonight. The Klamath Hydroelectric Settlement Agreement and the related Klamath Basin Restoration Agreement, KBRA, provide a framework for the removal of four Klamath River dams by 2020, contingent on the Congressional approval. Because the KBRA is non-severable from the KHSA, the secretarial determination process, including an environmental review under the National Environment Policy Act and the California Environmental Quality Act will include consideration of the combined impact of cost of both these agreements on fish population and the human communities. Efforts leading to a secretarial determination will follow the two separate but interrelated tracks of study. The first track is a set of scientific studies focused on determining whether the benefits of dam removal and implementation of the KBRA will advance fish population, will be in the public interest, can be done within the state cost cap, and can be done without any major unintended consequences. That's the end of the quote. There will be many unintended consequences. You have only addressed fish and water and some of the people, the tribal issues have been addressed. How about the loss of health, economic values of homes, ranch lands, farm lands, timber, recreational benefits? Over 246,000 people were estimated to use the fish and skiing and camping alone. Here are just a few more costs. You seem to have settled on the state cost to remove the dam of $\$ 400$.

(88) I can't understand with the economy like it is, we're fourteen trillion dollars in debt, how is this thing ever going to go through? Who can pay for it? Our communities are starving for money, our state's starving for money. Where does the money come from? And then to remove those dams doesn't make any sense at all. We need clean energy. Why did our forefathers ever build those dams in the first place? Would Klamath Falls, with everything we have in this community, even exist without those dams prior to now? There is no real guarantees in this KBRA as to are we really going to get a full allocation to water as the ESA takes precedence. And then after the judge's decision in the San Joaquin Valley -- that was a real nice presentation that you gave us -- but how do we really trust those figures? And then on top of that I'm already being charged in my electric bill for 
taking those dams out. Now, I wouldn't mind that money is taken out of my power bill if it was going to be for fish ladders. And I think most of the people in the community would say that's a good deal, we will buy fish ladders and fix those dams. But to be charged for taking them out without even -- I never even agreed to do that. It was just shoved down my throat like so many other things that are being done nowadays. It's ridiculous. Thank you for hearing me.

(13) I'm here tonight as a proponent of dam removal and restoration. I live and work on Upper Klamath Lake. I've been here for some 20 years. Back in the early '90s, I, along with 30 some other stake holders in the Basin, was appointed by then Senator Hatfield to work on these very issues. For the better part of 10 years we met monthly and wrestled with all these issues we're here talking about tonight. Restore tens of thousands of acres of wetlands, riparian habitat in Upper Basin. We brought a little more dialogue and certainty to the community. But there is a lot of work that still needs to be done as you're getting an ear full tonight. One of the things I was most pleased with working on the Hatfield Upper Basin working group was the acknowledgment and ultimately the deciding by Secretary Babbitt, former Secretary of the Interior, acknowledging that the four federal working advisory groups in the Basin would work collaboratively together to support each other's efforts. Heretofore, prior to that, there was a real division of Upper Basin and Lower Basin, very little dialogue up and down the street. It was illustrated by the four dams. We signed the agreement to cooperate and for the first time in a long time we started having meetings based on taking a true ecosystem approach to looking at our Klamath Basin resources. So I see both the efforts are going forward today to further that effort, and it looks like a good thing -- I think I speak with pretty much the consensus of what's left of the Hatfield group. Many of them are here tonight, they put in the time. I think are going to be supportive of your efforts in this Alternative 2. I think the thing that's most exciting for me beyond that is the ability to take some ownership and participate in what will become the biggest river restoration project anywhere ever. That is so exciting this day and age when water is becoming such a critical and devastatingly abused and overused resource. We can really cut some new ground here, and lead the way; put Klamath in a position not just to secure our own well-being here but can serve as a model for watersheds throughout the world for wise use and management for our aquatic resources. Thank you very much.

(12) Just remove the dams yesterday. Should never been built!

(135) I would first like to thank everybody for showing up and listening to our comments tonight. We also appreciate time out of your hands to come up here. I am a third-generation rancher, I have my farm inside the Klamath Reclamation Project, and when I say, "third generation," I'm trying to be third generation. 2001 was almost "it" for us, and I would like to see my ranch go through my life as well. And with this settlement, I believe that it gives me more of a consistent supply of water. And for future generations, I think that's a benefit to us all. Thank you very much. 
(11) Dam removal is an immediate necessity to protect the remaining runs of steelhead and salmon. In this day and age of technology and renewable energy hydropower is unnecessary and hurtful. There are other ways of providing irrigation as well.

(131) The country is BANKRUPT! The President is out preaching we need to spend Billions to build infrastructure to save the country. You are proposing to spend Billions to destroy infrastructure. The dams produce good clean electricity such as that needed to power casinos. I can tell you wind and solar as replacement for the hydroelectric power from these dams in a joke. If you don't believe this drop all the government subsidies and see how long these "Alternative Energy Solutions" last. I [illegible] dam removals and associated KBRA are a disguised attempt by several small/special interests groups, aligned with agendas tanging from personal enrichment, to driving citizens off their private property, to sending Oregon water to overpopulated Southern California. Removal of these dams will destroy a functioning ecosystem which has been in place for nearly 100 years. Hundreds of thousands of animals will be killed in the process. And why? No, not to save the fish as is being used for the excuse (since it will only harm fish). But, because a few greedy humans want to line their pockets and increase their power and control over their fellow citizens. Dam removal is not only wrong on all levels it is insane on all levels. Do not do it!

(89) I am opposed to the KBRA Settlement. I am outlining several areas I would like to speak to. I believe the dams should stay in, there is not a replacement for the electricity they generate to be replaced, not by solar or wind. This hydro power is clean and efficient and what is available to us in this Basin. Also I believe if the dam removal was off the table, there would be viable options for the fish to make it upstream, also until the water qualify [sic] which is naturally occurring in Klamath and Agency Lake, can be cleaned up, if it can, this is the fish' [sic] major problem. I do not believe that buying the Tribe the 90000 acre tree farm is equitable or even should have a place at the table. I do not see what the Tribe is giving up only what we are giving up, giving up reliable power sources for something we don't know what, only that it will cost us a lot. I see this as the $1 \mathrm{wt}$ baby steps of the Tribe moving forward with their agenda of getting their Tribal lands back, I think the Public should have a say in this, it's weird that this is even in a water settlement. They can go on and on about their history, their Spiritual ties to the land, the fish, the timber etc., but what about my ties, My grandparents parents immigrated from Germany, we have been a generational ranch with our Emotional and Spiritual ties to the land and the job of raising food for our Nation and our World, where do I come out with something to protect my rights to traditionally use water for irrigation and food and beef production? Again, the Government powers and courts should not have a right to give my rights and interests away to another group. No matter what the Tribe says, they did vote, they were paid etc. They have been given Tribal status and all that that implies. Also I resent the funding by the Federal Government, it's a lot of money that the US Government does not have. Ultimately us as taxpayers, foot these bills, and in these lean and trying times, I don't see how something with the price tag can be promoted much less funded. Again I resent that money would go here and not to more fundamental things like feeding America, housing America, helping the poor etc. One last trend I see having lived here many years, is more and more agricultural farm land is being retired from fanning, 
either being bought by wetlands or special interest groups, or farmers selling their water to these same interests, Again, where does this money to buy this water at such a high rate come from? It's in direct competition with farming/ranching. When a rancher sells his water, rents pasture for his cattle at the highest prices we've ever seen, and make more money on selling his water than keeping his cows on his own ranch, that is not right. Without the government dollars this could not happen, again, another reason Special Interest Groups are breaking our Country. If this KBRA agreement is followed there will be even more farmland retired, there comes a point where the Basin will not survive, the Jogging business is gone, the stores and shops have left in a lot of cases, what happens when farming is a long gone source of employment? I have more comments but will end for today, I hope these comments means something, that they aren't just for show with all the decisions already having been made, making this a mockery to take testimony etc.

(10) I unconditionally support option 2 -- full dam removal.

(132) We are 4 generations living on, in, and with the Klamath immediately below where the dams now exist and at the focal point of dam rhetoric. Years of seeing vast amounts of current science and documented history submitted by 'public comment' have failed to show a single change in the predetermined direction of this unaccountable special interest experiment. Therefore, I am submitting detailed comments regarding the Executive Summary and EIS separately and will here address the ethics component. Lets briefly recap this process to date. KBRA meetings which occurred In secret demanded unsupported preconditioned agreement to dams' removals and the tiered hierarchy of resource taking $\ln$ order to sit at the table. Seated Agencies helping create group preconditions and terms acted under the U.S. Secretary of Interior directives. In accepting those pre-conditions, members gained assurance of resources and benefits to 'provide for the needs of each other' (2005 KBRA Letter of Intent). To force the owner of dams ( $p$ agree to removals, many lawsuits were flied and an Immense 'wish 11st' was demanded to FERC as a condition for the pending dams' relicensing, limiting alternatives and intentionally making continued dams' operation unfeasible. At that point the Secretary created another secret KBRA related group (now KHSA\} to 'offer a solution' to Pacific Power preconditioned with Pacific Power submission to KBRA involvement and agreement with dams removal Intent. The Secretary then offered a choice to Pacific Power, be subjected to unaffordable 'wish 11st' costs for relicensing ongoing litigation from many of the same KBRA players, and the Inability to meet concurrently changed unattainable water quality permit requirements, or accept dams' removals along with massive percs and payoffs to be funded by the unrepresented ratepayers, taxpayers, and a promised Congressional Immunity from liability for removal damages caused to the region. Once compelled to comply, KBRA propaganda extolled the 'right' for Pacific Power to make a 'private property' economic decision. With those signatures the Secretary included the provision that the final review arid decision for dams' removals would fall to his subjective opinion. 'Science recommendations' to 'aid' his decision would come from the USGS, also working under his direction. And now, thousands of pages of parsed and selective 'reports' still needed an 'Executive Summary' to exclude the cautions, concerns, and negative conclusions Issued by even their own selected advisory committees. 
Expressions of concern over conflict of Interest met with Indignant cries of personal attack.

Later evidence of manipulations such as. the upper basin sediment study and abuses of regulatory authority have seen nothing but a repositioned continuance towards the same predetermined conclusion. This Summary ls a travesty of exclusion, unaccountability, and inaccuracies, and will provide file reference for a 'Secretarial Determination' he was Instrumental ln creating. This contrives to seek an Intended Agenda precedent which has successfully Ignored repeated regional majority submissions regarding the documented history, current studies, unaccountable regional and economic Impacts, the will of the affected majority, and the current and future regulatory devastation of our environment, It ls Ironic that the people who truly seem to care about the entire ecosystem In which we live are those unrepresented and In opposition to the pending dams' removals and KBRA disaster, and upon whom Is placed the burden of risk, cost and loss. You may argue that ethics Is not a review component of this EIS, but I submit to you that an unethically based process creates failed decisions posing an illegal Impact upon the salmon, environment, and her people.

(133) Hello, my name is [...], rancher from Butte Valley. In February 2010 I was working for Oregon State Senator Whitsett, and I frustratingly watched when the Klamath Basin Restoration and Dam Removal Agreements were signed in Salem, Oregon by Salazar, Kulongoskyi and Schwarzenegger. This is exactly what then California Governor Schwarzenegger told the audience: Quote: Today is a great time for celebration because if you think about just 15 months ago and we were all promising each other to do everything we can to go through our differences and to finalize an agreement to tear down those dams and say asta la vista to those dams, unquote. Now you come to us 18 months later saying that all this time you were doing unbiased research, that you want to listen to our opinion before you make a final decision on dam removal. We all know the decision has been made. Your boss has already spilled the beans in a publicity stunt.

In regard to PacifiCorp's private property rights, a California State Senator who publicly spoke of his one-on-one meetings, one-on-one meetings with PacifiCorp, made it clear in a December 2009 press release, "PacifiCorp faced a hostile regulatory environment that forced the company to get the best deal they could for their shareholders." And PacifiCorp was, quote, harassed by political interpretations of environmental laws, unquote. Your actions will create a great and harmful cost. When the toxic sediment from behind those dams is flushed down river killing fish and people, when a viable fish hatchery behind Iron Gate Dam is destroyed, and when farmers in the Tulelake Basin in future years have their water shut-off again, your names will be synonymous with those future man-made disasters. I hope you realize that your work is already being discredited. In the future, graduate students will be re-analyzing your biased research and will soundly discredit your reputations for your lack of sound scientific practices expected from all professional scientists. Primarily in regards to fish passage, your failure to understand the significance of the Shasta Nation Fish Bypass which solves all the problems without dam removal. Also please place in your arguments the ballot arguments for and against Measure G in November 2010. Siskiyou County was 79 percent against dam removal. In Tulelake, they were told that if the dams come down, then they will receive irrigation water. Many of us campaigned in Tulelake for no on Measure G. And we had a booth at the TBU County Fair. And we're proud to say your blackmail 
has failed. We had 77 percent against dam removal. The will of the people, sound science and common sense all oppose dam removal, and your lengthy report should reflect those facts.

(134) I own a home on Copco lake and I wish to comment on the EIS/EIR draft report that was placed on the Internet for Input concerning the 4 dams In Siskiyou County. Since I am not a scientist, but I am a concerned citizen, I cannot fully appreciate the necessity to even consider removing the dams, or the time Involved to conduct the study, or the expenditure of money our nation does not have, or the need for the removal of functioning dams that you, as Secretary of the Interior, and your department, wish to accomplish. I have many questions as to the validity of the report since most of the conclusions resulted In "No concrete evidence or conclusion ". I respectfully request the same courtesy that you afforded us to read and comment on the report, and I respectfully request that you please read my questions. I would appreciate an answer. Are you aware that Siskiyou County's unemployment rate Is higher than the national average of over 9"A 7 Are you aware that removal of the dams will seriously 1 mpact the one economic factor that helps to keep Siskiyou County afloat? Are you aware that our source of revenue Is: TOURISTS, FISHING! HUNTING! County Taxes on Real Estate and Property values and with dam removal that source will dissipate? Do you think more unemployment for Siskiyou County is the answer? Do you think the business community can stand the loss? Are you aware that Siskiyou County already has had financial setbacks with mining and logging curtailments? Why would anyone Intentionally destroy a 100 year old eco-system that is thriving with wild-life, on the premise that removal of the 4 dams will ultimately restore wetlands in another area? Wetlands are already established in the area You and your Agency wish to destroy! Removal of the dams would destroy a beautiful environment where white pelicans, ducks, geese, cormorants, eagles, osprey, Caspian terns, turtles, crawdad $\sim$, yellow perch, wild, native, rainbow trout, black bass, blue gill, deer, bear, cougar, raccoons, otter, squirrels, etc. all the wildlife that live peacefully in and around the lakes, all will suffer, the fish will die and the land will be turned Into an ugly, smelly, stinking, fish decaying, fly Infested wasteland as a result. Not only would this be a disgrace but could result In law suits no matter what is said otherwise. Are you aware that the Klamath River above Copco Lake has been designated a wild and scenic river and It has some of the best fishing tor wild, native rainbow trout that you will find anywhere and dam removal will be the demise of that resource for fishermen? Since Iron Gate Hatchery will be destroyed along with Iron Gate Dam, salmon will not increase but will be on their way to oblivion and this due to unscientific claims that dam removal will restore the salmon runs In the future .. Truth is: Salmon spawning grounds will be Inundated with silt and the salmon eggs will be smothered resulting In less salmon for future generations. Have you not heard the OUTCRY of the residents of Copco Lake and the people in the surrounding areas, and the Supervisors of Siskiyou County? Have you not heard the voices that have been shouting from the rooftops? KEEP OUR DAMS IN-TACT! How would you like it if You property was devalued by Assessors that were sent, not from your County, but from your State Capital, and the starting appraisal figure used was deliberately lower than it should have been due to controversy initiated by Your office over dam removal? Siskiyou County Assessor's Office has cried foul and I agree! The United States ls experiencing an economic crisis. We owe TRILLIONS OF DOLLARS to Foreign Governments. We continue to borrow 
money to fund foolish projects and the U.S. debt goes higher and higher. We need to stop spending money we don't have! The first estimates to remove Copco 1, Copco 2, Iron Gate, and JC Boyle were quoted at $\$ 200$ Billion Dollars. Now to fund removal and lower visibility, various creative accounting practices are being used to funnel funds into other budget areas, thus, estimates are now somewhat lower and may in actuality be much higher than Is predicted at present. When has any Government project been lower than expected? Who will benefit by dam removal? It certainly is not the residents of Copco Lake or Iron Gate or communities down river or Siskiyou County? Who Is it that will make a great deal of money on establishing an alternate source of energy to replace existing facilities, and the restoration projects to restore the land that have been mentioned in your scoping report? Where will Siskiyou County's water be diverted? Is Southern California in line to acquire our water? Is the Department of Interior in cahoots with those who Will benefit the most at the cost of Siskiyou County and Its residents? The dams were not built with flood control as Its chief mission but the dams have alleviated major flood problems to date, should dam removal become a reality major flood damage downstream could result In the future. You, as the Honorable Secretary of the Department of Interior, by advocating dam removal demonstrated to all of us in Siskiyou County that In your opinion people in our communities do not count. Does the end justify the means in your opinion? I hope that Is not your position and that your voice will ultimately side with the people of Siskiyou County In keeping our dams in-tact. Removing 4 Dams on the Klamath River is Irresponsible, wasteful, expensive, and foolish especially when more, not less electricity will be needed in the future. In this time of economic; crisis it Is criminal to remove facilities that provide- green, cheap, clean electricity for 70,000 families, electricity generated and not used is placed on a grid for future use. WHY PAV HIGHER UTILITY BILLS TO BUILD SOMETHING THAT MAY NOT WORK or would be more expensive? Solyndra fiasco could result who knows? WE KNOW WHAT IS WORKING WE KNOW WHAT WE WANT! WE WANT OUR KLAMATH DAMS IN-TACT!

(24) In the Klamath Secretarial Determination Process, I strongly encourage the Secretary of the Interior to select Alternative Two within the draft EIS/EIR as the preferred alternative for the Secretarial determination. Alternative two - full removal of the four mainstem Klamath dams and associated facilities - would have the greatest positive effect on Klamath anadromous fish populations of all the alternatives under consideration. Reading through the key conclusions from the draft EIS, it is clear to me that removing the four dams, in conjunction with the implementation of the KBRA, would have significant benefits for fish, wildlife, water quality, and human communities within the Klamath basin. To me the results of the draft EIS offer unequivocal support for the removal of the four Klamath dams. I hope that the Secretary of the Interior and other people involved with the final decision making process will come to the same conclusion. Dams alter river systems in dramatic ways, often with negative consequences for the associated aquatic biota. The four dams being considered for removal on the Klamath alter the natural flow regime of the river, block sediment transport, block access to spawning and rearing habitat for threatened anadromous fishes, and create conditions conducive to the proliferation of toxic blue-green algae and diseases that impact juvenile salmonids. Removing the four dams would be one of the most effective, if not the most effective, actions that could be taken to restore anadromous fish populations in 
the basin. The potential negative consequences of removing the dams are far outweighed by the potential benefits. The power produced by the dams is insignificant, especially compared with other hydropower facilities in the Pacific Northwest, so losses of production should not be a serious concern. The dams contribute little to flood control or irrigation, and the economic losses associated with declines in land value surrounding the reservoirs would likely be minimal. The draft EIS shows that removing the four Klamath dams will have significant, positive impacts on threatened anadromous fish populations in the Klamath basin, and, more broadly, that dam removal is in the public interest. I hope that the Secretary of the Interior will come to the same conclusion.

(90) All studies, including yours, confirm major damage to the stream conditions for years to come will be caused by Dam removal. You ignore the penalty fish and people will be forced to pay from Dam removal. This is evidenced on a small scale by the problems with Silt,debris,contamination, and flows caused by removal of the small Dams ( Savage Rapids , and, Gold Ray) on the Rogue River.

(91) Comments: There are so many reasons not to remove the Klamath dams that it is difficult to understand why it is even being considered: 1. The dams provide economical, clean. safe electric power 2 . There is substantial. convincing scientific evidence to show that fish populations in the river are more influenced by ocean temperatures, sea lion depradation (sic) at the mouth, and Indian fishing rights than by stream conditions. 3. A workable system for spawning and rearing smelts from returning salmonids already exists. 4. Silt release from the reservoirs will cause severe damage to fish habitat and recreational use of the river for many years, if not decades. 5. The "endangered" Coho salmon is apparently not even a native species 6 . Property values and tax base for private property around the lakes and downstream, as well as for the dams and powerhouses, will be decimated. 7. The dams help to regulate river flows with releases during the dry season and flood control in the winter. 8. Siskiyou County residents, the very people most affected by the dam removal, are opposed by a ratio of 4 to 1 . Oh, by the way, how many valid reasons are there to remove the dams? Zero.

(164) I'm against the dam removal. Since we are already paying for the dam removal on our power bill, does this indicate dam removal is a done deal? It's very suspect. If the dams are removed, a question regarding the massive sediment that would be released, would this be detrimental to the fish that are supposed to be saved? If the dams are removed, will the jobs KBRA keeps referring to be -- sorry -- building new dams, temporary work, or government jobs? Would the KBRA be allowed to allocate the water? They keep talking about water; who is paying the KBRA? How does the KBRA have such clout? If they are seeing it through, why do they keep seeming to be running the show? How will decommissioned plants that provided electricity to 70,000 homes be replaced? I don't understand, either, why giving the tribes the forest is going to be helping with the water. Is there something there that we don't understand? Two years ago, my husband and I rode down I-5 south to, on our way to San Diego, and outside of Los Banos, California, thousands of acres were totally dead, 
hour after hour, mile after mile. These once beautiful almond trees and other crops sit vacant, and running parallel to these vacant crops are just the California viaduct. So it isn't a lack of water but it's the delta smelt that has usurped the farmers' water, and the devastation occurs. Some of those owners are paid off in cash to keep quiet because of the endangered fish. Does that sound familiar? Will the Klamath Basin follow suit? And it would be mind boggling, in my opinion, if we knew the total cost the Endangered Species Act has cost our nation and human lives. I hope these comments will be reviewed and given credence and not just put in some shredder or lost.

(116) I support Alternative 4 - I like fish, affordable clean energy, and protecting Native burial sites.

(136) I strongly urge you not to destroy the four dams on the Upper Klamath River. How will taking out dams improve water quality? Toxic sediment will pollute water, banks, riparian plant life, fish and underground aquifers. Toxicity of river and squifers may last 100 years or more! 40,000 Siskiyou County residents and their local, elected representatives were not included in the Klamath River Dam removal meetings. WHY? Four tribes exist in the Klamath Basin - the Shasta, Karuk, Yurok, and Hupa; the Shasta have been left out of all agreements and their sacred burial grounds will be destroyed when the dams are breached! A major impetus for dam removal is concern over the Coho salmon, a non-native species to the Klamath River; WHY? Hydroelectric power is both green and economical! How will the green, affordable energy currently provided by the four, hydroelectric dams be replaced? I do not understand why our government would go to the measures it has planned to hurt good people barely making a living off their land. I must let you know that I am appalled at the Government attempting the destruction of rural America and the water rights/property rights of our fellow citizens.

(115) I'm against the removal of the dams. I believe there can be better ways of moving fish up the river, fish ladders -- I'm not talking the little wimpy fish ladders, I'm talking good fish ladders that could support the tribes and support the farmers. I'm a third generation Klamath Basin person, and I would like my kids to be a fourth generation. If we don't have any water there will be nothing for my kids when they grow up.

(92) It is hard to imagine that in America removing our infrastructure would even be entertained. The ones joining in to kill America by any means are so happy to watch America slip to third world status by decisions like removing dams. Please do any thing within your power to save these Dams, then you can go to bed at night knowing you were part of America's solution, not the problem. Remember with the power generation problems of America, the food problems and flood control we need to be building dams, not removing. 
(93) I have a long list of comments that I have written, this is not what I'm going to say tonight. will put this in the comment box. First, let me say that we are all concerned about the plight of our environment and the fish and the wildlife who inhabit this area, but we ask you to consider the effects the dam removal will have on the people who live here. We share the environment, we live here. I should have as many rights as the fish or, you know, a deer that runs in my yard, he has rights, I have rights. Okay. And I'm just making a short statement. I feel, as many of the residents of Siskiyou County, that the dam removal is a terrible mistake. I think that this will be an economic disaster for all of us in Siskiyou County and that removal of the dam will do little or nothing to increase the fish counts on the Klamath River. Plus I'm afraid that the dam removal will create more problems than it will -- and it will cost millions of dollars to alleviate those problems. I ask only that you consider all the ramifications of dam removal before you go forward with possibly disastrous dam removal. Thank you for giving me this opportunity to voice my concerns. I have written lengthy comments which I would like to submit now. But I, once again, would like you to reconsider this project. I think also about the people whose lives will be affected.

(26) I am a resident of Arcata but frequent resident of the Lower Klamath River. I've had the good fortune to work in the Klamath for the last seven years, as a restorationist, as a geologist, and as a documentary film producer. And I have made two documentaries on the Klamath, one for the Yurok Tribe and one for American Rivers, that explore many of these issues. I filmed the FERC hearings and the water quality hearings, and I have to say I'm overjoyed to see this night arrive, where we're actually considering the four-dam removal. That's a huge victory for all of us. So, in regards to your analysis, a couple of the specific comments that I would like to kind of emphasize is that the jobs that are going to be resulting from a healthy fishery, the jobs that are going to be resulting from dam removal and fish barrier removal are, I think, underestimated in your DEIR. The restoration economy is an economy that promotes more health, economic health, more ecological health, and overall has very many widespread impacts that may be difficult to estimate but, I think, are currently being underestimated. I strongly support the Alternative No. 2, the four-dam removal and facilities removal. I would also settle, in economic uncertain times, to leave many of the facilities in place, just restore the free-flowing river and we can deal with facilities being on the banks of those rivers. I think the issue of property values around Copco Lake and Iron Gate Lake -- or Reservoir -- are overestimated, and I think we underestimate the benefits of a healthy fishery. I think property values, for a steelhead fisherman for salmon fisherman living along those banks, those folks would value that property very, very much, more so than simple view property, especially on the edges of a lake with toxic algae blooms. So, dam removal will provide incredible access to cold water flowing through the volcanic geologies of the upper -- of the tributaries that are flowing in the Copco and Iron Gate, and I think we really will benefit immensely from that and from having a free-flowing river. So, thank you very much.

(137) I am outraged that I have to take the time to write this letter. The fact that our Federal Government is pushing to remove four clean energy resources is ironic given the fact that 
this administration was going to be the "green jobs" leader. The environmental regulations that are killing California jobs and businesses are now plotting to destroy perfectly good energy resources. The recklessness of these actions will show over time that you helped destroy more lives, communities and families by removing the Klamath River dams. The cost of removing these dams is approximately $\$ 290$ million dollars with no plan to generate a replacement power source. Your inability to listen to the citizens of California is why many citizens are coming to the realization that our government is more committed to serving environmental activists than local and state citizens. [bold] An average of $80 \%$ of citizens VOTED NO on Dam Removal in Siskiyou County, California, and Klamath County, Oregon. [bold] Before blowing up dams why doesn't the government show the citizens what clean energy resource will be built to replace the power the dams generate. Show us the cost savings, and build the new energy plant before [bold] spending a quarter of a billion dollars destroying a perfectly good hydro-electric energy resource. [bold] Hydro-electric energy is 10 times cheaper than wind energy, and 20 times cheaper than solar. California energy costs are rising, businesses are leaving $\mathrm{CA}$ and many citizens are unemployed. Your inhumane decisions will not improve the lives of the citizens of California, but make it much harder for the people to pursue happiness (prosper). Based on the actions of the Federal Government I must assume fish and wildlife are more important than your fellow citizens. The cost of dam removal will be extremely expensive. Since rate payers will be paying for this cost, this will cause a large cost increase on electricity to rate payers, including homeowners and the elderly. I am very concerned about how the rate payers and tax payers are going to afford this increase in electricity costs. The actual cost of dam removal is largely believed to be in excess of $\$ 3$ billion and we will be the ones to pay the price. I urge you not to destroy the Klamath River Dams.

(94) McKinleyville resident, former fisheries biology student at Humboldt State University. As I watched the presentation here, I noticed that they kind of went over the settlement below and above those dams as a fairly innocuous situation. They estimated one to two years for the sediment to move out of the system. There is anecdotal evidence that that will not happen. Here in Humboldt County, many years ago, they had a dam called Sweasey. When they removed that dam, the sediment behind that filled up all the holes, some of them 60 feet deep, estimated -- filled up those holes with their holding places for the salmon in the wintertime -- I mean in the summertime -- plus it contaminated spawning gravels for miles and miles below that dam. California Fish and Game, some of the older employees may remember that incident. Local residents remember it vividly and have not forgiven Fish and Game to this day for that action. Anyway, if that impact is not addressed, in other words, that sediment should be trucked out and not allowed to go down the river, to flush that river out might take another hundred-year flood. It's not going to come out in one or two years. It's going to take many, many years. And in the meantime, we're going to lose salmon production below those dams. For how many miles? That's yet to be determined. Also, I don't hear any comment at all on who is bearing the cost for removal of those dams. I'm guessing it will probably fall on the citizens of California and Oregon. I want to know if it's being addressed, as PacifiCorp, who is ultimately owned by Warren Buffett, I think they could probably afford the cost of the removal of most of the -- afford most of the cost of removal of those dams. 
But I haven't heard anybody address that situation. Who is going to pay for the removal of those dams? Thank you.

(22) As a resident of the California North Coast for over 40 years, I whole heartedly support full removal of the four lower dams on the Klamath River: J.C. Boyle, Copco 1, Copco 2 and Iron Gate. Dam removal will reduce the toxic bluegreen algae that now threaten human health in the warm reservoirs behind the lower dams. It will reopen salmon access to some former spawning streams. If, as a result, the salmon increase in number, commercial ocean fishermen, sports fishermen and Indian tribes will benefit. For countless centuries the salmon have played a vital ecological role here, transporting marine nutrients inland and serving as food for eagles, bears and other animals. Without salmon, we would be sadly diminished here on the California North Coast. I am troubled, however, by some components of the Klamath Basin Restoration Agreement (KBRA) that has been linked to the Klamath Hydropower Settlement Agreement (KHSA). It appears that under the KBRA, salmon will not be guaranteed the amount of water they need to survive in the Klamath River and in some of their upper basin spawning streams. In this time of climate change, precipitation and therefore total amount of water available in the Klamath Basin may diminish. The upper basin farmers, however, are to be guaranteed at least minimum water to meet their needs. Are potatoes really more important than preventing the extinction of salmon species that play a major ecological role? I don't think so. Likewise, I am disappointed that the KBRA will do little to rebuild the upper basin Klamath marshes that are vital if water quality is to be restored in the Klamath River. Salmon health depends upon water quality. I am particularly troubled by a provision in the KBRA that will force the Hoopa Valley Tribe, our close neighbors to the east, to relinquish their water rights under the recent Trinity River Maintem Fishery Restoration Record of Decision. I thought our nation had moved beyond breaking treaties with the Indians. Thank you for considering my comments. Please send me notice of any future hearings or decisions regarding the removal of Klamath dams.

(124) I support the restoration of fisheries and habitat of the Klamath River Watershed but do not support removing the dams as proposed. The two alternatives in your EIR that I support are: Alternative one - no action, Alternative four - keep dams with fish ladders. Do not release the sediment Save the fish and ALL the aquatic life. An estimated 22 million cubic yards of fine sediment and aggregate will be released down the Klamath River if the four dams are simultaneously removed. Whether it is the height of the winter flows, or not, the release of this much sediment will smother the river system and kill all living organisms... many of them endangered. THIS IS AN ILLEGAL TAKE. No one knows for sure what will happen and no modeling ever protrays what actually happens. Imagine mud covering one square mile that is 13 to 20 feet deep! This sediment will destroy salmon runs, spawning areas, deep holes, and wash into our bays. Additionally it will negatively affect the water that is pumped out for public consumption as well as the equipment. This sediment will impair the environment affecting water clarity and purity! This amount of sediment will sterilize the river for many years. It has been admitted this is an "experiment" - we can't afford this kind of experiment! Investigate the original statements for fraudulent information, use current real science. It is not beyond the scope of work for government agencies to provide 
false information. According to this article [www.examiner.com link]. The feds provided "equivocal or bad science" in order to divert two years' worth of water from the state's central valley farmland, according to a 279-page opinion issued by U.S. District Judge Oliver W. Wanger in Fresno, California. Furthermore, Judge Wanger also determined that many of the government scientists provided "false" and "incredible" testimony in order to support a "bad faith" preservation plan. Specifically named in the opinion were scientists from the U.S. Bureau of Reclamation and the U.S. Fish and Wildlife Service. These very same departments are involved in the study to remove the Klamath Dams. How can be trust any information from these people? Hydropower is a renewable energy and important for our future. The state of California has a mandate that $1 / 3$ of the enrgy produced must come from renewable sources and currently $12 \%$ is produced from hydropower. BUT the state does not include this power in its calculations! The four hydro-electric dams have been producing enough power for 70,000 homes and businesses AND have potential to produce enough to power 150,000 homes. This is true green electricity. How many solar panels or windmills will be needed to replace this amount of energy? At what cost? Include alternatives to aid returning salmon past the dams. The EIR is incomplete because it does not include other alternatives that have been provided. The federal agencies and CA DFG will not consider them. The federal and state governments are broke. It could cost $\$ 450$ million to remove the dams without tearing out the structure of removing the sediment. When these additional costs are factored in, and they need to be to save the river, then the costs will go up dramatically. The FERC licensing and environmental requirements may be a cheaper alternative. The Feds will be paying out millions of TAX PAYER money; besides the cost of the dam removal there will be millions spent in grants for fake and fraudulent RESTORATION. Nearly half a billion dollars has been spent with very little to show for it. How was these monies been spent? Several federal and state agencies will spend $\$ 493$ on fisheries programs like, \$63 million on restoration projects on the Sprague, Williamson and Wood rivers,; $\$ 67$ million for the fringe wetlands around Upper Klamath Lake and fish diversions for the Keno Dam; \$92 million for water conservation and ground water management; $\$ 47$ million is budgeted for acquisition of lease of water rights, water conservation and land management programs; and \$7 million for modification of dikes on the Wood River. A total of \$338 million would support implementation of the water deal - things like paying for farmers to idle land and not farm, porivde lower power rates to pump water; $\$ 65$ million for tribal economic development and environmental management; each tribe will also get \$14 million for fisheries management. The Salmon River Restoration Council will get \$10 million for their porjects. The Klamath tribes would like fishing rights on the Klamath River from Iron Gate to Interstate 5. Does this mean no one expects the fish to get to Klamath Falls where their territory is? The Klamath tribes also get $\$ 21$ million to acquire water on a year-to-year basis for environmental needs. This is a 50-year act with funding only for the first 10-years. $\$ 1.5$ billion is just the tip of this environmental "iceberg". Please save our dams. Including the above, dams are important to be able to maintain water for storage for times of need during drought. We need our dams. Thank you.

(16) I support alternative 2 within the draft dam removal EIS/EIR - full removal of four Klamath River dams. The draft EIS/EIR correctly shows that alternative 2 is the best option 
for fisheries restoration, job creation, and the reduction of toxic pollution. Option 2 is supported by a growing body of scientific research and best serves the pubic interest.

(138) If this is for salmon. I don't believe it will ever work - the Klamath Lake is to [sic] shallow - to [sic] warm- etc. to support a good salmon population. You would have to drain down the lake \& williamson river, wood river etc. to get a good cold water flow through the lake and there goes any storage for farmers. I believe any farmers that are for this are "farming us Tax payers or (the government) for compensation that has been promised them during any water shortage year. I believe if you are an opponent and the majority is in opposition; it will not matter the bureau of rec and (money) powers to be will do what the [sic] want. I also wounder [sic] if there isn't some future plane [sic] in the works that the general public hasn't been told yet.

(95) It is insanity to remove the Greenest Power available. Fish are not more important than Humans. Dam removal will cost the Klamath basin thousands of jobs. It will destroy agriculture in this high desert environment...Annual rainfall is only 15 inches.

(28) Greetings, I have worked in various aspects of watershed restoration and salmon recovery for 15 years for the Mattole Restoration Council, likely the oldest watershed restoration group in the country. The opportunity that you have before you to approve of the removal of 4 dams on the Klamath River is the single largest and most crucial salmon restoration project of the century! Having been admittedly skeptical of the process that guarantees flows to farmers, I can now compromise for the sake of the health of the river and accept the agreement that many different stakeholders worked hard to finalize. Please do everything in your power to remove these dams on the most productive river in California. Please approve of this process so that our children will still be able to witness a salmon run. This river is critical to the restoration of all our west coast salmon runs south of Alaska. Thank you so much for helping save the Pacific salmon, a species that has been here for 6 million years.

(139) friends Think American. The Coho salmon chose not to fight in the American Revolution. They all went to Canada. Do not destroy the dams Use common sense, do not ever put lower animals ahead of humans. You have been lied to by environmentalist. who seek power and control over you and me. If you drill holes in the bottom of the boat in which you are a passenger, guess what? You go down with the rest of us. God Blessed America, all we have to do is abide by his rules... we are made in his image, not the Coho salmon. Do not destroy the dams... to do so makes no sense!

(140) I urge you not to destroy the Klamath River Dams. It has not been proven it will help our fall run Chinook salmon; that cannot be proven but dam removal could destroy the run you do not know, you cannot know, because there are too many unknowns. You have no 
science to back up this move: NONE! In fact, there are many scientists who said exactly that (see attached example as well as concerns of the National Research Council within the past decade). If you do this it will be tantamount to a taking, an unlawful taking, an unconstitutional taking! You will destroy green hydropower, parts of entire communities and regions, the livelihood of countless citizens - the very people our own government urged to settle in the Klamath Basin and Siskiyou County. The Klamath Basin Restoration Agreement (KBRA) (upon which dam destruction is based) was and still is bogus - it was never open, never transparent and was arrived at behind closed doors by a cabal of special interests who had literally black-mailed the emotionally and financially exhausted agricultural units that signed on to it. They signed on only to gain respite from the lawsuits and lead normal lives in exchange for a "certainty of water" - three other promises you cannot possibly keep. If you try this, you will be stopped in Congress, the Courts, by your own pocketbook or an outraged public. The Federal Government is already broke. So are the states. You cannot claim dam destruction will cost less than estimated? You cannot know this. When did a government estimate ever come in low? I'll tell you when: NEVER! People and maintain already fragile economies that have been brought to their knees by the also bogus spotted owl controversy that killed the regions primary industries: logging, lumber and forest products. In this case we must put people before fish and get focused on positive steps that will help the salmon runs. Look at the runs up the river now in California. They are on the rebound because we got a wet year and good ocean conditions. These runs are cyclic. The salmon will return, perhaps not to pre-1900 levels but if that's what you want stop commercial fishing, stop recreational fishing, stop tribal gill-netting, stop river pollution, and start improving the habitat we've got. The salmon spend $83 \%$ of their lives in the ocean - that's the nursery and Mother Nature is in charge of it, not the USBR or the Department of Interior. I repeat: Do not try to destroy the dams, the power they generate, the flow control they provide and the thousands of hours of recreation provided by the lakes behind the dams and the Klamath River itself below Iron Gate Dam. You will waste more of our time and money - and ultimately we will all lose.

(81) I am writing today to express my support to save the Dams on the Klamath river. These dams provide critical watershed, a source of clean energy, a source of water for fire suppression in our forests, but most importantly to save the livelihoods of our ranchers and farmers and their way of life. This area is also a great source of food that feeds untold numbers of people. This is critical we must save our dams.

(141) I want to formally say I am $100 \%$ against the removeal [sic] of the 4 Pacificcorp dams on the Klamath River. This entire movement is a patronization of the environmentalists' desire to decivilize our human race from adherence to electricity generation by dams, to patronize the politically powerful Indian caucus both in Sacramento and Washington DC, to unconditionally destroy the water rights used for food cultivation and recreational purposes, and to ultimately destroy the entire ecosystem of the Klamath River downstream due to the excess sediment movement and the lack of any stored water flow for the summertime. This dedaming will be terminal in all environmental aspects - immediately eliminating electricity for more than 100,000 homes and causing the price per kilowatt to escalate and impact the consumer. To permanently change the private water rights to the State and Federal 
government ownership (i.e. a major cluster mess from then on), to ensure the loss of farm land production and land ownership due to foreclosures, and to finally transition the land and supply of water to an "idealist's" idea of make it may have been like it 150 years ago before man developed the land. I again state I am 100\% against any decommissioning of the 4 Klamath River dams. Stop immediately!

(111) The proposed Klamath Basin Restoration Agreement is the poster child of what is destroying our nation's economy. All the ingredients responsible for sinking this great nation have been included. I represent no one but myself, a retired college educated forester with nearly 7 decades of common sense experience in the northwest including the Klamath Basin where I was born. Up until the mid 1980's Klamath Lake was full of suckers, the ocean and rivers were full of salmon, the farmers and refuges received unlimited water and family wage jobs were abundant. The only constants contributing to those successful times were full utilization of our public lands (including logging), an extensive salmon hatchery program and unlimited water for agriculture and refuges. The sucker population has always been as variable as Klamath Lake. They have evolved to survive ever-changing habitat in a shallow lake along with variable Great Basin weather cycles. Historically, in late March, fishermen would line the banks of the Williamson River and try to snag spawning mullet. The runs were highly variable depending on weather cycles and natural die offs. The biggest complaint my family had duck hunting on Klamath Lake from the 1940?s thru the 1980?s was the dog rolling in dead suckers. These die offs still occur today regardless of lake levels. Most years, prior to the "new science," the marshes were too dry to hunt ducks. My uncle who was a teenager in the late 1800?s (before any dams), grew up in a house along side Link River and remembered its flow reduced to a trickle as the lake naturally drained to it's historic low level. The suckers evolved in a lake that was reduced to mud flats every summer. Today, logging on public lands is virtually zero, Klamath Lake is kept artificially high, agriculture and refuges go without water, thousands of acres of productive farms on Klamath and Agency Lakes have been converted to marsh along with the re-channeling of Wood and Williamson Rivers. These actions are the complete opposite of conditions that existed when the suckers were thriving. I have explained this to many of the young "scientists" that I have met at various boat launches. I have told them about the suckers observed in the warm springs surrounding Bare Island or the ones seen spawning in the "man made" creek under the leaky hydro power pipe slated to be decommissioned on Link River. The "deer in the headlights" response and my personal observations, have convinced me the sucker issue is more political than science. If they ever find life on Mars, it will likely be a sucker! This fish is a survivor and should not be listed as endangered. Up through the mid 1980?s hatcheries filled the rivers and ocean with millions of tons of healthy salmon. Weyerhaeuser's Aqua Culture project at Coos Bay was dumping millions of salmon directly into the ocean. Weyerhaeuser abandoned the venture because most of their salmon, were supporting profits and jobs of a thriving sport and commercial fishery. Since then political science has determined a slight difference in DNA even though the hatchery and wild fish originally came from the same parents. For a fraction of the cost of the KBRA the salmon problem could be solved with hatcheries. As for the DNA...his country can no longer afford to be God! The salmon and the citizens that catch, eat and make a living from them can not tell the difference because there isn?t any.! It is political science that is wrecking our lives, not 
DNA! We all need to get over it and realize our survival as a nation is now endangered! The various Native American tribes have evolved into society's "sacred cow". Every American's family tree includes bad experiences and persecution. Buying the Klamath Tribe a tree farm is nothing short of paying off a ransom. And finally, tearing out four perfectly good hydro power dams is more than insanity...it is shear stupidity! To say jobs are created by borrowing money we do not have and using it to tear down clean hydro electric facilities in today's troubled economy is beyond insane. If it is cheaper for Pacific Power to tear down the dams than it is to re-license them, then solve the problem by reduce red tape, government regulation and bureaucratically associated costs. Everything, including hatcheries, should be done to restore common sense back into the solution and find ways to keep the dams viable so they can continue to provide not only clean electricity but real wealth for our nation's future. Political correctness, the endangered species act, failing to create new wealth, borrowing what we do not have and spending all the wealth created by our parents generation on "feel good projects" is destroying America. Government intrusion based on political junk science has turned rural America into a ghetto which is spreading into urban areas. The need for a KBRA should have never existed in the first place! Everything necessary to keep society alive is either grown or mined in a viable rural area. The proposed $\$ 800$ million for the KBRA would be better spent on everything from rural roads and schools to restoring multiple use on public lands. Every creature that lives on earth will be worse off if this country is allowed to go bankrupt. We can either try to turn this madness around while we still have a chance or allow ourselves and the animal kingdom to sink into a tar pit like a thrashing dinosaur.

(30) Dam removal and the Klamath Basin Restoration Agreement will be good for the Klamath Basin and its communities. Restoring the river to some point closer to its natural baseline will promote harmony in the socio-ecological system. Hundreds of people have worked tirelessly on this plan, including finding middle ground where there seemed to be none. The KBRA is a comprise between all stakeholders in the basin, and balances the interests of all.

(142) Please accept this letter of inquiry into the removal of four dams on the Upper Klamath River. This will wipe out clean affordable, electrical power to 70,000 homes, release tons of sediment from behind the dams and make the river less reliable for irrigation. The river will become a mere stream in the summer, a flood threat in the spring and toxic. How will the release of toxic sediment into the river ecosystem, caused by the breaching of the dams be mitigated? How will the green, affordable energy currently provided by the four hydroelectric dams be replaced? This plan should be rethought and discussed with the communities to be destroyed. This is still America, is it not? I think loss of 70,000 people's way of life is not excusable. One of the reasons that California is in such bad economical shape is because of government policies in rural areas. It is time we protected our working citizens and stop any more destruction of our rural communities. I think there are other ways to protect Coho Salmon, perhaps in other areas. There is nothing acceptable about the current plan. Consider a vote on this plan. The American way of life is under attack. Please STOP the REMOVAL of the four dams in Northern California and Southern Oregon. 
(143) First, I got a, uh, a -- a heart felt thanks to the county supervisors and the other local governments who are engaging in this coordination to try and bring some sanity to this process. Thank you very much. Um, we hear a lot about all this promised water and these promised jobs that are going to show up. Um, well, as I remember, all of this started when our great and glorious and all-knowing government reneged on promised water in the Klamath Basin. You know, they -- they ruined the economy of the Klamath Basin. They - and never has any of these warm and fuzzy, so-called environmentally friendly projects ever produced net jobs, not even the famed Redwood National Park. How are you going to get jobs out of Klamath River? I'm sorry. The KHSA, it began with the railroading of PacifiCorp by unelected, unaccountable government bureaucrats who latched onto each and every proposal for, um, the relicensing issue. Um, you know, I'm sorry, but I just don't see what, say, Quon trails (phonetic), new Quon trails might have to do with it, about water quality and cleaning up dams. The -- now, what you are up to is just railroading more people, driving down our property values, threatening the water that we have, and driving out our jobs; all of this for the superstitions of select tribes and warm and fuzzy feelings of stakeholders who aren't even from this area. You know, here a couple weeks ago, I heard on the radio, where they are -- they were releasing additional water to -from Iron Gate to draw the salmon up the river prematurely for some Karuk shindig, and these guys were threatening the very salmon what this is all supposed to be about.

(144) First I would like to thank you for this opportunity to speak to you on this most serious issue of Dam Removal. There are many of you... not aware of the serious financial impact, or the serious loss of our property rights that will result with the removal of these dams. I would like to site a few examples; the former Savage Rapids Dam located in So. Oregon. Since the removal of this dam, Pacific Power increased its power rates to businesses $17 \%$ to residents by $14 \%$. There are four dams in Siskiyou County, which provide green energy their removal would impose a tremendous cost to the taxpayers. The energy generation that is now in place, if destroyed, from my understanding, would be replaced by natural gas generators (a natural gas line that runs from Nevada). Electrical generation provided by natural gas would be at an exorbitant cost far out of reach of what the people could afford to pay on a power bill. The production of this type of energy would put far more emissions in to our air. From history by those opposing the burning of hydrocarbons, environmentalists would be against. The estimated figures of this newly supplied energy would be on the average three to four times higher which is another financial burden. Further injury, dam removal would affect recreational revenues that tourism brings, including the loss of employment that facilitates local businesses. With this increased financial burden, land owners and business people are in jeopardy of losing their property and businesses. I believe the reasons for dam removals; comes from the implementation of Agenda 21 (sustainable development). I also believe it is responsible for the recent closure of dredge mining, another employment "confiscation". Sustainable development was ushered in by the United Nations and was signed by executive order by Presidents' Bill Clinton and George H.W. Bush. This "soft law" was never ratified by Congress. I would like to point out, the signing of this executive order, by these Presidents' is against Article 1, Section 10 of the Constitution of the United States... which 
is; THE LAW OF THE LAND! NGO's (non-governmental organizations), are groups that work in partnerships with government entities to push environmental controls and "over the top" regulations. The implementation of Agenda 21, was unveiled in 1992 during the United Nations Conference on Environment and Development (UNCED), known as the Rio Earth Summit. These three powerful international NGO's, the World Wide Fund for Nature (WWF) the World Resources Institute (WRI) and the International Union for Conservation and Nature (IUCN) influence the objectives and methodology of the international environmental agenda in reports such as: World Conservation Strategy, published in 1980, global Biodiversity Strategy, published in 1992, and Global Biodiversity Assessment, published in 1996. I would like you to know, a copy of this biodiversity map has been given to you and further information can be obtained through Freedom Advocates. Org. Sustainable development has no respect or concern for the human population, but uses the environment as the "guise", to take away our unalienable rights, by implementing regulations that force the citizen's of this great national, out of jobs and property. Case in point; the spotted owl (endangered species act) destroyed the timber industry in the Pacific Northwest from Northern California to Canada which not only closed hundreds of mills, but destroyed thousands of jobs, ruining the tax base for many counties and worst of all... took away the timber tax revenue for schools. Noticeably these acts have caused financial hardships and loss of employment to many in Siskiyou County plus those connected economically. The American citizens in most cases are law abiding, support regulations and laws of the environment and most are stewards of the lands. We do not need... nor do we want implemented strategies that require surrendering our God given unalienable rights which are firmly planted in the U.S. Constitution! As a veteran of Vietnam I took an Oath to support and Defend the United States Constitution not only for the sake of its citizenry but also for my family and their future. The "intent" of the document written by our Founding Fathers was to protect this Republic and "We the People". In the government's decision on dam removal... it will either follow THE LAWS OF THE LAND or take a path propagated by the United Nations that does not respect, recognize nor support the United States Constitution.

(31) uglification and abuse of Earth for profit - Do what we need another way.

(32) I'm in support of alternatives 2 and 3. Due to improved health and populations of fish species, particularly salmon. Which are a cultural and economic resource in this area. In addition, I believe it is extremely important to increase water available to wildlife preserves, reduce algal bloom formations due to lack of natural flows, and increase long term water quality including dissolved oxygen and lower water temperatures.

(145) Stop now on KBRA \& KHSA. It was done in secret and was used to get it passed. (Say "yes" or you will never get any water.)

(33) i am a nature lover w/ a fisheries background...i believe that instream water quality \& quantity is the key issue for the Klamath system, and that removal of the dams in question is 
one major step toward restoration of the watershed. in the name of future generations and their enjoyment of this area, I encourage you to consider dam removal \& further restoration measures.

(34) I just wanted to say today I wanted to see that it wasn't overlooked the positive psychological impact that the removal of the four dams will have upon communities along the river. I think -- I believe that once the dams are removed and that the river is restored to its natural state, that people will feel better, and the environment -- with the improvement of the environment and the quality of life, I think that humans will feel better about themselves and our place on this earth. And I think that's all I wanted to say. I also wanted to thank you all for sitting and listening to us over and over again. Thank you.

(146) I am contacting you to express the urgency in rejecting the mere suggestion of closing the four dams on the Upper Klamath River. The DEIR and DEIS are nothing more than political, their recommendations are detrimental to the surrounding communities. Putting the life of a SALMON above human sustainability is beyond ridiculous and you can't possibly expect the citizens to not realize this as yet another step to government takeover of private property. It appears none of you ave considered the pollution from eliminating these dams (that being water and air pollution) and the remaining fish that will be destroyed. The affects [sic] of this pollution will destroy population and the electrical loss to 70,000 homes further prove the threat. Also, there were thousands of residents and officials that were never included in the meetings to discuss the dam closures. This fact alone should challenge both reports. Please re-evaluate these reports and look beyond their biased opinions to further an agenda. Our Country is at stake.

(165) Shame on you. You are ready to destroy homes, property values and a way of life for many and you don't care as long as you get the dams removed. That, in my opinion is unAmerican. You are willing to take a renewable source of energy from us at a time of great need. That is unAmerican. You blame the dams for reduced salmon runs yet you don't go after the gillnets at the mouth Klamath river. That is simply not telling the truth. Leave the dams in place, pull the nets at the mouth of the river and then compensate the gillnetters for their loss of revenue. Then you will see the fish return. I have heard your organization called some extreme things even environmental nazis. Keep it up and I will have to agree.

(121) Here now I vote for and support implementation of Klamath Facilities Removal Public Draft Alternative \#5, that provides for retaining and improving with fishways, both J.C. Boyle Dam and Copco II Dam, so that for all native Klamath River fish that migrate in Klamath River above Klamath River mile 180, fish passage is safely possible at and past J.C. Boyle Dam and Copco II Dam at all times, and that provides for removing both Copco I Dam and Irongate Dam, so that both Copco I Dam reservoir and Irongate Dam Reservoir cease to exist, and natural Klamath River fish that migrate in Klamath River above Klamath River mile 180, at all times where Copco I and Irongate Dam are removed at. Here now I vote 
against the KHSA section 6.4.1 (A) decommissioning and removal or the Link River East and West side hydropowered electricity generation facilities. Here now I vote for that the Klamath Facilities Removal Public Draft EIS “assumption” that “... in the EIS for alternatives where dams are not removed, the KBRA, as currently signed by the parties, would not be implemented" is erroneous and wrong. The assumption is demonstrably wrong in the case where some less than all of the dams are destroyed per the following KBRA pg 30 quotation... [extensive quotes omitted] I estimate that a post 2008 Chiloquin Dam removal, shortnose and Lost River sucker recolonization of the Sprague River drainage, likely has redistributed the 2008 Upper Klamath Lake shortnose and Lost River sucker population density. Per eyewitness accounts, it was estimated that a Williamson River area sucker fish die off in the immediately previous 20 years or so, possibly was due to a volume or recreational drug manufacturing chemicals having been dumped into the Spring Creek tributary of the Williamson River; as eyewitnesses observed an unusual foam-like reside floating on the Williamson River, near the same time that numerous sucker fish commenced dying in the Williamson River.

(35) These dams are not needed....

(151) Thank you for having us here tonight. My name is [...], and my family celebrated a hundred years of ranching in this basin this summer. We believe settlement, not litigation and the status quo, will create another hundred years. I want my children to have the opportunity to ranch in this basin in the future. Ranching is what we love to do. "No solution" means crisis. As we start thinking of people running for office in this basin, looking towards our future, there needs to be some very tough questions asked about where the solutions are, and if there are no solutions, we need to point that out, because it's nice to pretend like things will be okay if we just leave the dams in, but I think we all know that that's not what has been going on. So anyway, no solution means crisis, and I think we have had enough of that. So our family supports these agreements and the hard work that's been put in by everybody throughout the basin to try to come up with solutions, and we look forward to more solutions.

(112) The reason I'm running for public office is to represent the taxpayer, who should have been the $24^{\text {th }}$ party at the table of 23 , that was sadly neglected and left out. I am opposed to the removal of the Klamath dams and the KBRA, as well. The long-term financial impact to the county of Klamath will be disastrous. The county will lose millions of tax dollars from the loss of the J. C. Boyle Dam, plus the devaluation of surrounding and affected parties. Nowhere is this addressed in the KBRA or in any of your reports that you will destroy the tax base of Klamath County. J. C. Boyle Dam, alone, produces $\$ 500,000$ a year in yearly tax revenue. There is no provision in the DEIS to adequately compensate the county of Klamath for this tax loss. Our schools would go underfunded, our law enforcement would go to bare bones, our local government would be decimated with the loss of tax revenues generated not just from the dams but from all the affected properties. As to that alleged 4700 jobs that some speakers have referred to, they are short-term, at best. The existing executive order of President Obama requires that all government contract jobs must be filled by union workers. 
This means the vast majority of our local county citizens will get nothing out of this deal but higher taxes, higher utility rates, and worse, continued devaluation of their property. I sincerely ask Secretary Salazar to reject dam removal and stop spending our money, our tax dollars, on pork barrel projects such as the one that you are giving us now. They only benefit, at best, a few citizens, a few small groups of people, at the expense of every taxpayer out here in this county. As I said, the 24th party to the agreement was never represented, and for that, any citizen of any consciousness must reject this, and we ask you to reject this.

(36) I support Alternative 2 of the Klamath Draft EIS/EIR proposal (full removal of the Iron Gate, Copco1, Copco2, and J.C. Boyle dams).These dams are decimating what used to be the west coast's third most productive steelhead and salmon fisheries, and strangling the area's economy. Alternative 2 will help restore salmon runs (dramatically increasing steelhead populations), and ensure predictable water deliveries to irrigators. The dams don't make economic sense: if upgraded to modern standards they'll actually operate at a \$20 million annual loss. Even the owner (PacifiCorp) wants these privately owned dams taken out I support healthy fisheries and a healthy local economy (dam removal brings many jobs to the area) -- and I support Alternative 2.

(113) We had dam removals forced down our throats up here on the Rogue River. People are still madder than hornets at the government and the environmental folks. I won't go into the scientific rhetoric. The Klamath dams are old. So what? If fish passage is the issue, improve that. In the case of Savage Rapids dam here in Grants Pass... a gravity feed irrigation dam, our self reliant pumping system was replaced with electric pumps. Now, we have a couple hundred thousand dollar electric bill to pay every year. The grid goes down, I've got no irrigation water at the house. So much for self sufficient. If the dams need upgrades or replacement with better systems, that is one thing. Going backwards by total removal, that is insanity. Where is the replacement energy production to the grid? A coal plant in Utah? The Klamath river runs opposite most other Pacific rivers. It starts off warmer and dirtier. As the water heads down the canyon, it gets cleaner and cooler. The dams inventory water... let it cool... and control the water flow and temp, not only for wildlife, but human use. There tends to be accumulation of silts behind the dams that often contain toxins. Our Gold Rey dam was removed in a rush. The Army Corps never dredged out the silt behind the dam. This is the same with Savage Rapids. The fact is: this silt has cemented the bottom of our best spawning holes in the Rogue River!! Historic spawning gravels and deep cold water holes... such as the one at Pierce Riffle... are now half the depth, and the bottom of the river looks like some body poured concrete down there. The government has ruined the spawning holes on the Rogue. If you want to save coho, well... better take back some of the water getting pumped out of the Trinity, and stop the Russian and Korean trawlers from mugging the fish off shore in the gulf of Alaska. You could produce more coho at the hatchery, maybe reduce the king production slightly. That is an option. The tribes take is basically non monitored. It's their right to a portion of the fisheries. It's not their right to decimate the fishery. It's not their right to take the water rights from the white eyes, just for spite. The govt plays one group against another. The govt encourages one group with subsidies to harvest even more fish, yet 
attempts to attack innocent water users up stream if they so much as harm one fingerling. The government's behavior on this issue is bipolar - manic depressive.

(37) The dams on the Klamath need to be removed as soon as possible. If they are not, the salmon may not last long enough for the river to be un-dammed. I urge this organization to call for an earlier year of dam removal than 2020. As it is, the salmon may not last that long.

(38) Dam removal is critical if we are going to restore water quality to the point where fish populations can be recovered along with tribal. commercial, + recreational fishing.

(39) I strongly support the full removal of all four PacifiCorp dams on the Klamath River.

(127) I ranch here in Klamath Falls. I belong to several local, state and national organizations. Today I do not represent those organizations, and today those organizations do not represent me. I'm here to have a couple of comments about the draft EIS. Number one, it is a draft. It must be edited. Number two, it is illegitimate. It's based on purchased science with predetermined conclusions, political science. What it amounts to is a pretty big biological experiment. In the draft, the economic concerns don't seem to have any basis to them. I think it is quite large. I have a -- I don't have two binders - it would be nice if it was, time to comment on them was extended. So it is basically a biological experiment. I'm more concerned about the social experiment. The social experiment that is going on should be alarming and disturbing to everyone here in this room. The social engineering of this direction that uses smoking mirrors of consensus and designated quorums has been deliberate while deceptive. This is what's frightening. Deception, coercion, threats to our liberty and civil rights. This certainly has fractured our communities. In conclusion, I point out the status quo does not exist in natural resources. Thank you.

(126) Anyway, I'm requesting if we can get an extension of the time line to review the reports. There's no way that a bunch of farmers, or people that are working, in 60 days can go through a 1,864-page report. It's impossible to do that in 60 days and still work all week, and we are in full harvest. It's unfair, for all the farmers who are in harvest right now, to only give them 30 days (sic). So I am requesting now, and I will request in writing also, that I would like to extend this. And second of all, this study that you guys did, it doesn't do anything to help the problems that we had here in the Klamath Basin. Our problems here in the Klamath Basin stem from the Endangered Species Act. Under the KBRA, there is not one word mentioned to fix any of the Endangered Species Act that caused our problems in 2001. No one takes that into consideration. Dam removal is another thing. Those dams belong to PacifiCorp that you want to remove. PacifiCorp is owned by Warren Buffett. The state of Oregon and the state of California are charging us to take out the richest man in the world's dams? That doesn't make a lot of sense. On top of that, he's going to sell us the 
expensive green power, and dirty power from cogeneration plants. This whole thing is completely political, and I have written my Congressmen and I have called for a full Congressional investigation of the whole damned thing. Thank you very much.

(114) These are the books that we are all supposed to have. We've had less than 30 days to come here and talk about it. This is just going to be a partial. I just began. I still work and everything. I'm kind of busy. I'm going to look at them all. It sounds like they start off illegal. On the first day, I faxed you a formal request for more time to review these two huge books. Well, I received more time. In California, north of Santa Barbara, there is a lake named Cachuma. Cachuma's water used to quench for a small community east, above Santa Barbara. Now most of that water goes south. Some of the small town's wells were shut off due to the EPA rules. Some water was replaced with Trinity River water. What change has occurred in this small town, a small tribe used to play bingo, grew to one of the largest money-making casinos. Casinos need lots of electricity and water. Since 2001 Klamath County residents repeatedly told authorities the cold water came to the Klamath River from the Trinity River. The fish problem occurs from parasites who flourish in warm water. Upper Klamath River and its dams should be left alone. Please re-license and repair the dams and cause no harm to the remainder of the system. I'm sincere.

(40) It's about time you cleanup the problems with the dams on the Klamath river get off your butts an get it done [sic]

(147) Anyway, we want a strong vote, who wants to take the dams out? Who don't want to take the dams out? It is the consensus that Senator Merkley and Wyden wants, and this thing is going to cost a billion and a half dollars and we don't have it. What I see here is a bunch of California people trying to tell us in Oregon what to do with our water. Now, we can handle our own water. You don't have to. You're a fatal state and you don't deserve to tell us what to do. So we will do our own, we will do our own water. You can go back down to your fatal state and we will take care of our water ourself. We might build a bigger dam one of these days, or we will sell you the water and power. Thank you.

(41) I support removal of the dams on the Klamath River in order to assist salmon migration. Our years of "development" have unknowingly brought immeasurable damage to our environment. We must do what we are able to repair the harms we have caused and leave our children a hopeful heritage.

(96) I am against this. It is my contention that this entire project is not needed and is a wasted effort of time and money. Iron Gate has been a great place for recreation. I do not believe the propaganda about the salmon being endangered. 
(2) I support the removal of all dams on the Klamath River and its tributaries. The wetlands and marshes of the upper Klamath basin must be restored so that the salmon can survive. I also support an absolute minimum flow of 1,300 cubic feet per second at the Iron Gate gauge during the dry season. The Secretary of the Interior must ensure that more water from the Trinity River stay within the watershed.

(1) As a northern CA resident, former Mendocino County planning commissioner (20002006) and long-time advocate for restoration of salmonids and their fishery in this region, I write in support of the rapid removal of all dams on the Klamath River and its tributaries. Restoration of historic wetlands and marshes in the upper Klamath basin would enhance that restoration, as wetlands and riparian zones near the river filter out pollutants and provide breeding areas for the insects on which juvenile salmonids feed. Besides elimination of dams, salmonid restoration also will require adequate minimum water flows in the Klamath and its tributaries, especially during dry season. Since NMFS is requiring such minimum flows to attain ESA compliance, DOI Secretary Salazar should "bite the bullet" and set adequate minimum flows for the Klamath River basin and its tributaries.

(118) Keep the dams - They are green. Put in sophisticated ladders. Manage the water accordingly.

(148) I live in Fort Jones where I have a small ranch. We use Pacific Power for electricity and we get our ag water from the well. My first comment concerns the DOI mission statement which is right behind the front cover, which does not mention protecting the people here in this room. My second statement is concerning the abstract page which states that the EIR/EIS is prepared in accorddance with NEPA and CEQA. Firstly, because both acts require coordination, which hasn't been done in this case, with the county of Siskiyou, referred to earlier. If fact, I would point out that by letter dated May 12, 2010: The county of Siskiyou board of supervisors, specifically requested Secretary Salazar that coordination should take place in accordance with the county comprehensive land use and resource management plan. The Secretary's response by Mr. Stopher, I believe, on June 14th, 2010, the county was advised that the EIS/EIR would specifically describe inconsistencies which it doesn't contain. Apparently the plan does not review the no action plan in detail and specifically how the funds, some three billion dollars in all, could be spent better than removing green power plant that produces efficiently enough electricity for this area. The plan looks only at downstream benefits only and is not considering the detrimental impacts on land values and the quality of life costs associated downstream as a potential result of dam removal. In Siskiyou County alone with a 20 percent reduction in value, which could take place over a period of time as the dams are taken out, could result in a loss of nearly a billion dollars to Siskiyou County valuation according to the assessor's office. The total assessment value is about four billion in Siskiyou County. Five, the secretary of the Interior has been rightfully criticized on misrepresenting scientific facts and manipulation of scientific information to achieve the Administration's desired results. In the case of the dams removal process, the Secretary has developed a bogus survey referred to earlier, which I looked at 
fairly thoroughly, and that survey, which was of 12,400 homes throughout the US, doesn't consider Siskiyou County's interest in having the dams stay. In fact, Measure G, which everyone here knows about, 80 percent of the people approve keeping the dams in place. Six, the decision to breach the dams by Mr. Salazar instead of taking them out is relatively a new approach and is not really seriously evaluated as to its impact. Finally, I point out nowhere is there an identification of where the electrical power that replaces the power that is taken out is going to come from. What will be its cost, will be another question everybody ought to wonder about.

(149) There are many lakes with no cattle upstream of the them and they have algae just like Klamath Lake. So what is the real quality problem - what is the real cuase. Sulfuric Hot Springs? So taking out the Dams will not help the lake - the source of the problem. So what is the point of hundreds of millions being thrown at it. We do not trust the Dept. of Interior!

(44) Native people have always taken care and loved the land and all her inhabinants. We were never influenced by greed such as corporations. What those whose voice is heard through profit do not understand is we are concerned about our land that not only provides for us, but for their children also. Please consider the damages done and future damage to come if you do not remove these dams.

(45) I support the removal of the four dams historically blocking many miles of salmon and steelhead spawning and rearing habitat. Life for fish. Jobs for man. Slam dunk.

(46) I strongly support Alternative 2, full removal of 4 dams on the Klamath River. As you know, this would restore over 420 miles of salmon habitat, giving critical aid to our declining salmon population. Thank you very much.

(4) I am here because I am for the dam removal. I have heard people talk about flood control, and I like to think I don't look my 60 years, but I am, and I've lived all 60 years on the Klamath River, and if you see the ' 64 flood, you will not say a dam is for flood control. I've seen the river raise eight feet in less than an hour because the dams were cracking. They cannot hold back the water. You talk about water? You haven't seen water. We have been in a drought now for the last four years. This place, when I grew up in Northern California and on the lower Klamath, it would rain and not let up, and it poured down for 40 days straight and the sun won't come out, so we had that kind of water. And that dam will not hold it, they let the water go and you don't have any control over it. The other thing I'd like you guys to know, um, Klamath does not mean "stinking," it means "rapid," and that was a real slur to the Klamath people. Um, and for property values, I don't know how to tell the people that are on Copco Lake and stuff like that, but I don't know anywhere where property values have not dropped. We are deceiving ourselves if we think that 
things are going to be better if they keep the dam. All of our economies are gone. Um, we are in a really hard situation. I think we are now in a depression and we have to learn to live with that. We are going to lose money, that's all there is to it, but we didn't -And you talk about livelihoods and stuff like that, we are all lost without fish, without -- we no longer have guides on the lower Klamath for fish guides. We have lost those incomes, but fish will bring it back. Um, you talk about voting, um, people with 80 percent; well, the other counties, we have a right to vote, too, and you seem to think your county outweighs -Siskiyou outweighs Del Norte, Humboldt, and Trinity, so -- That's all I have to say. I think we should cooperate with each other, and that's all I have to say.

(48) Since the Klamath dams have led inexorably to massive loss of anadromous spawners for several species, removal as soon as humanly possible is the most economical method to prevent government financial losses through necessary implementation of costly mitigation and litigation. Historically, this free-running river supported numerous Native tribes, many, many sport fishermen, and several distinct ecosystems. All of these individuals, groups, and living systems suffer irreparably from each moment those dams exist. As you know, these dams are not assets, but liabilities to their owners, as well as to the future health of citizens, native species, and even distant commercial fisheries and other industries. Other dams still licensed are also implicated in the species loss, and this, too, impacts the necessity for expeditious removal. If a significant portion of the Klamath can be restored to health and productivity, when the time occurs for removal or superior replacement of those, the species temporarily eradicated and endangered have a far stronger chance for repopulation. For these and other reasons, these dams must be removed as soon as humanly possible. Thank you.

(120) Reasons the Klamath Dams Should Remain Standing:

I am a rancher along the Shasta River who has served on the local resource Conservation District Board and have been very active in restoring my stretch of the River and a tributary for the salmon for the last 20 years. I also keep the local City wastewater from polluting the River with year-round storage and subsequent recycle on my pastures. 1.Flushing put the sediment stored behind the dams by use of winter flow may do damage to the runs of Coho Salmon during December. The runs on the Shasta in recent years according to CA Fish \& Game counting stations, have been running from about 10-26 until 12-26, and on the Scott River from 10-26 until 12-24. Some of the large floods, such as 1964 occur during late December. 2.The poor water quality in the four hydro-electric dams is not caused by the water in storage there, but by the discharge from the Upper Basin, chiefly from Upper Klamath Lake, Lake Ewana, and especially by return flow from project irrigators and the Wildlife Refuge through the Klamath Straits. If the problem was because of storage in these reservoirs, then places like Shasta Lake and Trinity Lake would also be charged with poor quality water. 3.That poor Upper Basin water quality is reason enough to not encourage the salmon to move upstream. In addition, tributaries above Iron Gate that might be used for spawning, are few in number and habitat space until getting above Upper Klamath Lake. 4.This poor quality water should be used for more irrigation in the Upper Basin, so that the springs below J.C. boyle Dam and the various Klamath R. tributaries would comprise a greater portion of the River's warm season flow, keeping the warm season flow cooler. 
Discharges from the dams could also be drawn from deeper colder water, as it now is at Shasta Dam. 5.Probably the number one cause of fish take in the River is from diseases to intransit smolts, returning to the estuary. The River is being mismanaged in a way that causes more disease, and has nothing to do with the dams. The flow is kept too high during the summer, which fosters higher populations of poychaete worms, Manayunkia speciosa, the host for the two myxosporean parasites, Ceratomyxa Shasta and Parvicapsula Minibicornis. Lower flows, according several scientific reports, should help to dry out some of the streambed where the worms live, destroying them and their habitat. Summer is not the time that either smolts or adult spawners use the River, so maintaining significant flow by releases from Upper Klamath Lake should not be as important as controlling disease. Smolts move out in the spring and adults come up in the fall. High winter flows are also recommended for flushing out the worms and parasites. These measures of River management that the lay person can easily understand, and don't need scientific studies to confirm. [links to a fws technical report, and 3 newspaper articles] 6.Another alternative to save the fish in the long run is to close down Iron Gate Hatchery. Mismanagement is probably destroying the wild population by raising 2-year old steelhead, which have been found to stay as residents in the River, consuming wild as well as hatchery smolts that are leaving the system. In addition, many scientists feel that hatchery fish compete with wild salmon for food, lessening the numbers of preferred wild salmon. The waste outfall from the Hatchery is probably also causing all kinds of bad repercussions to the River, such as providing nutrients to grow more habitat for the Polychaete worms. Thank you for hearing my concerns, as well as, listening to my 3 minutes at the Yreka hearing on Oct 20, 2011

(49) I support alternative 2; please save the fish \& the river. we are running out of time.....

(122) I have been fishing on the Klamath River for steelhead since 1976. My father and uncle fished the Trinity and Klamath Rivers beginning in the 1950s and 1960s. Based on their inputs and my own experience, the number of fish has significantly declined over this period of time. I feel dams on the Trinity and Klamath were the first major blow, but, over-fishing by both sport fisherman and Native American gillnets, logging, farming (pollution and water flow effect), etc. all have taken a toll. Fortunately, over the years there has been ongoing efforts to control the "catch" and increase the escapement for salmon and steelhead. Even though there are legal circumstances under which you can keep a salmon or steelhead, I practice "catch and release" only for many years now because of my perceived decline in these fisheries. I think it is a must due to the dwindling number of these incredible fish. Unfortunately, I do see more gillnets than ever and it seems commercial gillnetting is now allowed. This practice seems to be taking most of the larger fish. As to the river's health, what ever happened to the sturgeon I used to see in the Klamath. The eels are gone. Spring runs are abysmal. These fish are a valuable part of our ecology and a wonderful resource and I really support any effort to preserve them for future generations. But, I am very skeptical this will happen.

(97) Please don't destroy four perfectly good, reliable dams in our valley. We need these. 
(3) I am a Yurok woman that lives along the Klamath Trinity River, I live by means of fishing \& hunting. The river is most important to me because it's all we have, there are very few jobs and no power poles to bring us electricity. So therefore we fish to survive. I know personally the impact of our low water level and the toxic algae that grows well w/ warm water. Please hear our plea to UnDam the Klamath.

(52) I support Steelhead Salmon and Alternative 2 of the Klamath Draft EIS/EIR proposal. Please remove the dams!

(123) There is NO good reason to destroy these strategic, economically sound dams. The science is flawed that supports removal. Removal will not save the fish. $80 \%$ of the local population has voted against removal. They're interests should be heard. One dam in S. Oregon recently removed is DAMAGING THE FISH AND HABITAT! The environmental consequences of removal is more damaging than leaving them alone. HYDRO

ELECTRICITY..our cleanest, cheapest, best renewable resource......we need the dams. Speaking as people with Native American ancestry, we believe it is time that we all have the same rules and rights. A majority of citizens have spoken against removal. The removal of these dams cannot and will not make the Karuk or any tribe 'whole' again. History is history. The 21 st century needs the dams.

(150) It is sad that you don't respect our American history and against individualism and wanting in the end result by destroying the dams in N. California and Oregon etc. so you can hasten us into this horrendous Agenda 21. If you go along with this, we know where your heart is and that you want no more private ownership of lands everywhere. Don't pretend it is for the environment because what you are doing is destroying the environment and will cause flooding etc. I feel it is a sham that you are pulling this over on us and we are going to spread the word far and wide what is taking place. I beg you as an American please reverse your thinking. If you do, I would whole heartedly thank you!!!!

(152) The process that took place with the project irrigators, tribes, and some fishing men from the coast, to come up with KBRA was unconstitutional as it was done behind closed doors and the general public did not have a chance to vote on the issue. The only people that benefit from this is the project irrigators who will get cheaper power rates, the tribe will get 90,000 acres of timbered land paid for by tax payers and there is the fishing industry that is hoping that more salmon will come into the rivers. With all the sediment going down the river and lodging in the gravel, all the way to the coast the spawning beds will be ruined for years and the salmon will not have a place to lay their eggs. In the mean time all the rest of the population ends up paying for the removal of the dams. There is no gain for those rate payers and the dollar value loss of the property around those dams is not even figured in the cost of removal. The property around the dams will be worthless. So, is the Government 
prepared to buy the property that will be affected? Is it worth the loss of power providing dams just to satisfy the want of Indians, fishermen and a few irrigators? I did not have a choice and I am already paying more money on my power bill to pay for the removal of the dams. The Constitution states that all citizens are to be treated equally. Making rate payers pay for the removal of the dams to satisfy three groups that will gain is not being treated equally. We the citizens of Oregon and this great country of America send representatives to Washington DC to protect our Constitutional Rights. We depend on those representatives to treat all citizens on an equal basis. Removing dams to satisfy a group of three and making the rest of the population pay for the removal is not giving equal representation from our politicians we sent to Washington. I would like to hear from you and read how you can justify backing the dam removal.

(53) As a fisheries major from Humboldt State University and former biologist for NMFS I am in support of the dams being removed. I will never forget the pictures of massive fish kills due to increase water temperature. These situations are preventable. Step one is to remove the dams.

(153) PLEASE NOTE THAT I AM HERE TO SUPPORT ALL THE RANCHERS AND FARMERS OF OREGON AND NORTHERN CALIFORNA. THESE PEOPLE NEED OUR HELP IN THIS UGLY SITUATION GOING ON THERE AND I DO NOT UNDERSTAND WHY OUR GOVERNMENT WOULD GO TO THE MEASURES IT HAS PLANNED TH HURT GOOD PEOPLE BARELY MAKING A LIVING OFF THEIR LAND.. REMOVAL OF ANY OF THESE DAMS WILL DESTROY AFFORDABLE ELECTRICAL POWER TO MANY HOMES IN BOTH NORTHERN CALIFORNIS AND OREGON. DO NOT OPEN THE DOORS FOR THE FUTURE FOR "THE U.N."S AGENDA 21" , TAKING AWAY PROPERTY RIGHT FOR OUR PEOPLE BY THE YEAR 2030. PUT EVERY MOVE UP TO THE VOTE OF OU PEOPLE. REMEMBER YOU WORK FOR THE PEOPLE OF THIS GREAT COUNTRY, THEY DO NOT WORK FOR YOU.

(54) I STORNGLY support the proposed dam removals, river restoration, and river management project. Clearly there will be some short term negative impacts cause by the construction/demolition operations. Some people will lose whatever recreation benefits are afforded by the arguably silted up and algae bloom prone lakes. Obviously in the West, "Water is for fighting over". So the issues of the irrigators will always be loudly heard. Nevertheless, it must be obvious on the face of it that the overall environmental benefits of such a project will/would be profound, and far outweigh the parochial issues of all of the many, and often competing groups who have financial interests at potential risk. I am a great believer in, and supporter of, the Endangered Species Act. As time has passed, I have become ever more convinced that man drives species into extinction at his own grave risk. I really believe that there is potential tipping point in the destruction of the natural world, which, when passed, will result in man's following into extinction all of the species he was previously driven there. That said, anything we can do to not only stop this destruction, but 
actually restore some of it, will be to our massive credit as a people. Not to restate the obvious but, as much of a profound triumph the implementation of this project would be, there is also great value in its example for what can be done, and a beginning for even more spectacular efforts in the future. I suppose that the evaluators and sort of referees of this project must remain neutral, so I hope that this final bit is not inappropriate. Still, I cannot let this opportunity pass without offering my heartfelt thanks to everyone involved in trying to take this project forward. You are, without a doubt, doing the Lord's work. I honor you for it.

(154) The dams are to important to the ranchers, farmers and all the people of Siskiyou County. Their rights are more important than a fish that is not even native to the area. What kind of government do we have to through out the rights of it's citizen without any representation.

(99) I think it is wrong for taking these dams out on the Klamath River. The energy produced by the hydro electric production cannot be replaced. Damage to the river after the dams are removed and the loss to the community.

(55) I am writing to express my support for alternative 2, removal of the four dams and restoration of the Klamath River. The Native American tribes, who managed to maintain robust salmon runs for 8000 or so years before they were decimated, were some of the most prosperous tribes in North America.This wealth was created largely by the bountiful salmon runs that provided both sustenance and the basis for trading. In the 150 years since the arrival of the Caucasians, various short-sighted practices have transformed the landscape from one of great plenty to one of unsustainability. Extensive gold mining and logging silted in many of the creeks. The dams, built to extract electricity, ensured that the pulses of water from winter storms were not strong enough to wash that silt out to the ocean. They also created water temperatures downstream that increase the risk of disease in salmon and mortality for many juveniles. These extractive practices were put into place without a clear understanding of the devastating results. Today, however, we are beginning to comprehend the extent of the damage we have caused. We understand that another 50 -year license to operate the dams would doom one of the greatest salmon runs on the earth. Forever. It would also leave the people of this region impoverished for the long run. It is time to try to reverse this process before it is too late. I request that you remove the dams and restore the river. Adopt alternative 2 . Now, before it is too late.

(155) I'm writing this letter to object to the proposed removal of four dams on the Klamath Rivers from Iron Gate, Copco I, Copco II and the IC Boyle Dams. The total cost of dam removal and implementation after removal exceeds $\$ 1.9$ billion. Irresponsible expenditures during a national economic crisis. Also some of the $\$ 1.9$ billion would need to be paid by the state of California which is bankrupt. Not a good or wise use of funds. The result of removing dams will have the effect of putting over several hundred farms and ranches out of permanent food production and destroy over one third of the economic base of this county. 
Shasta Valley agricultural operations in 2006 (95.15 million) amounted to 56\% of total economic output for Siskiyou County. The ripple effect of destroying food production in rural areas is not just economic, but food shortages, this raising prices and [illegible] the people. Also [illegible]. It seems that the true goal is to destroy the economy, [illegible] the people, take over the land and destroy the environments which removing dams would do. I guess this furthers Agenda 21 doesn't it? God only knows where you got the idea that the only option is to remove the dams because "maintaining THE DAMS AS THEY ARE IS SIMPLY NOT A LEGAL OPTION." I wonder who decided this and if it's [illegible] "law" just because something is a law doesn't mean its right moral or ethical. In closing you could say I definitely am opposed to dam removal.

(117) I believe that the Draft EIS/EIR makes a compelling case to keep the dams in place in order to preserve and enhance safe passage for the fish and other life there. I support Alternative 4 - the $\mathrm{NO}$ dam removal/fish passage option. I believe that fish are an essential component of the environment there. I also want to leave the tribal burial sites intact, AND I want affordable clean energy. Please support and vote for Alternative 4.

(119) I am writing to let you know my opposition to the Klamath Dam removals. This is an unnecessary and expensive endeavor that can be accomplished in a much better way. Specifically the "Shasta Nation anatropous tunnel by pass alternative to dam removals" Dam removals will destroy an established 100 year old aquatic and waterfowl habitat in the river and reservoirs, not to mention the long term sediment impacts which to this date have not been addressed. The cost of the Tunnel By-Pass proposal is estimated to be $\$ 50$ million, or $1 / 6(17 \%)$ of the cost of fish ladders and 1/20 (5\%) of the cost of dam removals. A few of the goals of this project which I support are to prevent the destruction of the Shasta Nation's aboriginal cultural, heritage and burial sites under water behind the dams; Maintain clean Hydro-Electric Power for 70,000 homes; Maintain flood protection for downriver cities, roads, bridges, and private property; Protect property owners and property values adjacent to the river and reservoir; and to redirect funding proposed for dam removals to this project, which will have positive economic and environmental benefits for Northern California and Southern Oregon. please do not allow for the removal of these dams. Thank you for your serious contemplation and understanding in the VERY sensitive issue.

(56) Please place these comments in the Public Comments file regarding Klamath River dams removal. My wife, [...], and I feel it is by far the best action to remove all 4 dams. It would be cheaper for us rate payers than building the fish ladders [that were supposed to be there decades ago.] It will improve the environment by ending the high water temps producing toxic algae blooms and disease organizims that kill salmon. It will improve our jobs picture by the construction work, short term, and better commercial fishing and better tourism for sport fishing. It will be better for wildlife in general restoring river habitat in a river canyon with a real river, not a series of scummy, hot lakes. It will help the majority of farmers by stopping the lawyers fighting and give more stability for water deliveries. It goes with what our community voted on that the majority want the KBRA to happen. 
(57) These dams on the Klamath must be removed for future generations of fish to achieve their full potential. The fact is keeping the dams is not sound financially.

(58) Be on the right side of history. Remove the dams. Restore this river to functioning, living habitat for the fish, the people and all the creatures. Restore the beauty of this river, welcome the salmon finally returning and re-establishing, marvel at the many tourists coming to savor the healing of this magnificent river.

(100) Please do not remove dams that have been there for years. The Klamath provides irrigation water, hydro electric power and recreation to the area. All are needed for the area. The Coho is not native to the area and removing the dams is too high a price to pay for a non native fish that doesn't spawn that far up river anyway. This is pure craziness. Stop with trying to remove these dams.

(101) I have only recently become aware of what has been proposed for the general Scott Valley region. As one who was fighting the environmental battle long, long before it was the politically correct thing to do I am, frankly, aghast at what has been planned. This assault on private property rights will be detremental to the environment after is said and done. I close in the sincere hope that sanity will prevail in this matter.

(107) You are wrong in saying that homes values above the dams will decrease - our home at Copco already has in reality. We do not have to sell at this point. [illegible] we did [illegible] according to current actual values we would lose at least $1 / 2$. You claim that when the dams come and [illegible] values would increase - before dams the summer flow was very low in summer - and often flooded in winter. You claim the loss of [illegible] reservoirs - before you announced the dam removal we had many people stay and recreate in Siskiyou for the lakes for fishing and boating the our lakes \& rivers. We see as many as 18-20 boats [illegible] [illegible] We find many of your claims to be unbelievable, However the loss of clean power for 70,000 homes and [illegible] to be unacceptable. There are no "clean" replacements being offered. Your agenda makes no sense! [illegible]

(102) Fact: Fish are record in numbers in Alaska. Our waters are too warm. There are more than 5 options. Pacific Corp wants to avoid litigation Govt. is willing to spend billions. Govt should spend those billions to put in fish ladders - in the name of fish \& help clean rivers and fix dams. This is what our govt. should be spending this money on. Not fulfilling on massive land grabs and being aggressive towards land owners. Not increasing fees and creating hardships on it's people. Fact: $85 \%$ of coho salmon spawn within twenty miles of coast. Govt. should not own fisheries \& land it created hardships for locals and then overtook. 
KHSA is not signed by all required parties.

(60) I wanted to voice my opinion in favor of dam removal. Dams have choked off a major source of food, cultural subsistence and economic benefits. Dams, in this area more than most, perpetuate the legacy of abuse against indigenous tribes. Dams also strangle the ecological integrity out of the rivers and the surrounding vegetation. Therefore, I support the immediate removal of all dams on the Klamath River and its tributaries. I also support the restoration of all historic wetlands and marshes in the upper Klamath basin, including Lower Klamath Lake, Tule Lake and Upper Klamath Lake.

(156) I've been following this issue for some time. It is my belief that beyond the advisory vote which resulted in a large majority against the dams removal, (no small feat), and the almost daily reiteration why the removal is harmful, what bothers me the most is how this situation came about. The process was deeply flawed, mostly due to it not being open to the public. When the general public was made aware of it, it seemed to be a done deal. Only an uproar from those folks affected brought it to a head and now, lo and behold, the citizen's are being asked for their input. Too little, too late in the trust department. For those of us that live in this rural area, our way of live will be forever negatively affected.

(61) I just want to add my voice to those who want to see the dams removed from the Klamath River as soon as possible.

(157) Why are the votes of the people not worth anything? The people have voted to not remove the dams but I guess it doesn't matter what the residents of Siskiyou County feel. Just another case of Bureacratic misspending, mismanagement and corruption.

(62) I support Alternative 2 of the Klamath Draft EIS/EIR proposal (full removal of the Iron Gate, Copco1, Copco2, and J.C. Boyle dams). * These dams are decimating what used to be the west coast's third most productive steelhead and salmon fisheries, and strangling the area's economy * Alternative 2 will help restore salmon runs (dramatically increasing steelhead populations), and ensure predictable water deliveries to irrigators * The dams don't make economic sense: if upgraded to modern standards they'll actually operate at a $\$ 20$ million annual loss * Even the owner (PacifiCorp) wants these privately owned dams taken out I support healthy fisheries and a healthy local economy (dam removal brings many jobs to the area) -- and I support Alternative 2.

(63) As a lifelong citizen of Oregon, and the Earth I want to thank you for your work on the Klamath River. The theft of Native land, Water Rights and destruction of the Rivers lifeblood that is needed to sustain the wildlife native to this land has to end, not only is it morally right, it is one more step towards restoring then natural balance to an area long abused by ranchers, 
and farmers. For too many years "resorce extraction" has been the mantra of those who are so myopic that they won't look beyond their own pocket books and political power. May Mother Earth make you strong, and give you direction and wisdom as you continue to help reclaim our lands and help us begin to heal the scars left by those who want to destroy the Natives of our lands.

(64) Please Support Alternative 2- Full Dam Removal. This alternative provides the greatest benefit to the Klamath River watershed, fisheries, and eliminates future tax payer dollars that would be needed to maintain parts of the aging dam infrastructure.

(158) WE VERY STRONGLY OBJECT TO THE REMOVAL OF THE KLAMATH RIVER DAMS. WE HOPE YOU WILL LISTEN TO THE CONCERNS OF THOSE DIRECT CITIZENS WHO WILL BE DIRECTLY EFFECTED [sic] AND HARMED IF THE DAMS ARE DESTROYED.

(27) I support alternative 2 within the draft dam removal EIS/EIR - full removal of four Klamath River dams. The draft EIS/EIR correctly shows that alternative 2 is the best option for fisheries restoration, job creation, and the reduction of toxic pollution. Option 2 is supported by a growing body of scientific research and best serves the public interest.

(66) I totally support Alternative 2, the removal of the dam on the Klamath River. We need to restore the important steelhead and salmon fishery.

(159) Please do Not remove the dam. The stupid and crazy nonsense that the EPA and the other enviro-whackos are perpetrating on the good people of this country, will not be tolerated any more. You uneducated, Fabian Socialist progressives are destroying this country and her freedoms. We will fight you every step of the way. We will Not allow you to be tyrants over us.

(160) Siskiyou County has voted to save the dams. Why is there still a movement to remove the dams? We are the People, and we have voted to retain the dams. Thank you for listening. I am a long-time resident of Siskiyou County, California.

(103) The dams you propose to destroy / "remove" are A VITAL PART OF THIS MORE ARID LANDS PRODUCTIVITY.... AND THE LIVELIHOOD OF THIS COMMUNITIES MORE THAN HARD WORKING RANCHERS/ FARMERS... In the LAST SERIOUS RECESSION aka STAGFLATION OF THE LATE 70's I witnessed the audacity of the "Spotted Owl Worship" that truly SHUT DOWN FOR THE LAST 40 YEARS THE 


\begin{abstract}
MAJORITY OF THE LUMBER INDUSTRY IN THE ENTIRE NORTHWEST. Your actions in tearing down dams and controlling these and any other resources by fiat or emotional politics have a VERIFIABLE HISTORY OF TERRIBLE CONSEQUENCES TO THE AREA'S INDUSTRIES AND ENTIRE ECONOMIES OF REGIONS OF A STATE. I PERSONALLY WITNESSED THE IRREPARABLE ECONOMIC AND EMOTIONAL DAMAGE TO THREE GENERATIONS OF TIMBER HARVESTING FAMILIES IN NORTHEAST CALIFORNIA. THE OVERFLOW OF THAT DID ALSO DESTROY MY SMALL FAMILY DENTAL BUSINESS TOO !! HAVE YOU EVER LIVED IN A $50 \%$ UNEMPLOYED SMALL TOWN?? PLEASE DO NOT TAKE AWAY THIS MOST NEEDED NATURAL RESOURCE ( WATER USES OF ALL KINDS ) FROM ANY PORTION OF ANY STATE'S LAKES, STREAMS AND RESERVOIRS. THANK YOU VERY MUCH
\end{abstract}

(67) I am writing to support the quick removal of all damns on the Klamath River and its tributaries. This urgently needed to restore wild fish populations, improve water quality and renew the river to its former glory, as well as to the Scott and Shasta Rivers. Actions are needed to restore wetlands and marshes, increase water flows, especially at the Iron Gate damn and the Trinity River. As someone who lives in close proximity to the area, this has great importance to me, my family and many friends who find the area to have vast importance for purposes of recreation. Beyond this, the area is in crucial need of restoration to bring back wild populations of salmon, so important to so many of us who live in the Pacific Northwest.

(68) I am a California constituent, friend and colleague of both tribal and agricultural parties. My Uncle was a Salmon fisherman off the North Coast. I understand the great need to balance all parties interests and concerns. I have seen directly the impact the dams have had on the quality of the river, the drastic decline in available food for the Karuk and other Native Americans living on the river. The water's toxicity have impacted culturally beneficial uses of the water. I urge you to adopt Alternative 2: full removal of all four dams.

(69) I'm a resident of Orleans, and I support Option 2, the full removal of the Klamath Dams. And thank you for taking our comments today. I'm part of the local Food Justice movement that's promoting healthy affordable, accessible, secure, and appropriate food for all. We promote both traditional and local food sources. Restoring the fishery would be one step in restoring the balance to this ecosystem and moving towards the goal of better nourishing and strengthening our community. I want to recognize that I'm a settler on stolen Native land and that, although I did not steal the land or take part in the massacres of Native people in this area, my living here is direct proof that I and other non-Native residents are benefiting from those events and from the ongoing effects of colonization and attempted genocide, as seen in policy that empowers certain destructive agency management practices and other extractive private industry. We benefit from the historical displacement of people and see an unequal balance in land ownership, as well as limited access to appropriate food and healthcare and other basic necessities. As settlers and non-Native people in this community, I believe it's our 
responsibility to proactively challenge and dismantle colonialist and white supremacist thought and behavior in the communities we identify ourselves to be a part of. While we all have good intentions in the work we do, I want to challenge myself and other non-Native residents to constantly question the cultural appropriateness of our actions, as we strive to align ourselves as allies with the original inhabitants of this area, if they will have us as allies and partners. After attending and video-documenting the Yreka hearings, I encourage the Department of the Interior to dismiss the testimony of those individuals whose comments were wrought with hateful white supremacist sentiment and patronization towards the downriver communities, and specifically Native peoples. Those who spoke at the Yreka hearing, with a clear air of entitlement to their way of life, especially when touting having lived in the area for four generations, are living in denial or at least not recognizing that it was some of their predecessors who are responsible for the massive loss of life and culture in this area. A daughter of a rancher in the Valley condescendingly demanded to now here tribal people would get their food when farmers were out of business. One Copco resident said, "The lake is the centerpiece of our pleasurable existence," and added that it was the ones who wanted dam removal who are selfish. Numerous people refer to downriver communities as special interest groups and ask, "What about," quote, "the people," as if they were the only people. Another man said that what was needed was a sustainable economy, not a sustainable environment, as if the two were not connected. Another Copco resident as quoted in the October 4th Siskiyou Daily, saying, quote, "They tell us the Indians have to get in the water every day because of their religion, but we're still waiting to see a single dead Indian." This was in regards to toxic algae. These sentiments are racist and ignorant. Those who are benefiting from exploitive resource extractive industry are not the ones with the solutions to problems that their industries created. When Upper Basin residents demand that you, quote, "take the rights of the people, not just the fish, into account," remember that down here our lives are completely intertwined with the fish, and, therefore, the rights of the fish are the rights of the people.

(70) Take the dam down! Free the river. Please

(71) I agree that removal of the dams will benefit the salmon and the economy. The fisheries will continue to decline so long as the dams exist. Let's get it done, as soon as possible.

(72) We support Alternative 2- Full Dam removal to restore the watershed to its natural state together with its fishery and relieve all the attendant costs to taxpayers due to untold maintenance issues with the aging structure.

(125) I have recently been made aware that several dams are scheduled for removal. Why do we continue to dismantle this important part of our infrastructure? We will never be able to rebuild them given the extremist view of environmentalism in this country. Why are fish more important than people/farmers/citizens. How will taking out dams improve water quality? Klamath is naturally warm and polluted up stream * Area of headwaters is volcanic 
and rich in minerals, including basalt, magnesium and phosphorus * System of four dams filters out the minerals and allows the water to cool How will the green, affordable energy currently provided by the four, hydroelectric dams be replaced? * Existing four dams provide hydroelectric power * Hydroelectric power is both green and economical * Current system provides enough electricity to power 70,000 homes How were "stakeholders" determined? * 40,000 Siskiyou County residents and their local, elected representatives were not included in the Klamath River Dam removal meetings * Four tribes exist in the Klamath Basin - the Shasta, Karuk, Yurok, and Hupa; the Shasta have been left out of all agreements and their sacred burial grounds will be destroyed when the dams are breached A major impetus for dam removal is concern over the Coho salmon, a non-native species to the Klamath River; why? * Coho salmon are not native to the Klamath and were planted in the river in the late 1800 's * Coho are not natural to the Klamath and yet millions of fish produced at the Iron Gate fish hatchery are not included in the river population because they are not considered natural * Coho typically spawn within 30 miles of the ocean; first dam on the Klamath is 187 miles upstream.

(161) First of all, I'd like to say that I represent almost 80 percent of the voters in Siskiyou County, including that area of Tulelake which is in the upper basin, and had those three precincts in Tulelake been included in the Klamath County election on dam removal, you would have had a resounding "no" on dam removal in this upper basin and in this mid-river part of the Klamath River. Now, I find it almost appalling that nowhere in the entire presentation this evening, that there is no mention of the Klamath Basin Compact of 1957, where both states, both governors, the Congress of the United States, and then-President Eisenhower, signed that compact, and there's no law out there that supersedes that, not that we could find. I think it's appalling that the information put out today is, as the secretary said in San Francisco at the Commonwealth Club, we have a predetermined outcome and we are going to work toward that outcome. With that in mind, you have deceived and you have not been forthwith with the real estate holders of the area, and that's the people. Thank you.

(7) The Klamath has been home to Native Americans for 1,000 of years. We have taken possession of land and not been responsible. We dam rivers which we all know creates unsafe sediments deposition, higher water temperatures that cause algae blooms, fragmentation of habitat, deprivation of free nutrient flow, blocked crucial spawning resources i.e. noiyo rock, changed rain patterns and much, much more. It's up to you us to lead the country by example to reopen the biggest salmon producer next to Alaska. We owe it to the Native Peoples, to ourselves and to our children and grandchildren. We have to learn to coexist and find new ways to support our continuously growing population. We must change the way we think or go extinct. This dam is the most important removal in California in the past 100 years I'm sure. I'm also sure that we don't know the true effects that a dam can have until we remove it and collect biological data. It certainly can only get greater. We should remove the dam because of the environmental impact it's having on the fish, amphibians, birds, mammals, macroinvertabrates. These are things that no amount of mitigation can bring back once they're gone and the state or country surely doesn't have the money to fix the environment once we have demolished the ecosystem with poor decisions. 
The dam has never made sense and no dam ever will. Dams kill the biodiversity of the area by limiting keystone species' i.e. salmon, steelhead, lamprey etc.

(73) Hello. My name is [...], and I work for Klamath Riverkeeper. I'm also a Siskiyou County resident, just barely, almost a Humboldt County resident. I'm a few miles away. And I grew up on the river and certainly have a stake in the outcome here today and for years to come.

I was at the Yreka meeting, as you know, and last night's Orleans meeting and have had a chance to kick around in my brain some of the things -- issues at stake here and the things that people had to say at those meetings and the things you have in your document. And I would like to ask that you all consider the value of a restoration economy in this Basin versus an economy that extracts resources, uses them up, degrades them, spits them out the other side and we have to restore them and figure out how to find the money to do that. It's very costly, and I would argue that the value is significantly less. I think it's difficult to deny, if you take a close look at the literature, that restoration economy has a lot more value, and it's going to be protecting the integrity of those resources. You'll be able to go on and use those resources in future generations. That's a lot more sustainable. That has a lot more value. Please take a look at that in your document when you are looking at the economic impacts. And I think we can debate for a long time about how adverse those might be. And, certainly, you heard from residents of Central Siskiyou County who feel that there are adverse impacts to their economy, but please weigh that against what it means to have a restoration economy in this Basin. And I would also add, on that topic, that this meeting tonight is located in a place where local citizens and public officials, very much to their credit, have figured out how to do a restoration economy, how to build that up. And, you know, so it might be worth taking a look, also, at how that's done and how people have done it right, like the folks around here. I would also like to note, when I was watching the presentation tonight, the significance of dams as historic sites, or "culturally historic sites" was the way I believe you said it, to me and, I think, to many people I work with, dams -- these dams are outdated. And their value, as cultural sites, that's a thing of the past. And I think other speakers here tonight have touched on it, Mr. [...]. This is an era of dams coming out. And what will truly be historic and has the most historic value today is four dams out of the Klamath River. That's Alternative 2. Please adopt it.

(74) I believe that it is essential to remove the four dams as contemplated in the KBRA. It will bring harmony to our basin and restore the natural balence that is critical to the Klamath River. The power generating losses will be minimal, the ecosystem and economic gains will be significant.

(75) The age of dams has passed. To save our salmon and clean water, we must remove the Klamath dams.

(76) I support alternative 2.Save our future! 
(77) I've been a guide on the Klamath River for 18 years. I spend the majority of my May, June on the Klamath; and then I return to the river in October; and guide there through the fall months. I have left the river now in the summer months because the river has become extremely unhealthy. The river, when the river gets really, really hot in the summer months I call it a stew. It just, it blooms these huge algae, blue green algae, blooms in the river. I can't even fish people on the river. The blooms have got so bad the river smells. A lot of you folks see the river when it's fishing good, sure, spring and fall after we've had some rain and precipitation. But this river is suffering from June, July and September. The river is not healthy; and this is what has caused the salmon kill that we had in the year 2002.The river has still not recovered since that kill. And I might add that because the river is so -- the gravel, the gravel doesn't move, people. The salmon, it is like trying to make love on Interstate 5, you just can't do it, okay. I have to add if I got stuck in Oroville, Redding or Hornbrook, California and was denied springs and colder water I would be depressed and declining, too.Okay, so we need to find some alternative to get these salmon back in the river because they were there, they were there all along. I would like to know the guy that is still alive from 1905 that is saying that the river dried up completely. There was no one alive then or right now, they are not alive. The other thing that I might mention is, hold on here, let's take the two drainages. Let's take the Trinity River, and let's take the Klamath River, and let's compare them. Look at the gorges, how you're climbing, climbing, climbing. You get to Ishy Pishy Falls, you get clear past the gorge; then you continue on, you're still climbing. And you finally reach that place, just perfect for spawning, right? That place on the Trinity is Big Barn and Junction City. That's where it starts. You have got 40 miles of the best love-making gravel until you get to Lewiston Dam. When you finally get to the top to where it is perfect to make love and spawn as a salmon, you got five miles and then you got Iron Gate Dam. And that is exactly why our salmon are declining in numbers. It's because of Iron Gate Dam

(104) As both an American Citizen and a California resident, I challenge the Draft Environmental Impact Report (DEIR) and the Draft Environmental Impact Statement (DEIS) which allegedly supports the removal of four dams from the Klamath River. The removal of the dams is driven by the supposition that it will save the Coho Salmon. What it will do is provide the salmon with an unnaturally warm and polluted breeding environment which may actually result in the elimination of the salmon from that river. The headwaters of the Klamath river is naturally warm and polluted, for it is volcanic and rich in minerals, including basalt, magnesium and phosphorus. The present system of four dams filters out the minerals, allows the water to cool, and rids the waters of the pollution. There are two basic questions that the DEIR and DEIS do not address. They are: 1. How will the release of toxic sediment into the river ecosystem, caused by the breaching of the dams, be mitigated, and how will the green, affordable energy currently provided by the four hydroelectric dams be replaced? 2. Why is it that our government intends to severely harm the people of this already economically decimated area where ranchers and farmers already are barely making a living off their land? 
(163) I do not think that alternatives to dam removal were explored. Such as fish ladders, trucking fish as is conducted on the Columbia River. Dean Brockbank, Vice President and general counsel of Pacific Corp was quoted as saying "the Government made it very clear from a public policy point of view that they did not want these dams relicensed once that became clear, we shifted our framework from relicensing to a settlement involving a possible dam removal framework." This statement makes it clear that the top level officials within the Department of Interior conspired to orchestrate the removal of dams from the beginning and that the rest of his discussion was simply window dressing and not a sincere attempt to settle the issues with all options available. And even with dams out the fish well need to be trucked past Keno Dam and its reservoir. Why are we worrying about dam removal if our schools are having problems? The Klamath schools need 47 million dollars to make the needed repairs but instead we are putting all our effort and money into dam removal. Obviously our priorities aren't straight. Therefore I am against dam removal.

(78) The Klamath River used to have one of the largest coho salmon runs in the United States but now they're almost extinct. Please remove all dams on the Klamath.

(109) The tribes in Klamath have proven they cannot manage anything. A select few live well and the rest are in poverty. We paid them 21 million for the ruby pipeline, where did that money go? The dams are there and should stay, How can we supply water without some form of storage. We have done enough for this bunch who are self-serving and will never work for the whole of the tribe.

(162) We've been assessing how the radical enviornmentalists [sic] have wormed there [sic] way into almost every water district in the U.S. They start at the water manager and offer him future positions and under the table deals. After the manager is in cahoots with radical enviros, they get the manager to bring their deal to the table with the board members that manager works for. The board members that fall into the manager's recommendation on agreements with radical environmental groups have at this point started representing the water manager's interest and not the people who elected them to the board. This has happened in every water take over re; Central Valley Project Improvement Act, San Joaquin river settlement, and again in the Klamath river restoration that is so mixed up the farmers are kept out of secret meetings. We as business men do not let our irrigators tell us how to or who to buy sell or trade important assets of our farms. So why are we allowing our water managers to negotiate our most vital asset to our farms for us with the radical environmentalists. Board members need to wake up and remember who they represent or be replaced. No more water managers should be sitting at the table when it comes to our property negotiations. Board members please protect the property owners that ELECTED you. NO KBRA!!!! This is a strong message from the following citizens of Klamath County.

[signed by 201 people], towns of Klamath Falls, Chiloquin, Merrill, Keno, Malin, Sprague River, Bonanza, Bly, LaPine, Midland, Cave Junction, Dairy, Eagle Point, Fort Klamath 
Additional pages with text reads: We the undersigned, are concerned citizens who urge our leaders to act to Stop the Validation of the KBRA and Hydro agreements and amend the ESA. [signed by 54 people]

(79) The time has come to remove all four dams on the Klamath. They have outlived their intended usefulness and have become not only a liability to the region but remain a MAJOR hindrance to the steelhead and salmon runs that once were so abundant on the Klamath River.

(6) After attending various public hearings, scoping meetings and researching alternatives, I have concluded that Alternative 2 [approves of dam removal] is the best for the long term environmental health and economy of the Klamath River region along w/ KBRA + KHSA. The success of other dam removals, i.e. Savage Rapids, Elwah, and Condit demonstratively predict likewise success with the Klamath River Dams. I would like to see consideration/compensation for Siskiyou Co + Shasta Tribe for their losses with flooding, etc. If possible, I request protection/diversion of Lost River Suckers and Shortnose Suckers in the upper reaches of the Klamath River by the Keno Dam/Reach in the transfer to the Bureau of Reclamation.

(106) I'd like to take this time to make my feelings known about the Klamath River Dam Removal. I am against the removal of any of the Dams that are in place today. They help control water flows and retain water for irrigation. Removing Dams will flush millions of tons of sediment downriver choking fish and covering spawning beds killing billions of eggs and salmon fry. DON'T REMOVE THE DAMS !!!

(105) The thing I want to point out is what's going on in this basin today is at the behest and direction of the Department of the Interior, Bureau of Land Management, Department of Fish and Game. How this all came to be was by implementing their plans and programs. I have concern just on general principle that this time they are going to get it right. What I do know is that these dams and all of the structures put into the rivers and streams in this county were put there to enhance the environment, the economic environment of this county. I'm not sure how you can tell me, if you read Dr. Gallo's report closely, how that is going to impact or provide opportunities of Siskiyou County. It's not. What Dr. Gallo's report says is that 78 percent of the benefits will accrue to Del Norte and Humboldt counties and coastal fisheries. Today you can't fish in the Shasta River or Scott River. Today if you go to the Shasta River or the Scott River, you have fences on both sides of the river, not only to keep the cattle out but to keep the people out as well. So the issue is about the economy. We are the seventh poorest county in California. We had timber here until 1995. We had 22 operating mills. We had 6,000 living wage jobs. We have two mills left in this county, and I think there is something like 300 employees. So I don't know how you can overcome that type of a loss. We lost dredge mining because of North Coast Regional Water Quality Control -- North Coast Regional Water Quality Control Board's actions and decisions about 
dredge mining. So all we have left is agriculture. It's a marginal place to run agriculture, it always has been. We only get water on average once every seven years, that is how often Lake Shasta even fills, every seven years. What we do need to be concerned about is sustainable economy, not a sustainable environment. If you look at the growing economies in this world. Brazil, the fastest growing economy in this world, 80 percent of their electrical power comes from hydroelectric. if you look at China, that amazing economy you might know about, they are putting in hydroelectric to power their economy. If you look at India, they are putting in hydroelectric to power their economy. I'm not sure how agriculture in this county is going to be able to survive when they are forced to pump water from wells to irrigate their fields and raise their crops. Thank you.

(98) I think it's important that you listen to the people. The FERC report points out that there is an estimated 20 million cubic yards of sediment accumulated behind the four hydroelectric dams. The CBA report worries that that may a gross underestimate of the actual amount of sediment. The Draft Environmental Impact Statement does not appear to mitigate that sediment away. In fact, the Department appears to be planning on just blowing the dams and allowing the sediment to go down the river and see what happens. As the good doctor said, a grand experiment to see what happens to our river. Dennis, you and I go back a long time. I have to question your science on this. That amount of sediment is equal to two million ten yard dump trucks of river sediment, silt and organic material. Two million dump trucks, regular ten wheelers, lined up from head to heel, will stretch about 12,500 miles. Halfway around the planet. If you look at it in a different way, if you were to dump one truck load every five minutes, every day, every week of every month of every year it would take nearly 20 years to dump all that sediment into the river. It appears that our government has two sets of standards, two sets of regulations. One of them for our private citizens wherein they hold the private citizen to a standard that severely restricts and virtually bars their activities in or near rivers. That standard holds private citizens legally responsible for contaminating the rivers with sediment or other lead products. The other standard essentially allows the government to do whatever they wish so long as that purpose is politically correct and adheres to the desires of the environmentalist's agenda. The standards simply chose to ignore the potential liabilities. It further attempts to absolve PacifiCorp and all authorities of a legal responsibility for all that sediment. How can we justify dumping the equivalent of two million dump trucks of sediment into the Klamath River to expedite the politically correct demolition of the Klamath River dams, while at the same time citing and prosecuting foresters, farmers and lands owners and cattlemen for stirring up a little sediment for making a living. Thank you.

(5) These Dams are inefficient, are throttling the fish population and the resulting economic effects that industry could have which would benefit local economies and indian tribes, AND the dams cause toxic releases of blue green algae that make the river unusable for everyone. Clearly they need to be removed, and the only argument against it is a dent to a company's profitability. Time to start putting profits ahead of common sense, human welfare, and basic river ecology. 


\section{(110) CONCERNS ABOUT REMOVAL OF DAMS ON KLAMATH RIVER}

We have lived in Klamath 59 years. Dale worked in timber industry, first at Crescent Plywood, then Arrow Mills and then Simpson Timber Co for 28 yrs. until retirement time, after spotted owl got his job. When we came here they had everything we needed, so didn't need to go to Crescent City for anything, There were grocery stores, motels, restaurants, bars, service stations, grades school, churches, drug store, movie theater, hardware store, baseball field, Greyhound bus service, a very close knit area with air field for service in case of fires etc . In 1953 there was a flood. We lived in Terwer Valley, Klamath Glen area in a 1 bedroom cabin with $2 \mathrm{yr}$. old daughter. When the flood came, friends can to stay with us. Some homes were lost of river side of air landing strip. In 1955 we lived north of Klamath at Camp Marigold. All homes by air field were lost \& many on river side of Terwer Riffle Road, and lots of damage and homes lost in Klamath town site. We helped people and businesses clean up to get back in business. In 1956 our 3rd child was born, a daughter. In 1958 we bought property in Klamath Glen, at our present location and lived in a trailer while we built our own borne as we could afford it. We move into it about Xmas in 1962, till had mop boards and door and window trims to At Xmas time in 1964 another flood hit us. It wiped out everything. on bot $\mathrm{g}$ of air field and river side of Riffle Road and a few others. -We had 64 inches of water in our house. Our front window was broken out back sliding glass door. our living room furniture floated out and into garage/the living room door. We didn't have a door on garage yet. our by the shed and lots of stuff floated around and found things by river later. 1964 flood washed Klamath out and we need it back. We had $2 \mathrm{ft}$, of mud inside the house, We scooped it up and threw it out the windows to haul off later. we had to take off sheet rock and take out the insulation in the inside walls. Then we had the fire truck come in and hose out all of the inside of the house and we had everything moved out of the house. It had to dry before we could replace anything. All drawers were warped and had to build new drawers. We had to do it all as we got the money to do it, We had mud all under house and had to build a sled to take under and fill and pull out and haul the mud out, The whole ground in all of the Valley was 2 feet or more taller than before from mud and stuff floating down the river from all the other damage above us, 'many river banks washed out so much all along. They brought in trailer houses from Knob Nester, MO. and we lived in it until we could move back into the house. It was $2 \sim$ or 3 yrs. to have enough money to buy and time to re do everything. No money to hire help,. all our own. We had friends from Eureka came up and helped us pull mud from under house. It washed out part of the bridge, so had to come in and out on ferry crossing the river We had to throw all food away that was ,--min water, that wasn't in tincans/as it could get into all things that were not mechanically sealed, lots got some poisoning from not throwing out. Please do not take the dams off the river as no one will be safe and fishing will be bad from all the silt corning down the river, it won't 'help fishing. All people should be considered \& it has been much better since the dams were built to keep us all safer. We know many of the Indian families were in the flood too and all would be washed away and nothing of Klamath left, The dams are the best thing that has happened for Klamath to still be on the map. We get our power from there too and that will be very damaging to all of us physically, mentally, and financially. We are urging that you all work against removing the dams and see that it does not happen, Leave the dams up and keep us safe and dry. 
(80) Having studied the alternatives and being very familiar with the Klamath as a rafter, hiker and fishermen, I believe that alternative 2 is the best choice-- complete removal--in the long run. In the short run the cost savings of 3 has some merit, but we should be thinking of seven generations, not just a few years!

(29) If you don't act SOON and take down all the dams, there won't be any SALMON left to worry about. It's called extinction. 